\author{
UNIVERSIDADE DE SÃO PAULO \\ INSTITUTO DE ENERGIA E AMBIENTE \\ PROGRAMA DE PÓS-GRADUAÇÃO EM CIÊNCIA AMBIENTAL
}

MARIANA DE OLIVEIRA LAGE

IDENTIFICAÇÃO E CLASSIFICAÇÃO DE ÁREAS URBANAS PROPÍCIAS À EXISTÊNCIA DE CRIADOUROS DO

MOSQUITO AEDES AEGYPTI VIA SENSORIAMENTO REMOTO.

SÃO PAULO

2021 


\title{
IDENTIFICAÇÃO E CLASSIFICAÇÃO DE ÁREAS URBANAS PROPÍCIAS À EXISTÊNCIA DE CRIADOUROS DO MOSQUITO AEDES AEGYPTI VIA SENSORIAMENTO REMOTO.
}

\author{
Versão Corrigida
}

Tese apresentada ao Programa de PósGraduação em Ciência Ambiental do Instituto de Energia e Ambiente da Universidade de São Paulo para obtenção do título de Doutora em Ciência Ambiental.

Orientador: Prof. Dr. José Alberto Quintanilha Coorientador: Prof. Dr. Francisco Chiaravalloti Neto 
AUTORIZO A REPRODUÇÃO E DIVULGAÇÃO TOTAL OU PARCIAL DESTE TRABALHO, POR QUALQUER MEIO CONVENCIONAL OU ELETRÔNICO, PARA FINS DE ESTUDO E PESQUISA, DESDE QUE CITADA A FONTE.

\section{FICHA CATALOGRÁFICA}

Lage, Mariana de Oliveira.

Identificação e classificação de áreas urbanas propícias à existência de criadouros do mosquito Aedes Aegypti via sensoriamento remoto. /

Mariana de Oliveira Lage; orientador: José Alberto Quintanilha. - São

Paulo, 2021.

$172 \mathrm{f.:} \mathrm{il;} 30 \mathrm{~cm}$.

Tese ( Doutorado em Ciência Ambiental) - Programa de PósGraduação em Ciência Ambiental - Instituto de Energia e Meio Ambiente - Universidade de São Paulo

1. Risco ambiental. 2. Solo urbano - aspectos ambientais. 3.

Arbovírus. 4. Microbiologia ambiental. 5. Área de risco - aspectos ambientais. I. Título. 


\section{AGRADECIMENTOS}

Eu não poderia deixar de agradecer as pessoas que me acompanharam e contribuíram para a realização da minha pesquisa. Então agradeço:

Ao professor José Alberto Quintanilha, pela orientação e amizade e principalmente pela contribuição na minha formação profissional nos últimos 6 anos.

Ao professor Francisco Chiaravalloti Neto pelos ensinamentos e, principalmente, pela disponibilidade de ensinar.

À profa. Dra. Linda Lee Ho, pela dedicação, pela orientação e assistência durante esse período.

Aos Colegas da SUCEN, de maneira especial, ao Gerson Barbosa pela parceria de dados e análises para a realização desse projeto.

Ao pessoal da empresa GDrones, de maneira especial, ao George Alfredo Longhitano pela ajuda na área do VANT.

À Dra. Camila Lorenz pela amizade, paciência e ensinamentos durante este período.

Aos colegas do Laboratório de Análise Espacial em Saúde (LAES) da FSP-USP e também do Laboratório de Geoprocessamento da EPUSP.

Ao Programa de Pós-Graduação de Ciências Ambientais da Universidade de São Paulo, pela oportunidade e pela confiança depositada.

À toda minha família, de modo especial aos meus pais e ao meu companheiro, muito obrigada pelo amor irrestrito e incondicional.

Aos meus amigos e colegas de trabalho por conviverem comigo num período de grande estresse e nunca me deixaram sem dar boas risadas.

E, finalmente, a todos que de forma direta ou indireta colaboraram com a conclusão deste trabalho. 


\section{RESUMO}

Não é tarefa fácil identificar e classificar áreas de maior risco para presença de criadouros do mosquito Aedes aegypti tendo como base apenas os indicadores entomológicos tradicionalmente utilizados nos programas de controle, como Índice Predial e de Breteau. Reflexo disto é a dificuldade em identificar também as áreas de alto risco para a ocorrência das arboviroses associadas ao mosquito, como Dengue, febre do Zika e febre Chikungunya. Estudos têm demostrado que o risco da doença está mais estritamente relacionado com a abundância dos vetores do que com sua presença. Sendo assim, o desenvolvimento de métodos adequados para identificação das áreas prioritárias tanto para o mosquito quanto para o caso de arboviroses, destas áreas para estes agravos, é tarefa primordial para aumento da eficiência e efetividade das medidas de controle a serem adotadas e otimização da aplicação de recursos. A pesquisa proposta analisou a utilização de Sensoriamento Remoto Orbital e de Veículo Aéreo Não Tripulado - VANT para a identificação e classificação de áreas urbanas com potencial risco para criadouros do mosquito Aedes aegypti no município de Campinas, sejam elas residenciais, comerciais, de infraestrutura de transporte, entre outros, e seu entorno. Como metodologia, identificou e validou aspectos de imagens de sensoriamento remoto característicos destas áreas; avaliou a relação entre os dados coletados no campo com a classificação espacial de risco com a ocorrência dos ovos do mosquito; e propiciando a utilização desta metodologia pelos serviços de saúde e de controle de vetores para que eles possam identificar previamente áreas de risco para a ocorrência dos locais com maior criadouro do mosquito, podendo gerar doenças como Dengue (e, consequentemente, Zika e febre Chikungunya) e priorizar a aplicação de medidas de vigilância e controle. $\mathrm{O}$ estudo foi realizado em quatro áreas do município de Campinas. Foram três áreas com presença de pontos estratégicos (locais com grande concentração de criadouros de Ae aegypti) classificados, respectivamente, de baixo, médio e alto risco para a presença do vetor, e uma área controle (sem a presença de pontos estratégicos). Nestas quatro áreas foram instaladas, e permaneceram durante um ano, armadilhas para captura de ovos do mosquito. A coleta de informações sobre as coordenadas geográficas destas armadilhas e o emprego da técnica de krigagem proporcionaram a construção de um mapa anual classificando as áreas de estudo segundo os quantis de número de ovos presentes nas armadilhas. Foram criadas regras sobre a ocupação dos solos com o uso de imagem de satélite de alta resolução e incorporadas à classificação supervisionada, para o reconhecimento das classes existentes nessas áreas e de seu entorno próximo, e imagens de ortofotos de VANTs, de modo a extrair feições do terreno relacionadas às situações de risco. A validação do uso da metodologia desenvolvida, foi feita utilizando a estatística Kappa. Como resultado, obteve-se que o mosquito apresenta a preferência em depositar seus ovos em classes do uso do solo mais escuras como sombra, cimento e asfalto. Isso demonstra a utilidade do sensoriamento remoto na identificação de diferenças paisagísticas em ambientes urbanos, utilizando uma abordagem geoestatística, e fornece indicações para investigações futuras. Outra análise, incluindo a variável temperatura da superfície terrestre, pode revelar relações mais complexas entre microhabitats de mosquitos urbanos e características de cobertura do solo. O processo metodológico para classificação de áreas de risco para proliferação do mosquito $A e$. aegypti e do seu consequente uso para controle das doenças Dengue, Chikungunya e Zika, é replicável em outras áreas sob diferentes condições melhorando a otimização na aplicação de recursos da efetividade no controle.

PALAVRAS-CHAVE: Aedes aegypti, Classificação em imagem, mapeamento de cobertura do solo urbano, imagem de alta resolução espacial, áreas de risco, Arboviroses e INLA. 


\begin{abstract}
It is not easy to identify and classify areas of higher risk for the presence of Aedes aegypti mosquito breeders based only on the entomological indicators traditionally used in control programs, such as the Breteau and Building Index. Reflecting this is the difficulty in also identifying areas of high risk for the occurrence of arboviroses associated with the mosquito, such as Dengue fever, Zika fever and Chikungunya fever. Studies have shown that the risk of the disease is more closely related to the abundance of vectors than to their presence. Therefore, the development of adequate methods to identify the priority areas for both the mosquito and the case of arbovirosis, from these areas for these diseases, is a primary task to increase the efficiency and effectiveness of the control measures to be adopted and optimize the application of resources. The proposed research analyzed the use of Remote Orbital Sensing and Unmanned Aerial Vehicle - UAV for the identification and classification of urban areas with potential risk for Aedes aegypti mosquito breeders in the municipality of Campinas, whether they are residential, commercial, transportation infrastructure, among others, and their surroundings. As a methodology, it identified and validated aspects of remote sensing images characteristic of these areas; evaluated the relationship between the data collected in the field and the spatial classification of risk with the occurrence of the mosquito's eggs; and provided the use of this methodology by health and vector control services so that they can previously identify areas at risk for the occurrence of the sites with the largest mosquito farm, which may generate diseases such as Dengue fever (and, consequently, Zika and Chikungunya fever) and prioritize the application of surveillance and control measures. The study was conducted in four areas of the municipality of Campinas. There were three areas with the presence of strategic points (sites with a high concentration of Ae. aegypti breeders) classified, respectively, as low, medium, and high risk for the presence of the vector, and one control area (without the presence of strategic points). In these four areas, traps for capturing mosquito eggs were installed and remained for one year. The collection of information on the geographical coordinates of these traps and the use of the krigagem technique provided the construction of an annual map classifying the study areas according to the amounts of eggs present in the traps. Rules on land use were created with the use of high resolution satellite images and incorporated into the supervised classification, for the recognition of existing classes in these areas and their immediate surroundings, and orthophoto images of UAVs, in order to extract features of the terrain related to risk situations. The validation of the use of the methodology developed was done using Kappa statistics. As a result, it was obtained that the mosquito has the preference to lay its eggs in darker soil use classes such as shade, cement and asphalt. This demonstrates the usefulness of remote sensing in identifying landscape differences in urban environments, using a geostatistical approach, and provides indications for future investigations. Other analysis, including the variable earth surface temperature, may reveal more complex relationships between urban mosquito micro-habitats and ground cover characteristics. The methodological process for classifying risk areas for Ae. aegypti mosquito proliferation and its consequent use for Dengue, Chikungunya and Zika disease control is replicable in other areas under different conditions, improving the optimization in the application of control effectiveness resources.
\end{abstract}

KEY-WORDS: Aedes aegypti, Image classification, urban land cover mapping, high spatial resolution imaging, risk areas, Arboviroses and INLA. 


\section{LISTA DE FIGURAS}

Figura 1: Cronologia dos satélites de Observação da Terra ................................................... 41

Figura 2 - Resposta espectral das bandas do sensor Worldview II. .......................................50

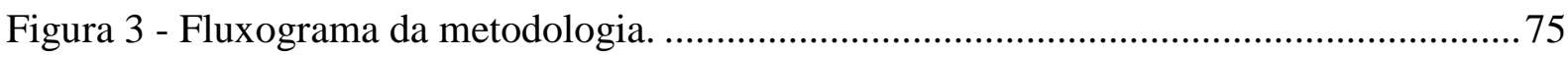

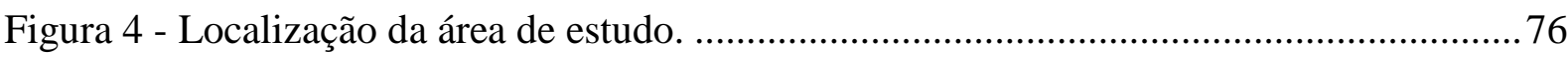

Figura 5 - Imagem de satélite das áreas de estudo. ........................................................... 79

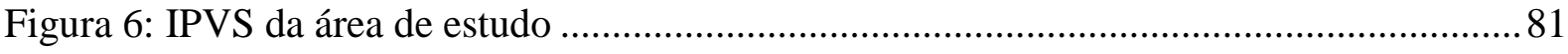

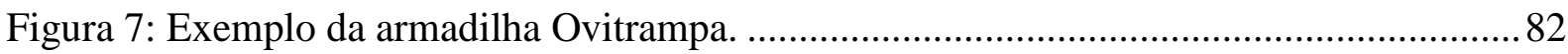

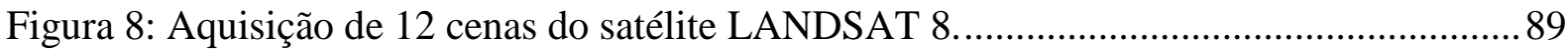

Figura 9 - Ilustração dos buffers criados a partir da localização dos imóveis ..........................91

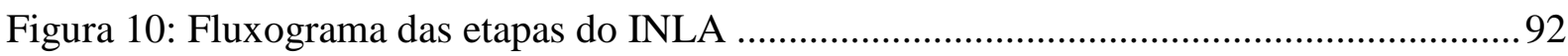

Figura 11 - Detalhes da localização das armadilhas na área de alto risco. ..............................94

Figura 12: Localização espacial das quadras trabalhadas de cada área de alto, médio e baixo

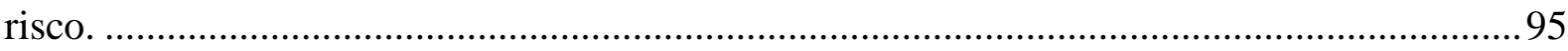

Figura 13: Fluxograma com destaque das etapas relacionadas à classificação supervisionada.

Figura 14 - Foto georeferenciada do VANT nas áreas de alto risco e de controle................. 101

Figura 15 - Foto georeferenciada do VANT nas áreas de médio risco e baixo risco............. 101

Figura 16 - Classificação das 4 áreas de estudos pelo algoritmo Mahalanobis...................... 103

Figura 17 - Classificação das 4 áreas de estudos pelo algoritmo Minimum Distance. .......... 103

Figura 18 - Classificação das 4 áreas de estudos pelo algoritmo Parallelepiped. ................... 104

Figura 19 - Classificação das 4 áreas de estudos pelo algoritmo Maximum Likelihood....... 104

Figura 20 - Fluxograma com destaque das etapas relacionadas à Krigagem Ordinária......... 108

Figura 21 - Semivariograma da krigagem nas áreas de estudo. ........................................... 109

Figura 22 - Krigagem ordinária das armadilhas nas áreas de alto risco e controle................110

Figura 23 - Krigagem ordinária das armadilhas nas áreas de médio risco e baixo risco........ 110

Figura 24 - Fluxograma com destaque das etapas relacionadas à correlação da classificação supervisionada com a krigagem ordinária.

Figura 25 - Vínculo entre o uso do solo e as maiores evidências de ovos nas áreas de alto risco e controle.

Figura 26 - Vínculo entre o uso do solo e as maiores evidências de ovos nas áreas de médio risco e baixo risco. 
Figura 27 - Fluxograma com destaque das etapas relacionadas à correlação com a temperatura de superfície com a krigagem ordinária.

Figura 28 - Temperatura de superfície calculada pelo método Planck Equation nas áreas de alto risco e controle.

Figura 29 - Temperatura de superfície calculada pelo método Planck Equation nas áreas de médio ricos e baixo risco.

Figura 30 - Temperatura de superfície calculada pelo método Mono Window Algorthim nas áreas de alto risco e controle.

Figura 31 - Temperatura de superfície calculada pelo método Mono Window Algorthim nas áreas de médio risco e baixo risco.

Figura 32 - Sobreposição da krigagem ordinária com a temperatura de superfície calculada pelo método Planck Equation nas áreas de alto risco e controle.

Figura 33 - Sobreposição da krigagem ordinária com a temperatura de superfície calculada pelo método Planck Equation nas áreas de médio risco e baixo risco.

Figura 34 - Sobreposição da krigagem oridinária com a temperatura de superfície calculada pelo método Mono Window Algorthim nas áreas de alto risco e controle.

Figura 35 - Sobreposição da krigagem oridinária com a temperatura de superfície calculada pelo método Mono Window Algorthim nas áreas de médio risco e baixo risco.

Figura 36 - Fluxograma com destaque das etapas relacionadas ao resultado das classes que apresentam risco ou proteção em correlação com a quantidade de casas positivas.

Figura 37 - Localização dos imóveis na área de baixo risco.

Figura 38 - Apresentação dos buffers de 5, 10 e 15 metros.

Figura 39 - Mapa da classificação supervisionada no buffer de 5 metros.

Figura 40 - Mapa da classificação supervisionada no buffer de 10 metros.

Figura 41 - Mapa da classificação supervisionada no buffer de 15 metros.

Figura 42: Mesh da área de trabalho

Figura 43: Resultado da colinearidade dos buffers estudados. 


\section{LISTA DE TABELAS}

Tabela 1: Resumo da bibliometria, referente as publicações encontradas no site Dimensions com a palavra-chave "Dengue; Remote Sensing".

Tabela 2: Resumo da bibliometria, referente as publicações encontradas no site Dimensions com a palavra-chave "Dengue; Geostatistics".

Tabela 3: Resumo da bibliometria, referente as publicações encontradas no site Dimensions com a palavra-chave "Dengue; Thermal Image". .................................................................. 30

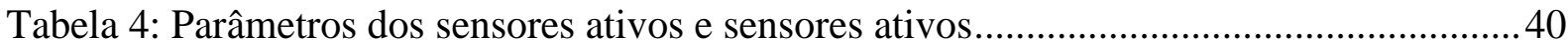

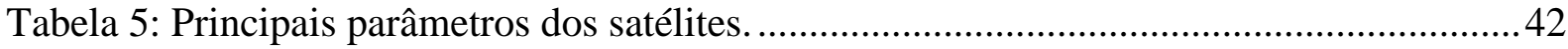

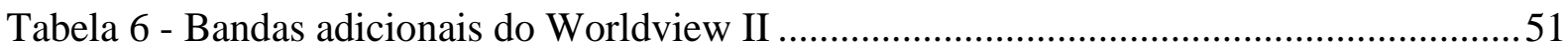

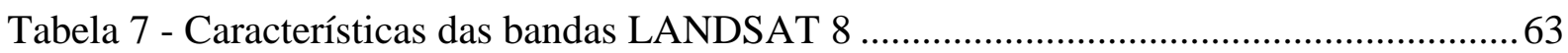

Tabela 8 - Emissividade de diferentes materiais na faixa 8 a $14 \mu \mathrm{m}$.....................................69

Tabela 9 - Amostras das 10 classes definidas para a classificação supervisionada ................. 87

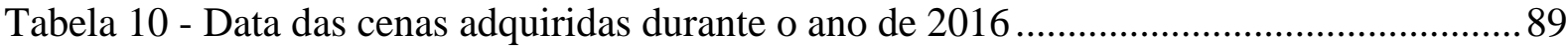

Tabela 11 - Recorte de informações do banco de dados das armadilhas .................................95

Tabela 12: Número de ovos, percentual de positividade e média de ovos por armadilha nas quatro áreas avaliadas, em dois ciclos de visita. Período compreendido entre outubro/15 e setembro/16.

Tabela 13: Número de recipientes com larvas, e número de larvas de Ae. aegypti nos pontos estratégicos, segundo risco, em dois ciclos de visita. Período compreendido entre outubro/15 e setembro/16.

Tabela 14: Valores do Índice Kappa para cada classificador.

Tabela 15: Matriz de confusão da classificação.

Tabela 16: Percentual dos tipos de classes por área de estudo.

Tabela 17 - Porcentagens das classes nas áreas com maior coleta de ovos obtidos pela krigagem.

Tabela 18- Média da temperatura de superfície para cada um dos métodos realizados nas áreas de alta quantidade de coleta de ovos.

Tabela 19 - Informações do banco de dados dos imóveis.

Tabela 20 -Informações do banco de dados realizado para a metodologia INLA no buffer de 5 metros. 


\section{LISTA DE QUADROS}

Quadro 1: Resultado da metodologia INLA no buffer de 5 metros....................................... 133

Quadro 2: Resultado da metodologia INLA no buffer de 10 metros.................................... 134

Quadro 3: Resultado da metodologia INLA no buffer de 15 metros..................................... 134 


\section{LISTA DE GRÁFICOS}

Gráfico 1: Frequência da publicação anual, referente as publicações encontradas no site Dimensions com a palavra-chave "Dengue; Remote Sensing'.

Gráfico 2: frequência da publicação anual, referente as publicações encontradas no site

Dimensions com a palavra-chave "Dengue; Geostatistic".

Gráfico 3: Frequência da publicação anual, referente as publicações encontradas no site

Dimensions com a palavra-chave "Dengue; Thermal Image".

Gráfico 4 - Percentual de positividade de armadilhas (A: Alto Risco; M: Médio Risco; B:

Baixo Risco; C: Área Controle). 97

Gráfico 5 - Número de recipientes com larvas de Ae. aegypti em Pontos Estratégicos, segundo ciclo de visitas e área de classificação do PE (A: Alto Risco; M: Médio Risco; B: Baixo Risco). 99

Gráfico 6: Frequência pela distância dos imóveis da área de estudo 131 


\section{LISTA DE SIGLAS}

DATUM: Dado (Latim)

ESA: European Space Agency

ETM+: Enhanced Thematic Mapper

EXIF: Exchangeable Image File Format

FAPESP: Fundação de Amparo à Pesquisa do Estado de São Paulo

GPM: Global Precipitation Measurement

HRV: High Resolution Visible

IA: Inteligência artificial

IBGE: Instituto Brasileiro de Geografia e Estatísticas

ICM: Índice de Condição da Moradia

INLA: Integrated Nested Laplace Approximation

IPVS: Índice Paulista de Vulnerabilidade Social

LSE: Land Surface Emissivity

LST: Land Surface Temperature

MCMC: Markov Chain Monte Carlo

MDE: Modelo Digital de Elevação

MODIS: Moderate Resolution Imaging Spectroradiometer

MSS: Multispectral Scanner Subsystem

NASA: National Aeronautics and Space Administration

NDBI: Normalized Density Building Index

NDVI: Normalized Difference Vegetation Index

NDWI: Normalized Difference Water Index

NIR-1: Near infrared-1

NIR-2: Near infrared-2

ODS: Objetivos de Desenvolvimento Sustentável 
OLI: Operational Land Imager

OMS: Organização Mundial da Saúde

PE: Pontos Estratégicos

PEC: Proposta de Emenda Constitucional

PNCD: Programa Nacional de Controle da Dengue

REM: Radiação Eletromagnética

RF: Random Forest

SAR: Synthetic Aperture Radar

SCA: Single Channel Algorithm

SfM: Structure from Motion

SIG: Sistemas de Informação Geográfica

SINAN: Sistema Nacional de Agravos de Notificação

SRTM: Shuttle Radar Topography Mission

SUCEN: Superintendência de Controle de Endemias

SVM: Support Vector Machine

TIRS: Thermal Infrared Sensor

TKin: True kinetic temperature

TM: Thematic Mapper

Trad: Radiant temperature

TRMM: Tropical Rainfall Measuring Mission

USGS: United States Geological Survey

VANT: Veículo Aéreo Não Tripulado

VIF: Variance Inflation Factors 


\section{SUMÁRIO}

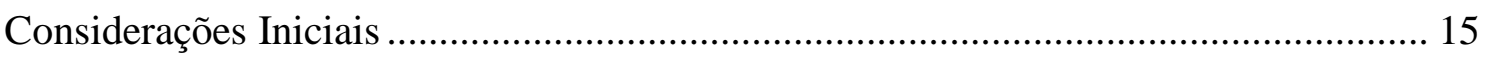

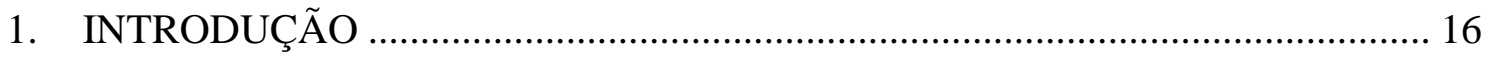

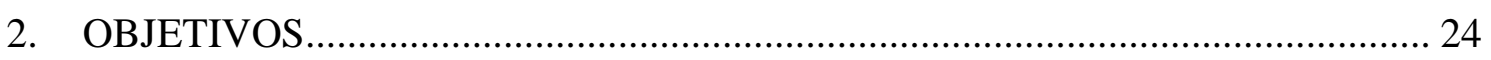

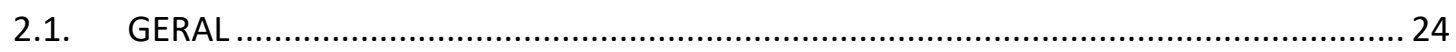

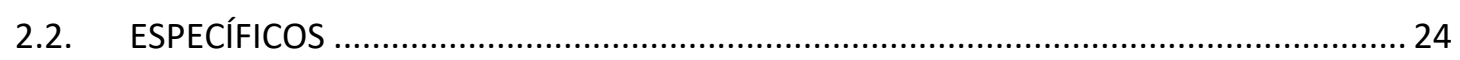

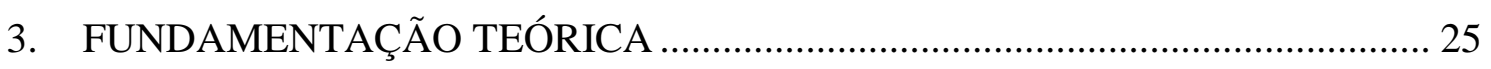

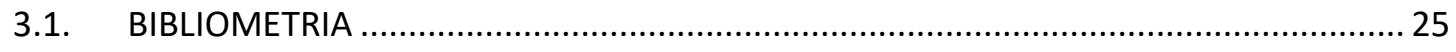

3.1.1. Palavras chaves: Dengue; Remote Sensing ....................................................... 26

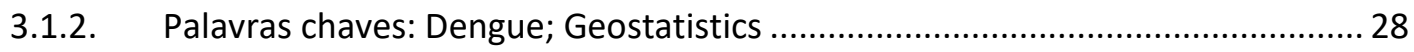

3.1.3. Palavras chaves: Dengue; Thermal Image........................................................ 30

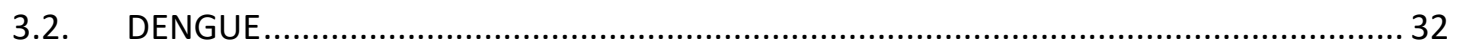

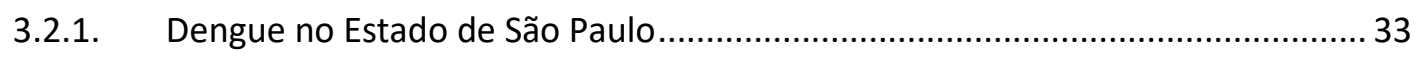

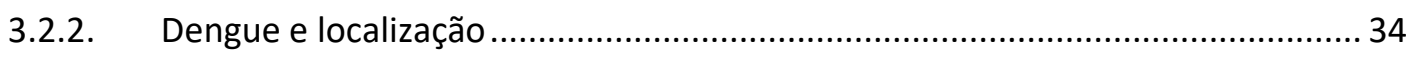

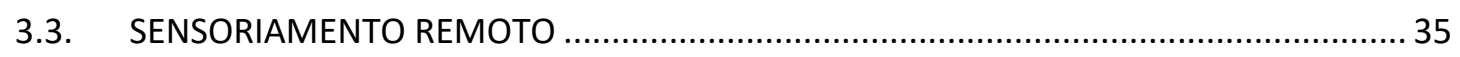

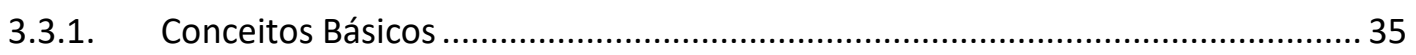

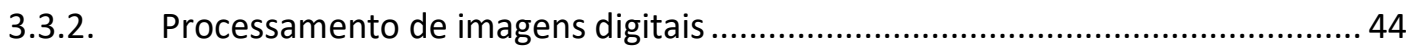

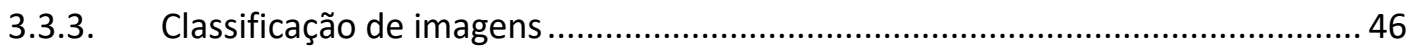

3.3.4. Classificações supervisionadas: Interpretação de imagens baseada em

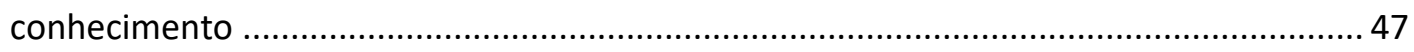

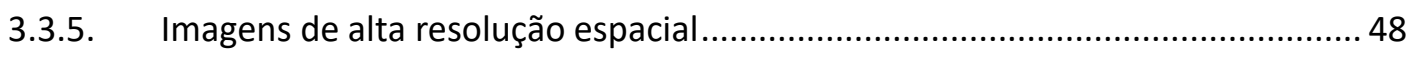

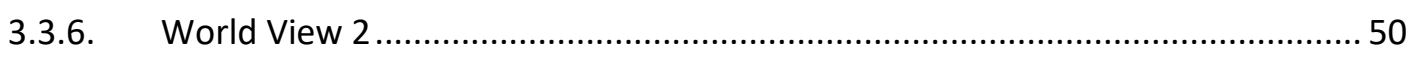

3.3.7. Algoritmos de Classificação Supervisionada por pixel ........................................ 51

3.3.8. Sensoriamento remoto aplicado a estudos urbanos .......................................... 52

3.4. O USO DE GEOPROCESSAMENTO E SENSORIAMENTO REMOTO NA ÁREA DA SAÚDE 53

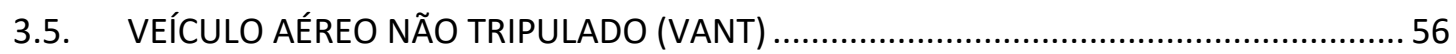

3.6. AVALIAÇÕES DA ACURÁCIA DE RESULTADOS NAS CLASSIFICAÇÕES DE IMAGENS .... 58

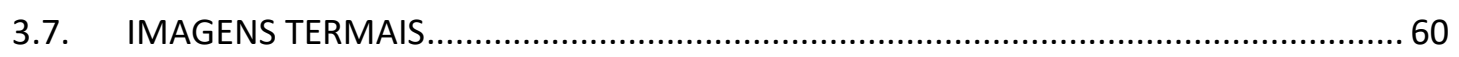

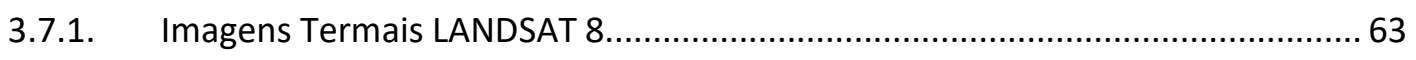


3.7.2. Imagens Termais para Análise de Temperatura em Áreas Urbanas....... 64

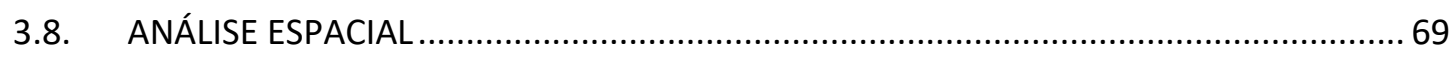

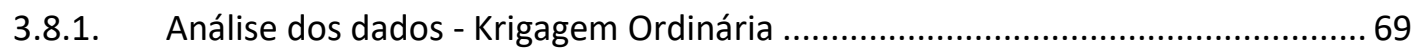

3.8.2. Integrated Nested Laplace Approximation (INLA) …….................................... 71

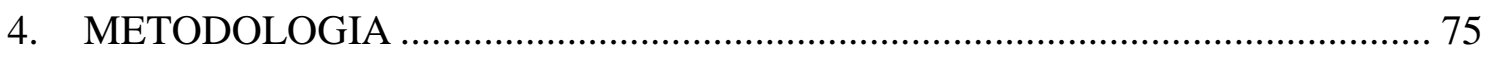

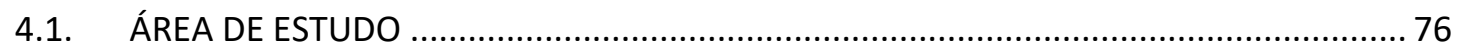

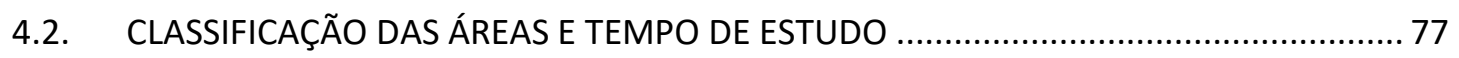

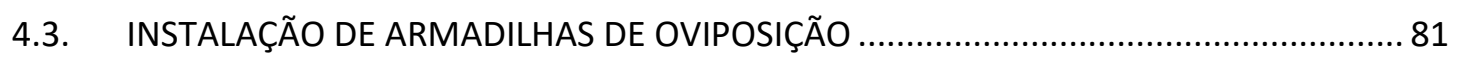

4.4. COLETA DE DADOS RELACIONADOS AOS IMÓVEIS RESIDENCIAIS .................................. 83

4.5. AQUISIÇÃO E SELEÇÃO DAS IMAGENS DE SATÉLITE E VANT DE ALTA RESOLUÇÃO ... 84

4.6. CLASSIFICAÇÃO DA COBERTURA DO SOLO DA ÁREA DE INTERESSE............................ 86

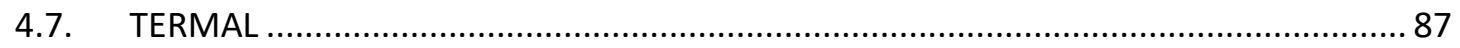

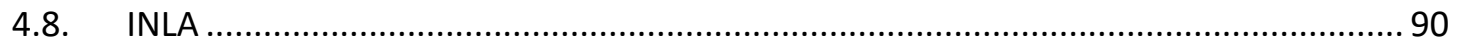

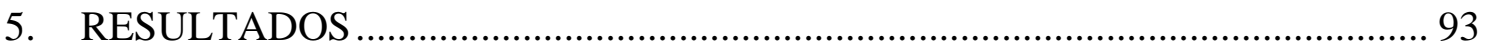

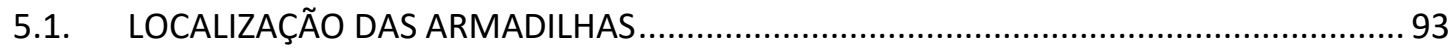

5.2. POSITIVIDADE DE ARMADILHAS NAS ÁREAS AVALIADAS ........................................ 96

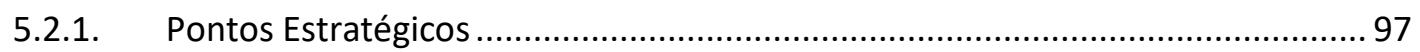

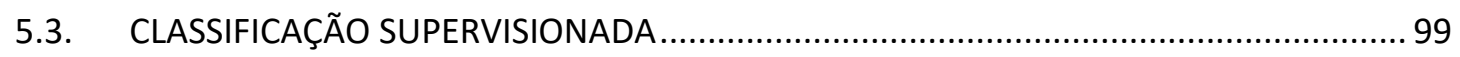

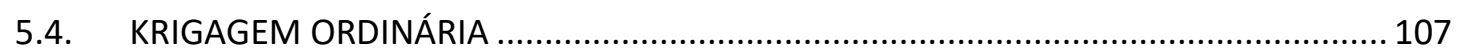

5.5. ASSOCIAÇÃO ENTRE OS RESULTADOS DA KRIGAGEM E DA CLASSIFICAÇÃO NA

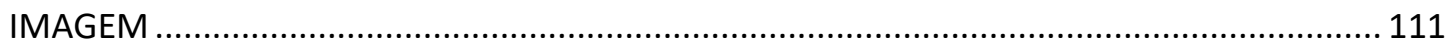

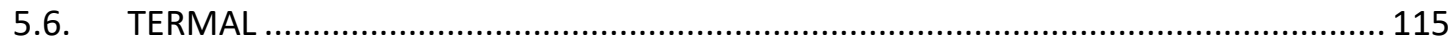

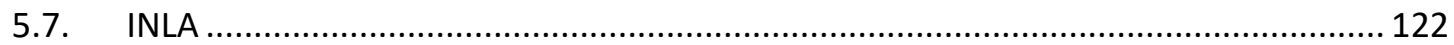

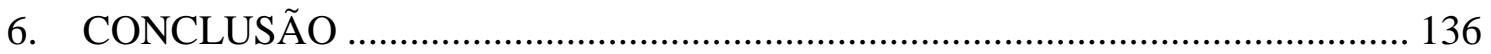

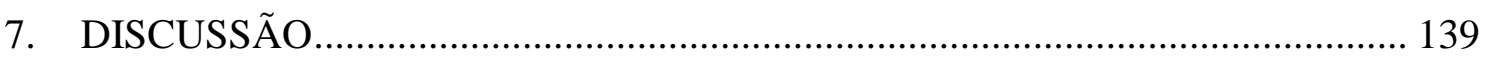

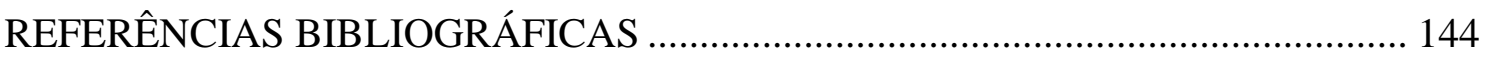




\section{Considerações Iniciais}

A presente pesquisa está vinculada ao Projeto de Pesquisa financiado pela Fundação de Amparo à Pesquisa do Estado de São Paulo (FAPESP) “Avaliação da importância de Pontos Estratégicos na dispersão do vetor Aedes aegypti, e o Uso de Índice de Condição da Moradia (ICM) e Imagens de Sensoriamento Remoto na identificação de áreas de risco para a presença de Ae. aegypti", processo $\mathrm{n}^{\circ}$ 15/06687-3, que teve como objeto de estudo o município de Campinas - SP.

O estudo da pesquisa da FAPESP, mencionado anteriormente, foi submetido para aprovação pelo Comitê de Ética na Plataforma Brasil, conforme certificado de apresentação para avaliação ética número: 43813015.9.0000.0059 e aprovado conforme Parecer número 1.082.780. O seu objetivo foi avaliar a real contribuição dos chamados Pontos Estratégicos (PE), isto é, neste caso, locais com grande concentração de criadouros de Ae. aegypti. Os Pontos Estratégicos são cadastrados seguindo alguns critérios como ramo de atividade, recipientes existentes, rotatividade dos recipientes e adoção de cuidados pelo responsável do imóvel. Os PEs têm sido alvo constante nos planos de intensificação do controle do vetor propostos em períodos interepidêmicos (DE TOLEDO et al., 2006; MINISTÉRIO DA SAÚDE, 2009).

Os imóveis considerados como PEs recebem uma pontuação e são classificados segundo classes de importância em grande, média e pequena. Além dessa classe de importância, são avaliados anualmente e qualificados quanto ao risco de infestação em alto, médio e baixo (BARBOSA et al., 2019).

Partindo dessa perspectiva, esta Tese objetiva a realização de estudos que mostrem a viabilidade do uso de produtos e instrumentos de Sensoriamento Remoto para identificação e avaliação de áreas com potenciais riscos para proliferação do mosquito Ae. aegypti, neste caso, aquelas áreas propícias à instalação de ovos pelas fêmeas, e, ao gerarem mosquitos adultos, consequentemente transmissão da Dengue, Chikungunya, Zika. Foram utilizadas áreas do município de Campinas, conforme delineado para a execução do Projeto FAPESP supracitado. 


\section{INTRODUÇÃO}

Ae. aegypti é o único vetor de importância epidemiológica nas Américas reconhecidamente transmissor do vírus da dengue (CÂMARA et al., 2007), além de transmitir outros vírus, como o da febre amarela urbana, da Chikungunya e da Zica. A luta contra esse vetor tem sido intensa desde as primeiras iniciativas de combate ao vetor de Ae. aegypti coordenada pelo próprio Oswaldo Cruz, em 1903. Porém, mesmo após tentativas de erradicação, o Ae. aegypti continua presente em todo o território nacional, causando seguidas epidemias de dengue (BARBOSA; LOURENÇO, 2010).

Atualmente a Dengue está presente em todos os estados brasileiros. Junto com outras arboviroses, também têm ganhado atenção especial do poder público. A febre Chikungunya foi identificada no país em 2014, e até 2016 estava presente em 14 estados. A febre pelo vírus Zika foi detectada no país em abril de 2015 e também está presente no Brasil até os dias atuais ${ }^{1}$.

De acordo com a Organização Mundial da Saúde (OMS) (WHO, 2014) e com a Superintendência de Controle de Endemias (SUCEN), Ae. aegypti, (sendo a fêmea do mosquito o vetor das arboviroses), está bem adaptado em áreas urbanas, possui hábitos diurnos, alimentase de sangue humano e sua proliferação acontece em água limpa e parada, acumulada em diversos tipos de recipientes (SCARPASSA; CARDOZA; CARDOSO, 2008). A presença das doenças transmitidas pelo mosquito aumenta nos meses de temperaturas mais quentes e com maior pluviosidade, período em que o mosquito tem melhores condições de reprodução (COSTA et al., 2008).

A incidência de dengue, tem crescido em todo o mundo, especialmente nos países tropicais onde a temperatura ambiente e a umidade favorecem a proliferação de mosquitos. De acordo com a OMS (OMS, 2014), acima de 40\% da população mundial está em risco de adquirir infecção pelo vírus da Dengue, sendo endêmica em 115 países, principalmente no Sudeste Asiático e na América Latina, e estima-se que 390 milhões de infecções pelo vírus ocorram no

\footnotetext{
${ }^{1}$ Números apresentados no Boletim Epidemiológico - Monitoramento dos casos de dengue, febre de chikungunya e febre pelo vírus Zika até a Semana Epidemiológica 5, 2016.
} 
mundo anualmente, resultando em 24 mil óbitos. Em 2015, o Ministério da Saúde confirmou a notificação de aproximadamente 1,4 milhão casos de dengue no Brasil, resultando em mais 750 óbitos, sendo em torno de $60 \%$ deles no estado de São Paulo (BRASIL, 2016). O número de casos de dengue notificados à OMS aumentou de 0,5 milhão em 2000 para mais de 4 milhões em 2019, o maior número já registrado. Isso incluiu mais de 3,1 milhões de casos apenas nas Américas, dos quais mais de 25.000 foram classificados como graves (OPAS/ WHO, 2020).

Algumas causas têm sido apontadas como condicionantes à proliferação de Ae. aegypti, como o fluxo rural-urbano e as consequentes condições insatisfatórias de saneamento e habitação, resultando numa concentração urbana muito elevada em médias e grandes cidades (TAUIL, 2001).

Com relação ao controle do vetor Ae. aegypti, uma série de intervenções são desenvolvidas rotineiramente com base no Programa Nacional de Controle da Dengue - PNCD. Uma das estratégias atualmente utilizadas para o controle de Ae. aegypti, procura priorizar locais que contêm grande quantidade de potenciais criadouros de formas imaturas do mosquito, que se mantêm em numerosos tipos de recipientes, principalmente pneus, caixas d'água, latas, garrafas, entre outros objetos que retenham água.

Uma questão importante que se levanta no controle do vetor está relacionada à produtividade do foco do mosquito, ou seja, podem existir localidades com grande número de focos de pequeno porte, que tendem a ter baixa produtividade para as formas aladas do vetor e, por outro lado, um único foco de grande porte pode apresentar grande produtividade, além de contribuir para a manutenção de pequenos focos do mosquito. Importante evidenciar que na década de 1980, quando o Estado de São Paulo começou a identificar a reinfestação por Ae. aegypti, foi apresentado que na região de São José do Rio Preto, que a maioria das detecções de focos e infestação domiciliar pelo vetor (73\%) se deu através de pesquisa larvária em PEs (CHIARAVALLOTI - NETO, 1997). Um determinante primário para a densidade da população de mosquitos adultos está no número e tipo de recipientes disponíveis em um dado ambiente (ALDSTADT et al., 2011).

Uma das formas de estimar o risco de ocorrência destes agravos (doenças que o mosquito veicula), tendo como base indicadores entomológicos, é por meio do uso dos chamados Sistemas de Informação Geográfica (SIG) e das ferramentas de análise espacial, sendo que alguns autores já apontaram para o benefício que estes recursos poderiam ter no aprimoramento das atividades de vigilância e controle da dengue ( NIÑO, 2008; SANCHEZ et al., 2010; CHIARAVALLOTI-NETO et al., 2015). A convergência dos locais com altos níveis 
de infestação por Ae. aegypti é um passo importante para a identificação de prováveis locais para a ocorrência dos agravos veiculados pelo vetor e poderia proporcionar planos de enfrentamento mais adequados para a ocorrência de futuras epidemias de febre do Zika, Dengue e Chikungunya (BRADY et al., 2015).

É essencial que se considere a escala geográfica na vigilância epidemiológica de agravos veiculados por vetores, uma vez que sua manipulação permite uma visão mais aproximada dos processos de dispersão vetorial e da dinâmica da transmissão ( ZELLER et al., 2013; CHIARAVALLOTI-NETO et al., 2015; VARGAS et al., 2015). Nesta questão, indicadores do potencial de proliferação obtidos por armadilhas para a contagem de ovos depositados, utilizados em conjunto com SIG e ferramentas de análise espacial, podem resultar em mapas cujo nível de detalhamento seja até por quarteirões, sendo possível identificar quais são os quarteirões de alto risco para a infestação vetorial e também para a ocorrência dos agravos associados.

O debate que se coloca, dada a falta constante de recursos humanos e financeiros na área de saúde, é que não haveria capacidade operacional suficiente para identificação dos quarteirões-chave, por exemplo, em toda a área do território brasileiro infestada por Ae. aegypti. Uma forma alternativa e mais econômica de identificá-los seria utilizar imagens por sensoriamento remoto para classificar os quarteirões segundo o risco de ocorrência do vetor de modo a priorizar as intervenções das autoridades responsáveis e otimizar o dispêndio dos recursos disponíveis.

Segundo Achee et al., (2015), a expectativa é de que quando uma vacina efetiva para dengue esteja disponível, os programas de saúde pública continuarão a depender do controle de vetor porque as duas estratégias se complementam e se aprimoram. Diante disto, e da não existência de vacina para Zika e Chikungunya, o controle vetorial provavelmente continuará a ser uma ferramenta importante para o controle destas arboviroses e, por isso, deve ser técnica e cientificamente aprimorado.

O PNCD preconiza o desenvolvimento contínuo de ações de controle dirigidas aos PEs, que incluem ações específicas tanto para o controle de formas imaturas, como as formas adultas, do vetor. No entanto uma grande quantidade de municípios não consegue realizá-las conforme preconizado, quanto à periodicidade, envolvimento do proprietário, ações de vigilância sanitária efetivas e o tratamento químico. No Estado de São Paulo, a positividade em imóveis não residenciais e de grande porte, como escolas, presídios, clubes, hospitais é maior que a 
positividade encontrada nos imóveis residenciais, medidos através do Índice Predial (BARBOSA et al., 2012).

Com relação aos potenciais criadouros de Ae. aegypti disponíveis nos imóveis, a possibilidade de encontrar imóveis que, por determinadas características, possam oferecer maior quantidade de criadouros do mosquito, poderia ajudar o programa de controle de vetores, economizando recurso e tempo gasto na sua eliminação. Nessa linha, Tun-Lin; Kay; Barnes (1995), apresentaram um índice conhecido como Índice de Condição de Moradia (ICM), que considera as condições do imóvel, de seu quintal e o grau de sombreamento atribuindo escore padrão para essas informações e define um índice que pode ser relacionado à produção de recipientes.

$\mathrm{Na}$ área de Geografia da Saúde, o estudo das doenças e de saúde é realizado através dos conhecimentos geográficos, ou seja, a análise do território como ambiente para caracterização da população e de seus problemas de saúde, abordando a relação das condições e características do ambiente, como sociais e econômicas da população, à caracterização e identificação das áreas de risco à saúde (CARVALHO; SOUZA-SANTOS, 2005).

Nas ações de vigilância entomológica, rotineiramente é coletada uma gama de informações sobre vetores, relevantes para o conhecimento dos fatores determinantes de sua dispersão, porém as características das unidades domiciliares são pouco conhecidas. A complexidade do controle, evidenciada pela diversidade de recipientes e de situações epidemiológicas distintas, sugere a utilização de recursos capazes de possibilitar uma visão mais abrangente da ocorrência, da dispersão e da densidade dos vetores. Uma das possibilidades seria a utilização de imagens por sensoriamento remoto para classificar domicílios ou quarteirões segundo risco de ocorrência do vetor, isto é, imóveis ou conjunto de imóveis que pudessem ser considerados chave para o controle do vetor e da doença.

Moloney et al., (1998) utilizaram imagens de baixa resolução espacial para avaliar a presença de criadouros de Ae. aegypti, porém, o uso dessas imagens apresentou resultados limitantes. Beck; Lobitz; Wood, (2000), apresentaram o uso de sensoriamento remoto como novas oportunidades na área da saúde, podendo mapear variáveis ambientais relacionadas a vetores e outras doenças. Alguns estudos têm investigado o potencial desta ferramenta para identificação de áreas de risco para ocorrência de doenças metaxênicas (ZOU; MILLER; SCHMIDTMANN, 2006; EISEN; LOZANO-FUENTES, 2009; LITTLE et al., 2011; RATMANOV; MEDIANNIKOV; RAOULT, 2013; ALMEIDA; WERNECK; RESENDES, 2014; MORENO-MADRIÑÁN et al., 2014). Herbreteau et al., (2007) analisaram 30 anos do 
uso de Sensoriamento Remoto na área de epidemiologia, e identificaram que o uso generalizado de dados espaciais pré-processados e imagens de satélite de baixa resolução espacial em estudos epidemiológicos têm resultado em baixa adequação a questões biológicas.

Com o avanço da tecnologia, os estudos recentemente conduzidos sobre áreas urbanas se utilizam de satélites de alta resolução espacial ou de produtos hiperespectrais gerados por plataformas tais como aviões (em geral, os mesmos ou de mesmo porte que os utilizados em levantamentos aerofotogramétricos tradicionais) e Veículos Aéreos Não Tripulados (VANTs ou drones).

Uma vez que se trabalhe com sensoriamento remoto, uma das ferramentas principais refere-se às técnicas de classificação das imagens. Os algoritmos tradicionais de classificação realizam a classificação pixel a pixel, ou seja, consideram a informação espectral de cada pixel (menor elemento da imagem) para definir regiões homogêneas, podendo ser executados através de métodos estatísticos ou determinísticos. As técnicas tradicionais se baseiam, portanto, apenas na distribuição dos níveis de cinza nas diversas bandas espectrais de uma imagem, podendo ser supervisionadas ou não supervisionadas. Uma das críticas realizadas aos classificadores tradicionais quando se trata de classificação de imagens do ambiente urbano, haja visto sua grande diversidade de materiais, é a sua limitação de distinção de materiais diferentes, porém com resposta espectral semelhante (SOARES MACHADO et al., 2014).

De acordo com Huang et al., (2014), classificação é um problema clássico e básico em muitas áreas do sensoriamento remoto e tem sido amplamente estudado. Ainda segundo esses autores, a classificação fornece um conjunto de parâmetros iniciais fundamentais para várias aplicações do sensoriamento remoto, tais como o mapeamento da cobertura/uso do solo e avaliação ambiental (como ora proposto neste projeto), detecção de mudanças e análise da paisagem.

Como alternativas às imagens de satélite, surgiram no mercado para aplicações de mapeamento, a tecnologia de VANTs (LAGE et al., 2017). Esta tecnologia proporciona baixo custo de aquisição de dados e alta qualidade geométrica, assim como permite que os resultados sejam integrados ao SIG (TAHAR; AHMAD, 2011). Os VANTs podem ser usados para diversas aplicações tais como, documentação arqueológica, agricultura de precisão, cadastro de propriedades, segurança e outras (EISENBEISS et al., 2009).

Uma das grandes vantagens dos VANTs, comparado com os veículos tripulados é a possibilidade de ser usada em situações de alto risco, sem comprometer vidas humanas e 
permitir a obtenção de imagens em dias com alta densidade de nuvens. Além disso, podem ser usados em áreas inacessíveis tais como zonas montanhosas e desérticas, florestas densas, planícies de inundação, zonas com ocorrência de terremotos e bem como zonas com ocorrências de cenas de acidentes (LI et al., 2011). No caso do estudo em foco, permite a observação de imóveis fechados/abandonados ou aqueles que o proprietário não permite a entrada e a visita a trechos urbanos de difícil acesso, como rampas sem asfalto, estreitas e escorregadias (pós chuva), como já constatado em Campinas.

Outra linha de estudo é o de analisar o comportamento do mosquito nos domicílios, que também é possível com as imagens de satélite como artigos publicados por Vargas et al. (2015) e Cole (2007). O que difere do presente projeto com os demais estudos é a interligação dos resultados obtidos em campo em uma cidade grande como Campinas, com a classificação de imagens e as análises espaciais envolvidas.

De acordo com Jensen (2009), as informações sobre a temperatura superficial podem ser obtidas por sensoriamento remoto, tendo em vista que o calor interno de um alvo é convertido em energia radiante e para a maioria dos alvos existe uma alta correlação positiva entre a temperatura cinética verdadeira do alvo e o fluxo radiante proveniente dos mesmos. Nesse sentido, a temperatura de superfície diz respeito ao fluxo de calor dado em função da energia que chega e sai do alvo, sendo de suma importância para o entendimento das interações entre a superfície terrestre e a atmosfera (ADILSON STEINKE; TORRES STEINKE; HIROO SAITO, 2010).

Uma das vantagens do sensoriamento remoto termal é a de proporcionar, em tempo sincronizado, uma densa rede de dados de temperatura de áreas sobre a superfície terrestre, além de permitir o monitoramento e o estudo multitemporal das mesmas. O sensoriamento remoto termal também apresenta desvantagens como o exagero de ruídos e perda de textura devido à atenuação do sombreamento, outro ponto é que não há distinção entre alvos de comportamento espectral semelhante (AMORIM, 2017). As imagens gratuitas disponíveis para a realização do cálculo da temperatura de superfície permitem apenas trabalhar em grandes áreas e com distinções do uso e cobertura do solo.

A hipótese é de que a classificação em imagens de sensores orbitais de alta resolução espacial e algoritmos de classificação de imagens que, associadas às informações do entorno, permitam a identificação de áreas de potenciais criadouros de Ae. aegypti. Neste sentido o processamento das imagens obtidas pelo VANT permitirá a visualização de locais e imóveis não acessíveis pela forma regular, ajudando ao combate e no controle do mosquito e 
consequentemente das arboviroses transmitidas, e permitirá ao programa de combate ao mosquito a otimização de tempo e recurso na intensificação de ações em áreas mais restritas, economizando recursos e tempo gasto na eliminação do mosquito. Esta agilidade significa possibilidade de interferência em tempo hábil evitando desperdício de recurso e aumentando a velocidade de resposta para a intervenção necessária.

Começou durante a Rio+20 um processo de construção coletiva, valendo-se de um conceito que estabelecerá um novo marco global de desenvolvimento, baseado em um novo conjunto de Objetivos de Desenvolvimento Sustentável (ODS), os quais devem guiar os líderes e governança global para superar grandes desafios e garantir um futuro melhor para as novas gerações. Sendo um projeto para a realização de ações relacionadas à pobreza, sustentabilidade do planeta e para garantir que paz e prosperidade a todos (UN, 2014). Entre eles está o $3^{\circ}$ ODS, no qual essa tese está relacionada.

O Objetivo do $3^{\circ}$ ODS da Agenda 2030 tem como finalidade a promoção da saúde física e mental e o bem-estar, com o intuito de aumentar a expectativa de vida para todas as pessoas. Sobretudo, também alcançar a cobertura universal de saúde e acesso a cuidados de qualidade. Acima de tudo, o compromisso é também para acelerar os progressos alcançados até o momento.

Em função do que foi apresentado, consideramos que este projeto tem relevância para o desenvolvimento científico, tecnológico e de inovação. A relevância para o desenvolvimento científico está relacionada ao uso de armadilhas, em conjunto com SIG, técnicas de análise espacial e de sensoriamento remoto para identificação de quarteirões-chave e de sua relação com a ocorrência de Ae. aegypti e, consequentemente, de febre Zika, bem como Dengue e febre Chikungunya.

A relevância para o desenvolvimento tecnológico está em conseguir identificar as regiões de alto risco somente com o uso de sensoriamento remoto (satélite + VANT), sem a necessidade permanente da realização de levantamentos entomológicos. Isso, na prática dos serviços de saúde e de controle de vetores, poderá resultar em otimização na aplicação de recursos e melhoria da efetividade no controle não só do mosquito como também das arboviroses transmitidas por ele.

Devido ao fato de muitas vezes a análise se tornar custosa do ponto de vista computacional, há pesquisa estatística a fim de se buscar alternativas para esta abordagem. Rue et al. (2009) propuseram o método determinístico de aproximação INLA (do inglês, Integrated 
Nested Laplace Approximation) como forma de realizar inferência bayesiana de forma aproximada em modelos latentes gaussianos de forma rápida e eficiente.

O projeto traz inovações ao propor a incorporação de novas ferramentas para a vigilância e controle de vetores, como o uso de armadilhas, uso de SIG e de técnicas de análise espacial, e uso de imagens de satélites e de ortofotos produzidas por VANTs e também a utilização o modelo INLA. 


\section{OBJETIVOS}

\subsection{GERAL}

Propor uma metodologia para a utilização de imagens de sensoriamento remoto de alta resolução espacial e de VANTs, para o reconhecimento de áreas de risco para criadouros de $A e$. aegypti, e a identificação de prováveis locais para a ocorrência dos agravos veiculados pelo mosquito no município de Campinas.

\subsection{ESPECÍFICOS}

- Estimar, por meio da metodologia de krigagem, a distribuição espacial do indicador de quantidade de ovos do mosquito Ae. aegypti coletados nas armadilhas;

- Identificar via imagens de sensoriamento remoto obtidas por satélites e por VANTs, padrões espaciais e espectrais nas imagens que melhor caracterizem as áreas com risco de criadouros do mosquito;

- Avaliar os resultados da aplicação de técnicas de processamento de imagens para a indicação de áreas prioritárias;

- Identificar correlação da temperatura de superfície da área de estudo com a quantidade de ovos do mosquito Ae. aegypti coletados nas armadilhas.

- Identificar classes do uso e ocupação do solo que apresentam as áreas com risco ou proteção de criadouros do mosquito através da metodologia denominada INLA;

- Coligar os dados provenientes de levantamentos feitos pela Imagem de Satélite, VANT e análises espaciais para otimização das rotas de campo e priorização das visitas aos domicílios e ações pelos técnicos; 


\section{FUNDAMENTAÇÃO TEÓRICA}

\subsection{BIBLIOMETRIA}

A revisão bibliográfica conforme Webster e Watson (2002) é considerada uma etapa inicial para qualquer pesquisa científica, assim como, definir as palavras-chaves da pesquisa que se deseja desenvolver. Para Biolchini et al. (2007), é utilizada como um instrumento para mapear trabalhos publicados, para que o pesquisador elabore uma síntese do conhecimento existente sobre o assunto.

De acordo com Narin, Olivastro e Stevens (1994), bibliometria compreende-se como uma técnica quantitativa e estatística de medição dos índices de produção científica, baseado em um conjunto de leis e princípios empíricos para o estabelecimento dos fundamentos teóricos. A bibliometria foi empregada nessa tese com o escopo de determinar o nível de desenvolvimento e perspectivas futuras na área da saúde pública com novas tecnologias, focando na doença da Dengue e o sensoriamento remoto e geoestatistica.

O desenvolvimento desta análise bibliométrica fez uso do software livre VOSviewer, que se utilizado com dados originados de uma fonte confiável, apresenta resultados igualmente confiáveis. Ainda sobre o pré-processamento, o VOSviewer possui várias opções para redução de dados, que são apresentadas na ocasião em que o usuário busca executar seus recursos. Da mesma forma, o VOSviewer possui recursos que atendem às etapas propostas por Salini (2012), a saber: extração de rede (Network Extraction) e normalização (Normalization), utilizando recursos de associação de força, índice de equivalência, etc., mapeamento (por clusters ou outras técnicas), análise, visualização e interpretação.

Um cluster ou aglomerado representa elementos que de alguma forma possuem ligação. Há elementos diretamente ligados e aqueles indiretamente ligados. O VOSviewer possui opção de produzir alguns mapas considerando se serão mostrados todos os itens ou apenas aqueles interligados. As representações que o VOSviewer produz são em duas dimensões, ou seja, considera-se a plotagem dos itens no mapa a partir dos eixos $\mathrm{X}$ e $\mathrm{Y}$.

$\mathrm{Na}$ análise bibliométrica foram examinados os tipos de documentos publicados (artigos, artigos em revistas, artigos em conferências, erratas, revisões, entre outros) através das palavras chaves propostas pelo autor - que se tratam de terminologias derivadas dos títulos originais das obras, a multi-autoria - documentos escritos por mais de um pesquisador, e o índice de colaboração que consiste na média de coautores nos documentos analisados, além de uma breve 
análise de produtividade por autor, apresentando os principais e mais relevantes pesquisadores a respeito do assunto e respectivas publicações ao longo do tempo. Para a pesquisa de trabalhos publicados foram utilizadas duas bases de dados acadêmicos, as quais tem-se acesso, sendo elas: o Google Scholar e Dimensions ( https://app.dimensions.ai/discover/publication). Foram buscadas produções anteriores ao mês de maio de 2020, por um período de 20 anos.

Para atingir o maior número possível de trabalhos relacionados, buscou-se a combinação de palavras chaves sobre o tema em questão, sendo as utilizadas: "Dengue; Remote Sensing", "Dengue; Geostatistics" e "Dengue; Thermal Image". Assim, permitindo encontrar artigos publicados em inglês ou português, nas revistas indexadas nas bases utilizadas neste estudo.

\subsubsection{Palavras chaves: Dengue; Remote Sensing}

A busca genérica retornou 19.860 publicações cientificas no site Dimensions, e no Google Scholar foram encontrados 11.600 documentos. Destes, inicialmente foram filtrados por área do conhecimento e selecionados somente os relacionados ao setor de saúde pública, permanecendo assim 6.132 documentos. O resumo dessas informações é apresentado na Tabela 1.

Tabela 1: Resumo da bibliometria, referente as publicações encontradas no site Dimensions com a palavra-chave "Dengue; Remote Sensing".

\begin{tabular}{|l|c|}
\hline \multicolumn{1}{|c|}{ Descrição } & Resultados \\
\hline Documentos Publicados & 19.860 \\
\hline Documentos Filtrados & 6.132 \\
\hline Citações & 108.000 \\
\hline $\begin{array}{l}\text { Média de citações por } \\
\text { documento }\end{array}$ & 5,45 \\
\hline Autores & 6.036 \\
\hline Multi-autoria (2 autores ou mais) & 4.529 \\
\hline \multicolumn{1}{|c|}{ Tipos de documento } & Resultados \\
\hline Capítulos de livro & 9.948 \\
\hline Artigos & 4.444 \\
\hline Monografias & 1.426 \\
\hline Outros & 4.042 \\
\hline
\end{tabular}

Fonte: Elaborado pela autora. 
O Gráfico 1 apresenta a frequência das publicações no decorrer do tempo, anualmente, nos últimos 10 anos, sendo que no ano de 2020 foram contabilizadas apenas as publicações até maio.

Gráfico 1: Frequência da publicação anual, referente as publicações encontradas no site Dimensions com a palavra-chave "Dengue; Remote Sensing'.

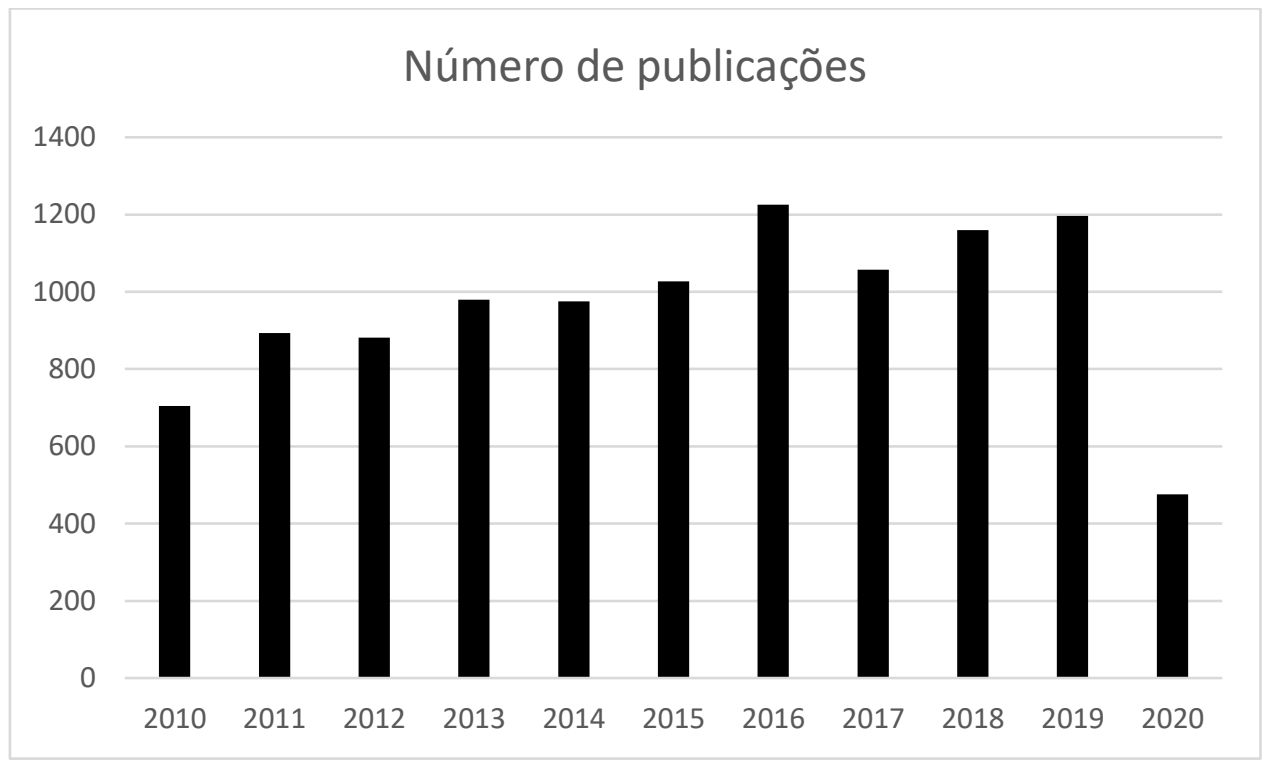

Fonte: Elaborado pela autora.

Os países que mais publicaram artigos científicos dos documentos filtrados a respeito das palavras-chaves foram Estados Unidos da América com 330 publicações, Reino Unido com 140 e a China com 188 publicações. O Brasil é o oitavo colocado no ranking com 69 publicações. Foram classificadas as principais palavras no título dos documentos de acordo com a frequência de ocorrência, neste caso: "Climate Change", "Health human" e "Mapping".

O estudo de Kalluri et al. (2007) é o que contem maior número de citações com 284 até o momento. Esse trabalho faz uma revisão do uso do sensoriamento remoto para a classificação de imagens do uso do solo para identificar, caracterizar e cartografar os habitats de doenças transmitidas por vetores que evoluíram significativamente ao longo dos últimos 25 anos. A convergência desses dados com os dados epidemiológicos georeferrenciados e a colaboração e a disponibilidade de especialistas multidisciplinares ajudam ao controle das doenças transmitidos por arboviroses.

Khormi e Kumar (2011) também apresentam um estudo com muitas citações onde modelam áreas onde existe um risco de prevalência da dengue, em função da relação espacial entre os casos de dengue e os diferentes parâmetros socioeconômicos. O sensoriamento remoto 
é empregado para verificar as densidades de casas, largura dos telhados e larguras das casas, resultando em um dado para agregar no modelo de regressão, com o objetivo de identificar os níveis de risco de dengue e descrever associações entre os casos de dengue e fatores socioeconômicos. Os resultados mostraram que houve uma forte associação positiva entre os casos de dengue e fatores socioeconômicos.

\subsubsection{Palavras chaves: Dengue; Geostatistics}

A busca genérica retornou 20.675 publicações cientificas no site Dimensions, e no Google Scholar foram encontrados 6.380 documentos. Destes inicialmente foram filtrados por área do conhecimento selecionado somente os relacionados a setor de saúde pública, permanecendo assim 4.851 documentos, como o resumo dessas informações apresenta na Tabela 2.

Tabela 2: Resumo da bibliometria, referente as publicações encontradas no site Dimensions com a palavra-chave "Dengue; Geostatistics".

\begin{tabular}{|l|c|}
\hline \multicolumn{1}{|c|}{ Descrição } & Resultados \\
\hline Documentos Publicados & 20.675 \\
\hline Documentos Filtrados & 4.851 \\
\hline Citações & 54.000 \\
\hline $\begin{array}{l}\text { Média de citações por } \\
\text { documento }\end{array}$ & 14,1 \\
\hline Autores & 7.110 \\
\hline Multi-autoria (2 autores ou mais) & 5.577 \\
\hline \multicolumn{1}{|c|}{ Tipos de documento } & Resultados \\
\hline Capitulo de livro & 280 \\
\hline Artigo & 3.253 \\
\hline Monografia & 24 \\
\hline Outros & 17.118 \\
\hline
\end{tabular}

Fonte: Elaborado pela autora. 
O Gráfico 2 apresenta a frequência das publicações no decorrer do tempo, anualmente, nos últimos 10 anos, sendo que no ano de 2020 foram contabilizadas apenas as publicações até maio.

Gráfico 2: frequência da publicação anual, referente as publicações encontradas no site Dimensions com a palavra-chave "Dengue; Geostatistic".

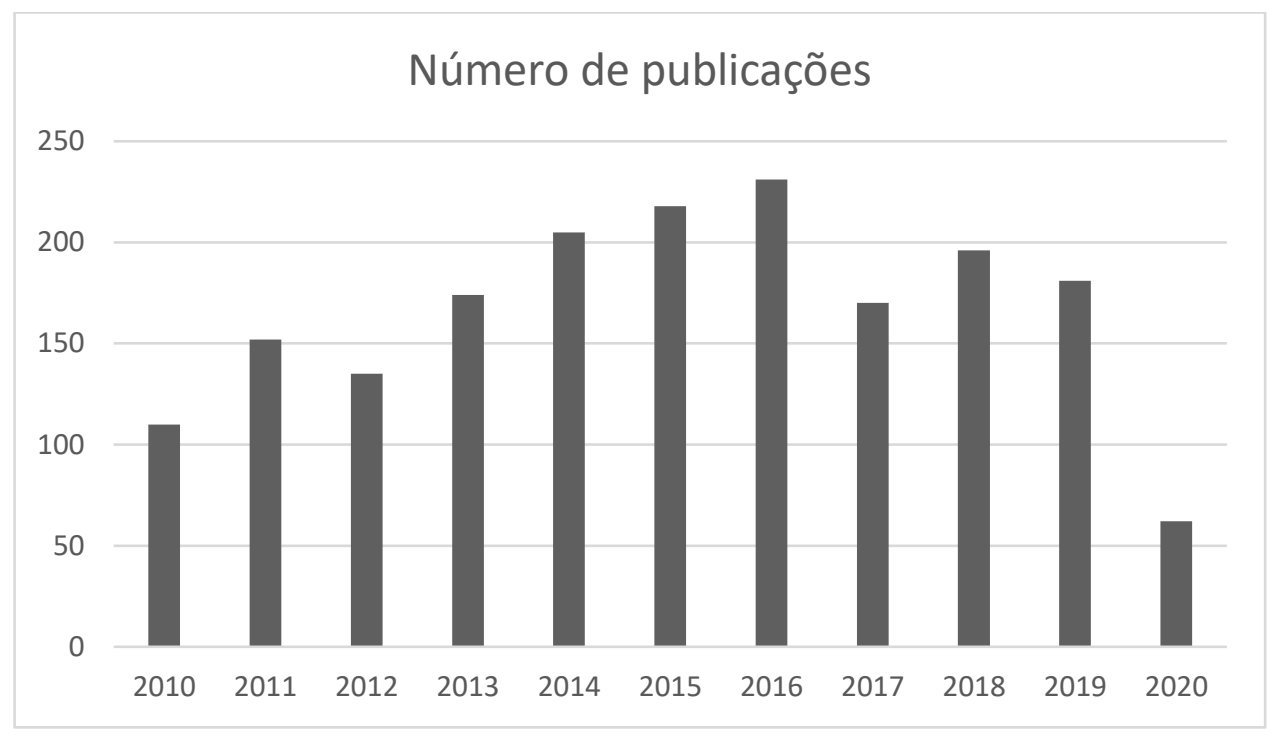

Fonte: Elaborado pela autora.

Os países que mais publicaram artigos científicos dos documentos filtrados mais relevantes a respeito das palavras-chaves foram China com 309, Estados Unidos da América com 134 publicações e Índia com 79 publicações. O Brasil é o décimo quinto colocado no ranking com 17 publicações. Foram classificadas as principais palavras no título dos documentos de acordo com a frequência de ocorrência, neste caso: "Method", "Remote Sensing Image" e "Detection".

Diggle et al. (2002) apresentam um dos estudos mais relevantes nesse conjunto de palavras-chaves, onde desenvolve um modelo linear misto espacialmente generalizado para descrever a variação da prevalência da malária entre uma amostra de crianças residentes na Gâmbia (país da África Ocidental). Utilizando o método Baysiano com dados coletados no país de crianças com presença de parasitas maláricos no sangue, se possuem ou não uma rede na cama denominada mosqueteira e também com informações geradas por imagem de satélite informando a vegetação do ambiente em que essas crianças moram. Assim os resultados confirmaram e quantificaram as variações espaciais e não espaciais do aumento progressivo da prevalência com os efeitos de proteção das mosqueteiras, indicando o uso da rede como uma ferramenta de controle da doença. 


\subsubsection{Palavras chaves: Dengue; Thermal Image}

A busca genérica retornou 24.180 publicações cientificas no site Dimensions, e no Google Scholar foram encontrados 13.800 documentos. Destes inicialmente foram filtrados por área do conhecimento selecionado somente os relacionados a setor de saúde pública, permanecendo assim 5.675 documentos. O resumo dessas informações é apresentado na Tabela 3.

Tabela 3: Resumo da bibliometria, referente as publicações encontradas no site Dimensions com a palavra-chave "Dengue; Thermal Image".

\begin{tabular}{|l|c|}
\hline \multicolumn{1}{|c|}{ Descrição } & Resultados \\
\hline Documentos Publicados & 24.180 \\
\hline Documentos Filtrados & 5.675 \\
\hline Citações & 134.000 \\
\hline $\begin{array}{l}\text { Média de citações por } \\
\text { documento }\end{array}$ & 5,46 \\
\hline Autores & 8.572 \\
\hline Multi-autoria (2 autores ou mais) & 6.549 \\
\hline \multicolumn{1}{|c|}{ Tipos de documento } & Resultados \\
\hline Capitulo de livro & 16.681 \\
\hline Artigo & 4.931 \\
\hline Monografia & 615 \\
\hline Outros & 1.953 \\
\hline
\end{tabular}

Fonte: Elaborado pela autora.

O Gráfico 3 apresenta a frequência das publicações no decorrer do tempo, anualmente, nos últimos 10 anos, sendo que no ano de 2020 foram contabilizadas apenas as publicações até maio. 
Gráfico 3: Frequência da publicação anual, referente as publicações encontradas no site Dimensions com a palavra-chave "Dengue; Thermal Image".

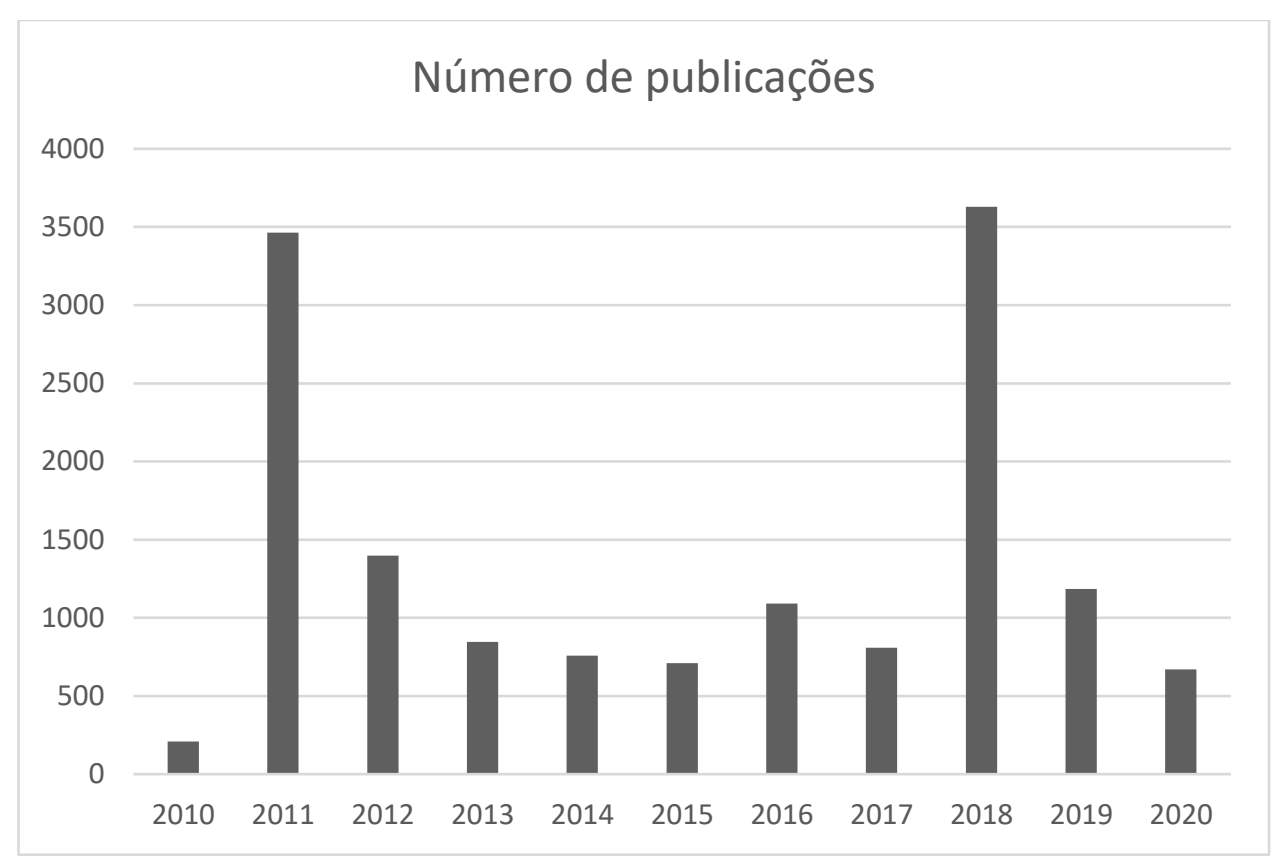

Fonte: Elaborado pela autora.

Os países que mais publicaram artigos científicos dos documentos filtrados mais relevantes a respeito das palavras-chaves foram Estados Unidos da América com 394, China com 200 publicações e Índia com 145 publicações. O Brasil é o quarto colocado no ranking com 122 publicações. Foram classificadas as principais palavras no título dos documentos de acordo com a frequência de ocorrência, neste caso: "Effect", "Mosquito" e "Impact".

Estudos que se destacam com número de citações, por exemplo Tun-Lin, Burkot e Kay (2000), empregaram as imagens termais para apresentar os efeitos da temperatura para o desenvolvimento de Ae. aegypti na Austrália. O resultado obtido mostra que o desenvolvimento do mosquito variou de acordo com a posição do recipiente (ou seja, sombreado ou exposto) e a disponibilidade de recursos alimentares, bem como inversamente com a temperatura. Estes dados indicam que os recipientes com abundância de matéria orgânica ou os que se encontram entre folhagem ou copas de árvores lugares mais frescos e com sombra (por exemplo, copos de plástico e pneus fora de uso) tendem a produzir maiores Ae. aegypti adultos, assim eles tinham um desenvolvimento mais rápido e uma melhor sobrevivência.

Outro estudo também da Austrália que aplicou a metodologia de imagens de satélite com o objetivo de analisar o impacto do clima com o mosquito Ae. aegypti foi Kearney et al. (2009), onde foi desenvolvida uma abordagem para calcular a profundidade da água e os ciclos 
diários de temperatura em recipientes com dimensões, captação e grau de sombra diferentes para avaliar a adequação do mosquito no habitat na fase do ciclo de vida aquática.

\subsection{DENGUE}

Dengue é uma doença viral de transmissão vetorial causada por um dos quatro sorotipos do vírus dengue (DENV-1, DENV-2, DENV3 e DENV-4), pertencentes ao gênero Flavivirus, da família Flaviviridae (TAUIL, 2001). É endêmica de regiões tropicais como o sudeste asiático, sul do Pacífico, África Oriental, Caribe e América Latina. Atualmente vem preocupando as autoridades em saúde em quase todo o mundo, devido à sua ampla distribuição e ao grande potencial para causar casos graves e letais (GUZMAN; HARRIS, 2015).

A OMS (WHO, 2014), considera a dengue um dos maiores problemas de saúde pública, com cerca de 100 milhões de casos anualmente no mundo, sendo que mais de 2,5 bilhões de pessoas vivem em área sob risco de infecção. É uma doença febril, que pode ser de curso benigno ou grave. Dependendo de suas manifestações recebe a seguinte tipologia: infecção inaparente, dengue e dengue grave.

O vírus é transmitido ao homem pela picada do mosquito fêmea infectado do gênero Aedes, em particular pela espécie Ae. aegypti (WHO, 2009). Ae. aegypti é uma das mais de 500

espécies de Aedes (Diptera: Culicidae), gênero com ampla distribuição e adaptabilidade. É considerada uma espécie autóctone do continente africano e acredita-se que a Etiópia tenha sido o centro da dispersão.

O vetor põe seus ovos nas folhas de plantas que armazenam água (p.ex. bromélias) ou nas paredes de recipientes, como pneus, vasos e pias, entre outros. São locais que se constituem em criadouros naturais e artificiais, respectivamente, sendo esses últimos os mais importantes do ponto de vista epidemiológico (BRASIL, 2016).

Os mosquitos se desenvolvem através de metamorfose completa e o ciclo de vida de Ae. aegypti compreende quatro fases: ovo, larva (quatro estágios larvários), pupa e adulto (MINISTÉRIO DA SAÚDE, 2001). Os ovos, que podem resistir por vários meses à dessecação, eclodem após a submersão. A transmissão dos vírus de dengue pode ocorrer depois de um período de incubação, no qual há multiplicação viral (MINISTÉRIO DA SAÚDE, 2001). Ao 
longo da vida, de aproximadamente dois meses, uma única fêmea de Ae. aegypti é capaz de transmitir os vírus da dengue até 12 vezes ou mais (MENDONÇA; SOUZA; DUTRA, 2009).

O mosquito possui hábitos domésticos e a grande variedade de criadouros potenciais encontrados no peridomicílio e no intradomicílio garante a manutenção de altas densidades de Ae. aegypti no meio urbano, potencializando os riscos de transmissão da doença (TAUIL, 2001). Uma vez que a dispersão de dengue se processa principalmente de domicílio a domicílio e de modo contínuo, em geral, epidemias de dengue nas áreas urbanas são explosivas e envolvem porções apreciáveis da população, especialmente durante as estações chuvosas quando existe uma maior abundância do vetor.

Os métodos de controle direto têm apresentado baixa efetividade e altos custos. Diante disto e da gravidade da doença, tem sido discutido e adotadas outras estratégias de prevenção, baseadas na participação comunitária, educação em saúde e na melhoria das condições socioambientais da população (FAVARO et al., 2013).

Os fatores de risco para transmissão da dengue estão relacionados aos chamados macrofatores e microfatores. Entre os macrofatores se encontram os fatores de risco sociais e ambientais e entre os microfatores estão as características biológicas do vírus, do vetor e do hospedeiro (RODRÍGUEZ CRUZ, 2002).

\subsubsection{Dengue no Estado de São Paulo}

No Estado de São Paulo, a transmissão de dengue, provada laboratorialmente, foi identificada pela primeira vez em 1987, nos municípios de Guararapes (30 casos) e Araçatuba (16 casos) (ROCCO et al., 2012).

O Estado de São Paulo, nos últimos anos, tem convivido com significativo aumento do número de casos e com o ingresso de novos municípios com casos. Observam-se picos epidêmicos aproximadamente a cada três anos bem como aumento do número de casos no ano subsequente (ROCCO et al., 2012).

No município de Campinas, em 1996 foi detectado o primeiro caso da doença. Desde o registro do primeiro caso, a doença vem sendo detectada anualmente na cidade, com a circulação, desde então, dos quatro sorotipos do vírus da dengue. O ano de 2007 foi marcado pela a maior epidemia de dengue na cidade, com incidência de 1.089,4 casos/100.000 habitantes 
(ROCCO et al., 1998). Segundo a Prefeitura de Campinas até o início de setembro de 2019, foram confirmados 25.576 casos de dengue no município de Campinas.

Para Guollo et al. (2011), as variáveis demográficas contribuem para investigar a tendência do coeficiente de incidência de dengue (número de casos por 100 mil habitantes), identificando a distribuição temporal da doença. De acordo com o Sistema Nacional de Agravos de Notificação (SINAN), a distribuição dos casos confirmados de dengue autóctones no Estado de São Paulo em 2014, destacaram a cidade de São Paulo com 31.101 casos registrados da doença com uma Taxa de incidência de 261,45. A cidade de Campinas foi a segunda com maior registro de casos (42.122) identificando uma taxa de incidência de 3,65.

\subsubsection{Dengue e localização}

Segundo Ferreira e Chiaravalloti-Neto (2007) as condições socioeconômicas e ambientais têm grande influência na produção, distribuição e propagação de doenças. O mundo moderno apresenta as condições favoráveis para a rápida expansão da dengue. A urbanização acelerada criou cidades com deficiências de abastecimento de água e de limpeza urbana, com intensa utilização de materiais não biodegradáveis, como recipientes descartáveis, de borracha, plástico e vidro que proporcionam condições ecológicas favoráveis à transmissão dos vírus da dengue pelo Aedes aegypti (SINGHI; KISSOON; BANSAL, 2007; WHO, 2009).

O aprofundamento no conhecimento das condições de vida e das prioridades comunitárias, implantação de políticas de saneamento eficaz, regularização do abastecimento de água e difusão de informações geograficamente localizadas, parecem ser caminhos que apontam não só para reduzir vulnerabilidades à dengue e outras doenças, como também para uma melhoria da qualidade geral de vida da população (CLARO; TOMASSINI; ROSA, 2004).

A dimensão espacial é uma preocupação que se apresenta ao longo da história da epidemiologia e saúde pública, incluindo os registros que se referem ao pensamento de Hipócrates, que explorou a relação entre saúde e meio ambiente, com ênfase nas características físicas do ambiente e características culturais dos habitantes de um lugar. Destacando-se, nesse contexto, a notória e pioneira pesquisa de John Snow, nos estudos da cólera na Inglaterra em 1853 (PFEIFFER et al., 2008). 
A evolução do conhecimento, sua especialização e segmentação em diferentes áreas, tem levado ao desenvolvimento de abordagens teóricas e metodológicas que têm contribuído para a compreensão da saúde a partir de perspectivas diferentes, como uma expressão da relação entre o espaço-sociedade (SILVA, 1997).

Assumindo-se o pressuposto de que a doença é considerada uma manifestação do indivíduo, as condições de vida são manifestações do lugar (CLARO; TOMASSINI; ROSA, 2004). O lugar, por sua vez, é pensado como um espaço organizado para análise e intervenções, no qual se deve buscar a identificação da situação de saúde com os seus determinantes culturais, ambientais e sociais (LOPES; NOZAWA; LINHARES, 2014).

Nesse sentido, a unidade espaço/população tem, então, a possibilidade de ser uma unidade em que operam os processos determinantes (condição de vida), expressam-se os problemas de saúde e desenvolvem-se as ações de saúde e bem-estar. O espaço geográfico é uma categoria de síntese que abriga a dimensão simbólica das relações sociais, na qual se expressam os fatores relacionados com o desenvolvimento das doenças e da sua distribuição entre os diversos grupos sociais (BARCELLOS; BASTOS, 1996).

Os estudos locais permitem a observação de variáveis e indicadores que em outros níveis de análise não seriam perceptíveis, uma vez que cada localidade possui uma historicidade própria, fruto de processos sociais e políticos singulares (FLAUZINO et al., 2009).

\subsection{SENSORIAMENTO REMOTO}

\subsubsection{Conceitos Básicos}

O sensoriamento remoto pesquisa a relação entre as características do objeto alvo e a energia eletromagnética refletida, emitida ou espalhada por ele. Por meio da identificação do comportamento espectral de superfície como o solo, água e vegetação, é possível associar informações qualitativas e quantitativas destes alvos (JENSEN, 2009). Deste modo, cada tipo de material ou superfície retrata determinadas características únicas de comportamento espectral, ou seja, cada alvo é identificado pela sua assinatura espectral, a qual está diretamente associada às suas propriedades físicas, químicas, biológicas ou geométrica (NOVO, 2010).

As imagens de sensoriamento remoto exibem propriedades espaciais que oferecem

vantagens para o estudo da superfície da Terra. É possível ver o que o olho humano, sozinho, 
não conseguiria. Também é praticável, através do processo de classificação de uma imagem, o reconhecimento de padrões, forma, tamanho, entre outras características (CAMPBELL; WYNNE., 2011). Tem por objetivo atribuir pixels ou regiões individuais (características semelhantes) a uma classe definida (KÖRTING et al., 2014). Segundo Monteiro; Lingnau; Souza, (2007), uma classe é definida por meio de critérios que servem para descrever os indivíduos que nela se encontram. Neste caso, os atributos espectrais e/ou espaciais caracterizam estes critérios.

De acordo com Cole, (2007), a expressão sensoriamento remoto surgiu para descrever o processo de observação, mensuração e identificação de objetos sem estar em contato com eles. Porém, segundo Jensen, 2009, esta é uma definição muito ampla, sendo também possível a obtenção de informações sobre objetos sem estar em contato físico com eles, por exemplo, o aparelho de telefonia móvel, celular. Desta forma, podemos concluir que é preciso estreitar a definição de sensoriamento remoto (ROSA, 2005).

A definição adotada nesse trabalho é a dada por Campbell e Wynne (2011). Para eles, sensoriamento remoto é:

\footnotetext{
“A prática de derivar informação sobre as superfícies terrestres e aquáticas da Terra utilizando imagens adquiridas numa perspectiva aérea, utilizando radiação eletromagnética numa ou mais regiões do espectro eletromagnético, refletida ou emitida a partir da superfície da Terra. A forma usual de representar as imagens é um conjunto de números gravados em modo digital - A imagem é representada por pixels que contém informação sobre o brilho de um objeto gravado digitalmente como um valor numérico" (CAMPBELL; WYNNE., 2011).
}

A aquisição de dados de sensoriamento remoto é feita por sistema de sensores, os quais são responsáveis pela conversão da Radiação Eletromagnética (REM) em um registro na forma de imagem ou gráfico que permita a interpretação do comportamento espectral do material de estudo (NOVO, 2010). Os sensores remotos podem ser caracterizados de acordo com diferentes resoluções sendo estas: temporal, radiométrica, espectral e espacial.

A resolução temporal de um sensor significa que no intervalo de tempo entre dois imageamentos sucessivos ou duas aquisições de dados. Este parâmetro é fundamental para estudos de processos periódico, como por exemplo, o e de monitoramento ambiental, pois a 
análise de dados temporais ajuda no entendimento de como o elemento ou fenômeno se compreende ou se está modificando com o passar do tempo (JENSEN, 2009).

A resolução radiométrica está vinculada à sensibilidade do sensor de detectar, registrar e reproduzir as variações nos níveis de energia (REM) refletida, emitida ou retro-espalhada pelo objeto alvo (JENSEN, 2009; NOVO, 2010). Crósta (1992) e Meneses (2012) afirmam que a resolução radiométrica é dado pelo número de níveis digitais (quantização) representando níveis de cinza usados para expressar os dados coletados pelo sensor, expressos em número binários (bits). Assim, altas resoluções radiométricas aumentam a probabilidade de se obter informações mais precisas acerca do fenômeno em estudo (JENSEN, 2009).

Outra particularidade é a resolução espectral, ou seja, quando a imagem é definida pelo número de bandas espectrais de um sistema sensor e pela largura do comprimento de onda coberta por cada banda (CRÓSTA, 1992). Meneses (2012) apresenta que além do número e largura das bandas, a posição das bandas ao longo do espectro eletromagnético também um é aspecto a ser considerado. Assim, quanto maior o número de bandas posicionadas em diferentes regiões do espectro eletromagnético e com faixas mais estreitas de comprimento de onda, maior será a resolução espectral do sistema sensor.

A resolução espectral, seus sensores podem ser especificados de acordo com a quantidade de bandas que é capaz de detectar. Sensores multiespectrais são capazes de detectar, por exemplo, quatro regiões espectrais de uma mesma cena, compreendendo bandas da região do visível, infravermelho próximo (NIR, sigla em inglês de Near Infrared), infravermelho de ondas curtas (SWIR, sigla em inglês de Short-Wave Infrared) e infravermelho termal (NOVO, 2010). Entre essas bandas podem existir lacunas (faixas de comprimentos de onda não identificáveis pelo sensor), e a largura das regiões do espectro são tipicamente maiores. Já os sensores hiperespectrais e ultraespectrais apresentam maior refinamento das faixas de comprimento de onda e maior sensibilidade com um maior número de bandas, podendo registrar espectros contínuos (mais de 100 bandas) para cada pixel da imagem (JENSEN, 2009; NOVO, 2010).

Resumidamente, a resolução espacial de uma imagem é determinada pela capacidade do sensor remoto em detectar objetos na superfície terrestre. Segundo Jensen (2009), há uma relação geral entre o tamanho de um objeto ou área a ser identificada e a resolução espacial de um sistema de sensoriamento remoto. Crósta (1992) destaca que quanto menor for o objeto possível de ser visto, maior deverá ser a resolução espacial da imagem. 
Nota-se, que a resolução espacial de uma imagem está diretamente vinculada ao nível de aquisição desta imagem. A altura do sensor remoto empregado em relação ao alvo define o que se convencionou chamar de nível de aquisição de dados. Estes níveis dependem do veículo ou sistema de suporte (denominado de plataforma) para a operação de um sistema sensor (NOVO, 2010).

Existem essencialmente três níveis de coleta de dados por sensoriamento remoto, que se diferenciam particularmente em relação a altitude da plataforma utilizada, sendo estes: nível de campo/laboratório, nível de aeronave e nível orbital (FLORENZANO, 2002; NOVO, 2010).

As plataformas terrestres, que coletam dados em nível de campo, muito utilizadas em espectroscopia de campo, também podem ser utilizadas em nível de laboratório com uso de dispositivos espectrorradiométricos manuais (MILTON et al., 2009). Importante destacar que medições de reflectância realizadas in situ são muito utilizadas para calibrar medidas de reflectância espectral obtidas por um sistema de sensoriamento remoto (JENSEN, 2009).

Os dados coletados ao nível de aeronave são mais adequados para aplicações com requisitos de alta resolução espacial, podendo ser adquiridos por sistemas sensores de varredura óptico-eletrônico, sistemas fotográficos ou radar, como o Light Detection and Ranging (LiDAR) é uma tecnologia óptica de detecção remota que mede propriedades da luz refletida de modo a obter a distância e/ou outra informação a respeito um determinado objeto distante, por exemplo, e a resolução espacial destes dados dependerá da altura do voo no momento do aerolevantamento (MORAES, 2002). Segundo Novo (2010), as aquisições de dados ao nível de aeronave podem ser aplicadas para: identificar alvos presentes em classes espectrais discriminadas em imagens orbitais; validação de dados orbitais; ou, para levantamento de informações específicas.

A energia registrada pelo sensor não se atribui necessariamente a um determinado objeto, mas, conforme sua resolução espacial, a um arranjo de objetos da cena que podem apresentar características diferentes, fazendo com que a imagem captada não represente com veracidade as características dos objetos nela presentes. Neste sentido, Florenzano (2002) destaca que a seleção do nível de aquisição de dados depende do objetivo para o qual os dados são adquiridos, pois esta escolha pode interferir no comportamento espectral dos objetos de estudo. 
Logo, as características espaciais, temporais, espectrais e radiométricas dos produtos imageados dependem, principalmente, da configuração do sistema sensor e da plataforma utilizada durante a aquisição de dados.

A escolha do sensor adequado ao projeto dependerá do objeto ou fenômeno de estudo e as informações e resultados que se quer obter. Certas regiões e bandas do espectro eletromagnético podem ser relacionadas com certas características químicas, biológicas e físicas do material de estudo. Assim, a seleção correta das bandas influenciará diretamente na resolução espectral do produto gerado, tendo em vista que esta escolha deve maximizar o contraste entre o objeto de interesse e os demais elementos (fundo) (JENSEN, 2011).

O conhecimento prévio do comportamento espectral do alvo de interesse também é importante na definição dos sensores, na definição do tipo de processamento a que devem ser submetidos os dados, assim como na definição da forma de aquisição dos mesmos (NOVO, 2010).

Após a seleção do sensor remoto mais condizente com o objetivo da pesquisa, e respectivamente da imagem a ser utilizada, cabe ao pesquisador ter o conhecimento sobre o tipo de processamento que será necessário que esta imagem possa, então, ser considerada como objeto final de análise e interpretação da superfície terrestre. Desta forma, serão discutidos a seguir alguns aspectos referentes ao processamento digital de imagens.

O sensoriamento remoto é uma tecnologia que avança rapidamente, principalmente impulsionado pelo desenvolvimento de sensores de imagem e aumentando o seu desempenho e a infraestrutura da informação, incluindo o processamento, armazenamento e comunicação. Além disso, as novas plataformas introduzidas, como por exemplo o VANT estão em rápido crescimento (COLOMINA; MOLINA, 2014; PAJARES, 2015; WATTS; AMBROSIA; HINKLEY, 2012). De fato, a taxa de mudança manteve-se continuamente aumentando nos últimos anos, como novos sensores de imagem, bem como poderosos métodos de processamento de dados/informação têm sido introduzidos e, subsequentemente, aumentando significativamente as aplicações, resultando num forte crescimento no mercado do sensoriamento remoto (PAJARES, 2015).

Os sensores de imagem são o componente central de qualquer sensoriamento remoto e vêm com uma grande variedade de sistemas espaciais, temporais e resoluções espectrais. As implementações de sistemas de sensores mostram diversidade, incluindo configurações de sensores únicos ou múltiplos, soluções de detecção ativa ou passiva (TOTH; JÓŹKÓW, 2016). 
As tecnologias de sensores têm mostrado desenvolvimentos notáveis na última década, e, em particular, a detecção óptica avançou muito devido à produção em massa de sensores amplamente utilizados em câmeras digitais e smartphones de consumo.

Os dados do sensoriamento remoto são coletados usando sistemas de sensores passivos ou ativos. Os sensores passivos ou ópticos utilizam apenas a REM natural refletida ou emitida a partir da superfície terrestre. A luz solar é a principal fonte de REM desse tipo de sensor. Já os sensores ativos utilizam a REM artificial, produzida por sensores como micro-ondas (RADAR, LIDAR ou SONAR), cuja a energia é gerada pelo próprio equipamento e depois registra a quantidade de fluxo radiante espalhado de volta em direção ao sistema solar. A diferença das suas características desses dois tipos de sensores é apresentada na Tabela 4.

Tabela 4: Parâmetros dos sensores ativos e sensores ativos

\begin{tabular}{|c|c|c|}
\hline Parâmetro & Sensores Passivos & Sensores Ativos \\
\hline Faixa espectral & Visível e infravermelho & Micro-ondas \\
\hline $\begin{array}{l}\text { Tipo de energia } \\
\text { eletromagnética }\end{array}$ & Não polarizada & Polarizada \\
\hline Visada & Nadir & Vertical \\
\hline Energia refletida & Reflectância & Retroespalhamento \\
\hline Efeito da atmosfera & $\begin{array}{l}\text { Absorção e } \\
\text { espalhamento }\end{array}$ & Sem efeito \\
\hline $\begin{array}{c}\text { Características do } \\
\text { alvo }\end{array}$ & Propriedades químicas & $\begin{array}{l}\text { Propriedades } \\
\text { geométricas }\end{array}$ \\
\hline
\end{tabular}

Fonte: Elaborado pela autora.

Os sensores espaciais com o objetivo de gerar imagens com satélites existem há mais de 40 anos. O satélite LANDSAT-1 foi lançado em 1972, seguido de SPOT-1 em 1986 e 
IKONOS em 1999 (Figura 1). As imagens adquiridas por estes sistemas são verdadeiramente acessíveis. Atualmente cerca de 50 países operam satélites para a detecção remota com diversos sensores e diversos propósitos. No Gabinete das Nações Unidas para os Assuntos Espaciais Exteriores, onde os lançamentos no espaço são registados, existem atualmente mais de 7000 registos de objetos lançados e aplicações de lançamento de mais de 70 países e organizações (TOTH; JÓŹKÓW, 2016).

Figura 1: Cronologia dos satélites de Observação da Terra

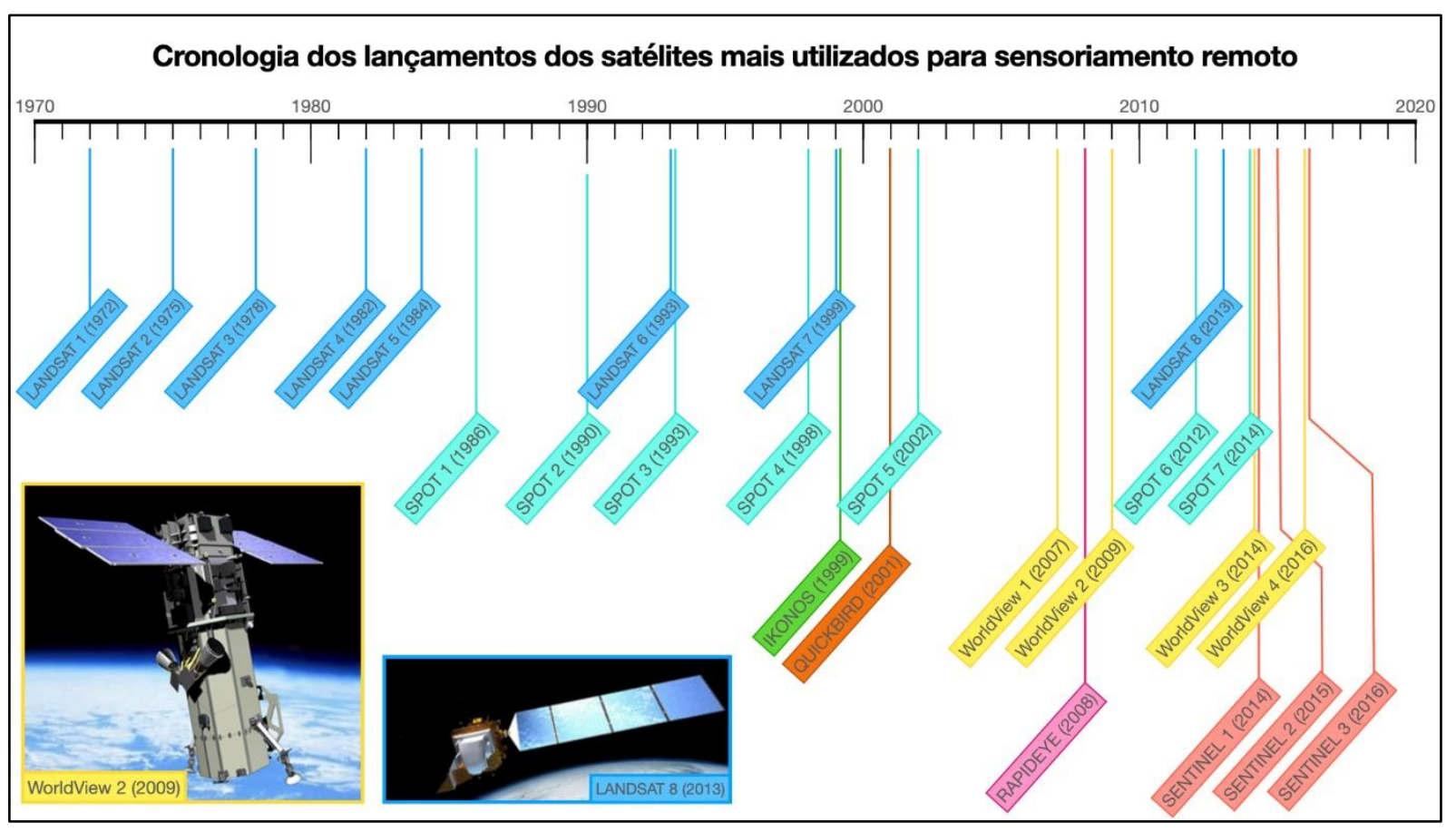

Fonte: Elaborado pela autora.

A Tabela 5 apresenta as principais categorias de satélites com parâmetros básicos de seus sensores representativos. Os sistemas baseados em satélite continuam a melhorar em imagem e desempenho, incluindo melhor resolução espacial e espectral como bem como a agilidade do sensor (POLI; TOUTIN, 2012). Os satélites orbitam com sensores específicos (KRIEGER et al., 2007), e, mais genericamente, em constelações, permitindo tempos de revisão mais curtos, assim qualquer ponto da Terra pode ser observado várias vezes ao dia (MURTHY et al., 2014). 
Tabela 5: Principais parâmetros dos satélites.

\begin{tabular}{|c|c|c|c|c|c|c|}
\hline Satélites & $\begin{array}{l}\text { Lança- } \\
\text { mento }\end{array}$ & País & $\begin{array}{c}\text { Situação } \\
\text { atual }\end{array}$ & Sensor & $\begin{array}{c}\text { Resolução } \\
\text { Espacial }\end{array}$ & $\begin{array}{c}\text { Período } \\
\text { de } \\
\text { Revisita }\end{array}$ \\
\hline LANDSAT 1 & 1972 & EUA & Inativo & RBV e MSS & $80 \mathrm{~m}$ & 18 dias \\
\hline LANDSAT 2 & 1982 & EUA & Inativo & RBV e MSS & $80 \mathrm{~m}$ & 18 dias \\
\hline LANDSAT 3 & 1978 & EUA & Inativo & RBV e MSS & $30 \mathrm{~m}$ & 18 dias \\
\hline LANDSAT 4 & 1982 & EUA & Inativo & MSS e TM & $80 \mathrm{~m}$ & 16 dias \\
\hline LANDSAT 5 & 1984 & EUA & Inativo & MSS e TM & $80 \mathrm{~m}$ & 16 dias \\
\hline LANDSAT 6 & 1993 & EUA & Inativo & ETM & $30 \mathrm{~m}$ & 16 dias \\
\hline LANDSAT 7 & 1999 & EUA & $\begin{array}{c}\text { Ativo com } \\
\text { restrição }\end{array}$ & ETM+ & $15 \mathrm{~m}$ & 16 dias \\
\hline LANDSAT 8 & 2013 & EUA & Ativo & OLI e TIRS & $15 \mathrm{~m}$ & 16 dias \\
\hline SPOT 1 & 1986 & França & Inativo & HRV & $10 \mathrm{~m}$ & 26 dias \\
\hline SPOT 2 & 1990 & França & Inativo & HRV & $10 \mathrm{~m}$ & 26 dias \\
\hline SPOT 3 & 1993 & França & Inativo & HRV & $10 \mathrm{~m}$ & 26 dias \\
\hline SPOT 4 & 1998 & França & Ativo & $\begin{array}{c}\text { HRV e } \\
\text { VEGETATION }\end{array}$ & $10 \mathrm{~m}$ & 26 dias \\
\hline SPOT 5 & 2002 & França & Ativo & $\begin{array}{c}\text { HRV e } \\
\text { VEGETATION e } \\
\text { VEGETATION-2 }\end{array}$ & $5 \mathrm{~m}$ & 26 dias \\
\hline SPOT 6 & 2012 & França & Ativo & NAOMI & $2 \mathrm{~m}$ & 3 dias \\
\hline SPOT 7 & 2014 & França & Ativo & NAOMI & $2 \mathrm{~m}$ & 3 dias \\
\hline IKONOS & 1999 & EUA & Inativo & PAN e MS & $1 \mathrm{~m}$ & 3 dias \\
\hline QUICKBIRD & 2001 & EUA & Inativo & PAN e MS & $60 \mathrm{~cm}$ & 3,5 dias \\
\hline WorldView-1 & 2007 & EUA & Ativo & PAN & $50 \mathrm{~cm}$ & 1,7 dias \\
\hline WorldView-2 & 2009 & EUA & Ativo & PAN e MS & $46 \mathrm{~cm}$ & 1,1 dias \\
\hline WorldView-3 & 2014 & EUA & Ativo & $\begin{array}{c}\text { PAN, MS e } \\
\text { CAVIS }\end{array}$ & $1,84 \mathrm{~m}$ & 3 dias \\
\hline WorldView-4 & 2016 & EUA & Inativo & Spaceview 110 & $1,84 \mathrm{~m}$ & 3 dias \\
\hline RAPIDEYE & 2008 & Alemanha & Ativo & REIS & $6,5 \mathrm{~m}$ & $1 \mathrm{dia}$ \\
\hline SENTINEL 1 & 2014 & $\begin{array}{c}\text { União } \\
\text { Européia }\end{array}$ & Ativo & SAR & $5 \mathrm{~m}$ & 6 dias \\
\hline SENTINEL 2 & 2015 & $\begin{array}{c}\text { União } \\
\text { Européia }\end{array}$ & Ativo & MSI & $10 \mathrm{~m}$ & 5 dias \\
\hline SENTINEL 3 & 2016 & $\begin{array}{c}\text { União } \\
\text { Européia }\end{array}$ & Ativo & $\begin{array}{l}\text { OLCI, SLSTR, } \\
\text { SRAL, MWR }\end{array}$ & $300 \mathrm{~m}$ & 2 dias \\
\hline
\end{tabular}


As primeiras constelações de satélites foram gradualmente formadas por satélite com sensores que a tecnologia permitia na época, com o passar do tempo eles foram atualizando e melhorando seus sensores e lançando satélites com um melhor desempenho. Famílias LANDSAT, SPOT E GEOEYE/WORLDVIEW representaram as primeiras constelações deste tipo. O sistema RapidEye já foi concebido como cinco satélites idênticos instalados na mesma órbita para reduzir o tempo de aquisição repetida (TYC et al., 2005). O programa Copérnico da Agência Espacial Europeia (ESA do inglês European Space Agency) inclui o Sentinel que se afasta do modelo padrão, uma vez que diferentes sensores serão instalados em satélites.

Um tipo muito específico de constelação multi-satélite é o 'comboio'. Onde os satélites equipados com diferentes sensores estão seguindo cada um na mesma 'pista' orbital com uma separação de tempo mais curto. Os mais conhecido, o A-Train (STEPHENS et al., 2002), quando atravessam o equador por volta das 13:30 hora local, é operado pela NASA do inglês National Aeronautics and Space Administration e parceiros internacionais e consiste em sete satélites: Aqua (2002), Aura (2004), CALIPSO (2006), CloudSat (2006), GCOM-W1 (2012), e OCO-2 (2014). A separação temporal entre esses satélites é inferior a $30 \mathrm{~min}$. Outra constelação de comboios é a Constelação da Manhã (COLOMB et al., 2004) cujo os membros são Terra (1999), SAC-C (2000), EO-1 (2000), e Landsat-7 (1999).

O sensoriamento remoto é muito afetado pelas tendências de desenvolvimento da ciência da computação e de tecnologias da informação. $\mathrm{Na}$ realidade, estas mudanças desempenham o papel principal sobre como evolui o campo do sensoriamento remoto. A necessidade de uma melhor percepção e modelação do nosso ambiente físico e social sempre existiu do lado da sociedade. O principal impulsionador da rápida evolução da ciência e da engenharia é atualmente o ritmo acelerado dos avanços tecnológicos; em particular, nas ciências materiais, nanotecnologias, dispositivos atômicos a frio, etc., resultando em uma criação rápida de novos sensores e hardwares. Consequentemente, a investigação algorítmica e o software estão geralmente atrasados em termos de explorar o potencial do hardware emergente. Os sensores podem fornecer muito mais dados que podem ser processados com as ferramentas e sistemas da atualidade. Isto leva à necessidade de novos métodos que são geralmente chamados Data Analytics que é possui o objetivo de fornecer soluções para os desafios do Big Data termo que se refere aos dados estruturados e não estruturados que são gerados diariamente (às vezes a cada segundo) pelas empresas. 


\subsubsection{Processamento de imagens digitais}

O processamento de imagens digitais é, segundo Gonzales e Woods (2000), uma matriz bidimensional de números inteiros, onde cada célula, denominada pixel (abreviatura de picture element) retrata uma medida discreta de radiância espectral. Nas imagens digitais os valores dos pixels podem ser somados, subtraídos, multiplicados, etc., e são, no geral, susceptíveis à manipulações estatísticas (CAMPBELL; WYNNE., 2011).

A imagem do processamento digital é carregada no computador por meio de uma série de equações matemáticas, assim os produtos dos cálculos para cada pixel são armazenados e constituem uma nova imagem digital que pode ser novamente manipulada (LILLESAND; KIEFER e CHIPMAN, 2008). Em Jensen (2009) podem ser encontrados muitos dos conceitos envolvidos no processamento de imagens digitais, notadamente para as imagens de sensoriamento remoto.

Lillesand et al., (2008) alegam que são ilimitadas as possibilidades de manipulação dos dados de imagens digitais. Entretanto, para fins didáticos essas formas de manipulação podem ser categorizadas em um ou mais dos 7 tipos de operações: retificação e restauração da imagem; realce na imagem; classificação de imagens; fusão de dados e integração com SIG; análise de imagens hiperespectrais; modelagem biofísica; transmissão e compressão de imagens.

Os procedimentos de pré-processamento da imagem registrada pelos sensores de um satélite incluem correções radiométricas, atmosféricas e geométricas. Como Liu (2007) indica, estes processos tem o escopo de restaurar as imagens, removendo os efeitos dos ruídos causados pela interferência atmosférica e as limitações dos sistemas de satélite, a curvatura do globo, desgastes e degradação dos sensores e deslocamento do satélite no espaço durante seu tempo de funcionamento.

A fim de extrair informações a partir de dados de sensoriamento remoto, é primordial o conhecimento do comportamento espectral dos objetos da superfície terrestre e dos fatores que interferem no seu comportamento (NOVO, 2010). Jensen (2011) ainda complementa que a maioria das pesquisas de sensoriamento remoto são fundamentadas no desenvolvimento de uma relação entre a quantidade de energia eletromagnética refletida, emitida, ou retroespalhada em bandas específicas e as características químicas, biológicas e físicas dos fenômenos em observação. 
Diferentes operações matemáticas são empregadas no processamento digital de imagens com o escopo de analisar imagens multiespectrais e/ou multi-temporais (imagens do mesmo locais obtidas em diferentes momentos temporais). Usualmente, na realização destas operações, a adição e multiplicação servem para realçar similaridades espectrais entre bandas ou diferentes imagens, enquanto que a subtração e a divisão servem para realçar diferenças espectrais (CRÓSTA, 1992).

Ainda segundo Crósta (1992), a razão de bandas é a mais utilizada, tendo em vista a sua capacidade de realçar determinadas feições da curva de assinatura espectral de alguns materiais naturais e, por isso, acaba sendo de particular interesse em aplicações em geologia, agricultura e meio ambiente. Nota-se também que se as bandas a serem divididas cobrem máximos e mínimos de absorção, assim como mudanças na inclinação da curva de assinatura, elas podem ser combinadas em pares de razões, com o objetivo de acentuar aspectos das assinaturas espectrais dos materiais. Trabalhos como os desenvolvidos por Crósta (1992), Castleman (1996), Lillesand et al. (2008), detalham esses procedimentos e operações.

As características das plataformas que transportam os sensores remotos desempenham um papel significativo no sentido da eficiência de que o espaço do objeto pode ser observado. O potencial de observação está diretamente relacionado com a uniformidade do espaço de observação percorrido pela plataforma, quanto maior o primeiro, maior o segundo, assim, idealmente, uma quase constante gama de objetos poderia fornecer dados detectados à distância um consistente nível de precisão. Claramente, este não é sempre um cenário realista para se alcançar na prática, entretanto existem várias maneiras de melhorar o potencial de observação. A solução mais evidente é a instalação de múltiplos sensores em diferentes orientações sobre a mesma plataforma, tais como câmaras de visão para a frente e para trás e/ou sensores LiDAR ligados nas plataformas móveis (PETRIE, 2011).

Esta abordagem representa a atual tendência dos sistemas multissensoriais. Não há muito tempo, o sensoriamento remoto baseava-se em um único sensor, como uma câmera de grande formato em plataformas aerotransportadas ou um gerador de imagens multiespectral num satélite. Com o avanço das tecnologias de detecção e de informática, os sensores tornaramse financeiramente mais acessíveis, e os modernos sistemas de sensoriamento remoto iniciaram a utilizar vários sensores, aumentando o número de sensores idênticos e/ou acrescentando sensores diferentes (ASNER et al., 2012; PAPARODITIS et al., 2012). 
Nesse trabalho, a metodologia adotada é a de classificação de imagens, que é um processo de atribuição de pixels a classes. Segundo Campbell e Wynne (2011), para gerar todos os objetos, os pixels são analisados individualmente em cada uma das bandas espectrais.

\subsubsection{Classificação de imagens}

Atualmente existem dois grandes conjuntos de métodos de classificação de imagens, classificação baseada em pixels e a baseada em objetos. Na classificação baseada em pixel apenas a informação espectral é utilizada para a categorização dos pixels em classes, já a classificação baseada em objetos, além da informação espectral, são utilizadas informações de contexto, de geometria e sobre hierarquia dos objetos para o agrupamento dos pixels em classes (SOARES MACHADO et al., 2014).

São muitos estudos comparativos entre os dois métodos, e considerando os resultados apresentados pela metodologia baseada em objetos, no ambiente urbano, destaca-se Shackelford e Davis (2003); Yan et al. (2006); Brito et al., (2008); Blascke (2010); Newman, Maclaren e Wilson (2011); Ouyang et al. (2011); Robertson e King (2011).

As classes formam regiões homogêneas e são identificadas por uma cor ou símbolo. No final do procedimento, com todos os pixels categorizados em classes, é formado um mosaico de regiões uniformes (CAMPBELL e WYNNE, 2011).

Para Garofalo et al. (2015), classificação é o ato de agrupar objetos com a mesma estrutura de dados e com o mesmo comportamento. Neste caso, cada objeto é uma instância de uma classe. Existe uma série de abordagens com relação aos processos de classificação. Rex et al. (2018) citam o exemplo dos classificadores pixel a pixel, que foram desenvolvidos baseados em características do pixel como unidade primitiva de informações a respeito dos alvos. Este tipo de classificador foi muito utilizado para imagens de resolução espacial variada, principalmente para imagens de sensores de média resolução. Com o passar do tempo, a evolução nas resoluções espacial e espectral possibilitou um aumento na capacidade discriminatória dos alvos, evidenciando a dificuldade de aplicação destes classificadores (BLASCHKE, 2010).

Em imagens com baixa resolução espacial, um único pixel pode armazenar a informação espectral de mais de um alvo, ou uma região heterogênea de um mesmo objeto. No entanto, nas imagens de maiores resoluções, um pixel possui informações espectrais semelhantes às de seus 
vizinhos, sendo a diferenciação entre um alvo e outro dada pela diferença entre agrupamentos de pixels. Por exemplo: em uma imagem LANDSAT 5 TM, cuja resolução espacial é de 30 metros, uma clareira com diâmetro do tamanho do pixel da imagem é percebida como um ponto homogêneo, porém, utilizando uma imagem de maior resolução, a clareira se torna um conjunto de pixels que pode, dependendo da resolução espacial e das diferenças internas, constituir diferentes objetos da clareira.

Outro tipo muito recorrente na literatura são os classificadores por regiões, como em Körting et al., (2014), entre outros. Segundo Luz, Santos e Antunes (2009) estes classificadores utilizam a informação espectral dos pixels, além da informação espacial, que envolve a relação entre os pixels e seus vizinhos. Eles buscam reconhecer áreas homogêneas nas imagens, através do processo de segmentação, baseando-se nas propriedades espectrais e espaciais das imagens. Estes classificadores são um esforço para simular o comportamento de um intérprete.

\subsubsection{Classificações supervisionadas: Interpretação de imagens baseada em conhecimento}

A classificação de imagens consiste no estabelecimento de um processo de decisão no qual um grupo de pixels é definido como pertencente a uma determinada classe. Assim, sistemas computacionais auxiliam o usuário na interpretação das imagens obtidas via sensoriamento remoto.

Os métodos de classificação podem ser agrupados a partir da presença ou não de uma fase de treinamento onde o especialista aplica sua interpretação do local estudado ao sistema. A metodologia não-supervisionada se resume quando o classificador do sistema, ou seja, o algoritmo escolhido, não utiliza nenhum conhecimento sobre as classes existentes na imagem e define, sem a interferência do especialista, a estratificação da cena, atribuindo uma determinada classe para cada grupo de pixels. Tal abordagem corresponde à técnica de segmentação de imagens, onde as mesmas são divididas em certas classes sem conhecimento prévio. O algoritmo define estas classes com base em regras estatísticas pré-selecionadas (RICHARDS; JIA, 1999).

A metodologia de classificação supervisionada refere-se quando existe um conhecimento prévio de algumas áreas em que se deseja trabalhar, o que permite a seleção de amostras de treinamento confiáveis. O algoritmo classificador opera com base na distribuição 
de probabilidade de cada classe selecionada (ADENIYI, 1985). Simplificando, o especialista inicialmente treina o classificador, para depois associar os demais pixels a uma determinada classe pré-definida, através de regras estatísticas preestabelecidas.

Para tal, são utilizados sistemas digitais para estas atividades interativas de análise e manipulação das imagens brutas, e o resultado desse processo é a produção de outras imagens, estas já contendo informações específicas, extraídas e realçadas a partir das imagens brutas (CRÓSTA, 1992). De acordo com Queiroz et al. (2004), existem vários métodos de classificação que buscam, através de diversas abordagens, identificar com acurácia a informação de cada pixel da imagem, classificando-o em categorias.

E de acordo com Campbell (2009), a metodologia de classificação supervisionada apresenta vantagens, sendo a principal aquela em que o especialista possui maior controle sobre o processo, a exemplo, pré-definir classes e identificar possíveis imprecisões graves pela análise das áreas de treinamento, e desvantagens, sendo a principal a de que o analista impõe uma determinada estrutura de classificação aos dados através da definição prévia das classes de informação. Estas classes podem não corresponder às classes reais existentes na cena imageada, ou não ser separáveis no espaço dimensionado.

Alguns dos algoritmos de classificação supervisionada são: Distância Mínima, Distância de Mahalanobis, Distância de Bhattacharya, Máxima Verossimilhança, Método do Paralelepípedo e o Método do Spectral Angle Mapper (CRÓSTA, 1992; CORREIA et al., 2004; RAGONI; CORREIA, 2007; BAPTISTA; BIAS, 2007; AMARAL et al., 2009; FIALHO MOREIRA et al., 2013).

\subsubsection{Imagens de alta resolução espacial}

O aumento da resolução espacial é entendido como um dos resultados mais promissores na evolução dos sensores orbitais. Dowman (2004) comenta que esta evolução possibilitou que novos tipos de dados surgissem no cenário do sensoriamento remoto. Este avanço tecnológico contemporâneo tem possibilitado incrementar o nível de quantização das imagens em sensores digitais aerotransportados e sensores orbitais, transpondo os usuais 8 bits de profundidade de cor, ultrapassando os 16 milhões de valores de cores possíveis para cada pixel. 
Neste sentido, a capacidade do sistema visual humano em discernir tonalidades de cinza não ultrapassa 30 diferentes níveis, porém, quando se trata de discernir cores, esse número aumenta para centenas de milhares. Mesmo que 30 diferentes níveis representem um número significativamente inferior aos 256 tons de cinza de uma imagem digital tradicional de 8 bits, na prática, utiliza-se uma resolução radiométrica mais refinada, a fim de que a energia refletida pelas feições da superfície terrestre possa ser apreciada na imagem digital (CRÓSTA, 1992).

A maioria dos sistemas de computação para manipulação e edição de imagens digitais foi desenvolvida para operar em imagens de 8 bits, ou em composições coloridas de 24 bits, por conseguinte, grande parte das metodologias de análise foi desenvolvida com base em imagens dos programas LANDSAT e SPOT, ambas com resolução radiométrica de 8 bits por banda.

Apesar de que as imagens de 8 bits possam se mostrar inadequadas para alguns tipos de análises dada sua limitação ao representas o objeto capturado, como por exemplo regiões cobertas por sombras ou com alta variação da iluminação solar, mais especificamente em imagens urbanas, o aumento da resolução radiométrica implica diretamente no aumento da quantidade de dados a serem processados e armazenados nos computadores. Portanto, em alguns casos, esse aumento pode ser considerado como fator decisivo para que as imagens dos novos satélites sejam reamostradas para 8 bits mesmo quando capturadas com uma maior amostragem. Outro problema passa a ser a dificuldade na interpretação e manipulação do histograma, visto que muitos dos aplicativos atualmente disponíveis não se encontram adaptados para operar com tal nível de quantização (PATINO; DUQUE, 2013).

Fitz (2008) afirma que o uso de sensores de alta resolução espacial para o mapeamento civil abriu um novo campo de aplicações. Por muito tempo os sensores espaciais de alta resolução foram limitados para uso militar, mas, com o fim da guerra fria, a situação mudou. Estes sensores ganharam várias versões comerciais, fazendo com que a competição reduzisse seus preços, tornando as imagens mais acessíveis.

A resolução espectral é tão importante quando a resolução espacial em estudo em áreas urbanas, dado que Jensen (2009) indica que a união destas permite, além de uma maior proximidade visual com o mundo real, também a exploração de feições. 


\subsubsection{World View 2}

O sensor WorldView-2 se encontra a bordo do satélite de mesmo nome. Este, por sua vez, faz parte da missão WorldView que iniciou com o lançamento do satélite WorldView-1 em 2007, e depois do WorldView-2 em outubro de 2009. O sensor WorldView-2 apresenta uma característica muito especial até o momento, pois, além de possuir aproximadamente $0,50 \mathrm{~m}$ de resolução espacial na banda pancromática, dispõe também de oito bandas espectrais estreitas, ou seja, cinco bandas localizadas na faixa do espectro eletromagnético visível e três na faixa do infravermelho próximo. Estas últimas com aproximadamente 2 metros de resolução espacial. Além das quatro bandas: Azul, Verde, Vermelha e do Infravermelho próximo-1 (NIR-1); presentes em outros sensores de mesma categoria espacial, esse sensor apresenta outras quatro bandas: Azul costeiro (Coastal), Amarelo, Borda do Vermelho (Red-Edge) e Infravermelho próximo-2 (NIR-2), como demonstra a Figura 2.

Figura 2 - Resposta espectral das bandas do sensor Worldview II.

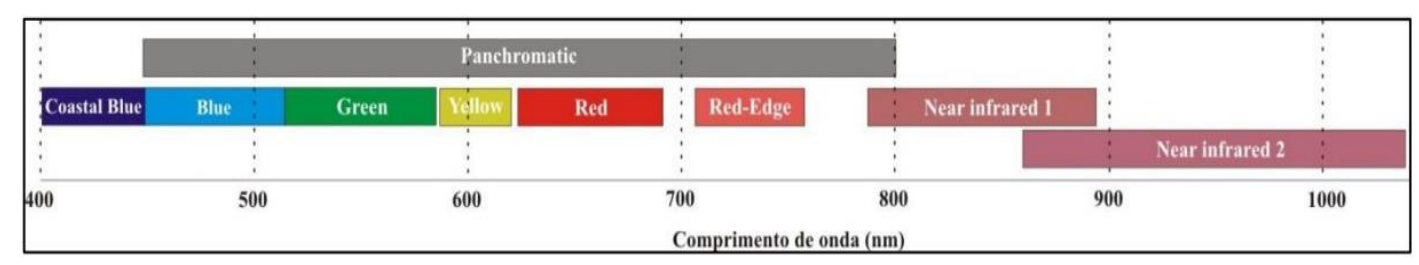

Fonte: Adaptado Digital Globe (2010)

Além da capacidade de discriminação dos alvos proporcionados pelas bandas no comprimento do azul, verde, vermelho e infravermelho próximo, comum na maioria dos sensores, o satélite WorldView II conta, ainda, com outras quatro bandas (Tabela 6). 
Tabela 6 - Bandas adicionais do Worldview II

\begin{tabular}{|c|c|l|}
\hline Banda & $\begin{array}{c}\text { Comp. De onda } \\
\text { mm }\end{array}$ & \multicolumn{1}{c|}{ Características } \\
\hline Costal Blue & $400-450$ & $\begin{array}{l}\text { Tem o papel de melhorar as técnicas de correção } \\
\text { atmosféricas e auxilia na realização de análise de } \\
\text { vegetação e é muito útil em estudos batimétricos. }\end{array}$ \\
\hline Yellow & $585-625$ & $\begin{array}{l}\text { Importante na deteç̧ão de alguns tipos de vegetação } \\
\text { específicas, já que detecta o amarelo, tanto em terra } \\
\text { como na água. }\end{array}$ \\
\hline Red-Edge & $705-745$ & $\begin{array}{l}\text { Estrategicamente posicionada no espectro, essa } \\
\text { banda é excelente para detectar a saúde da vegetação. }\end{array}$ \\
\hline 2 & $860-1040$ & $\begin{array}{l}\text { Sobrepõe a banda Near Infrared 1, mas é menos } \\
\text { afetada pela influência atmosférica, permitindo uma } \\
\text { análise mais ampla da vegetação e estudos de } \\
\text { biomassa. }\end{array}$ \\
\hline
\end{tabular}

Fonte: Adaptado DigitalGlobe (2010).

Além disso, vários estudos vêm encontrando novas aplicações para as bandas do sensor, como Ribeiro, Fonseca e Kux (2011), Passo et al., (2013), Hartling et al., (2019), Sun et al., (2019), Wu et al., (2019) com o objetivo de efetuar mapeamento de cobertura do solo em área urbanas.

\subsubsection{Algoritmos de Classificação Supervisionada por pixel}

Conforme Lillesand e Kiefer (1979), dentre os métodos de classificação supervisionada, os mais frequentes são a classificação por paralelepípedo (Single Cell) e a classificação por máxima verossimilhança (Maximum Likelihood).

O algoritmo paralelepípedo é definido pelo nível de cinza mínimo e máximo do conjunto de treinamento, os lados desta figura geométrica constituem os limites de decisão de determinada classe (CRÓSTA, 1992). Assim, pixels dentre este intervalo pertencerão a mesma classe específica, sem deixar de considerar que um dos fatores que mais afeta o desempenho 
deste algoritmo é correlação existente entre as bandas ópticas dos sensores atualmente disponíveis, principalmente aquelas na região do visível.

Enquanto o método de classificação por máxima verossimilhança baseia-se no cálculo da distância estatística entre cada pixel e a média dos níveis de cinza da classe previamente definida a partir de amostras de treinamento (DUTRA et al., 1981). Uma característica que se deve mencionar é que a seleção destas amostras deve refletir a variabilidade de cada categoria dentro da área estudada, não existindo um número ideal destas amostras para representar a classe de interesse.

Na ocasião da aplicação dos algoritmos que enfrente dificuldade na classificação dos intervalos, como em áreas urbanas, faz-se necessário reduzir a dimensão de cada amostra de treinamento, como por exemplo quatro pixels, evitando assim o efeito de bordas e faz do conjunto de valores espectrais definidor de classe mais confiável. O oposto ocorre quando da classificação de classes agroflorestais, por exemplo, que usualmente ocupam áreas mais homogêneas, sem grandes variações radiométricas, podendo o especialista, então, coletar os parâmetros estatísticos necessários a partir de amostras de treinamento igual ou superior, mas não muito, que 16 pixels cada.

Portanto, para uma apropriada classificação de imagens, durante a etapa de treinamento de amostras, deve-se fazer uso da ferramenta de análise de amostras, onde pode-se adicionar ou subtrair áreas até conseguir uma representação temática coerente com a estabelecida pelo usuário, assim permitindo avaliar o desempenho de cada amostra de treinamento em relação às demais e ao conjunto de classes estudadas.

\subsubsection{Sensoriamento remoto aplicado a estudos urbanos}

O zoneamento urbano é um dos muitos instrumentos técnicos aplicados por planejadores no controle do desenvolvimento das cidades. Em cada zona são atribuídas diversas restrições em variáveis como altura máxima de edificações, densidade de construção, extensão de área impermeabilizada e uso do solo assim o regulamento do solo é setorizado (WILSON et al., 2003). Como essas variáveis atuam de diversas formas nos processos atmosféricos e de trocas de energia do ambiente, regimes climáticos e o sistema hidrológico superficial e subterrâneo, são também setorizados os problemas ambientais, ecológicos e sociais. 
Neste sentido, as pesquisas uma vez realizadas com a aplicação da metodologia do sensoriamento remoto permitem a inclusão de novas visões da realidade ambiental. Os resultados do sensoriamento remoto oferecem dados consistentes da superfície terrestre de grande serventia para diversas aplicações, como: urbanas, agrícolas, geológicas, ecológicas, florestais, hidrológicas (JENSEN, 2009). As imagens de satélite são fundamentais para a coleta de informações de áreas urbanas em diferentes escalas temporais, espectrais e espaciais, o que torna possível analisar as mudanças no ambiente natural causadas pelo crescimento urbano (NETZBAND; JÜRGENS, 2010).

A dificuldade de trabalhar com áreas urbanas utilizando imagens de média resolução espacial, se deve a heterogeneidade das superfícies urbanas (concreto, asfalto, árvores, telhas, metal, dentre outros) (SMALL, 2002). Assim, diversas técnicas e estudos foram desenvolvidos para melhorar a precisão na caracterização dos tipos de cobertura da terra no espaço urbano, como por exemplo classificação híbrida (ALBERTI; WEEKS; COE, 2004), redes neurais artificiais (KYNOVA; DOBROVOLNY, 2015), dentre outros.

\subsection{O USO DE GEOPROCESSAMENTO E SENSORIAMENTO REMOTO NA ÁREA DA SAÚDE}

A ocorrência de doenças infecciosas caracteriza-se por padrões espaço-temporais distintos relacionados a aspectos ambientais mais ou menos favoráveis à proliferação das populações de reservatórios, vetores e agentes infecciosos (CORREIA et al., 2004). Devem ser considerados ainda, os diferentes perfis demográficos e socioeconômicos da população humana, assim como os distintos hábitos culturais e comportamentais que contribuem para padrões de ocorrência diferenciados das enfermidades.

A análise de dados distribuídos pelo espaço geográfico é bastante valorizada na gestão de saúde, por apontar novos subsídios para o planejamento e a avaliação das ações baseadas na análise da distribuição espacial das doenças, localização dos serviços de saúde e dos riscos ambientais (MONKEN; BARCELLOS, 2005).

Os fenômenos relacionados com a saúde tendem a ser heterogêneos no território, razão pela qual surgiu a necessidade de estudar essas variações espaciais, que não são só oriundas dos fenômenos de saúde, mas também dos determinantes físicos, econômicos, culturais ou mesmo 
populacionais. Por exemplo, as migrações humanas por motivos econômicos, como crise financeira, ou físicos, como um tsunami, têm papel muito importante na distribuição espacial das condições de saúde e doença. Em relação às doenças infectocontagiosas, a mobilidade humana pode afetar a transmissão e a difusão das doenças. Como exemplo, um indivíduo de uma zona não endêmica de malária, mas onde haja presença do vetor, que viaja semanalmente para uma área endêmica, por motivos de trabalho, pode ser infectado e transportar o parasita no corpo, no retorno ao seu lugar de origem, podendo propiciar a introdução ou a reintrodução da doença.

A possibilidade de se combinar as variáveis ambientais com os locais de incidência de doenças, junto com o avanço tecnológico (Geoprocessamento e Sensoriamento Remoto) vem transformando a epidemiologia paisagística nas últimas décadas (BARCELLOS et al., 2009). Esta sendo uma das áreas da epidemiologia que tem como premissa que se conhecendo as exigências ambientais dos transmissores e reservatórios de doenças, é possível prever riscos epidemiológicos através do conhecimento das variáveis ambientais, auxiliando a tomada de medidas profiláticas e de controle da enfermidade.

O uso do sensoriamento remoto se apresenta como uma possibilidade metodológica, que permite a caracterização de variáveis ambientais de interesse em estudos de endemias. As técnicas de classificação automática e semi-automática de imagens de sensoriamento remoto permitem ampliar e acelerar o processo de aquisição de informações ambientais relevantes no contexto dos estudos enfocando a interação ambiente-doença. Com o uso dos recursos de SIG, como ambiente computacional para integração dessas variáveis com outras relativas à ocorrência da doença e a caracterização do perfil social, econômico e demográfico, é possível montar um painel socioterritorial ampliado, que potencializa e amplia o olhar epidemiológico sobre potenciais focos e áreas de risco (CORREIA et al., 2007), permitindo diagnóstico eficiente da situação de saúde de determinada população, e criando alternativas eficazes para os desafios encontrados no controle e vigilância de endemias.

A gratuidade na obtenção de imagens de satélites de alta resolução, o desenvolvimento de técnicas de análise espacial e a inclusão de fatores ambientais no campo da Epidemiologia, têm possibilitado a expansão do conhecimento sobre a complexidade das interações entre condições ambientais e de saúde (CORREIA et al., 2004; MONKEN; BARCELLOS, 2005).

Adicionalmente às classificações não-supervisionada e supervisionada, e com a disponibilidade de imagens de alta resolução espacial e espectral, deu-se o desenvolvimento de novas metodologias capazes de criar condições para a incorporação de informações adicionais 
ao processo de classificação, como aquela orientada por objeto. Esta classificação consiste na inserção do conhecimento do especialista e parâmetros de cor, forma, textura e contexto. Conforme a natureza dos alvos naturais ou artificiais presentes nas imagens, a utilização de atributos de forma e textura podem contribuir significativamente no processo de reconhecimento de padrões (CARVALHO JÚNIOR et al., 2009), e ainda aliada à possibilidade de uso de regras de pertinência fuzzy faz com que o sistema possa "aprender" a interpretar cenas complexas a partir da inserção, por parte do analista, da lógica de interpretação de um intérprete humano (RIBEIRO; DE SOUSA; DE ARAÚJO, 2008).

De acordo com Viana et al., (2017), as imagens de sensoriamento remoto são uma fonte de dados muito útil para compreender os mecanismos de transmissão de várias doenças. Os autores forneceram uma revisão sistemática da investigação do sensoriamento remoto aplicado à saúde e mencionaram que o sensoriamento remoto fornece informação espacial sobre as condições ambientais para compreender as influências na saúde e indica diferentes fatores ambientais para diferentes doenças.

O estudo de German et al. (2018) desenvolvem um método para avaliar a oviposição de Ae. aegypti utilizando alguns índices como: Normalized Difference Vegetation Index (NDVI), Normalized Difference Water Index (NDWI), Land Surface Temperature (LST) Moderate Resolution Imaging Spectroradiometer (MODIS), e Tropical Rainfall Measuring Mission (TRMM)) / Global Precipitation Measurement (GPM) como variáveis de detecção remota para além das variáveis LST integrais para modelação de um conjunto de quatro anos de dados semanais de oviposição (Agosto 2011 - Julho 2015). Com os seus resultados, um conjunto completo de variáveis derivadas de satélite torna-se uma base para o sistema nacional de risco operacional que já estava sendo utilizado na Argentina.

Lorenz et al. (2020), estudaram o potencial das imagens de satélite remotas de alta resolução espacial para determinar características terrestres associadas às infestações por $A e$. aegypti em São José do Rio Preto/SP, Brasil. A ocorrência destes mosquitos pode estar relacionada com várias outras características específicas da paisagem, tais como fatores socioeconômicos ou ambientais, indicados por imagens de detecção remota classificadas, que melhoram a compreensão dos fatores associados às infestações urbanas de Ae. aegypti e à disseminação de arbovírus.

Para Parselia et al. (2019), é possível utilizar imagens de sensoriamento remoto para estimar variáveis que influenciam o ciclo de transmissão dos agentes patogênicos que conduzem às doenças transmitidas por mosquitos. Recentemente, a resolução espacial e 
temporal dos produtos de sensoriamento remoto disponíveis não eram suficiente para prever e modelar doenças epidêmicas como a malária, o dengue e o Vírus do Nilo Ocidental, mas, com o advento dos dados do satélite Sentinel, estes oferecidos gratuitamente pelo programa comunitário Copernicus, um novo cenário foi aberto aos investigadores das doenças epidêmicas.

De forma semelhante, Dlamini et al. (2019) consideram que a utilização anterior de produtos espaciais de detecção remota de alta resolução é limitada pelos custos de obtenção, apesar da boa resolução dos dados comerciais. O principal aspecto a considerar é a observação da cobertura terrestre, que está mudando com o advento dos VANTs e a captação de imagens espacialmente boas a custos relativamente baixos. Nesse artigo, os autores fizeram uma revisão de alguns dos trabalhos que tinham sido desenvolvidos para fazer avançar a tecnologia do sensoriamento remoto e as suas aplicações na cartografia de doenças e estudos epidemiológicos, compilando informação do sensoriamento remoto relevante para a cartografia de doenças.

\subsection{VEÍCULO AÉREO NÃO TRIPULADO (VANT)}

O dicionário Merriam-Webster define um VANT como aeronaves não tripuladas ou barcos guiados por controle remoto ou computadores de bordo. São também referidos como VANT, sistemas aéreos não tripulados (UAS - Unmanned Aircraft System), aeronaves não tripuladas (UA - Unmanned Aircraft), ou aeronaves remotamente pilotadas (RPA - Remotely

Piloted Aircraft). Às vezes o termo VANT é propositadamente alterado para UAS de modo a refletir os sistemas complexos que são envolvidos em operações de aviões não tripulados. $O$ termo RPA é tipicamente utilizado na Europa e pelo setor militar (WATTS; AMBROSIA; HINKLEY, 2012).

Desde a década de 1950, a principal função dos VANTs tem sido missões de reconhecimento aéreo. A partir de 2005, o desenvolvimento de VANT para fins militares ainda dominava a indústria (MOLINA et al., 2013). Ao longo das últimas décadas, VANTs de várias formas, tamanhos e capacidades têm sido desenvolvido tão rapidamente que seus potenciais para aplicações civis são esmagadores (MOLINA et al., 2008). Para maiores detalhes, consultar Lage et al., (2017). 
No caso do uso para sensoriamento remoto da superfície terrestre, os sensores embarcados nas plataformas são, obviamente, equipamentos chave nos sistemas VANTs. Inicialmente, os sensores eram meras câmeras fotográficas de filmes, normalmente de pequeno formato, monocromáticas e depois coloridas. Avançou-se para o uso de filmadoras portáteis e posteriormente de câmeras fotográficas digitais.

Mais recentemente, sensores digitais têm sido desenvolvidos ou adaptados especialmente para VANTs. Ficou comum a geração de imagens nas faixas do espectro eletromagnético correspondentes ao visível e infra-vermelho. Atualmente, há VANTs que embarcam sensores hiperespectrais, lasers e Synthetic Aperture Radar (SARs) (LONGHITANO; AMARAL; ALMEIDA, 2009).

Nos últimos anos, diversas pesquisas têm sido realizadas envolvendo não apenas o desenvolvimento e aprimoramentos nas plataformas VANTs, nos sensores embarcados e no sistema de transmissão de dados, mas também inovações e experimentações nos procedimentos e técnicas de processamento digital das imagens e dados obtidos pelos equipamentos, a fim de obter produtos de forma mais rápida e de melhor qualidade (LONGHITANO, 2010).

Através da elaboração de algoritmos, Mukherjee et al. (2009) extraíram pontos de interesses em diversas escalas de imagens hiperespectrais obtidas por VANTs. Zhou (2009) apresenta georreferenciamento de vídeo com precisão e quase em tempo real em pequeno VANT desenvolvido para monitoramento de incêndios. Laliberte e Rango (2009) determinam as melhores formas de medição de texturas associadas a escala de análise em imagens obtidas por VANT que apresentam altíssima resolução espacial em aplicação de monitoramento de vegetação.

A utilização de um VANT proporciona a captura de imagens de alta resolução, além de ter facilidade na realização de voos autônomos e baixo custo de manejo. Segundo Watts, Ambrosia e Hinkley (2012), através da utilização do Sensoriamento Remoto com a tecnologia VANT é possível obter imagens aéreas de locais de difícil acesso. Além do mais, o comando por controle remoto exclui a necessidade de um profissional embarcado e não oferece risco ao operador.

Jorge e Inamasu (2014) apresentam as vantagens da utilização dos VANTs, como por exemplo, o pouso e a decolagem em qualquer lugar; a capacidade de realizar a rota determinada e poder pairar em um ponto de interesse; de possuir tolerância maior para voar inclusive com ventos fortes; as imagens adquiridas geralmente possuem uma resolução espacial de 
centímetros e não sofrem com a cobertura de nuvens; uma alternativa potencial no processo de obtenção de imagens que auxiliam na identificação e caracterização de superfícies, cobertura e uso do solo; o baixo custo de manutenção e médio custo de aquisição e o transporte fácil. Já as desvantagens apontadas seriam que o VANT suporta pouca carga e o tempo de bateria.

Diniz e Medeiros (2018), apresentam o combate ao vetor Ae. aegypti e consequentemente às doenças que são transmitidas por ele, utilizando o VANTs, apresentandose como um método inovador, tecnológico, sendo viável e eficaz na obtenção de dados que contribuam à tomada de decisões e implementação de estratégias e ações. Com este método, é possível sobrevoar, de maneira segura, as residências, inclusive aquelas fechadas ou com moradores ausentes. Portanto, pode contribuir amplamente na identificação de prováveis locais com água parada e/ou em condições favoráveis à reprodução do referido inseto (AMARASINGHE et al., 2017).

\subsection{AVALIAÇÕES DA ACURÁCIA DE RESULTADOS NAS CLASSIFICAÇÕES DE IMAGENS}

Segundo Lu e Weng, (2007), a classificação da imagem é um processo complexo que pode ser afetado por muitos fatores. O uso efetivo de múltiplos sensores e a seleção de um método de classificação adequado são principalmente significativos para melhorar a precisão da classificação. As principais etapas da classificação da imagem podem incluir a determinação de um sistema de classificação adequado, seleção de amostras de treino, pré-processamento de imagens, extração de características, seleção de abordagens de classificação adequadas, pósclassificação, processamento e avaliação de precisão. A necessidade do usuário, a escala da área de estudo, condição econômica e habilidades do analista são fatores importantes que influenciam a seleção de dados detectados remotamente, o design do procedimento de classificação e a qualidade dos resultados da classificação.

Para Khatami, Mountrakis e Stehman (2016), a classificação de imagem de sensoriamento remoto é uma metodologia que converte imagens de sensoriamento remoto em novos resultados, passíveis de análises. O mapeamento usando imagens via satélite ou aérea aumentou exponencialmente nas últimas décadas, em parte devido à melhoria dos dados de 
disponibilidade e acessibilidade (YU et al., 2014). O mapeamento da cobertura terrestre é um processo complexo com inúmeros fatores que influenciam a qualidade do produto final. Um especialista de imagem tem que eleger de uma infinidade de opções incluindo tipo de imagem, algoritmo de classificação, treinamento/validação dos dados, recursos de entrada, técnicas pré e pós-processamento, dados auxiliares e classes de destino. A tomada de decisões pelos especialistas de imagem é caracteristicamente com base na sua experiência individual e experiência em oposição ao conhecimento coletivo do campo. A comunidade de sensoriamento remoto alcançou esforços consideráveis para melhorar a precisão do mapa de cobertura terrestre.

Dronova (2015) apresenta, num estudo específico em áreas inundadas, relações lineares entre exatidão geral e as classes estudadas, e a precisão geral e o tamanho da área. Ma et al. (2017) analisam principalmente a relação entre a precisão da classificação e o número de classes maior que aqueles existentes nas áreas de estudo. Os resultados da pesquisa mostram que existe uma correlação entre precisões de classificação e o número de classes. A precisão da classificação diminuirá com um aumento no número de classes e varia substancialmente com o tipo de cobertura terrestre.

De forma similar ao que Liang et al. (2017) afirmam em relação aos sistemas hiperspectrais, a comunidade de sensoriamento remoto concentrou sua pesquisa em melhorar a precisão da classificação desenvolvendo uma variedade de métodos espectrais-espaciais (os autores mencionam Lu e Weng (2007); Chen, Nasrabadi e Tran (2011); Fauvel et al. (2013); Moser, Serpico e Benediktsson (2013), e pouca atenção foi dada às configurações experimentais).

A avaliação de métodos de classificação em imagens multiespectrais requer um design cuidadoso de experimentos, como benchmark apropriado, conjuntos de dados, estratégia de amostragem para gerar treinamento e dados de teste, e critérios de avaliação apropriados e justos (FRIEDL et al., 2000; LU; WENG, 2007).

Para Liang et al. (2017), no âmbito da classificação supervisionada, encontramos que os projetos experimentais tradicionais para o processamento espectral são muitas vezes indevidamente utilizados no contexto do processamento espacial espectral, levando a uma avaliação de desempenho injusta ou tendenciosa. Este é particularmente o caso, quando para treinar e testar, as amostras são tiradas aleatoriamente da mesma imagem/cena. Esta é uma configuração comum na pesquisa de classificação (no caso dos autores, hiperespectral) devido à disponibilidade limitada de dados de referência e o alto custo da coleta de dados da verdade 
terrestre. Ainda segundo esses autores, na configuração experimental, a estratégia de amostragem desempenha um papel importante na aprendizagem e na avaliação do classificador. Uma estratégia de amostragem deve ser empregada para criar o treinamento e os testes conjuntos (RICHARDS; JIA, 1999; FOODY, 2002; KHATAMI; MOUNTRAKIS; STEHMAN, 2016).

A amostragem aleatória é uma escolha natural, uma vez que trata todos os dados rotulados igualmente e cada amostra seria selecionada com a mesma probabilidade. No entanto, por este método, algumas classes com pequeno número de amostras rotuladas podem ter uma quantidade de amostras muito menor que a expectativa. Portanto, um método de amostragem mais sofisticado, amostragem aleatória estratificada, é frequentemente usado (RICHARDS; JIA, 1999).

Para garantir que cada classe tenha amostras suficientes, primeiro agrupam-se as amostras marcadas em subconjuntos com base em seus rótulos de classe e, em seguida, é realizada amostragem aleatória dentro de cada subconjunto. Em termos do número de amostras de treino em cada subconjunto, normalmente requer que essa proporção de cada grupo deva ser o mesmo que na população. Em seguida, o restante das amostras é empregado como amostras de teste na etapa de teste. Este método é muito simples de implementar, reproduzível e de significância estatística. Muitas vezes os pesquisadores se referem à amostragem aleatória estratificada como aleatória simples.

Segundo Foody (2002), a comunidade de sensoriamento remoto muitas vezes tende a usar técnicas baseadas na matriz de confusão para a qual a aplicação e a interpretação corretas requerem a satisfação de suposições muitas vezes insustentáveis (por exemplo, o registro perfeito entre os conjuntos de dados) e o fornecimento de informações raramente fornecidas (por exemplo, o projeto de amostragem para aquisição de dados no solo).

\subsection{IMAGENS TERMAIS}

O avanço dos sensores remotos teve início na década de 1950, época na qual os militares iniciaram a utilizar imagens aéreas com fins de analisar a paisagem (SANTOS; ROMÃO, 2007). O emprego de técnicas de sensoriamento remoto pode ocorrer em imagens obtidas por sensores dispostos em nível orbital (imagens de satélite) ou suborbital (fotografias aéreas) (SANTOS; ROMÃO, 2007). E, independente da forma de obtenção dos dados, tem-se como 
objetivo fundamental a análise estática de uma cena do espaço, sendo útil para o mapeamento espaço-temporal da superfície (PETTA; FERNANDES; NASCIMENTO, 2008), além de gerar a análise da dinâmica da paisagem.

Do encontro das imagens de satélite às técnicas de processamento digital, possibilita- se novas análises sobre a cobertura vegetal do solo (DE OLIVEIRA et al., 2009). Assim, por mérito da evolução técnica das tecnologias envolvidas no sensoriamento remoto, possibilita-se a obtenção de imagens de satélite por meio da banda do infravermelho termal. No que tange a essa questão, Jensen (2009) destaca que todos os objetos que possuem temperatura acima do zero absoluto $\left(0^{\circ} \mathrm{K}\right.$ ou $273,15^{\circ} \mathrm{C}$ negativos $)$ emitem energia eletromagnética.

Ao realizar o mapeamento da temperatura da superfície terrestre por meio do infravermelho termal é possível a realização de "estudos do comportamento térmico das diferentes tipologias de cobertura do solo pelo fornecimento de informações relativas à temperatura aparente da superfície" (BARBOSA; VECCHIA, 1996).

Toda essa análise, da temperatura da superfície, é realizada a fim de apurar as áreas que formam "manchas de calor", que são, muitas vezes, dimensionadas em função dos usos da terra que sofreram transformações ao longo do tempo. Tal fato é corroborado por Amorim et al. (2009), utilizando-se do termo "ilhas de calor", conotação que pode ser caracterizada como sinônimo nesse estudo, como áreas com "manifestação do aumento das temperaturas causado por características físicas (alta densidade de construções, concentração de materiais construtivos de grande potencial energético de emissividade e reflectância) e as atividades urbanas".

Portanto, a dinâmica sobre a temperatura da superfície é uma medida de análise da qualidade ambiental de um determinado local, e correlacionando os dados com o uso e a ocupação do solo é possível examinar quais as áreas que exibem as maiores interferências na formação das manchas de calor.

O sensoriamento remoto termal permite analisar fenômenos e transformações ambientais que possam alterar a temperatura da superfície terrestre, tais informações podem ser utilizadas para propor melhores adequações na qualidade de vida, no que diz respeito ao conforto térmico da população (FERREIRA, 2012).

Estudos aplicado em técnicas de sensoriamento remoto orbital e sub-orbital são encontrados em trabalhos como Ponzoni (2002), Coelho (2009) e Jensen (2009), na 
identificação de áreas de riscos, estudos geológicos, geomorfológicos, crescimento urbano, conforto térmico, uso e cobertura da terra, entre outros.

Enquanto as pesquisas que utilizam imagens termais são variadas, destacando Rao (1972), primeiro a demonstrar que as áreas urbanas poderiam ser identificadas por meio de análises de dados na faixa do infravermelho termal adquiridos por um satélite. Outros pesquisadores, como Callejas et al. (2011), De Souza; Júnior (2012), Du et al., (2014), Amorm, Dubreuil e Cardoso (2015), Nunes et al., (2017), Zhou et al., (2019), e Mandanici et al., (2019) entre outros, também usaram sistemas de sensoriamento remoto infravermelhos termais para registrar o efeito de ilha de calor urbana, além de extrair informações de temperatura da superfície de diferentes materiais.

Outros estudos utilizaram sensoriamento remoto com o objetivo de associar a temperatura de superfície fornecida pelas imagens de satélite com as arboviroses. Misslin et al. (2018) realizou um estudo na Tailândia utilizando o satélite MODIS e o algoritmo TVX para o cálculo da superfície de temperatura obtendo um resultado da influência sobre o ciclo de vida do mosquito, partindo do pressuposto que a temperatura desempenha um papel crucial no potencial das epidemias de dengue. Assim, decifrar os efeitos das variações térmicas dentro das cidades poderia conduzir à identificação de zonas precisas de conforto térmico, favoráveis à sobrevivência das populações de mosquitos durante os períodos inter-epidémicos.

Na América Latina, por exemplo, Albrieu-Llinás et al. (2018), apresentam um estudo no município de Clorinda, na Argentina, de evolução temporal utilizando a imagem satélite SPOT-5 para obter variáveis de ocupação do solo, junto com os número de habitações infestadas por fases imaturas de Ae. aegypti no bairro e explorar os valores dos clusters ambientais gerados com informação fornecida por variáveis de detecção remota para explicar os diferentes comportamentos temporais iniciais observados.

A pesquisa de Araújo et al. (2015) é um exemplo de utilização das ferramentas de sensoriamento remoto no estudo das arboviroses, no Estado de São Paulo. Esses autores, utilizaram o sensoriamento remoto para a caracterização das ilhas de calor no município de São Paulo e encontraram que uma elevada temperatura da superfície terrestre, baixa umidade, e vegetação pobre, são fatores que favoreceriam a transmissão da dengue, o que permitiu associar os locais denominados como ilha de calor com a incidência da Dengue. 


\subsubsection{Imagens Termais LANDSAT 8}

Considerando as últimas três décadas, pode-se dizer que o programa LANDSAT apresenta um expressivo acervo de imagens, principalmente das missões LANDSAT 5 com o sensor Thematic Mapper (TM) e Landsat 7 Enhanced Thematic Mapper (ETM+). Desde 2013, já é possível contar com os produtos da plataforma LANDSAT 8 a qual disponibiliza imagens multiespectrais adquiridas a partir dos sensores Operational Land Imager (OLI) e Thermal Infrared Sensor (TIRS) (Tabela 7). A missão tem como principal objetivo dar continuidade às missões 5 e 7, disponibilizando imagens do visível e infravermelho com alta qualidade em termos de geometria de aquisição, calibração e características espectrais permitindo a comparação e detecção de mudanças globais, regionais e locais (USGS, 2015).

Tabela 7 - Características das bandas LANDSAT 8

\begin{tabular}{|c|c|c|c|}
\hline \multicolumn{4}{|c|}{ Características dos produtos LANDSAT 8 sensores Oli e TIRS } \\
\hline $\begin{array}{l}N^{\circ} \text { da } \\
\text { banda }\end{array}$ & Nome & $\begin{array}{c}\text { Comprimento de onda } \\
(\mu \mathrm{m})\end{array}$ & Resolução espacial \\
\hline Banda 1 & $\begin{array}{c}\text { Coastal/ } \\
\text { Aerosl }\end{array}$ & $0,435-0,451$ & \multirow{8}{*}{$30 \mathrm{~m}$} \\
\hline Banda 2 & Blue & $0,452-0,512$ & \\
\hline Banda 3 & Green & $0,533-0,590$ & \\
\hline Banda 4 & Red & $0,636-0,673$ & \\
\hline Banda 5 & NIR & $0,851-0,879$ & \\
\hline Banda 6 & SWIR 1 & $1,566-1,651$ & \\
\hline Banda 7 & SWIR 2 & $2,107-2,294$ & \\
\hline Banda 9 & Cirrus & $1,363-1,384$ & \\
\hline Banda 8 & Pan & $0,503-0,676$ & $15 \mathrm{~m}$ \\
\hline Banda 10 & TIR 1 & $10,60-11,19$ & \multirow{2}{*}{$\begin{array}{c}100 \mathrm{~m} \\
(\text { resampled to } 30 \mathrm{~m})\end{array}$} \\
\hline Banda 11 & TIR 2 & $11,50-12,51$ & \\
\hline
\end{tabular}

Os estudos relacionados à análise e monitoramento de áreas urbanas quanto ao uso e cobertura e informações sobre o campo térmico são tão importantes quanto a análise de relevo 
no qual a cidade está inserida, destacando a informações sobre altimetria, declividade e orientações das vertentes como fatores que influenciam na valorização do solo urbano bem como na variação térmica do ar e dos diferentes materiais urbanos. Neste caso, os produtos de sensoriamento remoto também podem auxiliar a partir de modelos digitais de elevação (MDE), como é o caso do MDE SRTM. A missão Shuttle Radar Topography Mission (SRTM) foi desenvolvida no ano de 2000 onde o objetivo foi a formação de um modelo de elevação mundial a partir do processamento dos dados coletados, compreendendo $80 \%$ de área do planeta entre as latitudes $60^{\circ} \mathrm{N}$ e $56^{\circ} \mathrm{S}$ (USGS, 2015).

\subsubsection{Imagens Termais para Análise de Temperatura em Áreas Urbanas}

O estudo do clima compõe diferentes elementos e fatores que atuam em conjunto para definirem e condicionarem o clima do lugar. Como elementos das variáveis globais apresentamse: a latitude, a altitude, a radiação solar, os ventos, as massas de água, a topografia, a vegetação, o solo; e como fatores climáticos locais: a temperatura, a umidade do ar, os movimentos das massas de ar e as precipitações (ROMERO, 2016).

A partir do processamento digital de imagens orbitais é possível extrair informações de diferentes áreas na superfície terrestre. Para tanto, o conhecimento da resposta espectral dos diversos alvos existentes nas imagens (solo, vegetação, área urbana, água) é um fator de suma importância.

No clima urbano as alterações da temperatura estão diretamente relacionadas com as leis da termodinâmica, pois a energia adquirida por um material em uma superfície urbana pode ser transferida através das interações de calor absorvido e transmitido para outros materiais. Para Voogt e Oke (2003), a radiação solar é uma energia transmitida por meio da oscilação do campo eletromagnético que atinge a Terra por ondas curtas. A radiação solar pode ser refletida e liberada para a atmosfera através das ondas longas emergentes da superfície por meio das construções urbanas (dependendo do material utilizado nas edificações) e pela morfologia urbana. Porém, as trocas térmicas no meio urbano ocorrem pelas diferenças de temperatura entre áreas e essas trocas podem ser por condução, convecção e radiação.

Na superfície do solo ocorre também variação de temperatura. As trocas de energia entre a superfície do solo e a atmosfera são efetuadas tanto por condução quanto por irradiação, podendo ocorrer oscilações de temperatura em ciclos diários ou anuais. Essas oscilações 
dependem da cobertura vegetal presente à superfície do solo, contribuindo sensivelmente na amplitude térmica diária do solo (VOOGT; OKE, 2003).

Em relação a característica espectral de áreas urbanas, pode-se dizer que estas não apresentam um comportamento espectral padrão devido a sua heterogeneidade. Assim, um pixel pode representar várias coberturas, o que dificulta uma classificação interurbanas. Estudos que envolvem área urbana e sensoriamento remoto dependem da resolução espacial das imagens orbitais. As imagens de média resolução espacial $(10-50 \mathrm{~m})$ podem ser utilizadas em estudos que visam a análise da mancha urbana. Já trabalhos que têm por objetivo identificar o espaço intraurbano devem considerar imagens de maior resolução espacial (SOUZA, 2012).

A cobertura referente à área urbana, geralmente, aparece na cor cinza-claro nas imagens em composição colorida verdadeira (bandas do visível), porque as superfícies urbanas basicamente são compostas por vias de asfalto e concreto, telhas, solo exposto e estacionamentos. Estes materiais refletem altas parcelas do fluxo radiante incidente do verde, vermelho e infravermelho próximo, contrastando com a vegetação que, geralmente, aparece em vermelho, verde ou magenta dependendo da combinação das bandas na composição falsa-cor (JENSEN, 2009).

As doenças entomológicas mais agravantes hoje em dia são provenientes de vetores de origem arbovirus, como o Ae. aegypti, encontrados principalmente entre as latitudes $45^{\circ} \mathrm{N} \mathrm{e}$ $35^{\circ} \mathrm{S}$ e menos frequentes em altitudes acima de 1.000 metros, devido às baixas temperaturas (ZARA et al., 2016). A incidência dos casos está associada ao aumento de temperatura, pluviosidade e umidade do ar, características que condicionam o aumento do número de criadouros disponíveis e também o desenvolvimento do vetor (RIBEIRO et al., 2006).

O desenvolvimento e hábitos alimentares do mosquito estão associados a temperatura, viabilizando a sobrevivência do mosquito entre as temperaturas de $15^{\circ} \mathrm{C}$ a $32^{\circ} \mathrm{C}$, que são ideais para o estágio larval do mosquito (ARAÚJO et al., 2015). Estudos indicam que a amplitude diária de variação da temperatura média contribui na disseminação e propagação do vetor, facilitando a infecção de um mosquito e subsequente a transmissão do vírus após a ingestão de sangue quando submetidos a temperaturas de $37^{\circ} \mathrm{C}$ (CARRINGTON et al., 2013). Os elevados índices pluviométricos registrados em cidades com acelerada expansão urbana em áreas ambientais, podem ser impactantes no escoamento do volume hídrico do lugar, promovendo um cenário favorável para proliferação de doenças vetoriais, já que a larva e ovos de vetores como o Ae. aegypti são mais frequentes em períodos de temperatura e índices pluviométricos elevados (VIANA; IGNOTTI, 2013). 
O mecanismo de agravos e óbitos das doenças infecciosas são indiretos e mediados por inúmeros fatores sociais e ambientais, com destaque para as áreas de transmissão de doenças relacionadas a vetores e o possível aumento de risco de incidência de doenças de veiculação hídrica. O ciclo de vida dos vetores, assim como dos reservatórios e hospedeiros que participam da cadeia de transmissão de doenças, está fortemente relacionado à dinâmica ambiental dos ecossistemas onde estes vivem (BARCELLOS et al., 2009).

Em alguns casos o solo apresenta uma resposta espectral semelhante à área urbana. Desta forma, uma alternativa para superar este fato é uma análise visual da imagem ou análise qualitativa. A análise visual pode contar com técnicas de interpretação que permitem abordar, além de dados espectrais, elementos como textura, localização, análise de contexto, brilho, como também o conhecimento que o analista tem da área de estudo. O ideal é selecionar as faixas espectrais onde a área urbana apresente maior contraste em relação às outras coberturas, a exemplo a faixa espectral do vermelho (visível) e infravermelho próximo.

Além de estudos relacionados à análise e monitoramento de áreas urbanas que consideram o espectro refletido, estudos relacionados ao clima urbano também podem ser abordados a partir do sensoriamento remoto. Ao considerar a resposta espectral de áreas urbanas no espectro emitido pode-se trabalhar com dados do infravermelho termal para determinar as variações das temperaturas nessas áreas.

Pesquisas sobre este assunto podem ser citados como: Chen et al. (2006) realizaram uma análise da relação entre ilhas de calor urbanas e as mudanças no uso e cobertura do espaço urbano; Liu e Zhang (2011) analisaram ilhas de calor urbanas a partir de dados LANDSAT e ASTER; Deng e Wu (2013) analisaram os impactos das composições biofísicas urbanas em ilhas de calor urbanas utilizando dados da plataforma LANDSAT 7 (ETM +); Alhawiti e Mitisova (2016) apresentam estudo semelhante para identificação das ilhas de calor na Flórida - EUA através dos dados do satélite LANDSAT 8 apresentando resultados que indicam que a maior temperatura da superfície do terreno foi observada em áreas residenciais e comerciais de alta densidade urbana perto do centro da cidade, e as temperaturas mais amenas foram localizada nas áreas costeiras; Dos Santos et al. (2017) estudam as ilhas de calor na Baixada Santista - SP utilizando imagens de satélite através do Normalized Difference Vegetation Index (NDVI) e o Normalized Density Building Index (NDBI) apresentando resultados positivos para um planejamento dentro dos centros urbanos sendo necessário mitigar o efeito das ilhas de calor e proporcionar conforto térmico em áreas urbanas. 
Para se obter temperatura de superfície é necessário converter os valores digitais das imagens para temperatura aparente ou de brilho e posteriormente realizar correções atmosféricas e da emissividade na imagem.

Os procedimentos para cálculo de temperatura de superfície foram realizados no plugin Land Surface Temperature Estimation (LST) desenvolvido por Ndossi e Avdan (2016) disponível no software QGIS. Então, para a estimativa da temperatura de superfície considerouse a correção apenas da emissividade, conforme a equação 2.

$$
T s=\frac{T b}{1+\left(\frac{\lambda T b}{\alpha}\right) * \ln \varepsilon}
$$

$\mathrm{Tb}=$ temperatura de brilho aparente ou registrada pelo sensor em Kelvin;

$\lambda=$ comprimento de onda médio do infravermelho termal;

$\alpha=\mathrm{hc} / \mathrm{K}=1.438 \times 10^{-2} \mathrm{~m} \mathrm{~K}$, onde:

$\mathrm{K}=$ constante de Stefan-Boltzman $\left(1.38 \times 10^{-23} \mathrm{~J} / \mathrm{K}\right)$;

$\mathrm{h}=$ constante de Planck $\left(6.28 \times 10^{-34} \mathrm{~J} / \mathrm{s}\right)$;

$\mathrm{c}=$ velocidade da luz $\left(2.998 \times 10^{8} \mathrm{~m} / \mathrm{s}\right)$

$\ln \varepsilon=\log$ aritmo natural da emissividade da superfície.

O cálculo do LSE (Land Surface Emissivity) conta com diferentes metodologias e as aplicações mais utilizadas e que, de acordo com Sobrino, Jiménez-Muñoz e Paolini (2004), são de fácil operação e apresentam bons resultados, são as imagens de LSE adquiridas a partir do NDVI. Neste caso, diversos trabalhos apontam o cálculo de LSE com valores de NDVI (VAN DE GRIEND; OWE, 1993; VALOR; CASELLES, 1996 e ZHANG; WANG; LI, 2006). Quanto aos métodos de conversão que compreendem também as correções atmosféricas, pode-se citar o Radiative Transfer Equation (BERK; BERNSTEIN; ROBERTSON, 1989) e Mono-Window algorithm (QIN; KARNIELI; BERLINER, 2001). Todas estas abordagens foram implementadas na ferramenta LST desenvolvida por Ndossi e Avdan (2016), disponibilizada a partir do software QGIS. Os autores implementaram quatro diferentes métodos de correção de imagens termais LANDSAT 5, 7 e 8. 
A imagem de emissividade foi calculada no mesmo complemento com os valores de NDVI, metodologia desenvolvida por Zhang, Wang e Li (2006) e implementada no LST. Segundo Ndossi \& Avdan (2016), as imagens LANDSAT 8 corrigidas pelo método Planck Equation exibiram os melhores resultados quando comparadas com medidas de temperatura in situ. As imagens de NDVI também foram geradas no LST.

Assim, para o segundo método denominado Mono-Window Algorithm considerou-se como dados de entrada a transmitância atmosférica, temperatura atmosférica média efetiva, perfil atmosférico, imagens de temperatura de brilho e de emissividade.

Ndossi e Avdan (2016), ao compararem os métodos de correção de imagens termais referentes a Planck Equation, Radiative Transfer e Mono-Window Algorithm, verificaram que os melhores resultados foram identificados para as imagens corrigidas com o primeiro método supracitado. Os autores ainda destacam que a função de Planck é a mais fácil de ser utilizada, pois não requer dados atmosféricos durante a passagem do satélite. Esse estudo optou por dois métodos, sendo eles o Planck Equation e o Mono-Window.

Ao analisar uma imagem obtida na faixa do infravermelho termal o especialista não deve levar em consideração a resposta espectral dos alvos no espectro refletido, mas sim sua variação no espectro emitido. Lembrando que todos os materiais que apresentam temperatura acima do zero absoluto emitem radiação termal como o resultado da mudança de estado de energia das partículas da matéria a partir do seu movimento aleatório das moléculas (calor cinético), a temperatura cinética verdadeira (TKin) pode ser medida in situ a partir de um termômetro. A concentração da quantidade de fluxo radiante emitido por um objeto pode ser chamada de temperatura radiante (Trad). Na maioria das vezes, existe uma alta correlação positiva entre a temperatura cinética e a temperatura radiante, sendo que os valores de TKin são um pouco maiores que a Trad devido à propriedade termal chamada de emissividade. Os sistemas de sensoriamento remoto registram a temperatura radiante de objetos da superfície terrestre e não a temperatura real e os dados são geralmente registrados na região de 10,5 a 12,5 $\mu \mathrm{m}$ (SABINS, 1986; JENSEN, 2009;).

Pode-se dizer que a emissividade traduz a capacidade de um material em transformar o seu calor em radiação, ou seja, de emitir radiação termal (JENSEN, 2009). Neste seguimento, um corpo negro ideal emite toda energia que absorve, apresentando a emissividade igual a 1. No entanto, os materiais da superfície terrestre não apresentam emissividade igual a 1, desta forma, seus valores variam no intervalo de 0 a 1 . Na Tabela 8 é possível verificar a emissividade de diferentes superfícies na faixa de 8 a $14 \mu \mathrm{m}$. 
Tabela 8 - Emissividade de diferentes materiais na faixa 8 a $14 \mu \mathrm{m}$

\begin{tabular}{|l|c|}
\hline \multicolumn{1}{|c|}{ Material } & Emissividade \\
\hline Água & $0,92-0,98$ \\
\hline Asfalto & 0,95 \\
\hline Bassalto & 0,95 \\
\hline Cimento/pedra & 0,97 \\
\hline Concreto & $0,71-0,90$ \\
\hline Grama & 0,97 \\
\hline Madeira & 0,9 \\
\hline Solo arenoso & 0,90 \\
\hline Solo siltoso seco & 0,92 \\
\hline Solo siltoso úmido & 0,95 \\
\hline Tijolo/vermelho e áspero & 0,93 \\
\hline Vegetação dossel aberto & 0,96 \\
\hline Vegetação dossel fechado & 0,98 \\
\hline
\end{tabular}

Fonte: (JENSEN, 2009)

As imagens adquiridas, no caso dos produtos LANDSAT, disponibilizam a temperatura de brilho dos materiais e não a temperatura de superfície propriamente dita. É neste aspecto que surgem alguns impasses quanto à conversão das imagens termais, já que diversas metodologias consideram os aspectos da emissividade para correção (NICHOL, 1994; VALOR; CASELLES, 1996; ADILSON STEINKE; TORRES STEINKE; HIROO SAITO, 2010), outras abordam as correções da emissividade dos alvos e correções atmosféricas (BERK; BERNSTEIN; ROBERTSON, 1989; QIN; KARNIELI; BERLINER, 2001; SOBRINO; JIMÉNEZ-MUÑOZ; PAOLINI, 2004).

\subsection{ANÁLISE ESPACIAL}

\subsubsection{Análise dos dados - Krigagem Ordinária}

O método da Krigagem ordinária é baseado na suposição de que as variações espaciais em qualquer atributo são geralmente irregulares e dependentes entre si. Portanto, a variação 
pode ser mais bem descrita por uma superfície aleatória, conhecida como variável regionalizada.

Tais variáveis se aplicam na distribuição de indicadores contínuos. A Krigagem ordinária é um processo de estimativa por médias ponderadas de valores em uma superfície contínua no espaço a partir de valores adjacentes, considerados como interdependentes por uma função denominada variograma, estimando assim valores para os locais não amostrados. Por meio de funções matemáticas, são atribuídos pesos maiores para pontos mais próximos aos pontos amostrais e pesos menores aos mais distantes, gerando assim uma superfície de pontos com base nessas combinações lineares de dados. O método da krigagem ordinária estima valores desconhecidos, a partir de um conjunto de $\mathrm{n}$ dados $\left\{Z\left(x_{i}\right), i=1 . . n\right\}$. O estimador é definido como:

$$
\hat{Z}_{i}=\sum_{i=1}^{n} \lambda_{i} * Z_{i}
$$

Onde: $\hat{Z}_{i}$ é o valor interpolado; $\lambda_{i}$ é o peso atribuído aos valores amostrados; $Z_{i}$ é o valor do atributo amostrado.

A krigagem é entendida como uma série de técnicas de análise de regressão que procura minimizar a variância estimada valendo-se de um modelo prévio, levando em conta a dependência estocástica entre os dados distribuídos no espaço (OLIVER; WEBSTER, 1990).

A diferença fundamental entre a krigagem e outros métodos de interpolação é a maneira como os pesos são atribuídos às diferentes amostras. Na krigagem, os pesos são determinados a partir de uma análise espacial, com base no semivariograma experimental. Além disso, a krigagem fornece, em média, estimativas não tendenciosas e com variância mínima.

Torna-se necessário ajustar o variograma experimental a uma função que represente a tendência da relação entre alcance e a continuidade. Isso é feito a fim de modelar fenômenos que possuem capacidade infinita de dispersão. Desse modo, as estimativas, obtidas valendo-se da krigagem, serão mais exatas e, portanto, mais confiáveis. Segundo Oliver e Webster (1990) o variograma possui as seguintes caracteristicas: 
- o alcance (a), que indica a distância a partir da qual as amostras passam a não possuir correlação espacial e a relação entre elas torna-se aleatória; toda amostra cuja distância ao ponto a ser estimada for menor ou igual à amplitude fornece informações sobre o ponto;

- o patamar $(\mathrm{C}+\mathrm{Co})$, que indica o valor segundo o qual a função estabiliza-se no campo aleatório, correspondente à distância "a"; mostra a variabilidade máxima entre pares de valores, isto é, a variância dos dados e, conseqüentemente, co-variância nula;

- a continuidade, pela forma do variograma, em que para h@0,g(h) já apresenta algum valor; essa situação, representada por Co, é conhecida como efeito pepita, o qual pode ser atribuído a erros de medição ou ao fato de que os dados não foram coletados a intervalos suficientemente pequenos para mostrar o comportamento espacial subjacente do fenômeno em estudo, isto é, não é capturado um fenômeno numa escala maior;

- a anisotropia, quando os semivariogramas mostram parâmetros diferentes para diferentes direções de amostragem.

\subsubsection{Integrated Nested Laplace Approximation (INLA)}

Um dos principais objetivos da estatística é realizar inferência sobre os parâmetros de um modelo. Na abordagem Frequentista, os parâmetros desconhecidos são considerados fixos e toda a análise é baseada nas informações contidas na amostra dos dados. Segundo Stern (2006), esta abordagem foi adotada de forma quase unânime pelos estatísticos durante a primeira metade do século XX.

Segundo Chiaravalloti-Neto (2017), uma crítica importante a alguns estudos que tem como objetivo modelar medidas de incidência ou prevalência calculadas em áreas (municípios, bairros, áreas de ponderação, setores censitários ou quarteirões) em função de covariáveis socioeconômicas, demográficas, ambientais e de serviços de saúde, é que eles não levavam em conta a dependência espacial da variável dependente em análise, o que feria os pressupostos básicos da modelagem por regressão. Uma alternativa para incorporar as informações espaciais é o uso de uma técnica estatística bayesiana denominada INLA (RUE et al., 2017). Ela permite tratar a heterogeneidade espacial e espaço-temporal de modo computacionalmente eficiente e mesmo considerar estruturas de dados mistas, ao levar em conta tanto a vizinhança (a 
dependência espacial) como a existência de estruturas hierárquicas de dados (BLANGIARDO e CAMELETTI, 2015).

A utilização de modelos lineares generalizados em análises estatísticas é cada vez mais comum devido à possibilidade de permitir descrever o comportamento de dados provenientes de diferentes distribuições de probabilidades, desde que estas pertençam a uma família exponencial. Com o uso desses modelos, o cenário ampliado, é possível descrever o comportamento de diferentes distribuições, também acomodar a variabilidade residual que não está sendo descrita.

Segundo Fong, Rue e Wakefield (2010), no caso de pequenas amostras, a estimação de parâmetros é feita por meio de uma abordagem clássica, e isto pode apresentar problemas, principalmente na estimação de componentes de variância, pois a interferência baseia-se nos estimadores de máxima verossimilhança. Para solucionar esse problema, é comum a abordagem Bayesiana, a qual é baseada em dados observados e permite a atualização de informação.

Dada a necessidade de ajuste de modelos hierárquicos, além dos modelos lineares generalizados mistos, de maneira eficiente e rápida, Rue, Martino e Chopin (2009) propuseram a estimação INLA. O método INLA é uma aproximação determinística para a inferência bayesiana para a classe dos modelos gaussianos latentes.

O método INLA aproxima de forma direta as distribuições a posteriori de interesse. Com isso, é possível realizar inferência com um custo computacional consideravelmente inferior e, consequentemente, com maior rapidez, além de não ser necessário lidar com problemas de convergência.

Além da dificuldade no diagnóstico da convergência e o alto custo computacional, em se tratando de inferência em modelos latentes gaussianos, os métodos Markov Chain Monte Carlo (MCMC) apresentam desvantagem do ponto de vista computacional devido à dependência dos elementos do campo latente entre si, além da dependência existente entre os hiperparâmetros e os parâmetros do campo latente. Com isso, o método INLA surge como uma alternativa para lidar com esses problemas.

Assume-se a seguinte estrutura hierárquica. 


$$
\begin{aligned}
y_{i} \mid \mathrm{x}, \theta & \sim \mathrm{p}\left(y_{i} \mid x_{i}, \theta\right) \\
x \mid \theta & \sim \mathrm{p}(x \mid \theta) \\
\theta & \sim p(\theta),
\end{aligned}
$$

em que $\mathrm{y}=\left(y_{1} \ldots, y_{n d}\right)^{\prime}$ são os dados observados, $\mathrm{x}=\left(x_{1} \ldots, x_{n}\right)^{\prime}$ os elementos do campo latente, $\theta$ é o vetor m-dimensional de hiperparâmetros, a distribuição de $y_{i} \mid x, \theta$ pertence à família exponencial e a distribuição de $x \mid \theta$ é gaussiana.

Assume-se que os dados observados são condicionalmente independentes dado o campo latente x. Com isso, tem-se que:

$$
p(y \mid x, \theta)=\prod_{i \in I} p\left(y_{i} \mid x_{i}, \theta\right)
$$

A distribuição a posteriori é dada por:

$$
p(x, \theta \mid y) \propto p(\theta) p(x \mid \theta) \prod_{i \in I} p\left(y_{i} \mid x_{i}, \theta\right)
$$

Rue et al. (2017) assumem que o campo latente x possui grande dimensão, mas que admite propriedades de independência condicional. Considera-se modelos que satisfazem a propriedade de Markov, ou seja, $x_{i}\left\lfloor x_{-i}\right.$ só depende de um subconjunto de $x_{-i}$, em que $x_{-i}=$ $\left(x_{1}, \ldots, x_{i-1}, x_{i+1}, \ldots, x_{n}\right)$. Neste caso, o campo latente é um campo aleatório markoviano gaussiano e matriz de precisão referente ao campo latente é esparsa.

Além disso, assume-se que o número $m$ de hipearâmetros é pequeno, por exemplo, $m \leq 6$. Assim, é possível fazer uso de métodos numéricos para matrizes esparsas muito mais rapidamente do que para cálculos com matrizes densas (RUE; MARTINO; CHOPIN, 2009).

Alguns estudos que apresentam com maiores detalhes como o INLA é aplicado são Bivand , Gómez-Rubio e Rue (2015), Lindgren e Rue (2015), Blangiardo e Cameletti (2015), Rue et al., (2017), Zuur, Ieno e Saveliev (2017) e Bakka et al., (2018). 
Outros estudos que utilizam a metodologia INLA na área de mapas e saúde são Schrödle e Held (2011), Ugarte et al., (2014), Carroll et al., (2015) e Moraga (2017), entre outros. Já na área de saúde pública voltada para dengue alguns estudos apresentando a relação de dengue com a metodologia INLA em suas análises são Costa, Donalisio e Silveira (2013), Costa et al., (2015), Adin et al., (2018), Chiaravalloti-Neto et al., (2019), e Bett et al., (2019), Lorenz et al., (2020) entre outros. 


\section{METODOLOGIA}

A metodologia consiste em apresentar os materiais e os processamentos utilizados em cada etapa do desenvolvimento do trabalho. A Figura 3 sintetiza um fluxograma dos principais passos seguidos.

Figura 3 - Fluxograma da metodologia.

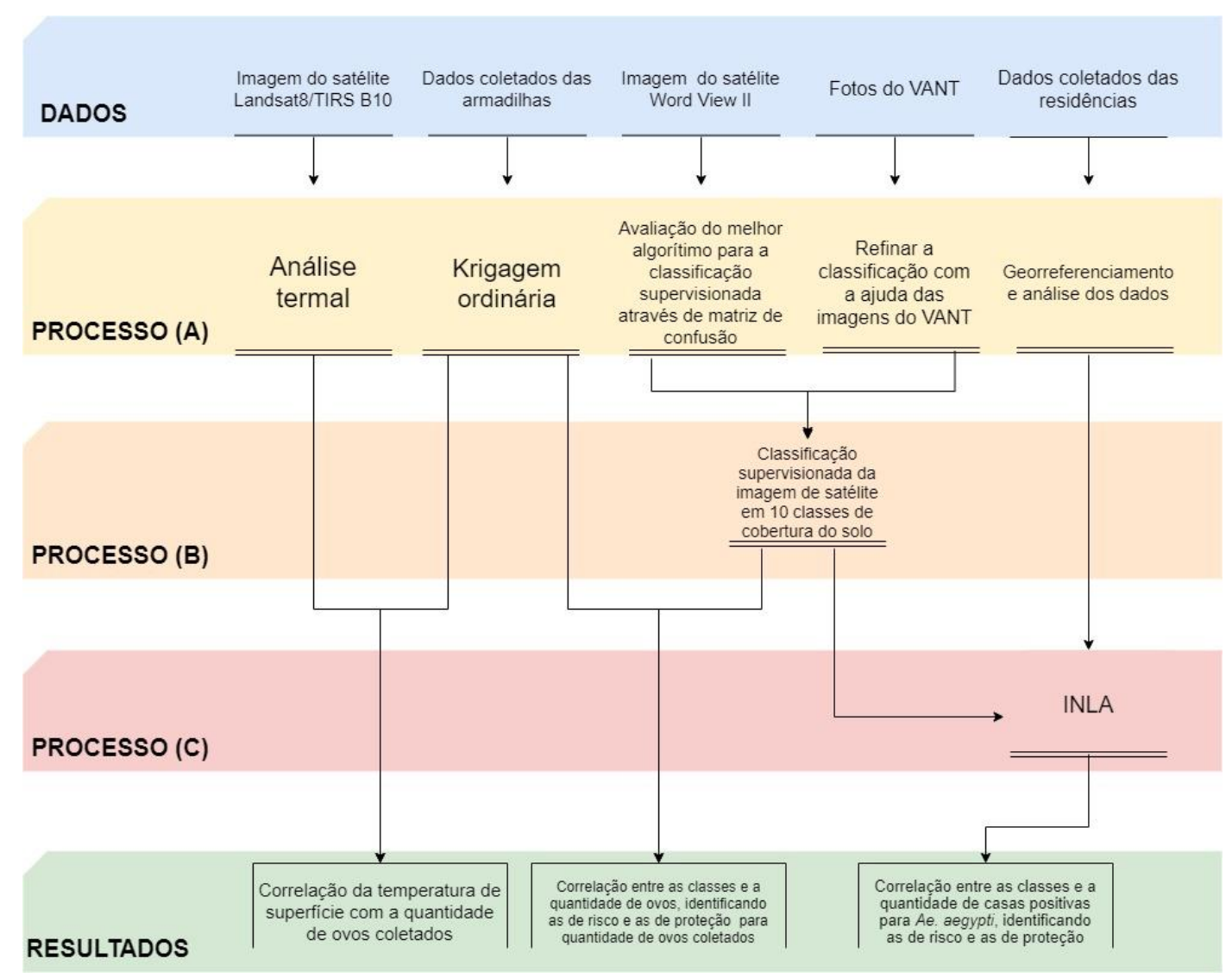

Fonte: Elaborado pela autora.

Os materiais utilizados para o estudo foram:

- Software ENVI 5.0 ®, para a preparação das imagem e classificação;

- Software QGIS Desktop 2.14.3® para as análises espaciais;

- Software R $®$, para as análises geoestatísticas e modelagens espaciais;

- Arquivo vetorial do tipo shapefile com o eixo de ruas das áreas de estudo fornecida pela Prefeitura de Campinas (2014).

- Imagem do satélite Word View II (12/08/2015); 
- Dados do Campo realizado pela SUCEN (outubro/2015 até setembro/2016);

- Imagens de VANT (13/04/2016);

- 12 Imagens do satélite LANDSAT 8/ TIRS B10 (uma imagem por mês durante o ano de 2016).

\section{1. ÁREA DE ESTUDO}

O município de Campinas está situado na região centro-oeste do Estado de São Paulo (4704'40' Longitude Oeste e 2253'20' Latitude Sul), numa altitude média de 640 metros acima do nível do mar. A Figura 4 expõe a localização do município de Campinas que apresenta área total de 795,7 km2, com 49\% de área urbana e população segundo o Censo 2010 igual a 1.080.113 habitantes, dos quais $98,3 \%$ da população total estão estabelecidas na área urbana (IBGE, 2013).

Figura 4 - Localização da área de estudo.

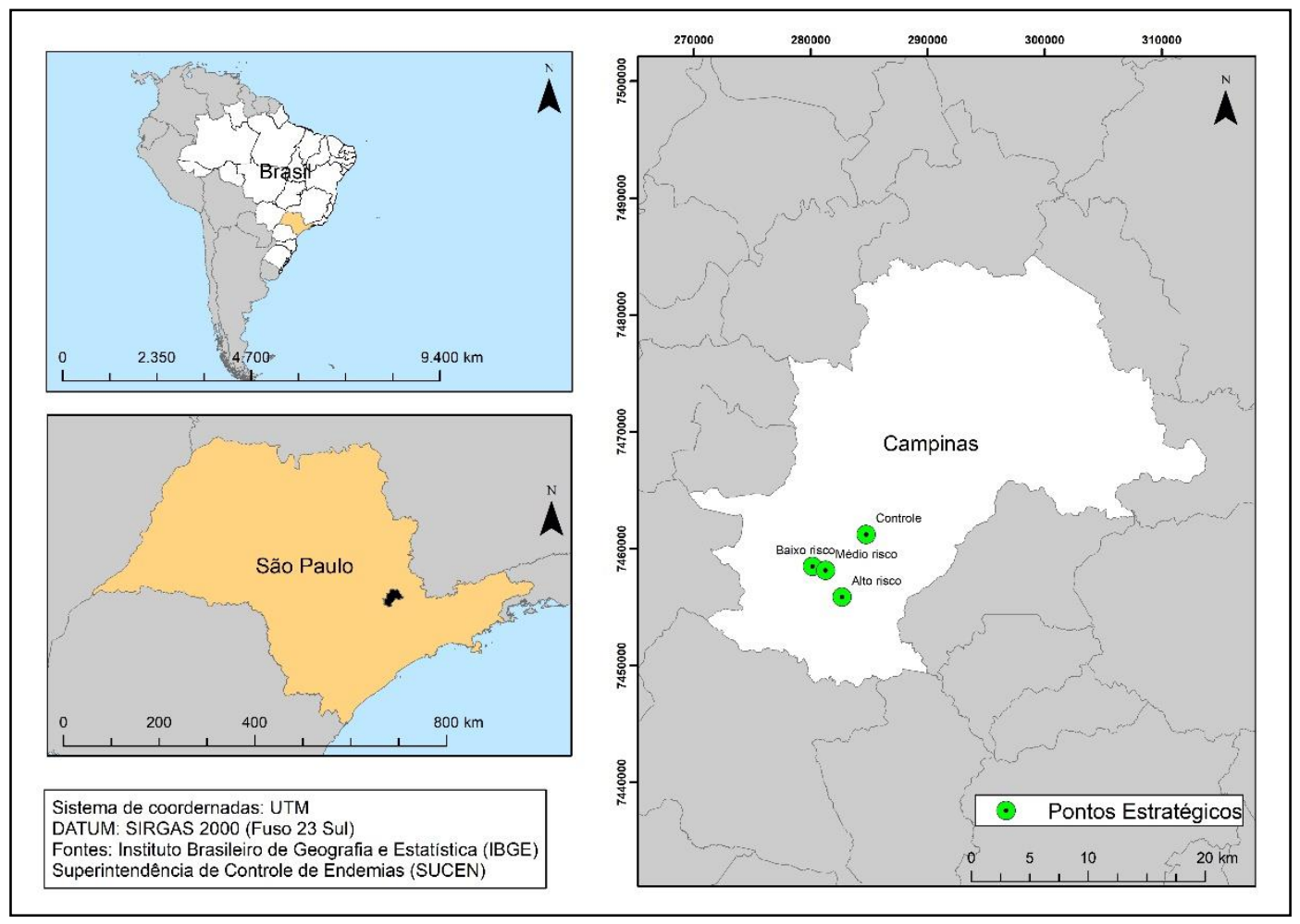

Fonte: Elaborado pela autora. 
A cidade tem a terceira maior população no Estado e tem uma elevada taxa de desenvolvimento humano $(0,805)$. O seu clima é quente e temperado, com temperatura média anual e precipitação de $19,3^{\circ} \mathrm{C}$ e $1315 \mathrm{~mm}$, respectivamente.

No período de 2010 a 2016 o município registrou aproximadamente 120 mil casos de dengue. Campinas é classificado pelo Ministério da Saúde como prioritário, pela sua localização geográfica e incidência de dengue, com várias rodovias importantes do Estado de São Paulo, além de três aeroportos sendo um internacional e dois estaduais, várias Universidades, grande polo industrial e centros de compras muito variados. Devido a estes motivos, com um grande fluxo de pessoas circulando nessas áreas, aumenta a possibilidade de transmissão das arboviroses e disseminação para outras áreas do estado e país (BARBOSA et al., 2012).

\subsection{CLASSIFICAÇÃO DAS ÁREAS E TEMPO DE ESTUDO}

Os PEs são propriedades, como lojas de pneus e depósitos, empresas de materiais de construção e depósitos de materiais recicláveis, com uma grande quantidade de potenciais locais de reprodução para as formas imaturas do mosquito (Barbosa et al., 2019). São cadastrados seguindo alguns critérios como: ramo de atividade, recipientes existentes, rotatividade dos recipientes e adoção de cuidados pelo responsável, e são qualificados quanto ao risco de infestação em alto, médio e baixo (BARBOSA et al., 2019). Para avaliar a influência dos PEs na dispersão do vetor Ae. aegypti, bem como se essa influência se diferencia de acordo com o risco de infestação, selecionaram-se quatro áreas, sendo três delas com PE classificado em alto, médio e baixo risco de infestação, respectivamente, e uma área controle, sem presença de PE.

As quatro áreas selecionadas foram trabalhadas durante 12 meses a partir de outubro de 2015 divididos em 4 ciclos de 3 meses cada: outubro a dezembro/2015 como ciclo 1 , janeiro a março/2016 como ciclo2, abril a junho/2016 como ciclo3 e por último de julho a setembro/2016. Tal período foi escolhido para abarcar a sazonalidade da infestação vetorial, sendo outubro o mês quando se inicia, geralmente, o aumento dos níveis de infestação (BARBOSA et al., 2019). 
O período Primavera/Verão é considerado mais favorável ao desenvolvimento do vetor (CHADEE, 2004; DOWLING et al. 2013; FAVARO et al. 2013; LADEAU et al. 2013; LITTLE ET AL. 2017; BARBOSA et al. 2019; LORENZ et al. (2020). Um fator que pode influenciar a abundância do vector em períodos que não a Primavera e o Verão seria a necessidade da população de armazenar água em períodos de seca, que coincidem com o Inverno no sudeste do Brasil. No entanto, isto é não o caso de Campinas, uma vez que a cidade não tem problemas de abastecimento de água, que tem uma cobertura de 99,55\%, segundo o IBGE. Cada um dos imóveis das quatro áreas foi visitado duas vezes e, em cada visita, os especialistas de campo procuraram potenciais recipientes Ae. aegypti e, ao encontrar larvas de mosquito e/ou pupas, amostras foram recolhidas e enviadas para o laboratório para identificação.

As quatro áreas selecionadas para avaliar a infestação de imóveis por Ae.aegypti (Figura 5) apresentavam diferentes níveis socioeconómicos e a presença, ou não, de pontos estratégicos com riscos diferentes para a presença do vetor.

A área controle apresentou o melhor nível socioeconômico de acordo com o censo do Instituto Brasileiro de Geografia e Estatísticas (IBGE) realizado em 2010, com um rendimento médio de $\mathrm{R} \$ 1807,00$ e 3,0 residentes por agregado familiar. Já as áreas de baixo e médio risco apresentaram níveis socioeconômicos intermediários, com um rendimento médio de $\mathrm{R} \$ 1285,00$ e $\mathrm{R} \$ 1138,00$ e 3,2 e 3,4 residentes por agregado familiar, respectivamente. A área de alto risco apresentou o pior nível, com um rendimento médio de $\mathrm{R} \$ 755,00$ e 3,5 residentes por agregado familiar. Também, a área controle não tinha a presença de pontos estratégicos, e as áreas baixo, médio e alto risco tinham pontos estratégicos com baixo, médio e alto risco para a presença do vector, respectivamente. 
Figura 5 - Imagem de satélite das áreas de estudo.

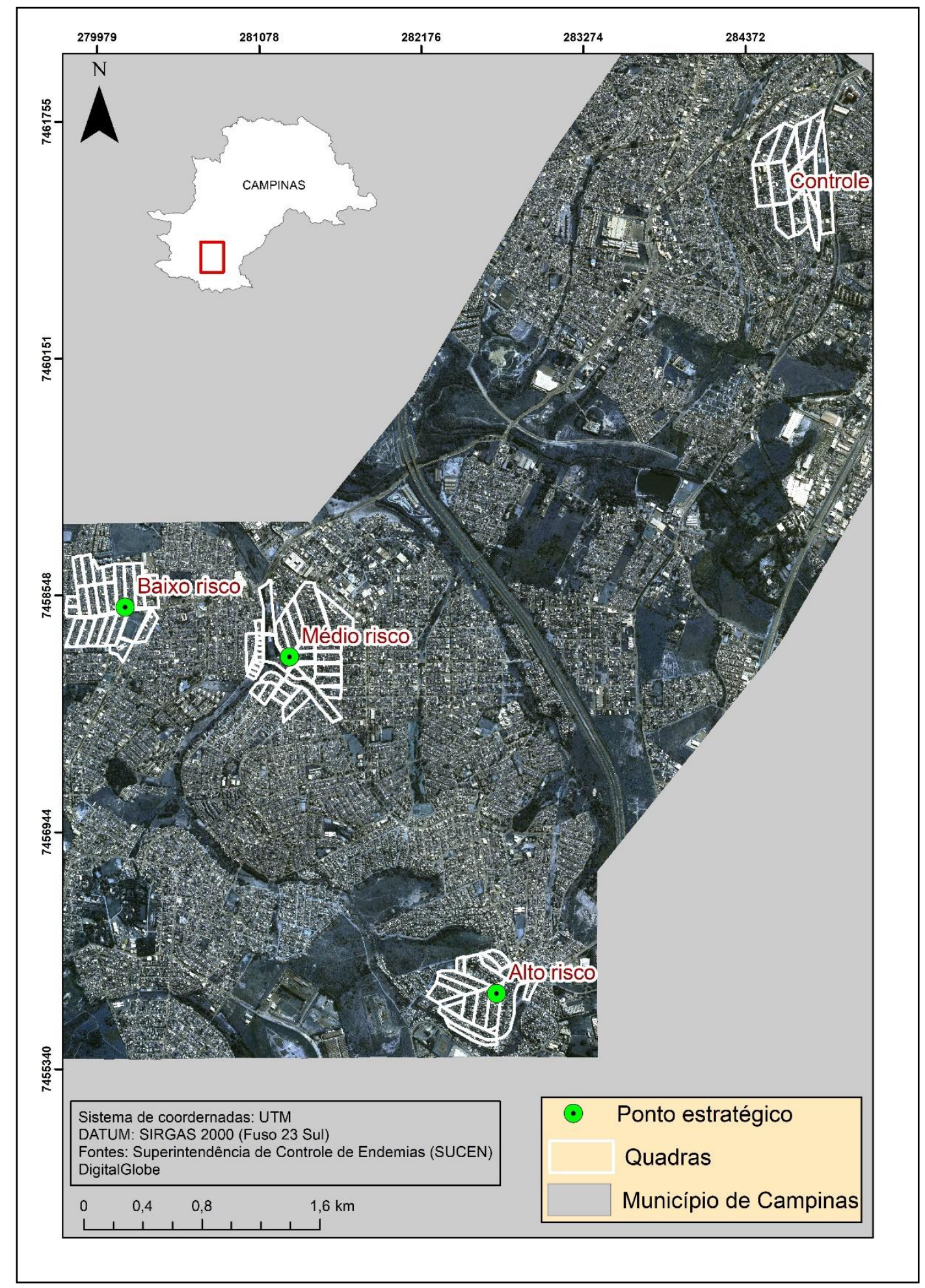

Fonte: Elaborado pela autora. 
O Índice Paulista de Vulnerabilidade Social (IPVS) é um indicador criado pela Fundação Seade, em parceria com a Assembleia legislativa do Estado de São Paulo, que permite visão detalhada das condições de vida nos municípios do Estado, com a identificação e localização espacial dos setores censitários de acordo com a vulnerabilidade de suas populações à pobreza. A tipologia dessas áreas se baseia nas informações do Censo Demográfico e leva em conta variáveis como a renda domiciliar per capita, o porcentual de mulheres de 10 a 29 anos responsáveis pelos domicílios e a situação de aglomerado subnormal (favela) do setor censitário (FUNDAÇÃO SEADE, 2013).

O IPVS, então, permite uma visão mais detalhada das condições de vida da população residente no município, com a identificação e localização espacial das áreas que abrigam os segmentos mais vulneráveis à pobreza. Para tanto, este índice baseou-se em dois pressupostos: o de que as múltiplas dimensões da pobreza devem ser consideradas em um estudo sobre vulnerabilidade social; e o de que a segregação espacial é um fenômeno presente nos centros urbanos paulistas e contribui decisivamente para a permanência dos padrões de desigualdade social característicos dessas localidades.

Com base nessas variáveis, são definidos sete grupos em que são classificados os setores censitários, levando em conta as diferentes condições de exposição da população residente à vulnerabilidade social. Com isso, foram identificadas áreas geográficas segundo o grau de vulnerabilidade de população residente. Portanto, o IPVS baseia-se em uma combinação entre as dimensões socioeconômica e demográfica, possibilitando classificar os setores censitários em oito categorias, segundo o grau de vulnerabilidade à pobreza da população neles residente: sem população; não classificado; baixíssima vulnerabilidade; vulnerabilidade muito baixa; vulnerabilidade baixa; vulnerabilidade média; vulnerabilidade alta; e vulnerabilidade muito alta. A Figura 6 Apresenta o IPVS na área de estudo, sendo que a área de alto risco é o local onde apresenta maior índice de vulnerabilidade, já as áreas controle e baixo risco não apresentam altos índices de vulnerabilidade social. 
Figura 6: IPVS da área de estudo

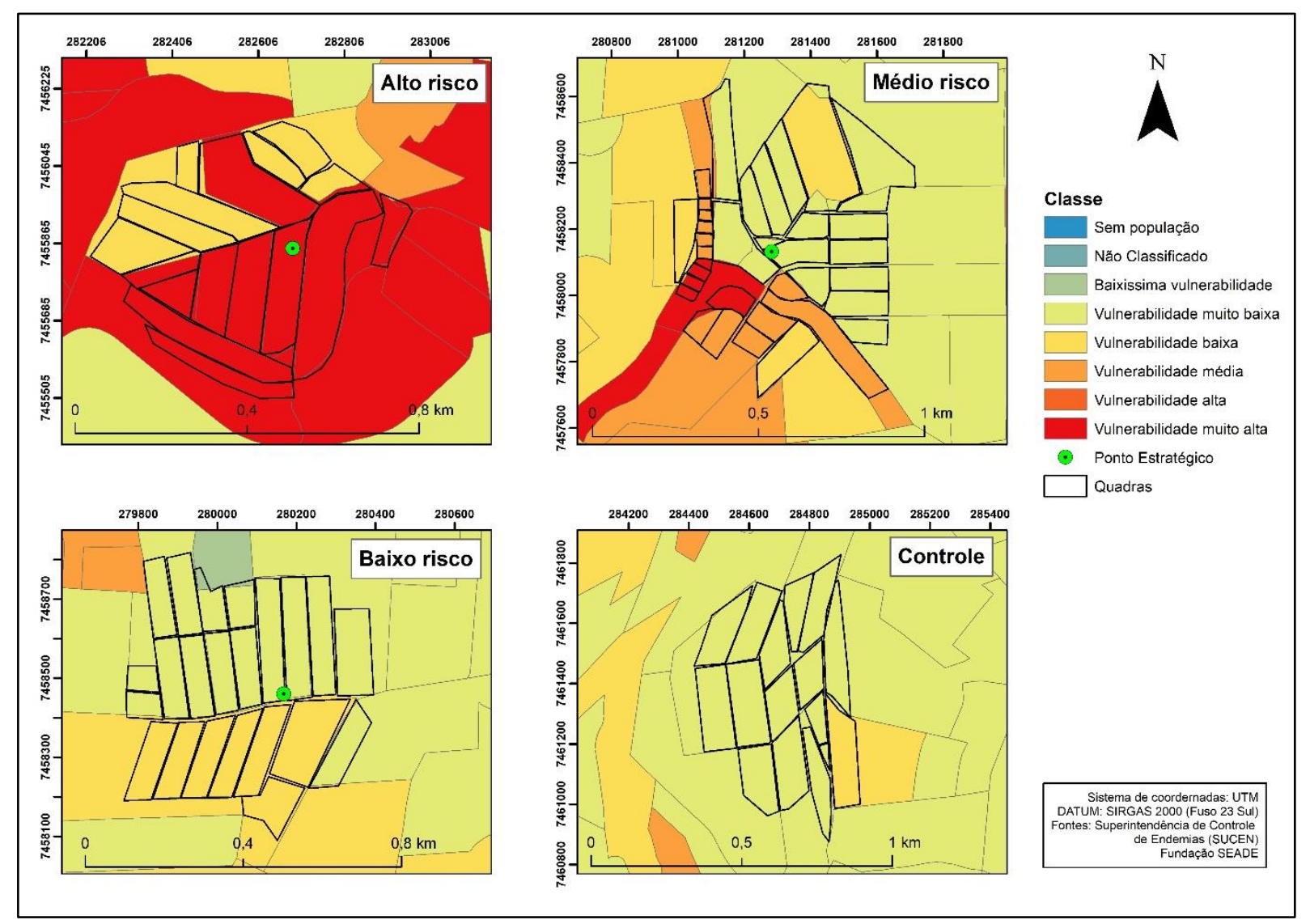

Fonte: Elaborado pela autora

\subsection{INSTALAÇÃO DE ARMADILHAS DE OVIPOSIÇÃO}

O método de Armadilhas de Oviposição - Ovitrampa - foi descrito em 1966 por Fay e Eliason, e refere-se a um recipiente preto, com boca larga, com uma paleta de madeira contendo lado áspero, colocada verticalmente em seu interior e preenchido parcialmente com água de rede pública de abastecimento. As palhetas contidas nesta armadilha permitem a contagem e identificação dos ovos de Ae. aegypti. O poder atrativo desta armadilha foi melhorado com adição de solução de infusão de feno a 10\% por Reiter , Amador e Colon em 1991.

A seleção dos imóveis para instalação das Ovitrampas foi feita de forma intencional, considerando as distâncias dos PEs e garantindo a distribuição em todas as direções. As armadilhas foram instaladas pela equipe da SUCEN, assim como seu monitoramento e a obtenção dos dados. A instalação foi realizada em peridomicílios, próximo das paredes dos imóveis em lugares sombreados e protegidos da chuva, preferencialmente a uma altura de 1 a 
1,5 metro, em locais onde as armadilhas não fossem afetadas por pessoas e animais, de preferência próximos a criadouros domésticos potenciais (caixa d'água, vasos de planta, tanque, etc.), tomando cuidado para evitar a competição destes com as ovitrampas. As instalações das ovitrampas ocorreram após conversa explicativa com moradores quando foi informado o objetivo e procedimentos adotados.

O período de exposição das ovitrampas foi de quatro dias em cada mês. Cada ovitrampa tem capacidade máxima de 1 litro, com "ladrão" para que o volume de água mantido não ultrapassasse $500 \mathrm{ml}$. Na primeira instalação, as paletas foram previamente lavadas e imersas em água de torneira por 72 horas com o intuito de retirar odores e produtos químicos. No interior da armadilha foi depositada uma paleta de madeira aglomerada (Eucatex), de tamanho padronizado $(15 \mathrm{~cm} \mathrm{X} \mathrm{2,5} \mathrm{cm),} \mathrm{na} \mathrm{posição} \mathrm{vertical} \mathrm{e} \mathrm{com} \mathrm{o} \mathrm{lado} \mathrm{áspero} \mathrm{para} \mathrm{cima} \mathrm{apresentada}$ na Figura 7.

Figura 7: Exemplo da armadilha Ovitrampa.

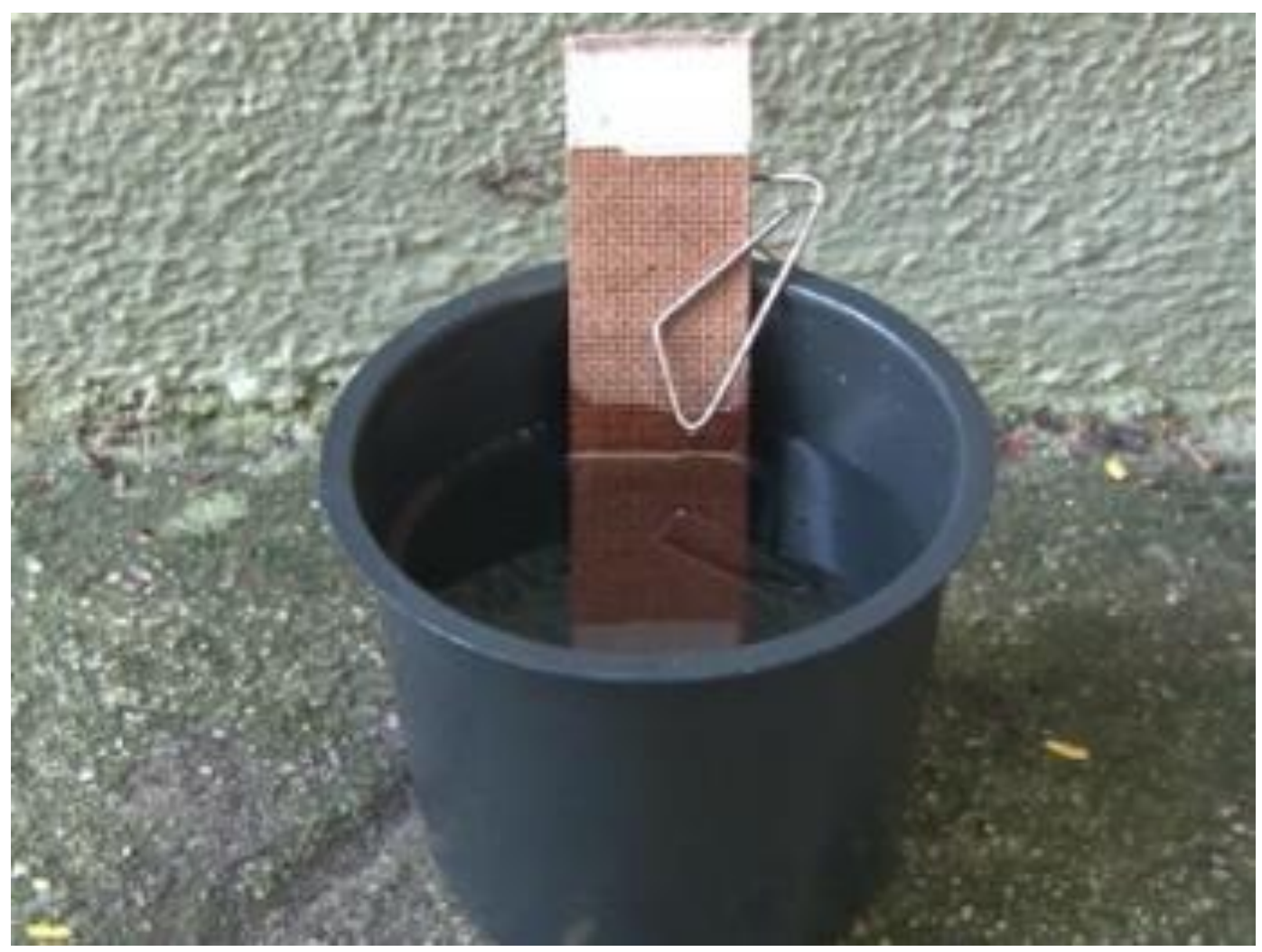

Fonte: Comunicação / Instituto Oswaldo Cruz. 
Em cada uma das quatro áreas foram instaladas 45 ovitrampas totalizando 180 armadilhas. Excetuando os PEs trabalhados, nestas áreas, não há nenhum PE a menos de 500 metros da borda da área.

$\mathrm{Na}$ retirada, as paletas de cada ovitrampa foram individualizadas e, imediatamente acondicionadas em grades, dentro de uma caixa térmica de isopor para transporte para o laboratório, quando então foram colocadas em bancada sobre papel toalha para secagem e quantificação, evitando assim a eclosão dos ovos. Todo o conteúdo líquido da armadilha foi eliminado, e a mesma lavada em água corrente com esponja e sabão de coco para eliminar ovos existentes na parede do recipiente possibilitando sua reutilização. As paletas tiveram seus ovos contados, com o auxílio de um microscópio estereoscópico. Os dados desta atividade foram registrados em boletins específicos para esta atividade.

\subsection{COLETA DE DADOS RELACIONADOS AOS IMÓVEIS RESIDENCIAIS}

Nas quatro áreas avaliadas, foi realizada atividade para acompanhamento da infestação e dos criadouros existentes, onde foram vistoriados todos os imóveis da área selecionada. Foram trabalhados 1.400 imóveis ao mês nas quatro áreas considerando a capacidade operacional (4 servidores trabalhando 10 dias em 1400 imóveis - 35 imóveis servidor/dia) a coleta dos dados foi realizada pela equipe de campo da SUCEN.

Sendo assim, a visita a todos imóveis de cada área foi completada em 3 meses, onde cada área foi trabalhada em $1 / 3$ de seus imóveis mensalmente, concluindo simultaneamente a cobertura das 4 áreas, evitando assim que a sazonalidade do vetor interfira na avaliação dos resultados. Durante a realização da atividade para acompanhamento da infestação, foram registrados e classificados todos recipientes potenciais criadouros de Ae. aegypti, além daqueles recipientes encontrados com larvas e/ou pupas. As larvas e/ou pupas, foram coletadas e identificadas em laboratório. Além disso, foi também realizada a classificação dos imóveis pelo ICM. Para maiores informações desse estudo ver Barbosa et al., 2019.

Conforme já comentado e considerando a sazonalidade do vetor, os imóveis foram visitados quatro vezes, sendo que o ICM foi medido para cada um dos imóveis em cada uma das visitas realizadas, buscando representar a condição do imóvel em todos os períodos do ano. 
A atividade de visita para acompanhamento da infestação consistiu em visita domiciliar a imóveis, residenciais e não residenciais, para ações de eliminação de criadouros e orientação aos responsáveis pelo local, quanto aos procedimentos necessários para manter o imóvel livre de criadouros potenciais para criação de larvas de Ae. aegypti.

Todos os imóveis trabalhados foram georeferenciados por GPS e identificados em uma base cartográfica digital.

Para o registro dos dados a serem coletados no campo, foi utilizado sistema desenvolvido especificamente para este estudo, na plataforma Android, instalado em celular, que ao final do dia foi carregado na base de dados web. A principal vantagem neste processo está na dispensa da digitação de boletins de campo, possibilitando assim uma rápida análise da informação trabalhada diariamente. Para o PNCD, esta agilidade significa possibilidade de interferência em tempo hábil evitando desperdício de recurso e aumentando a velocidade de resposta para a intervenção necessária.

\subsection{AQUISIÇÃO E SELEÇÃO DAS IMAGENS DE SATÉLITE E VANT DE ALTA RESOLUÇÃO}

A aquisição da imagem de satélite WorldView 2 ocorreu em 12/08/2015, cuja resolução espacial é de $50 \mathrm{~cm}$ no pancromático ou $2 \mathrm{~m}$ no multiespectral, indicadas para a identificação de alvos em áreas urbanas. Com o objetivo de refinar a classificação da imagem de satélite, foi realizado o voo do VANT em 13/04/2016.

Com o recente avanço tecnológico, VANTs surgem como uma alternativa na aquisição de imagens da superfície terrestre, apresentando grandes vantagens quando comparados a outros métodos, como menor custo, maior facilidade de operação e principalmente a possibilidade de geração de imagens com alta resolução, em questão de minutos.

A fotogrametria é uma técnica que captura informações de determinado objeto a partir de duas ou mais fotografias obtidas em diferentes ângulos. Em particular, a Structure from Motion (SfM) é uma técnica fotogramétrica onde orientação e posição da câmera é corrigida automaticamente usando imagens sobrepostas. A partir de algoritmos, pontos chaves são detectados na imagem, e se corresponderem ao mesmo objeto real, em diferentes imagens, são emparelhados (matching) para construir nuvens de pontos em três dimensões (3D), e a partir 
dessas nuvens gerar MDE e ortomosaicos (SNAVELY; SEITZ; SZELISKI, 2008; VASUKI et al., 2014).

Para o planejamento do voo utilizou-se o software MissionPlanner, onde foi definida a sobreposição das imagens segundo as recomendações de Agisoft (2016), que foram de $60 \%$ lateral e $80 \%$ longitudinal. Foi utilizado como base, o tamanho do pixel no terreno, sendo este de aproximadamente $3 \mathrm{~cm} /$ pixel.

A etapa de execução do voo se iniciou com a verificação dos equipamentos em solo, como não se percebeu problema, foi avaliado o ortomosaico de um voo realizado a $100 \mathrm{~m}$ de altura em relação base. Após essa verificação, foram adquiridos os dados e imagens a partir do VANT Phantom 3 da fabricante DJI.

Para o processamento digital dos dados obtidos pelo VANT foi utilizado o software Agisoft Photoscan 1.2.0. O alinhamento das imagens foi executado através da correlação das imagens sobrepostas devidamente orientadas, onde o algoritmo procura por pontos comuns nas imagens e os combinam, encontrando a posição da câmera em cada imagem e refinando seus parâmetros de calibração, gerando uma nuvem esparsa de pontos.

As cinco etapas básicas do processamento com o Photoscan são: (1) calibração automática da câmera - com base nos dados do EXIF (Exchangeable Image File Format) das fotografias; (2) alinhamento das fotos - a partir dos pontos em comum entre as fotografias; (3) geração da nuvem de pontos - com base nas posições estimadas das fotografias são identificadas as coordenadas x, y e z; (4) criação de um MDS de malha triangular - usando a nuvem de pontos como nós, é gerada uma estrutura do tipo vetorial com topologia do tipo nóarco que representa a superfície através de um conjunto de faces triangulares interligadas; (5) geração do ortomosaico - gerado a partir da texturização da geometria construída pela malha triangular (AGISOFT, 2018).

A avaliação do ortomosaico foi realizada por meio da aplicação da Proposta de Emenda Constitucional (PEC), segundo o Decreto-Lei nº 89.817/84 (BRASIL, 1984), utilizando o método proposto por Galo e Camargo (1994) de testes de hipóteses, baseado na análise de tendências e precisão. Sendo este um dos métodos mais completos dentre os existentes na literatura, pois além de avaliar o PEC, avalia também se no produto cartográfico existe alguma tendência nas componentes das coordenadas, indicando a existência de erros sistemáticos.

Portanto, a partir da obtenção de imagens de satélite e ortofotos de VANTs e utilizandose de técnicas de classificação de imagem de sensoriamento remoto, foram identificados 
aspectos característicos do uso do solo, de modo que locais com estas mesmas características possam ser identificados tanto por imagens de satélite e por ortofotos em outras áreas sem que haja a necessidade de realizar levantamento entomológico. Este objetivo do trabalho foi abordado nas seguintes etapas: preparação da imagem, seleção de amostras de treinamento, classificação, classificação orientada ao objeto e avaliação dos resultados.

\subsection{CLASSIFICAÇÃO DA COBERTURA DO SOLO DA ÁREA DE INTERESSE}

Dada a grande quantidade de alvos e respostas espectrais em áreas urbanas, para a classificação da cobertura do solo foi utilizada imagem de satélite de alta resolução e a técnica de classificação supervisionada.

Dessa forma, a partir da classificação de imagens de sensores orbitais de alta resolução buscou-se extrair/identificar feições do terreno que possam indicar a potencialidade do entorno de áreas para a reprodução do mosquito e transmissão das doenças associadas a ele.

Para a definição das classes de mapeamento foi realizado cuidadoso levantamento bibliográfico com o objetivo de identificar as principais características do ambiente, junto a experiência dos técnicos do campo da SUCEN, ou seja, os elementos e feições urbanas, associadas à proliferação do Ae. aegypti e das doenças e, assim, identificar as áreas de risco.

Foram definidas 10 classes, para a coleta de amostras na imagem de satélite para a realização da classificação supervisionada no software ENVI. As classes selecionadas foram asfalto, cimento, solo exposto, grama, piscina/água, sombra, árvore, telhado tipo 1 (material de telha), telhado tipo 2 (material amianto sujo), telhado tipo 3 (material amianto novo). A Tabela 9 apresenta os exemplos de cada classe na imagem de satélite. 
Tabela 9 - Amostras das 10 classes definidas para a classificação supervisionada

\begin{tabular}{|c|c|c|c|}
\hline Classes & $\begin{array}{c}\text { World View II } \\
\text { image sample }\end{array}$ & Classes & $\begin{array}{c}\text { World View II } \\
\text { image sample }\end{array}$ \\
\hline Asfalto & & Sombra & \\
\hline Cimento & & Árvore & \\
\hline Solo exposto & & Telhado tipo 1 & \\
\hline Grama & & Telhado tipo 2 & \\
\hline Piscina/água & & Telhado tipo 3 & \\
\hline
\end{tabular}

Fonte: Elaborado pela autora.

\subsection{TERMAL}

Um dos benefícios do sensoriamento remoto termal, é de proporcionar, em tempo sincronizado, uma densa rede de dados de temperatura de áreas sobre a superfície terrestre, além de permitir o monitoramento multitemporal da área de estudo.

Os satélites LANDSAT 7 e 8 possuem bandas que operam na região do infravermelho termal, e permitem aferir valores de temperatura de superfície de alvos sobre a superfície terrestre.

O satélite LANDSAT 8 foi lançado pela NASA em 11 de fevereiro de 2013, operando a uma altitude de $705 \mathrm{~km}$, numa órbita heliossíncrona com inclinação de $98,2^{\circ}$. O satélite possui o sensor OLI com 9 bandas espectrais e o sensor TIRS com 2 bandas espectrais no infravermelho termal, bandas $10(10.6-11.19 \mu \mathrm{m})$ e $1111.5-12.51 \mu \mathrm{m})$, com resolução espacial de 100m (U.S. DEPARTMENT OF INTERIOR, 2013). 
Cabe ressaltar que as imagens termais do LANDSAT 8 apresentaram anomalias devido à dispersão da luz difusa que chega ao sensor, o que ocasionou problemas de calibração nas imagens do satélite (U.S. DEPARTMENT OF INTERIOR, 2013).

Segundo Schott et al., (2014), estas anomalias abrangem diferenças na aparência radiométrica, alterações nos índices de calibração cruzadas entre detectores que se sobrepõem em matrizes adjacentes (resultando em formação de faixas) e os erros de polarização na calibração absoluta. Vários algoritmos foram testados pela United States Geological Survey (USGS), e uma correção inicial foi aplicada nas imagens a partir de fevereiro de 2014, entretanto a USGS ainda não recomenda o uso da banda 11 em virtude das anomalias existentes na mesma. A banda 10 do LANDSAT 8 pode ser utilizada após a calibração através de um modelo de transferência radiativa de emissividade e parâmetros para recuperação da temperatura da superfície, e oferece um erro de polarização residual inferior a 2 graus para a maioria dos alvos.

A Figura 8 apresenta que nesse trabalho foram adquiridas 12 imagens do satélite LANDSAT 8 órbita/ponto 219/076, disponibilizada no site USGS (http://earthexplorer.usgs.gov/). Foram selecionadas as imagens com condições meteorológicas semelhantes, e que correspondiam a mesma época do ano de 2016, assim sendo coletadas uma vez por mês como mostra a Tabela 10 . 
Figura 8: Aquisição de 12 cenas do satélite LANDSAT 8.

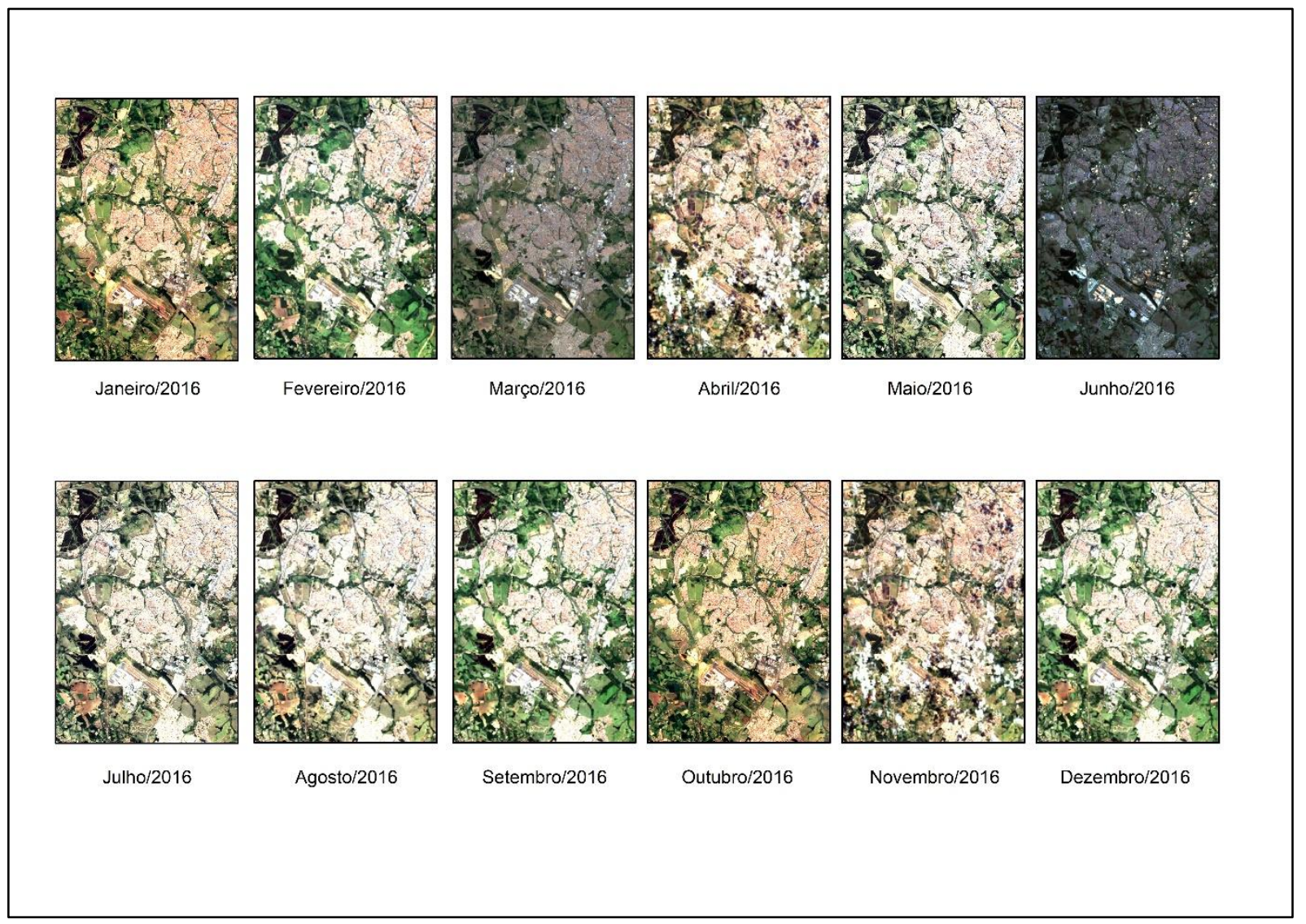

Fonte: Elaborado pela autora.

Tabela 10 - Data das cenas adquiridas durante o ano de 2016

\begin{tabular}{|c|c|c|c|}
\hline Mês/ 2016 & Data da imagem & Mês/ 2016 & Data da imagem \\
\hline Janeiro & $13 / 01 / 2016$ & Julho & $07 / 07 / 2016$ \\
\hline Fevereiro & $14 / 02 / 2016$ & Agosto & $24 / 08 / 2016$ \\
\hline Março & $17 / 03 / 2016$ & Setembro & $09 / 09 / 2016$ \\
\hline Abril & $18 / 04 / 2016$ & Outubro & $11 / 10 / 2016$ \\
\hline Maio & $04 / 05 / 2016$ & Novembro & $28 / 11 / 2016$ \\
\hline Junho & $28 / 06 / 2016$ & Dezembro & $30 / 12 / 2016$ \\
\hline
\end{tabular}

Fonte: Elaborado pela autora.

Foram utilizadas as imagens do visível e infravermelho próximo/médio do sensor OLI para a geração das composições coloridas, com resolução espacial de $30 \mathrm{~m}$. Com o intuito de estimar a temperatura de superfície utilizou a imagem do infravermelho termal do sensor TIRS 
(banda 10) com intervalo espectral de $10.6-11.19 \mu \mathrm{m}$ e resolução espacial de $100 \mathrm{~m}$ (reamostrada para $30 \mathrm{~m}$ ).

O processamento digital das imagens foi realizado no software ENVI e QGIS. Após todos os processamentos, as imagens foram recortadas considerando o polígono no formato shapefile das quatro áreas de estudo do município de Campinas.

As bandas referentes ao espectro refletido (verde, vermelho, infravermelho próximo e médio) foram adquiridas em reflectância de superfície. As bandas referentes ao espectro emitido (infravermelho termal) foram adquiridas em temperatura de brilho ou aparente.

\subsection{INLA}

Após o georreferenciamento dos imóveis das quatros áreas de estudo realizado, em seguida o banco de dados foi alterado, atribuindo-se valor 1 para os imóveis que se constatou a presença do mosquito e igual a zero para os imóveis em que não foi constatada a presença do mosquito.

A partir da geocodificação dos imóveis com seus respectivos atributos, foi realizada, em seguida, a criação de buffers com raios de 5m, 10m e 15m, em torno de cada uma deles (Figura 9). A criação dos buffers foi necessária, pois assim os imóveis que antes eram representados por pontos, passaram a ser representados por áreas de abrangência. Alguns estudos de arboviroses, no ambiente urbano, também utilizaram essa etapa, como por exemplo, Getis et al. (2003), Landau e Van Leeuwen (2012) e Lorenz et al. (2020), com a diferença de que no presente trabalho os buffers foram criados em torno de imóveis e nos estudos citados, os buffers foram criados em torno de locais de instalação de armadilhas. 
Figura 9 - Ilustração dos buffers criados a partir da localização dos imóveis

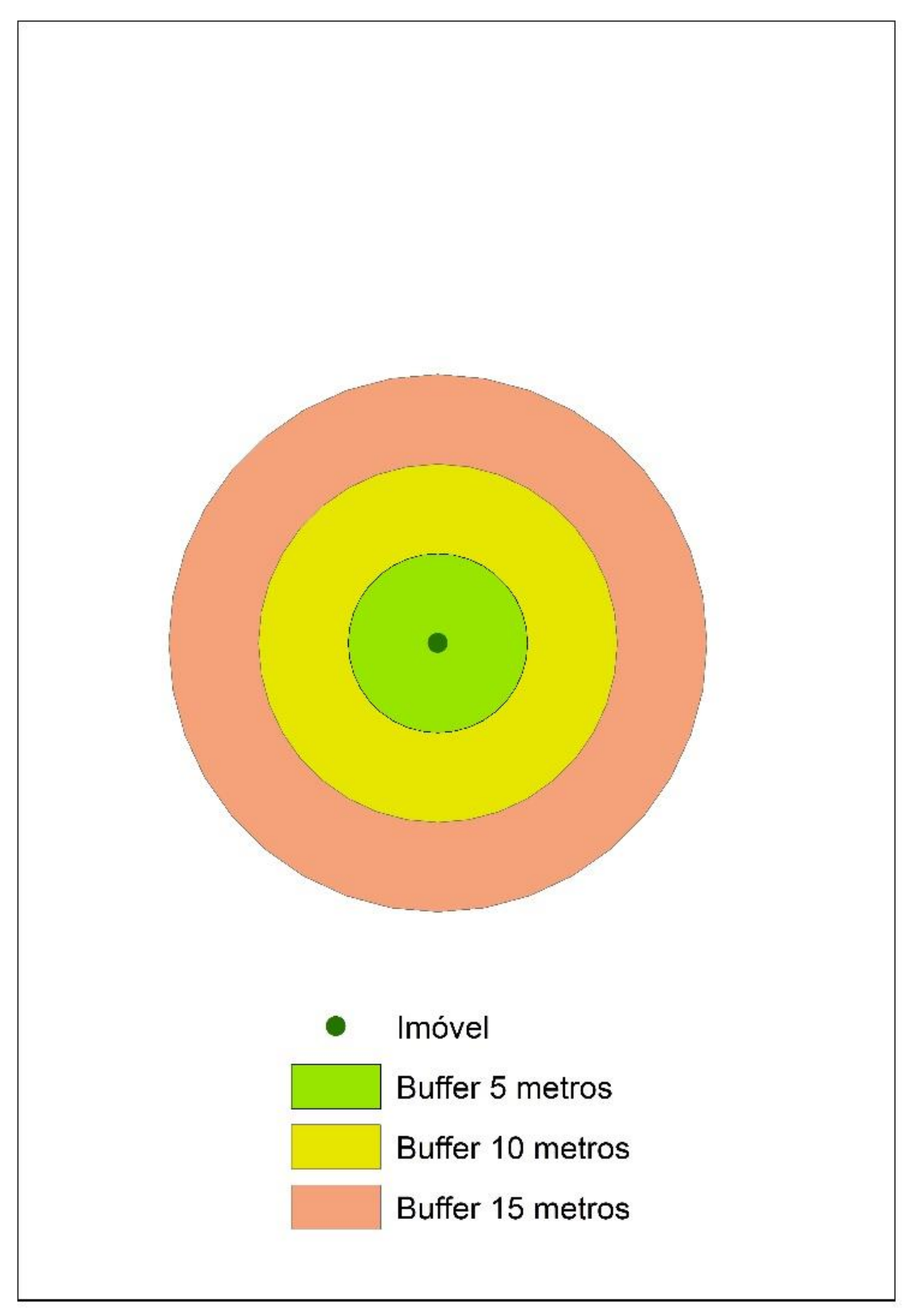

Fonte: Elaborado pela autora.

Com a classificação da imagem de satélite já realizada, foi associada a área dos buffers com as classes de cobertura do solo. Assim, foi possível medir a porcentagem de área que cada classe ocupou dentro de cada um dos buffers. Com essa informação estabelecida, criaram-se variáveis, cada uma delas representado uma classe específica, que foram consideradas como covariáveis no modelo INLA e com isso poder avaliar a associação das diferentes classes com a positividade dos imóveis para Ae. aegypti. 
O método INLA, proposto por Rue et al. (2017), realiza inferência Bayesiana, com base em modelos Guassianos latentes, de forma determinística e aproximada. Este método foi proposto como uma alternativa aos métodos de Monte Carlo via cadeias de Markov, que têm sua forma de inferência baseada em simulações.

Para compreender a essência do método INLA, é necessário familiarizar-se com: a Inferência Bayesiana que tem o escopo de interpretar a probabilidade como uma medida de credibilidade em um evento, ou seja, o quão confiante está do evento ocorrer; os modelos gaussianos latentes que apresentam a subclasse de um modelo de regressão aditiva; os campos aleatórios Markovianos Gaussianos que exibem as classe de algoritmos de hierarquização, e distribuição de probabilidade e aproximação de Laplace calculando o ponto máximo e ponto mínima da distribuição o fluxograma da Figura 10 apresentada os dados de input do INLA e o seu resultado.

Figura 10: Fluxograma das etapas do INLA
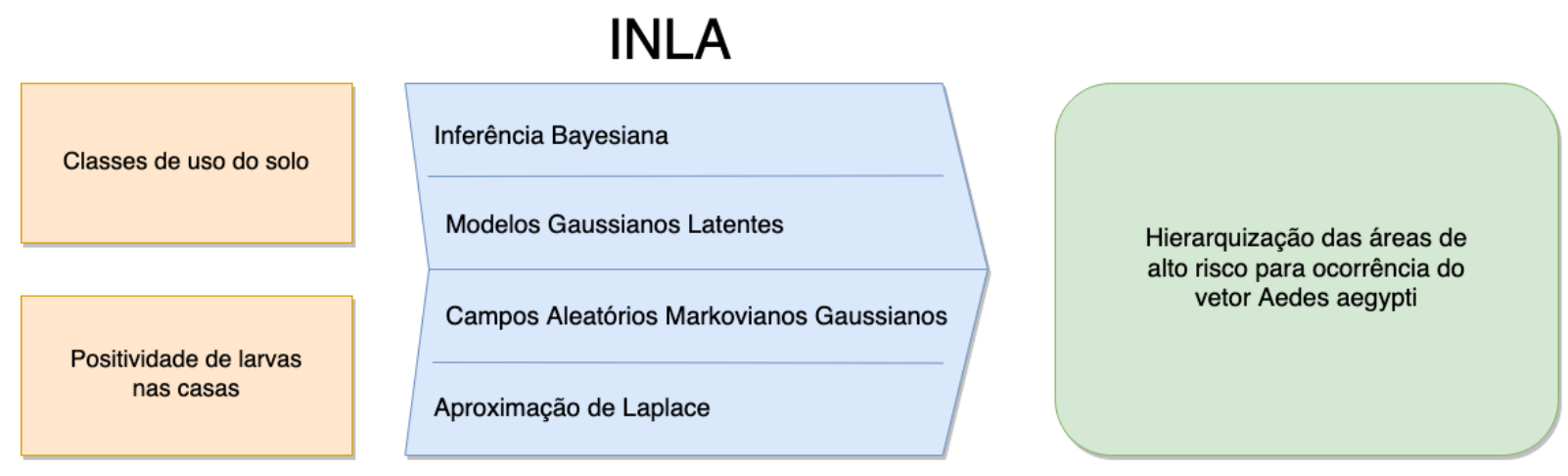

Fonte: Elaborado pela autora. 


\section{RESULTADOS}

\subsection{LOCALIZAÇÃO DAS ARMADILHAS}

No período de outubro de 2015 a setembro de 2016, foram avaliadas quatro áreas do município de Campinas, sendo três delas com presença de pontos estratégicos e uma área controle. No entorno dos pontos estratégicos, classificados como Alto, Médio e Baixo risco para presença do vetor, e na área controle, foram instaladas armadilhas de oviposição para avaliar a dispersão do vetor, num raio de 300 metros. Os locais de instalação das armadilhas foram escolhidos de maneira aleatória, conforme mostra a Figura 11 referente à área de alto risco. A Figura 12 mostra, além dos locais de instalação das armadilhas para as quatro áreas de estudo, as localizações dos PE nas áreas de baixo, médio e alto risco. 
Figura 11 - Detalhes da localização das armadilhas na área de alto risco.

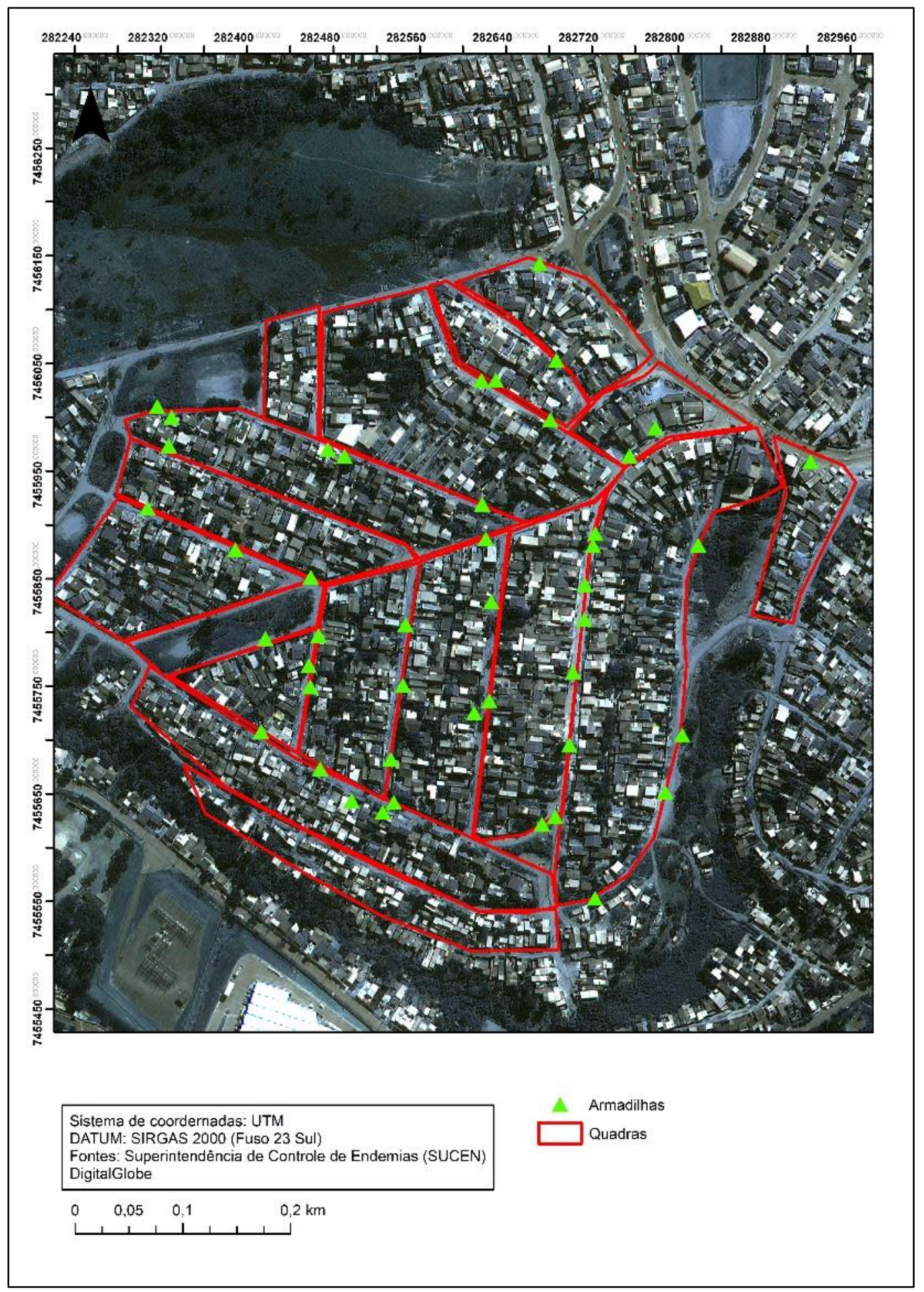

Fonte: Elaborado pela autora. 
Figura 12: Localização espacial das quadras trabalhadas de cada área de alto, médio e baixo risco.

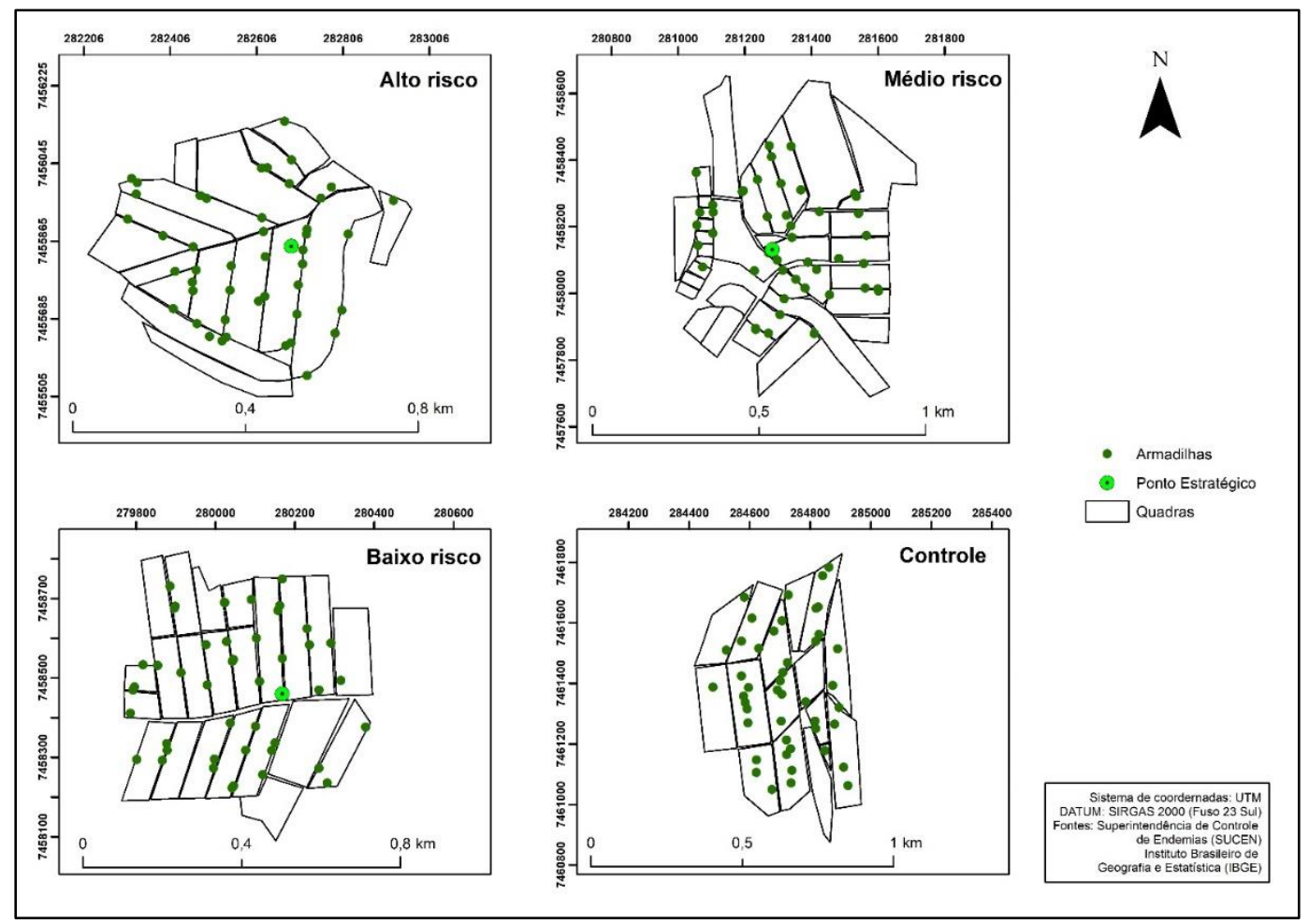

Fonte: Elaborado pela autora.

Com a coleta dos dados das armadilhas, criou-se um banco de dados com as informações, tendo um recorte desde apresentado na Tabela 11. Os dados aqui apresentados, após validação/conferência, se referem ao ano inteiro de coleta.

Tabela 11 - Recorte de informações do banco de dados das armadilhas

\begin{tabular}{|c|c|c|c|c|}
\hline ARMADILHA & UTM (N) & UTM (E) & Área & $\begin{array}{c}\text { No OVOS } \\
\text { Ae. aegypti }\end{array}$ \\
\hline 1 & $-282715,72$ & $-7456188,48$ & Médio & 30 \\
\hline 2 & $-282832,56$ & $-7455697,21$ & Baixo & 0 \\
\hline 3 & $-282502,96$ & $-7455795,47$ & Médio & 142 \\
\hline 4 & $-282503,53$ & $-7455897,39$ & Controle & 6 \\
\hline 5 & $-282510,47$ & $-7455843,21$ & Alto & 296 \\
\hline
\end{tabular}




\subsection{POSITIVIDADE DE ARMADILHAS NAS ÁREAS AVALIADAS}

Com relação as armadilhas, nota-se uma positividade alta nos dois primeiros ciclos, superando os $40 \%$. Nos dois últimos ciclos, esse número cai, mas ainda representa um grande percentual de armadilhas positivas. Com relação ao número de ovos coletados no primeiro ciclo, obteve-se números elevados de ovos praticamente em todas as áreas. Nos outros ciclos, a área com PE de Alto risco apresentou um número mais elevado de ovos, embora não necessariamente isso tenha se repetido no percentual de positividade das armadilhas (Tabela 12).

Tabela 12: Número de ovos, percentual de positividade e média de ovos por armadilha nas quatro áreas avaliadas, em dois ciclos de visita. Período compreendido entre outubro/15 e setembro/16.

\begin{tabular}{|c|c|c|c|c|c|c|}
\cline { 2 - 7 } \multicolumn{1}{c|}{} & Área & Alto & Médio & Baixo & Controle & Total \\
\hline \multirow{2}{*}{ Ciclo 1 } & Número de ovos & 1194 & 864 & 1028 & 1024 & 4110 \\
\cline { 2 - 7 } & $\%$ positividade & 51,1 & 44,4 & 51,1 & 40 & 46,7 \\
\hline \multirow{2}{*}{ Ciclo 2 } & Número de ovos & 1105 & 944 & 438 & 577 & 3064 \\
\cline { 2 - 7 } & $\%$ positividade & 55,6 & 48,9 & 45,5 & 60,6 & 52,2 \\
\hline \multirow{2}{*}{ Ciclo 3 } & Número de ovos & 446 & 313 & 284 & 140 & 1183 \\
\cline { 2 - 7 } & $\%$ positividade & 34,1 & 22,2 & 33,3 & 13,3 & 25,7 \\
\hline \multirow{2}{*}{ Ciclo 4 } & Número de ovos & 319 & 64 & 102 & 99 & 584 \\
\cline { 2 - 7 } & $\%$ positividade & 18,2 & 11,4 & 15,6 & 11,1 & 14,1 \\
\hline
\end{tabular}

Fonte: Adaptado BARBOSA et al., 2018.

O Gráfico 4 apresenta as positividades das ovitrampas, segundo as quatro áreas de estudo em quatro ciclos de visitas trimestrais, entre outubro de 2015 e setembro de 2016. A positividade das ovitrampas, nos dois primeiros ciclos, mostrou ser independente de existir ou não PE nas áreas. No ciclo 3 a positividade apresentou decréscimo, atingindo os menores valores no ciclo 4. Nestes dois ciclos, as áreas de alto e baixo risco foram as que apresentaram as maiores positividades. 
Gráfico 4 - Percentual de positividade de armadilhas (A: Alto Risco; M: Médio Risco; B: Baixo Risco; C: Área Controle).

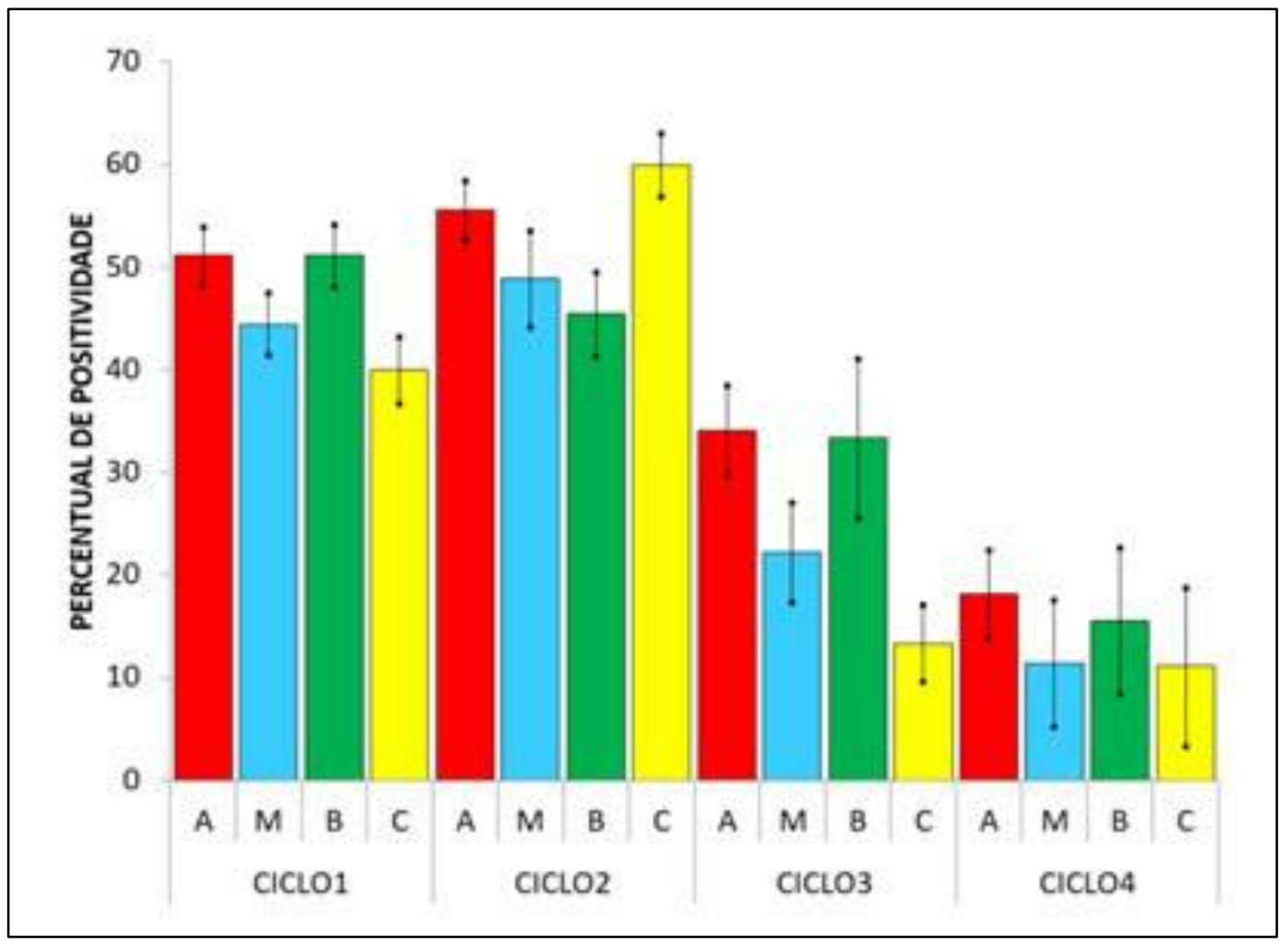

Fonte: BARBOSA et al., 2018.

\subsubsection{Pontos Estratégicos}

Observando, nos PEs, as quantidades de recipientes existentes e com larvas de $A e$. aegypti, nota-se a importância dos cuidados com esses tipos de imóveis, que, mesmo não sejam dispersores do vetor, apresentam grande número de recipientes e capacidade de produzir grande quantidade de mosquitos (Tabela 13). 
Tabela 13: Número de recipientes com larvas, e número de larvas de Ae. aegypti nos pontos estratégicos, segundo risco, em dois ciclos de visita. Período compreendido entre outubro/15 e setembro/16.

\begin{tabular}{|l|c|c|c|c|c|}
\cline { 2 - 6 } \multicolumn{1}{c|}{} & Área & Alto & Médio & Baixo & Total \\
\hline \multirow{2}{*}{ Ciclo 1 } & Número de recipientes existentes & 113 & 25 & 1 & 139 \\
\cline { 2 - 6 } & Número de recipientes com larvas & 54 & 11 & 1 & 66 \\
\hline \multirow{2}{*}{ Ciclo 2 } & Número de recipientes existentes & 69 & 31 & 62 & 162 \\
\cline { 2 - 6 } & Número de recipientes com larvas & 69 & 31 & 3 & 103 \\
\hline \multirow{2}{*}{ Ciclo 3 } & Número de recipientes existentes & 44 & 3 & 0 & 47 \\
\cline { 2 - 6 } & Número de recipientes com larvas & 12 & 3 & 0 & 15 \\
\hline \multirow{2}{*}{ Ciclo 4 } & Número de recipientes existentes & 6 & 0 & 0 & 6 \\
\cline { 2 - 6 } & Número de recipientes com larvas & 6 & 0 & 0 & 6 \\
\hline
\end{tabular}

Fonte: Adaptado BARBOSA et al., 2018.

Neste mesmo período, foram vistoriados 5.673 imóveis para verificar a presença de potenciais criadouros de larvas/pupas de Ae. aegypti e sua positividade. O PE da área de alto risco, como esperado, apresentou maior número de recipientes com larvas/pupas de Ae. aegypti do que os PE de médio e baixo risco, em todos os quatro ciclos de visita (Gráfico 5). As maiores quantidades de recipientes positivos ocorreram nos dois primeiros ciclos para todas as áreas. 
Gráfico 5 - Número de recipientes com larvas de Ae. aegypti em Pontos Estratégicos, segundo ciclo de visitas e área de classificação do PE (A: Alto Risco; M: Médio Risco; B: Baixo Risco).

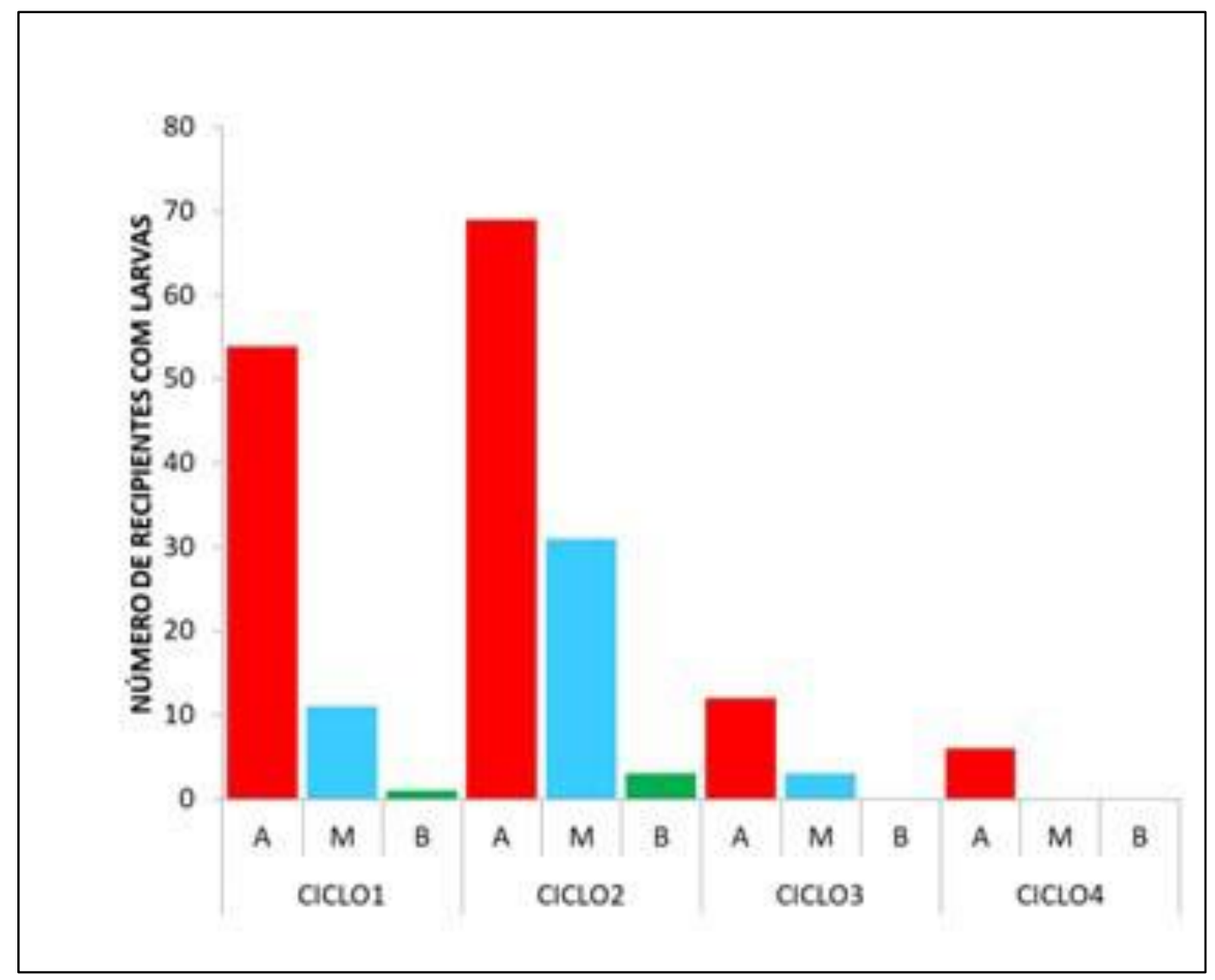

Fonte: BARBOSA et al., 2018.

\subsection{CLASSIFICAÇÃO SUPERVISIONADA}

Essa subseção apresenta o resultado da classificação supervisionada com a utilização dos dados de entrada da imagem de satélite do Word View II e as fotos do VANT. Foram utilizados 4 diferentes algoritmos de classificação supervisionada para avaliar melhor algoritmo, utilizando a metodologia Kappa. As imagens do VANT foram utilizadas para refinar a classificação, como na parte de amostras para a classificação e também para definição das classes nas 4 áreas de estudo como expõe a Figura 13. 
Figura 13: Fluxograma com destaque das etapas relacionadas à classificação supervisionada.

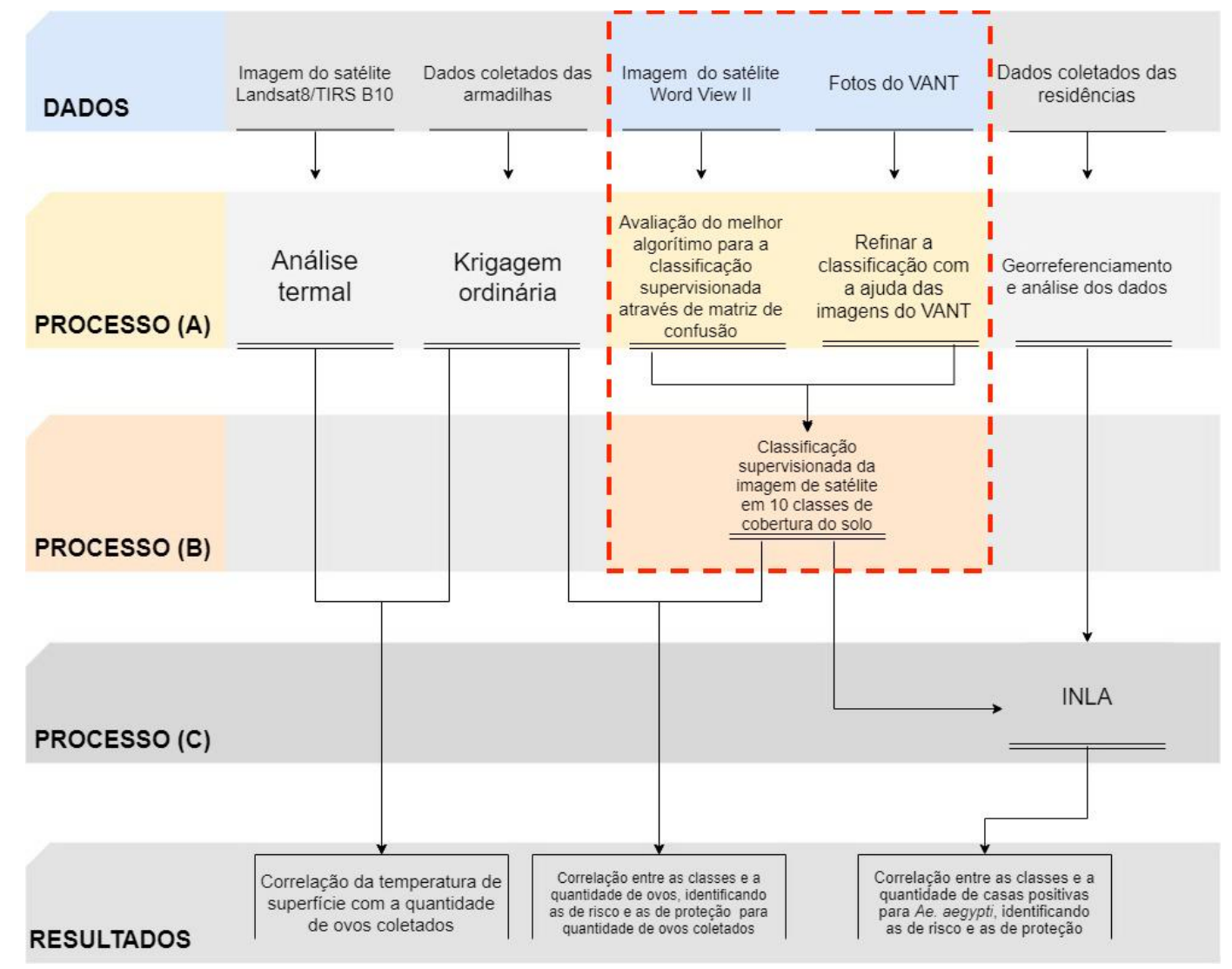

Fonte: Elaborado pela autora.

$\mathrm{Na}$ classificação foram selecionados pontos amostrais de cada tipo de uso do solo. Foram definidas 10 classes de uso do solo com a ajuda dos especialistas da SUCEN, sob a hipótese de que esses tipos de uso do solo são facilitadores ou inibidores para o desenvolvimento do mosquito. Com a ajuda das fotos dos VANT foi possível fazer essa coleta de amostras e também a definição das classes com uma maior precisão. As Figuras 14 e 15 apresentam a definição das imagens do VANT com maior detalhe nas áreas de estudo. 
Figura 14 - Foto georeferenciada do VANT nas áreas de alto risco e de controle.

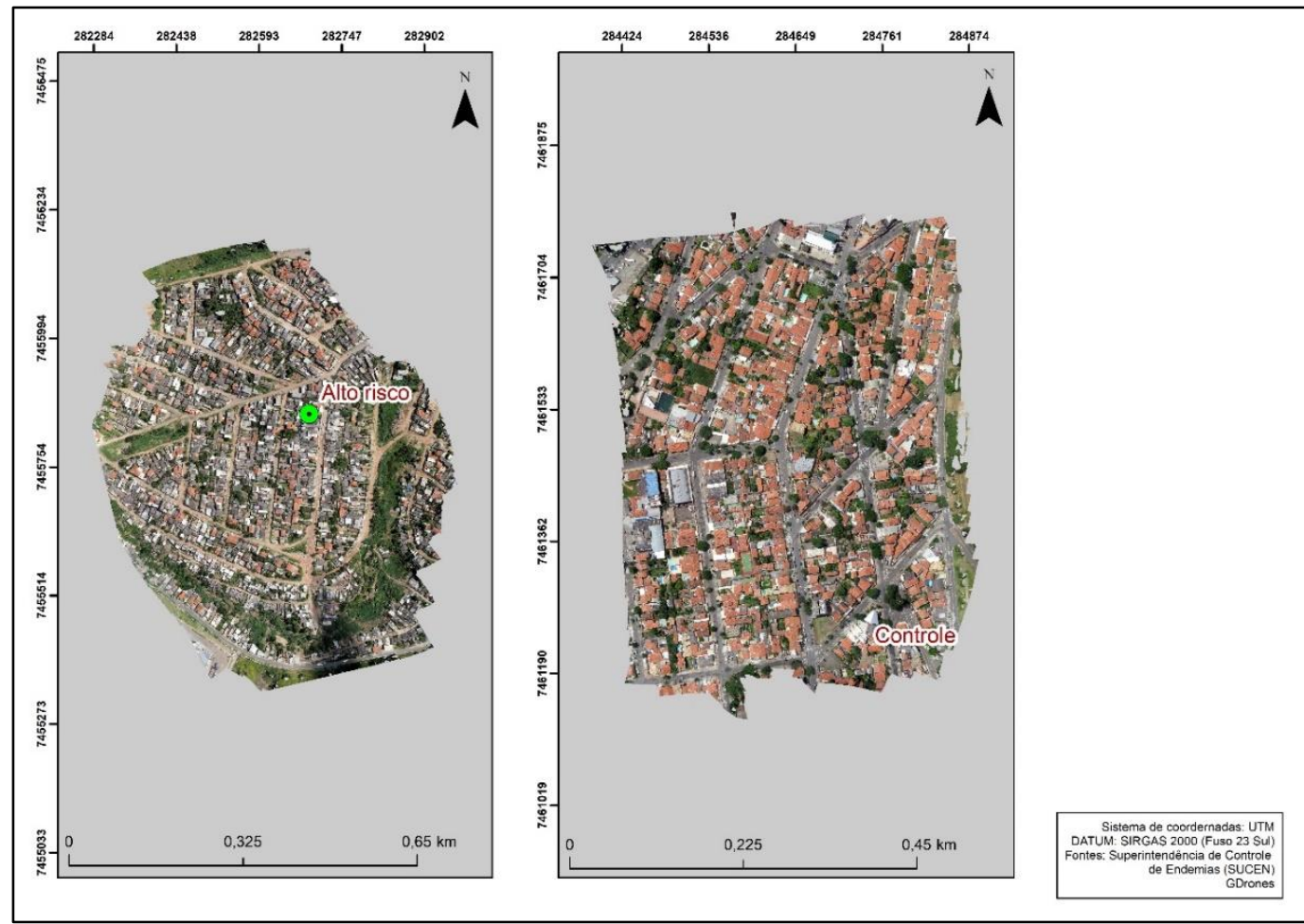

Fonte: Elaborado pela autora.

Figura 15 - Foto georeferenciada do VANT nas áreas de médio risco e baixo risco.

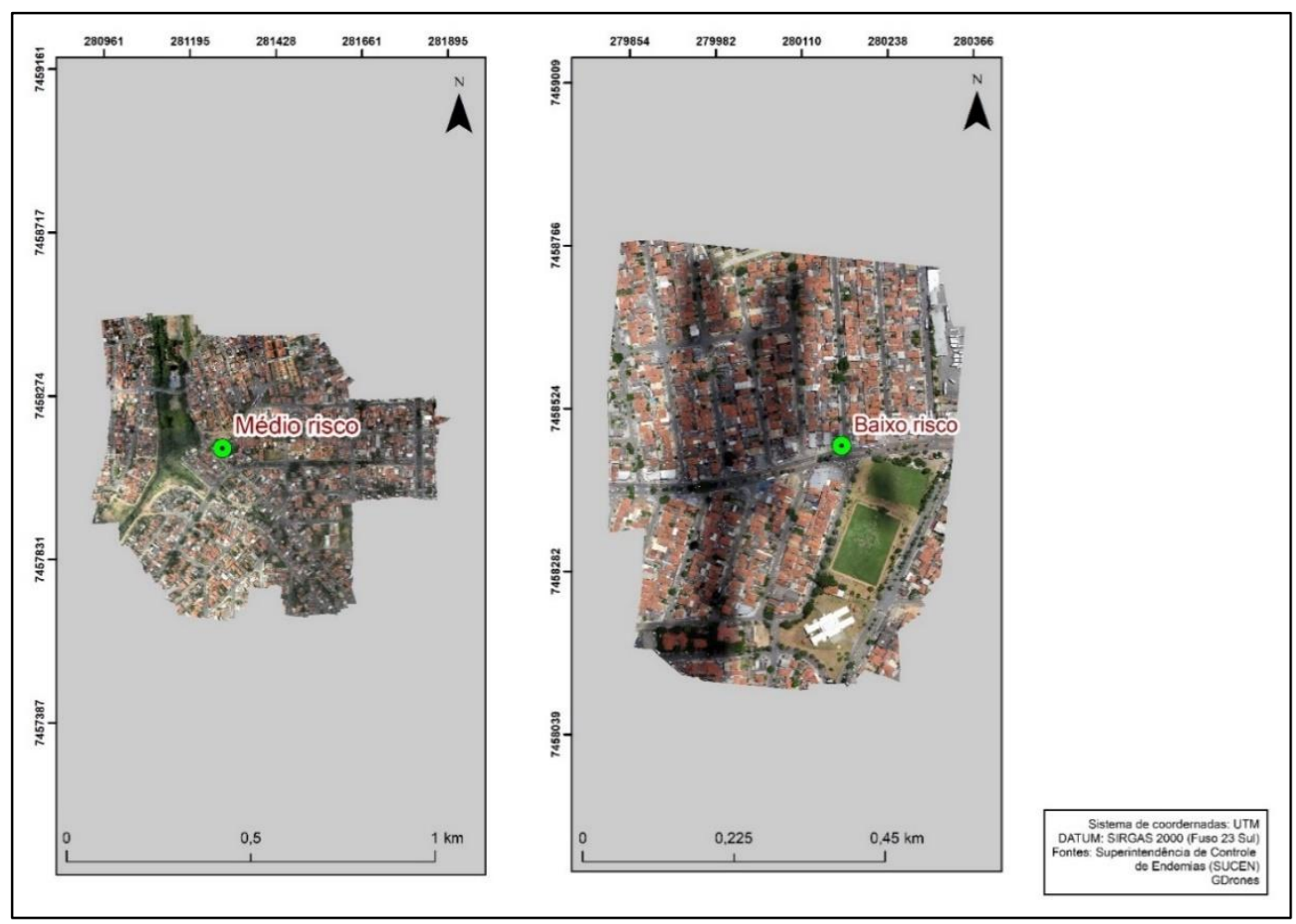

Fonte: Elaborado pela autora. 
Com a ajuda do VANT, foram definidas as seguintes dez classes do uso do solo: Asfalto, Sombra, Grama, Árvore, Solo Exposto, Piscina/água, Cimento, Telhado Tipo 1, Telhado Tipo 2 e Telhado Tipo 3. Os telhados foram divididos em 3 classes por serem muito diferentes em cor e também em textura, sendo o primeiro tipo telha, o segundo amianto mais deteriorado e o terceiro amianto mais novo.

Os classificadores utilizados nesse estudo foram selecionados por possuírem diferentes técnicas de classificação e também por constituírem os mais aplicados em estudos de classificação supervisionada. O classificador Maximum Likelihood é uma das técnicas de classificação supervisionada mais comumente utilizada. $O$ seu algoritmo calcula a probabilidade de um dado pixel pertencer a uma das classes, considerando como Normal ou Gaussiana a distribuição da amostra de treinamento, descrita pelo vetor de média e pela matriz de covariância do pixel (CAMPOS, 2016).

O classificador Mahalanobis Distance é calculado pela matriz de covariância, com os pixels classificados considerando as menores distâncias. Já o algoritmo usado no classificador Minimum Distance é medido pela matriz de covariância, com os pixels classificados considerando também as menores distâncias, mas com uma medida que é sensível à direção espectral da matriz. Por fim, o classificador Parallelepiped, estabelece limites superior e inferior para os valores de brilho de cada banda. Este intervalo é definido a partir de histogramas, com níveis de cinza, dos componentes espectrais disponibilizados pelos dados de treinamento. Os pixels são classificados dentro da faixa de decisão dos limites obtidos para todas as bandas que integram a classificação (CAMPOS, 2016).

Na segunda fase, depois de coletadas as amostras de cada tipo, foram testados os 4 tipos de algoritmos de classificação supervisionada no software ENVI 5.0 como demostram as Figuras 16, 17, 18 e 19. 
Figura 16 - Classificação das 4 áreas de estudos pelo algoritmo Mahalanobis.

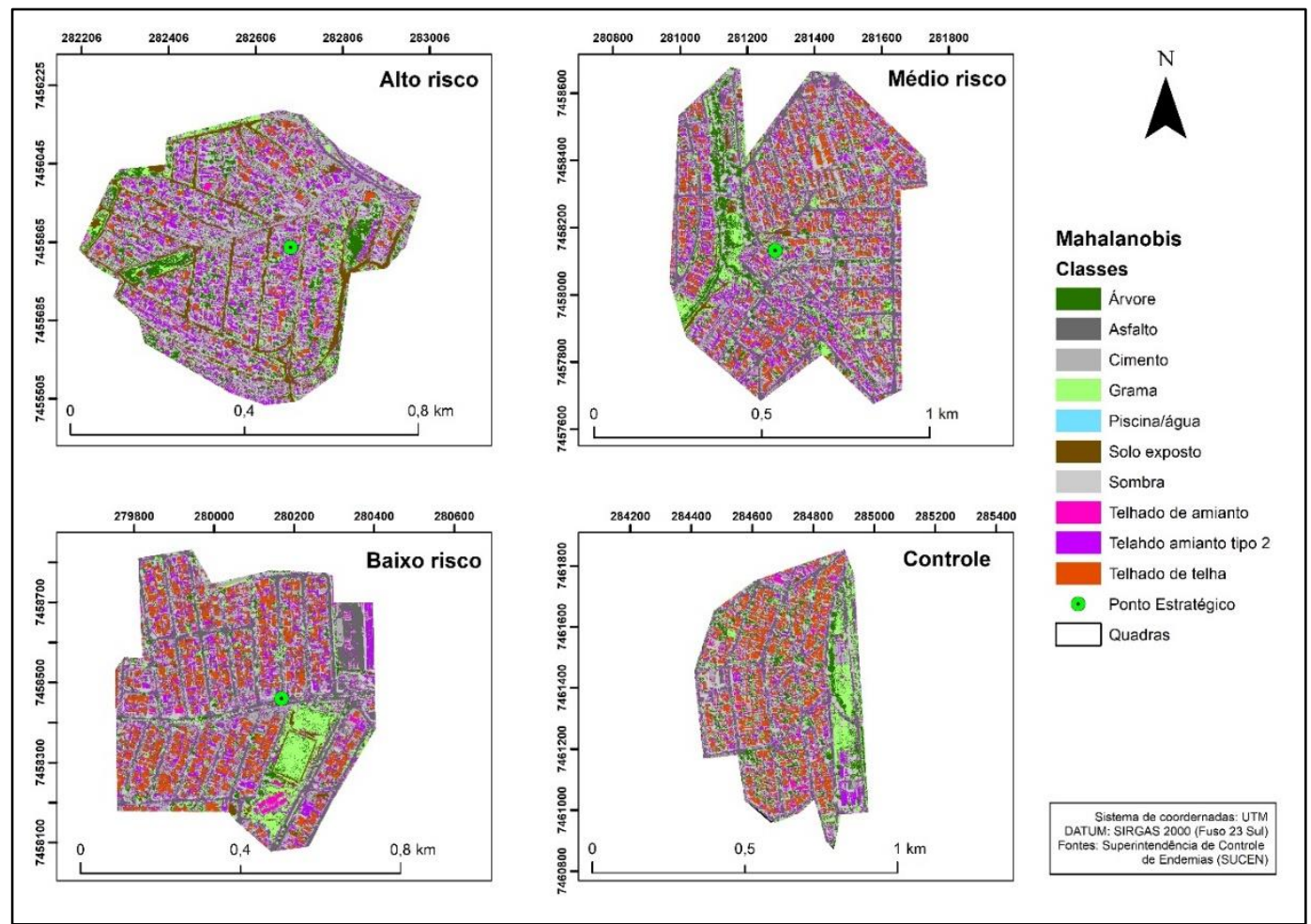

Fonte: Elaborado pela autora.

Figura 17 - Classificação das 4 áreas de estudos pelo algoritmo Minimum Distance.

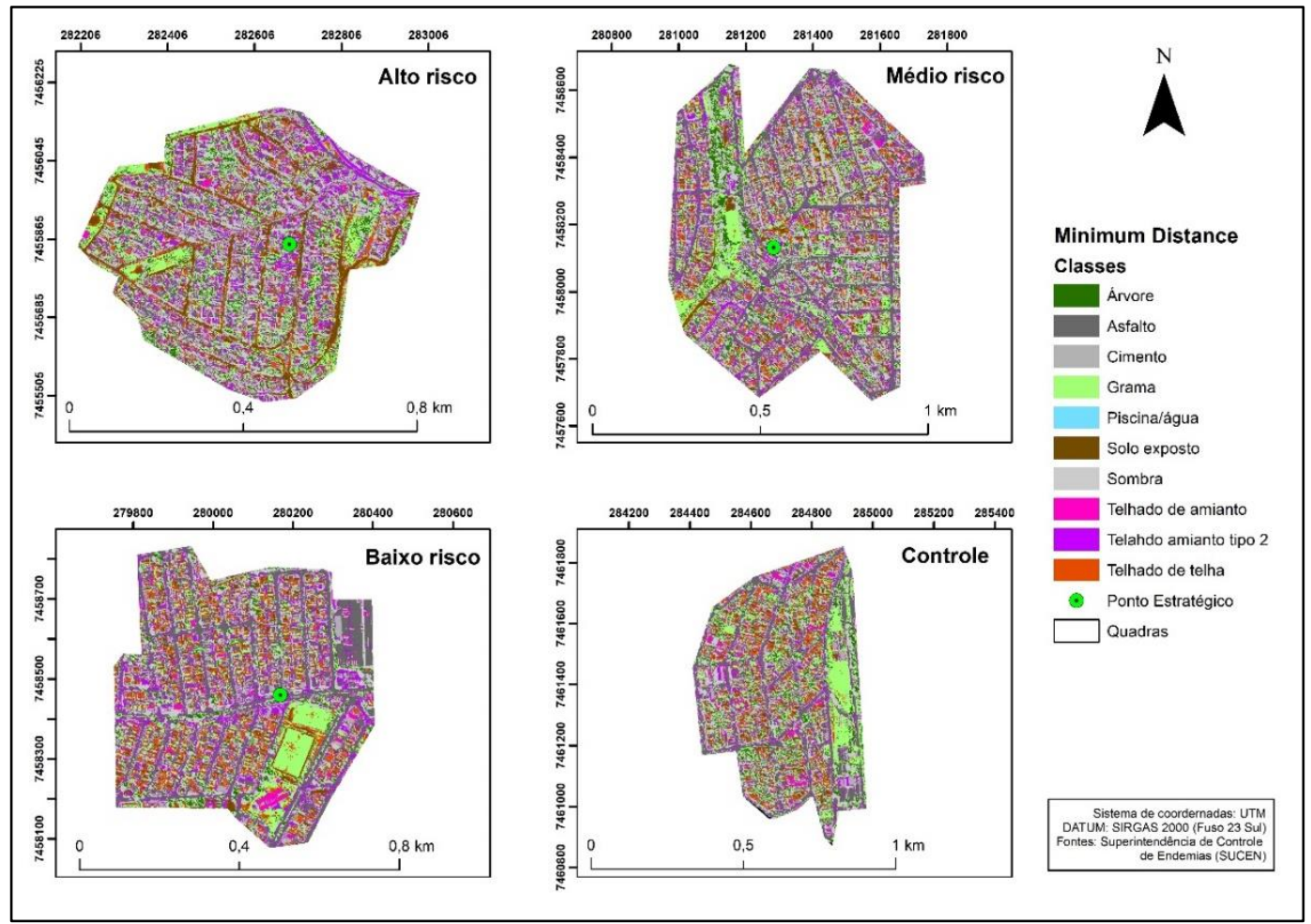

Fonte: Elaborado pela autora. 
Figura 18 - Classificação das 4 áreas de estudos pelo algoritmo Parallelepiped.

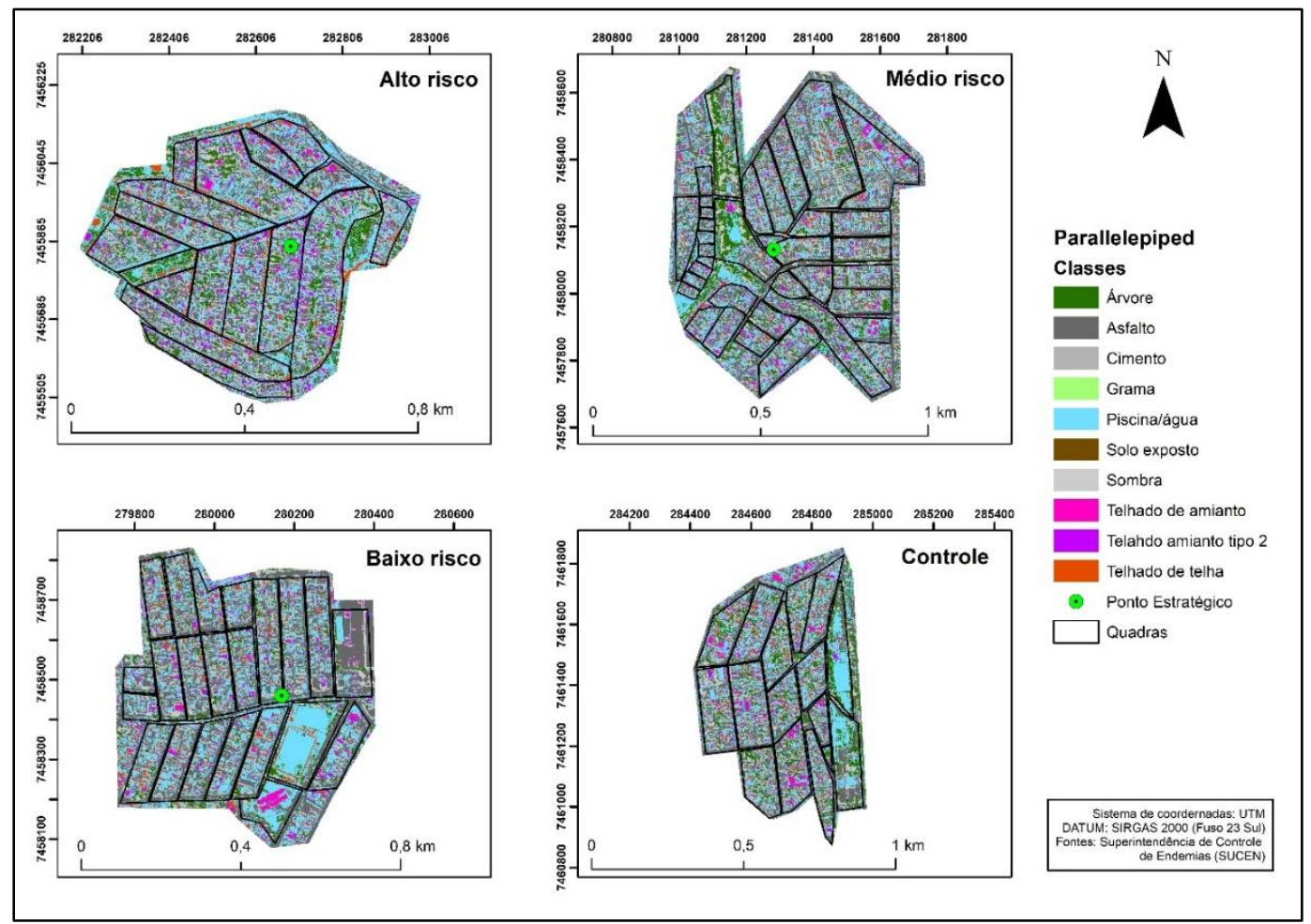

Fonte: Elaborado pela autora.

Figura 19 - Classificação das 4 áreas de estudos pelo algoritmo Maximum Likelihood.

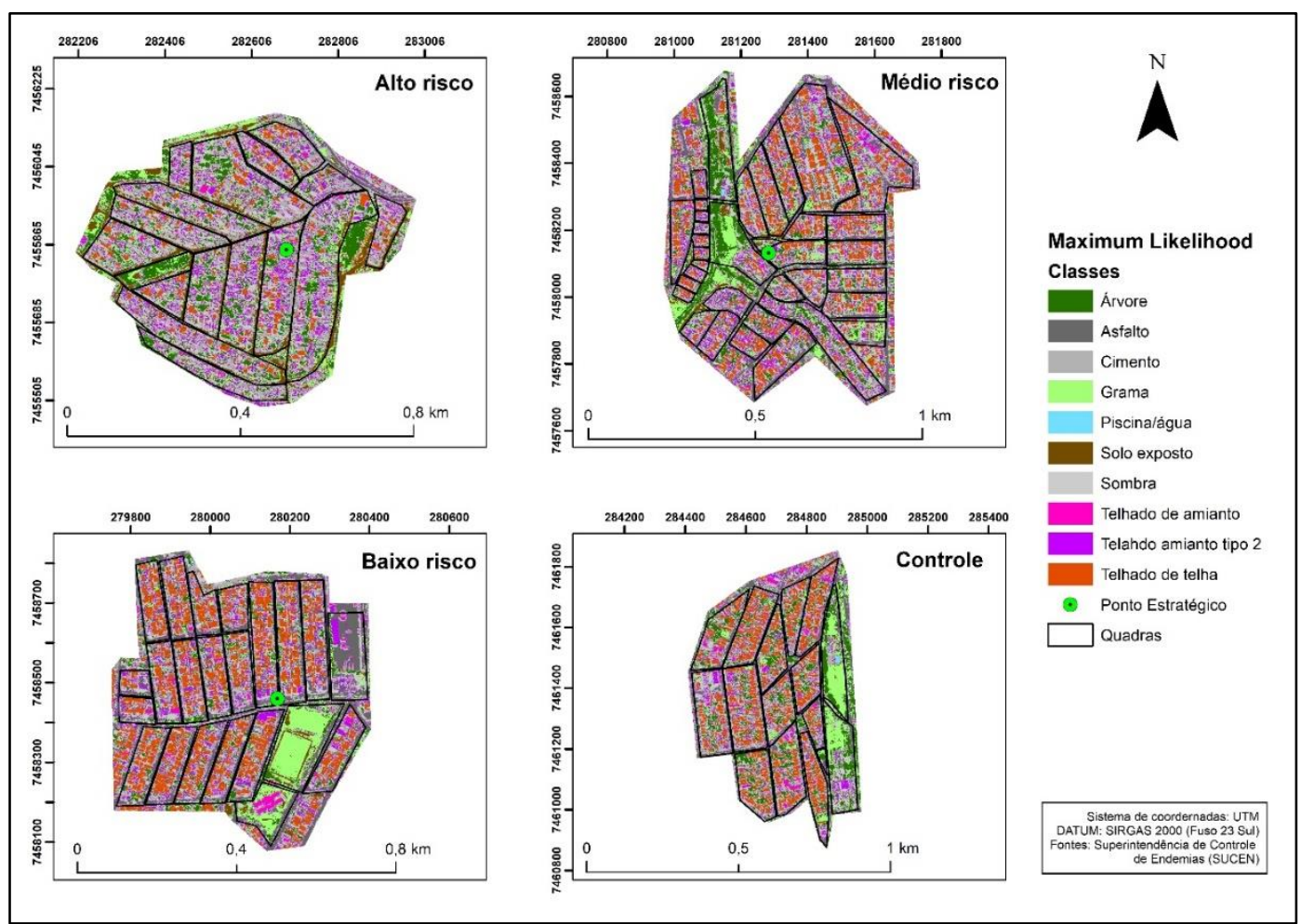

Fonte: Elaborado pela autora. 
Após a classificação supervisionada realizada, foi analisada a matriz de confusão e também o índice Kappa de cada algoritmo. Os índices Kappa de cada classificador foram (Tabela 14):

Tabela 14: Valores do Índice Kappa para cada classificador.

\begin{tabular}{|c|c|}
\hline Classificador & Valor do índice Kappa \\
\hline Mahalanobis Distance & 0,7435 \\
\hline Minimum Distance & 0,7067 \\
\hline Parallelepiped & 0,2778 \\
\hline Maximum Likehood & 0,8141 \\
\hline
\end{tabular}

Fonte: Elaborado pela autora.

Os classificadores, Mahalanobis Distance e Minimum Distance apresentaram um bom valor de Kappa, enquanto o classificador Parallelepiped apresentou um índice insatisfatório. O classificador Maximum Likelihood, com o maior valor de Kappa, foi o escolhido para o andamento das análises.

A classificação do mapa de ocupação do solo da região de estudo foi criada através da utilização da classificação supervisionada com o algoritmo Maximum Likelihood. A precisão global obtida foi de $84,96 \%$, e tinha um índice kappa de 0,8141. A matriz de confusão foi utilizada para fornecer uma visão do desempenho da classificação com cada uma das 10 classes.

Como pode ser visto na tabela abaixo (Tabela 15), a precisão para as classes árvores, grama, solo exposto, sombra, telhado tipo 1, telhado tipo 2, e telhado tipo 3, foi elevada, atingindo valores acima $80 \%$. No entanto, para as classes asfalto, cimento e piscina/água, o desempenho não foi o mesmo. O problema com as classes asfalto e cimento é de não possuírem um padrão específico, além de que em muitas amostras as árvores e telhados cobriam o pavimento, tornando difícil a identificação do que era pavimento pela proximidade e também com o valor de nível de cinza parecidos. Referente a classe piscina/água, o primeiro problema encontrado foi o baixo número de amostras desta classe na área de estudo, e por não possuírem padrões específicos. Isto aconteceu devido as áreas estudas escolhidas serem áreas de diversas classes sociais e estruturas urbanas diferentes, onde, por exemplo, quase não existirem piscina na área de alto risco, mas somente nas demais áreas. 
Tabela 15: Matriz de confusão da classificação.

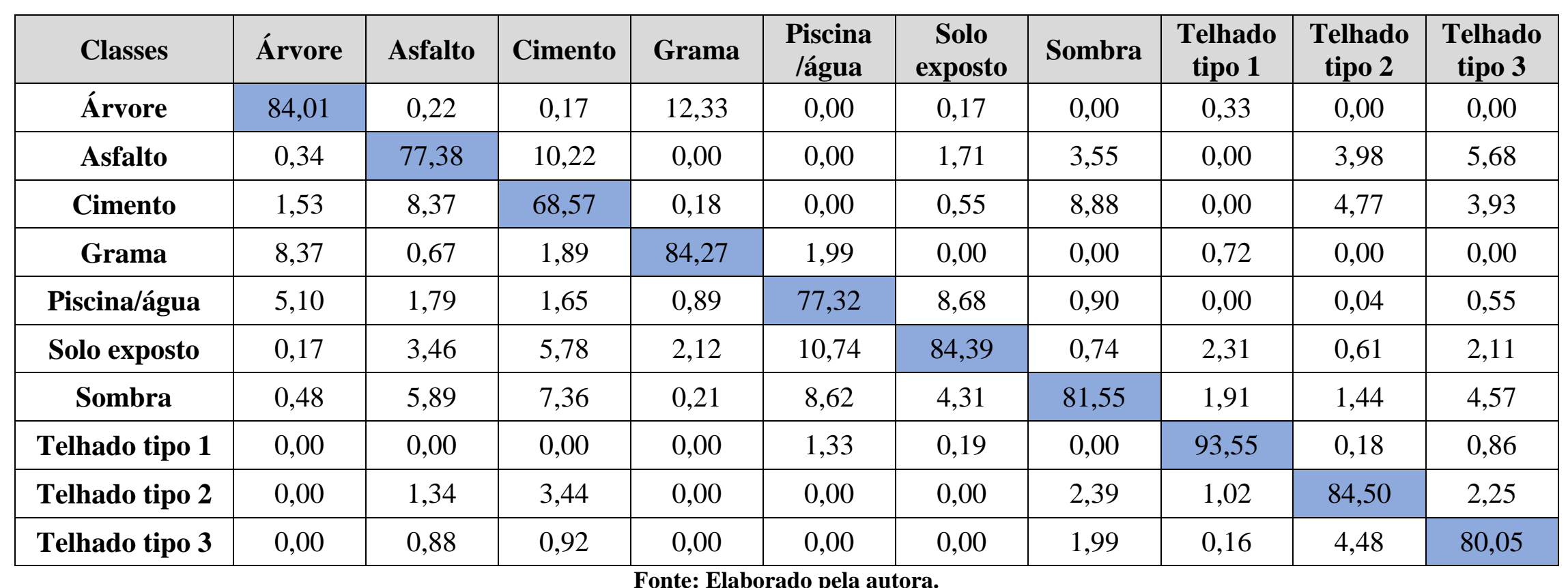


Após definição do algoritmo, deu-se início à análise dos dados da classificação, como mostra a Tabela 16. A área de alto risco teve maior predominância das classes Cimento, com $22 \%$ de sua área, e Sombra, com 17\%. Na de baixo risco, a predominância foi das classes Cimento e Asfalto, ambas com 18\%. Na de médio risco predominou as classes Sombra e Cimento, ambas com 16\%. Por fim, predominou na área controle a classe Cimento, com $17 \%$. A classe Cimento teve destaque, com um percentual alto, em todas as áreas, por fatores que serão analisados nas próximas etapas do estudo.

Tabela 16: Percentual dos tipos de classes por área de estudo.

\begin{tabular}{|c|c|c|c|c|}
\cline { 2 - 5 } \multicolumn{1}{c|}{} & \multicolumn{4}{c|}{ Área percentual \% } \\
\hline Classe & $\begin{array}{c}\text { Área de Baixo } \\
\text { Risco }\end{array}$ & $\begin{array}{c}\text { Área de Médio } \\
\text { Risco }\end{array}$ & $\begin{array}{c}\text { Área de Alto } \\
\text { Risco }\end{array}$ & $\begin{array}{c}\text { Área } \\
\text { Controle }\end{array}$ \\
\hline Árvore & 5,26 & 10,91 & 11,43 & 15,00 \\
\hline Asfalto & 18,42 & 14,55 & 3,76 & 10,00 \\
\hline Cimento & 18,42 & 16,36 & 22,86 & 17,50 \\
\hline Grama & 10,53 & 10,91 & 11,43 & 12,50 \\
\hline Piscina/água & 2,63 & 0,82 & 2,86 & 2,50 \\
\hline Solo exposto & 2,63 & 3,64 & 5,7 & 5,50 \\
\hline Sombra & 13,16 & 16,18 & 17,14 & 12,50 \\
\hline Telhado 1 & 15,79 & 12,73 & 8,71 & 15,00 \\
\hline Telhado 2 & 10,53 & 12,7 & 11,43 & 7,50 \\
\hline Telhado 3 & 2,63 & 1,82 & 4,86 & 2,50 \\
\hline
\end{tabular}

Fonte: Elaborado pela autora.

\subsection{KRIGAGEM ORDINÁRIA}

Essa subseção apresenta a o resultado da etapa da krigagem ordinária, que foi realizada a partir dos ovos do mosquito coletados durante o período de agosto/2015 a setembro/2016 nas 180 armadilhas espalhadas nas 4 áreas de estudo como expõe a Figura 20. 
Figura 20 - Fluxograma com destaque das etapas relacionadas à Krigagem Ordinária.

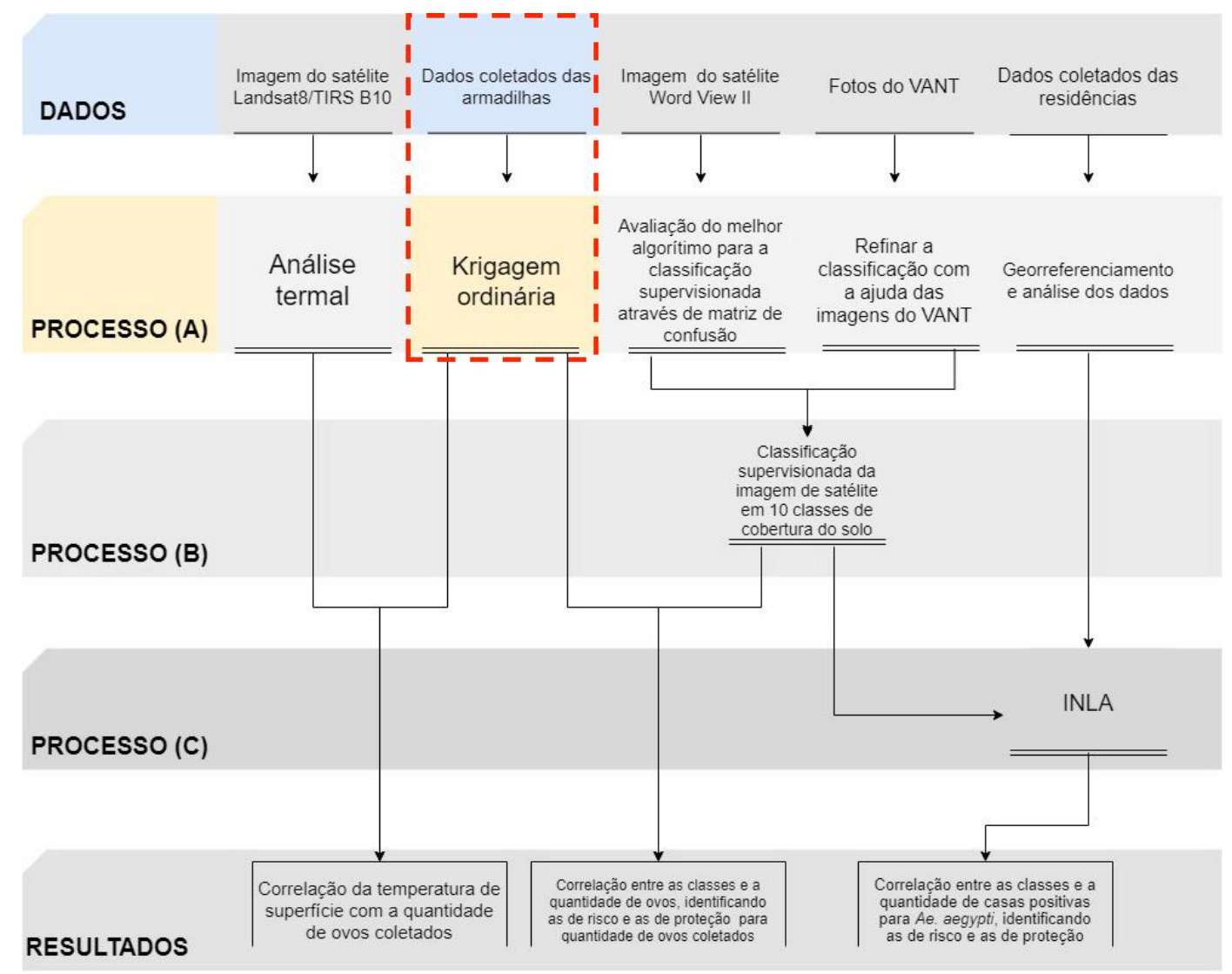

Fonte: Elaborado pela autora.

A metodologia geoestatística procura extrair, de uma aparente aleatoriedade dos dados coletados, as características estruturais probabilísticas do fenômeno regionalizado, ou seja, uma função de correlação entre os valores situados numa determinada vizinhança e direção no espaço amostrado. O método de estimativa básico utilizado é o da krigagem.

A krigagem ordinária foi realizada no software $\mathrm{R}$, utilizando o pacote geoR. O primeiro passo foi realizar a leitura de borda, ou seja, determinar uma área de estudo para a realização da krigagem. A segunda etapa foi a verificação da normalidade da variável dependente (quantidade de ovos coletados) e a modelagem usando as coordernadas dos pontos das aramadilhas. A terceira etapa foi a modelagem do semivariograma, sendo utilizado a função eyefit para realizar esses semivariogramas. E o último passo foi a realização da krigagem utilizando o variograma gerado pela função eyefit.

O semivariograma é uma ferramenta básica de suporte às técnicas de Krigagem, pois permite representar quantitativamente a variação de um fenômeno regionalizado no espaço. A Figura 21 apresenta os semivariogramas das áreas de estudo. 
Figura 21 - Semivariograma da krigagem nas áreas de estudo.
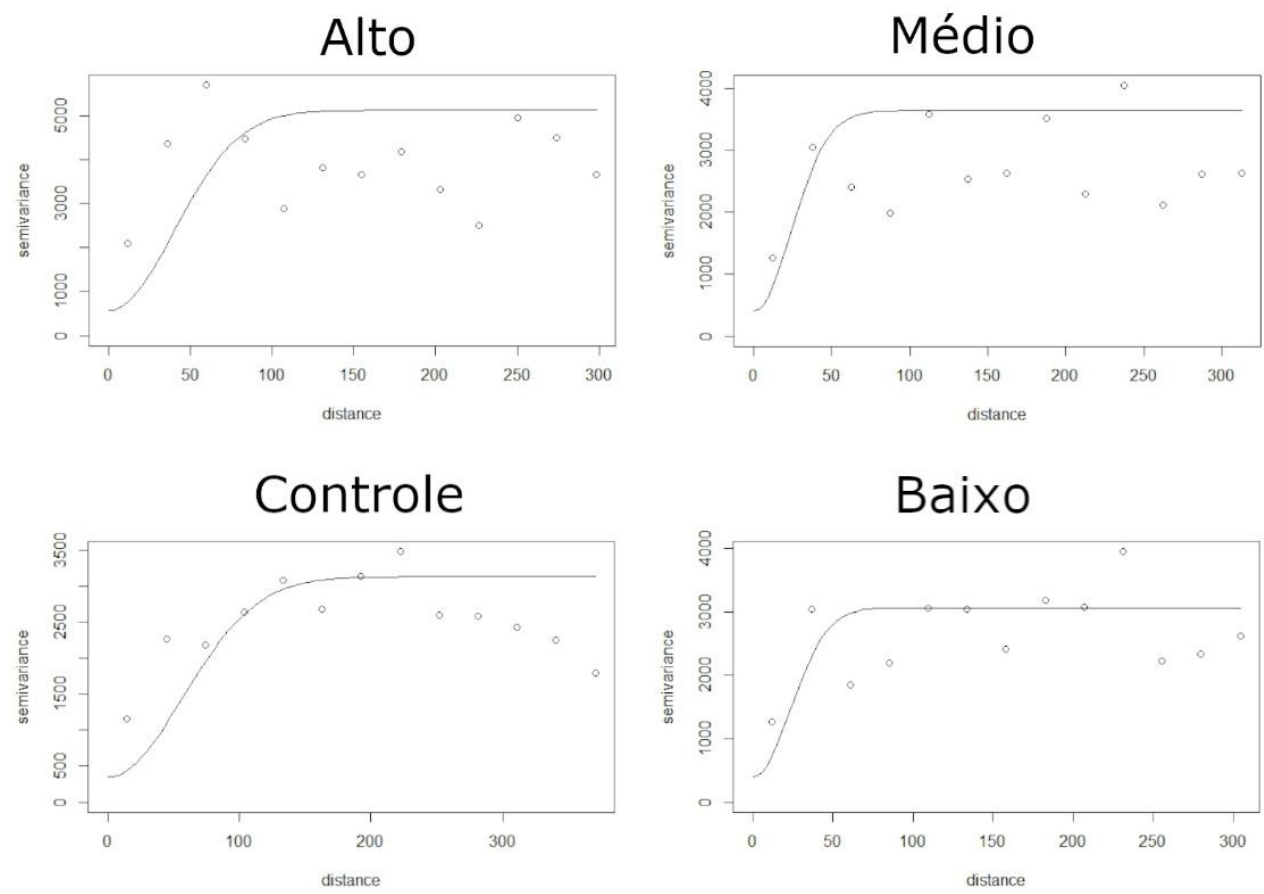

Fonte: Elaborado pela autora.

Foi realizada krigagem para interpolação dos valores referentes a armadilhas de oviposição. Apresentam-se as Figuras 22 e 23 com os resultados da krigagem para as quatro áreas de estudo. 
Figura 22 - Krigagem ordinária das armadilhas nas áreas de alto risco e controle.

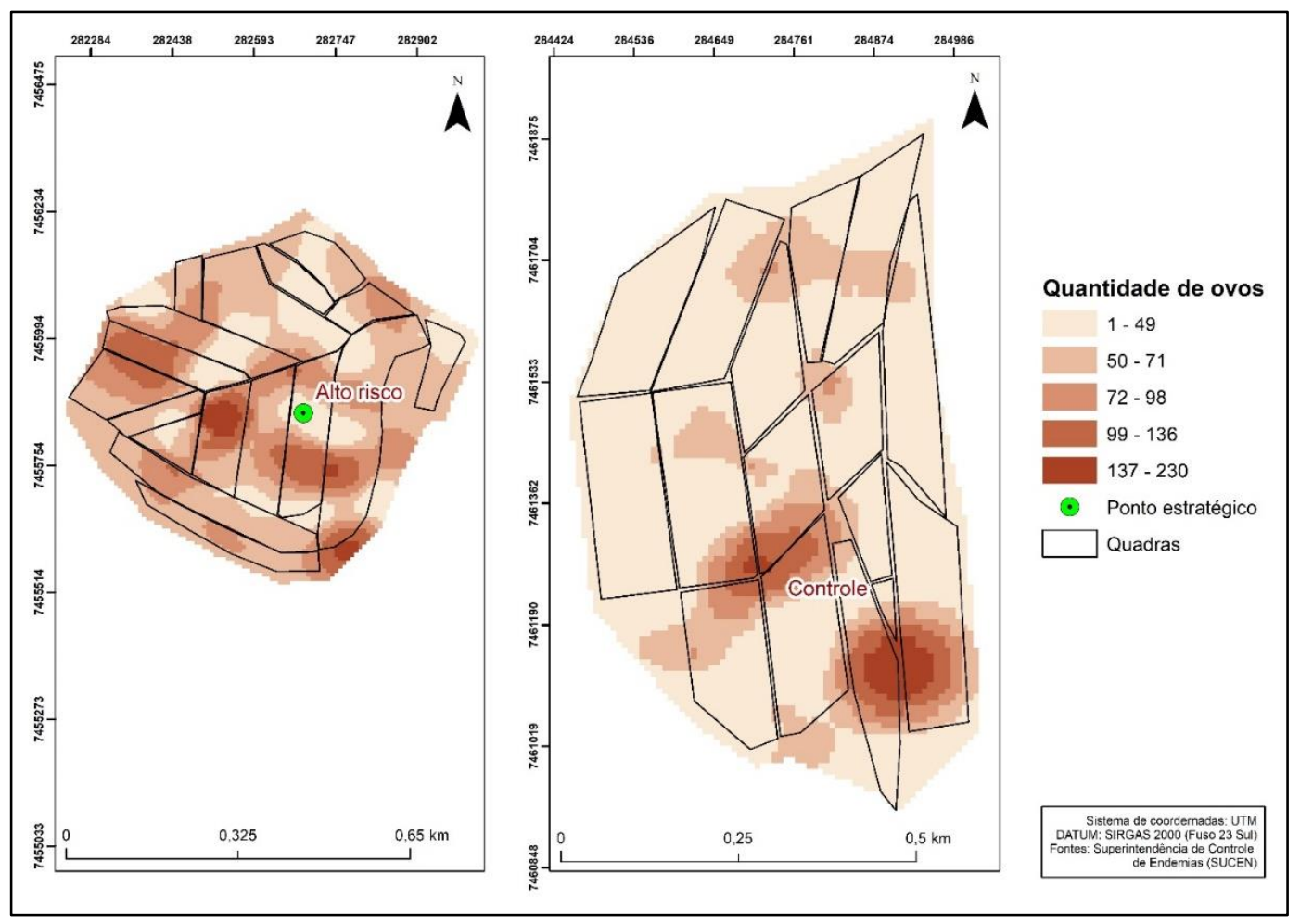

Fonte: Elaborado pela autora.

Figura 23 - Krigagem ordinária das armadilhas nas áreas de médio risco e baixo risco.

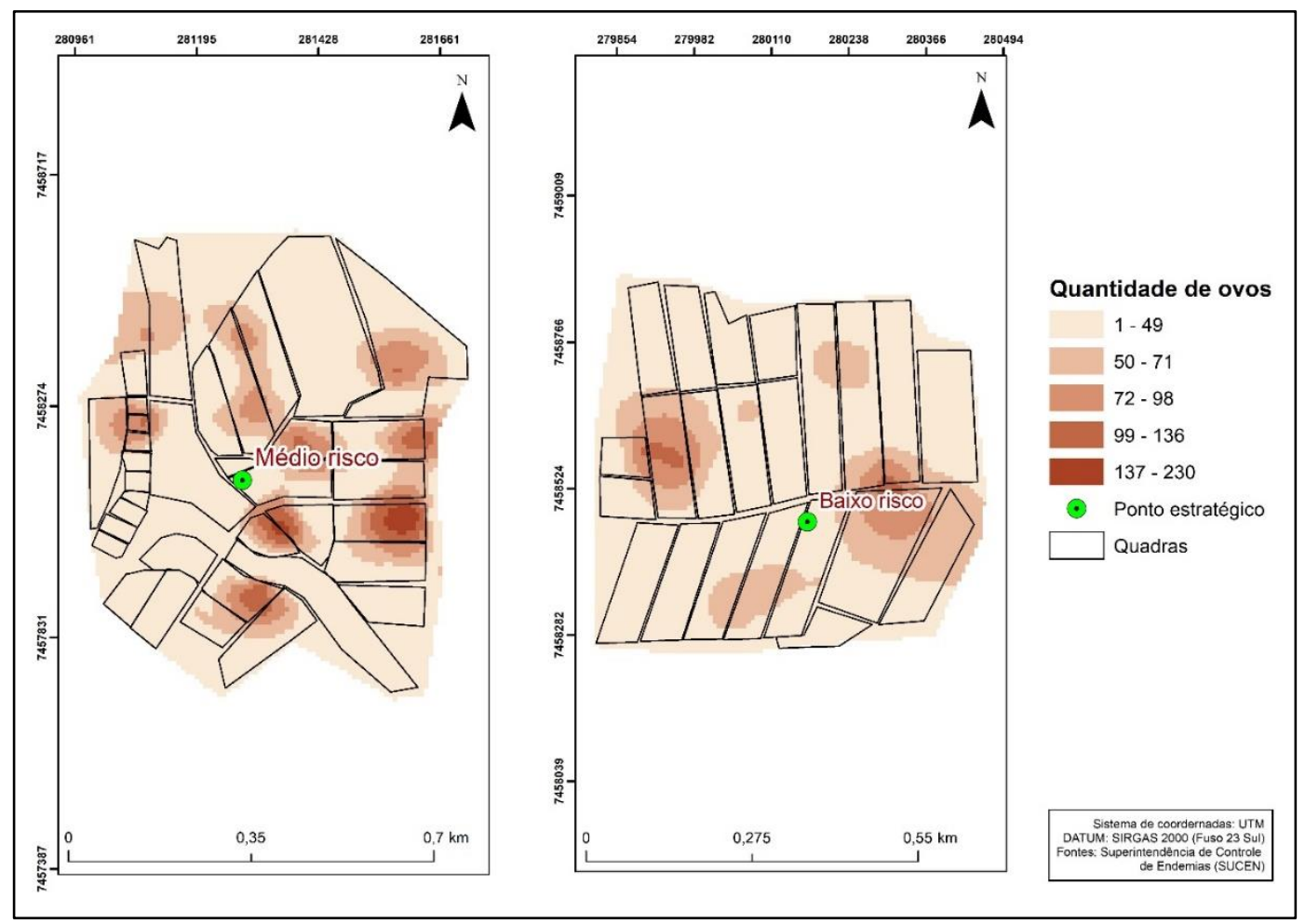

Fonte: Elaborado pela autora. 
Nota-se a distribuição da positividade das armadilhas por todas as áreas, com alguns pontos mais intensos. Assim, é possível delimitar uma área menor nas áreas de estudo e exibir quais são os pontos com maior quantidade de ovos coletados, prevendo as áreas com maior quantidade de mosquitos.

\subsection{ASSOCIAÇÃO ENTRE OS RESULTADOS DA KRIGAGEM E DA CLASSIFICAÇÃO NA IMAGEM}

Essa subseção apresenta o resultado da etapa de vínculo entre o resultado da classificação da imagem de satélite com o auxílio das fotos do VANT com o resultado da krigagem das armadilhas, selecionando-se as áreas com 99 ou mais ovos coletados durante o ano de estudo como expõe a Figura 24.

Figura 24 - Fluxograma com destaque das etapas relacionadas à correlação da classificação supervisionada com a krigagem ordinária.

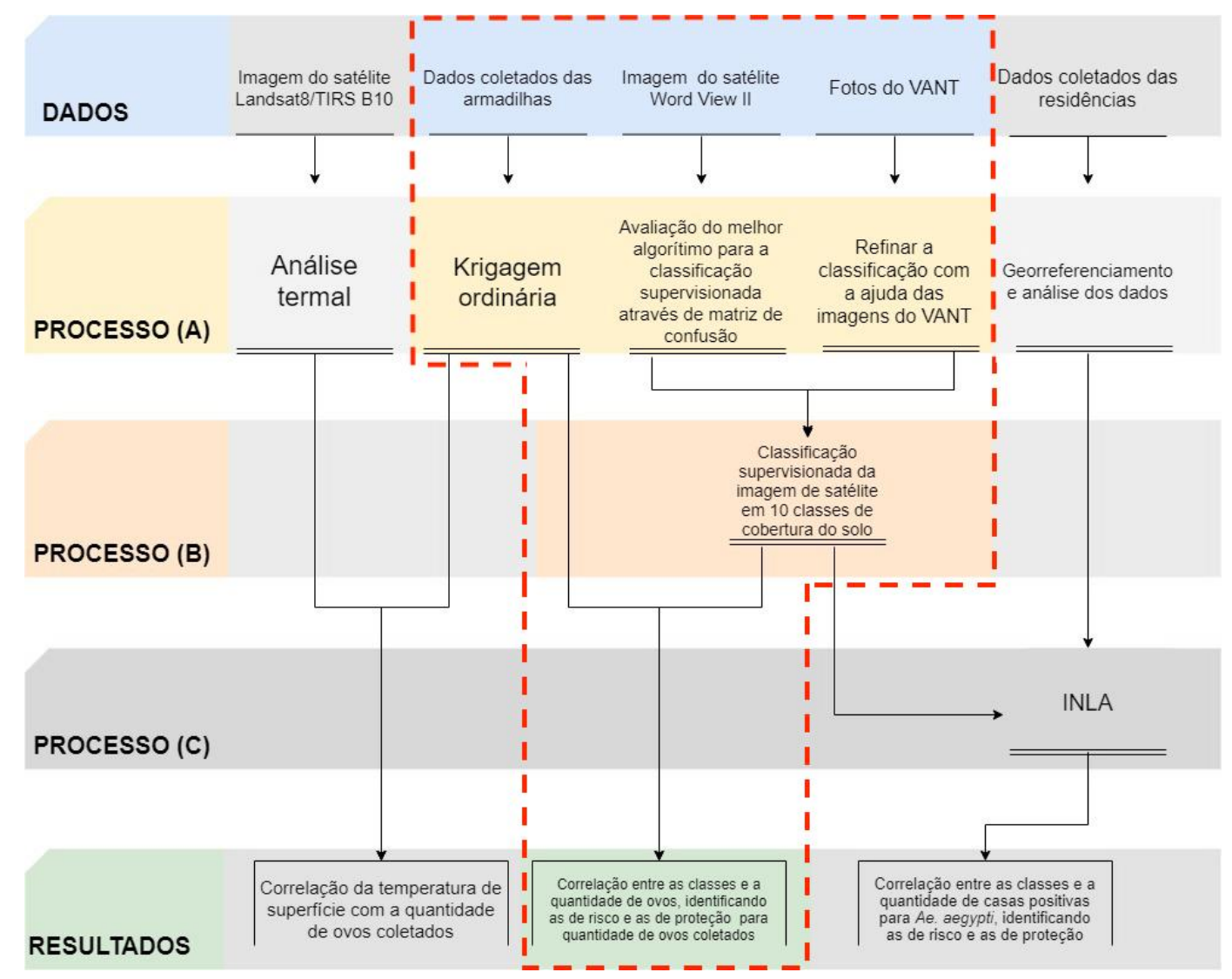

Fonte: Elaborado pela autora

Após realizada a classificação e a krigagem, utilizou-se a ferramenta "álgebra de mapas" na tentativa de associar os dois resultados, analisando os locais, obtidos via krigagem, com 
maior coleta de ovos nas armadilhas e relacionando-os com os tipos de uso do solo, obtidos via classificação (Figuras 25 e 26). 
Figura 25 - Vínculo entre o uso do solo e as maiores evidências de ovos nas áreas de alto risco e controle.

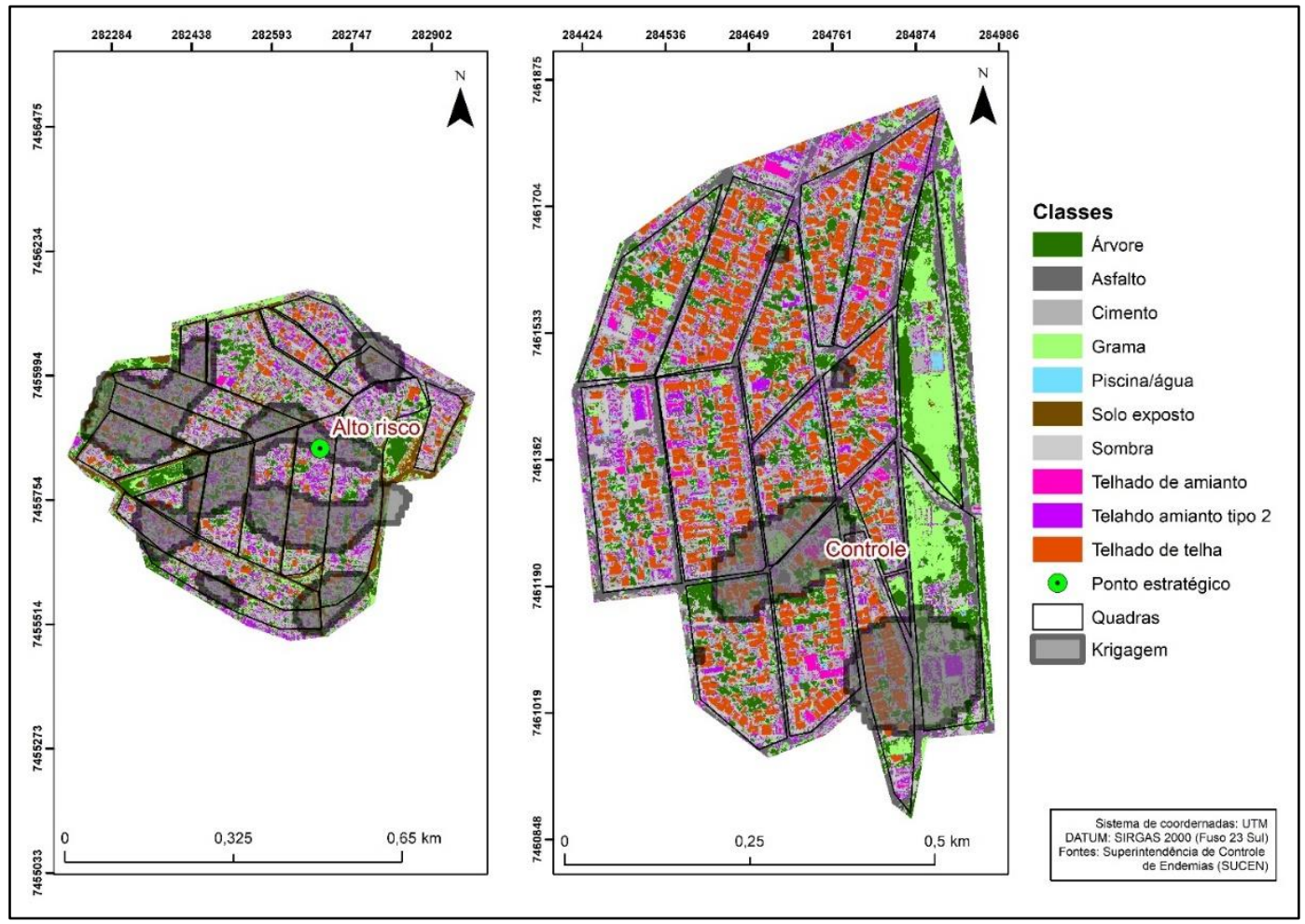

Fonte: Elaborado pela autora.

Figura 26 - Vínculo entre o uso do solo e as maiores evidências de ovos nas áreas de médio risco e baixo risco.

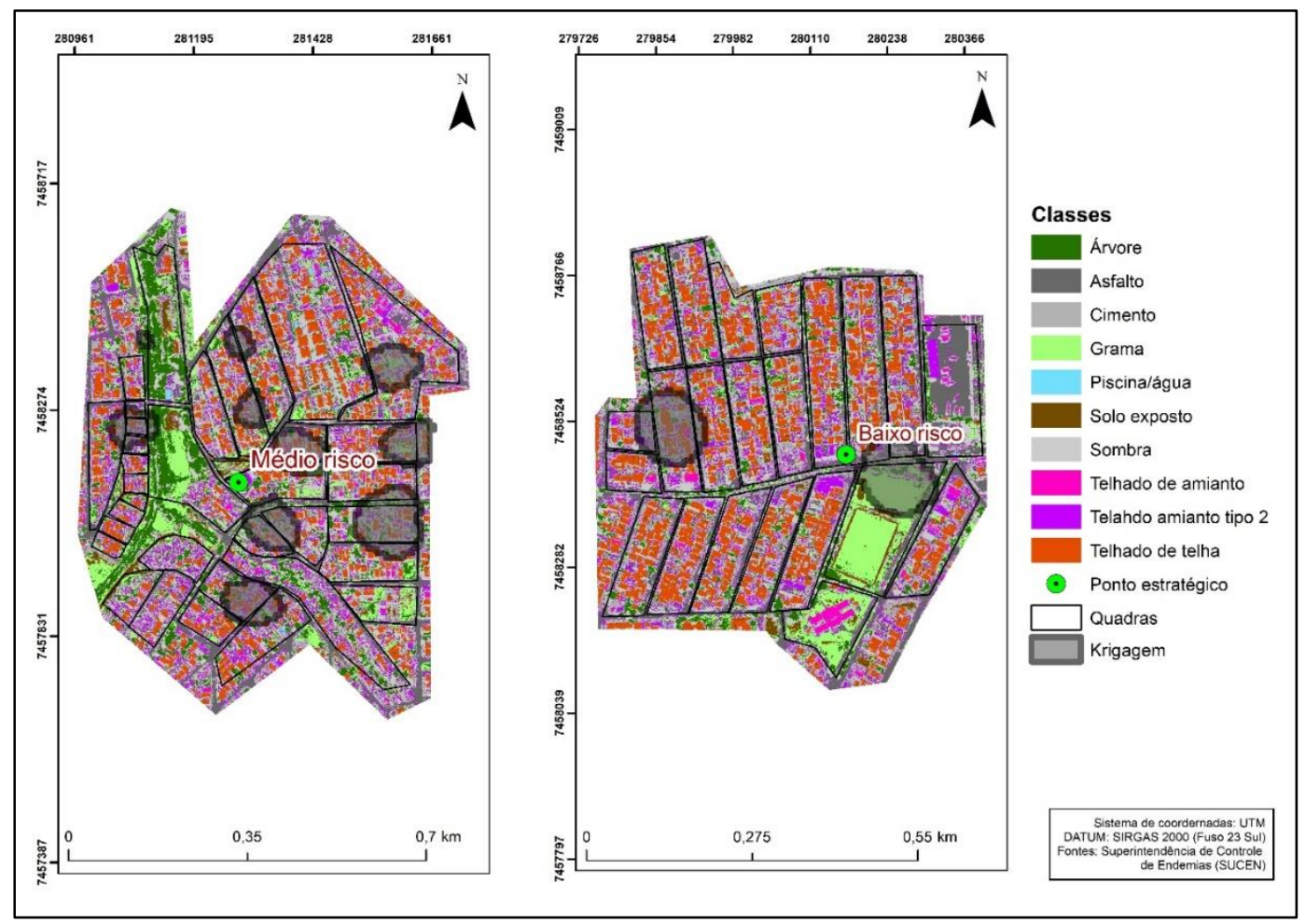

Fonte: Elaborado pela autora. 
A Tabela 17 apresenta a porcentagem de cada classe de uso do solo nas áreas, com destaque para aquelas com maior representatividade na coleta de ovos do mosquito durante o período. Os números em vermelho apresentam as maiores porcentagens de classes em cada região do estudo.

Tabela 17 - Porcentagens das classes nas áreas com maior coleta de ovos obtidos pela krigagem.

\begin{tabular}{|c|c|c|c|c|}
\hline Classes & Alto & Médio & Baixo & Controle \\
\hline Árvores & $12,68 \%$ & $10,46 \%$ & $6,31 \%$ & $19,89 \%$ \\
\hline Asfalto & $5,64 \%$ & $14,27 \%$ & $26,41 \%$ & $11,72 \%$ \\
\hline Cimento & $31,36 \%$ & $17,31 \%$ & $18,18 \%$ & $14,30 \%$ \\
\hline Grama & $4,24 \%$ & $11,75 \%$ & $6,55 \%$ & $13,54 \%$ \\
\hline Piscina/Água & $4,93 \%$ & $3,35 \%$ & $1,82 \%$ & $1,83 \%$ \\
\hline Solo Exposto & $10,39 \%$ & $2,21 \%$ & $1,17 \%$ & $0,65 \%$ \\
\hline Sombra & $5,48 \%$ & $23,55 \%$ & $16,23 \%$ & $16,67 \%$ \\
\hline Telhado Tipo 1 & $3,72 \%$ & $14,41 \%$ & $12,08 \%$ & $8,17 \%$ \\
\hline Telhado Tipo 2 & $16,79 \%$ & $1,13 \%$ & $11,09 \%$ & $11,45 \%$ \\
\hline Telhado Tipo 3 & $4,80 \%$ & $1,61 \%$ & $0,21 \%$ & $1,81 \%$ \\
\hline
\end{tabular}

Fonte: Elaborado pela autora.

Os resultados apresentados na tabela 17 exibem as classes que possuem maior tendência de existência de criadouros do mosquito. Para a área de alto risco, as classes Cimento, Telhado Tipo 2 e Árvores são aquelas que possuem maior porcentagem de área. Vale ressaltar que a classe Solo Exposto, indicativo da existência de ruas de terra, mesmo não sendo predominante, possui um valor considerável quando comparado com as demais áreas.

$\mathrm{Na}$ área de médio risco, com predominância de residências de médio padrão, as classes com maior área são Sombra, Cimento e Telhado Tipo 1.

$\mathrm{Na}$ área de baixo risco, com predominância de atividades comerciais, se destacam as classes Asfalto, Cimento e Sombra. Por último, a área controle, considerada de alto padrão na cidade de Campinas, possui as classes Sombra, Cimento e Árvores com aquelas com maior área. Classes como Grama, Piscina/água e Telhado Tipo 3, não tiveram destaque em nenhuma das áreas. 
Estes resultados, obtidos a partir do cruzamento de dados sobre quantidade de ovos do mosquito com informações sobre a cobertura do solo, revela uma possível tendência de o mosquito depositar seus ovos em lugares escuros, tais como cimento, asfalto e sombra.

\subsection{TERMAL}

Essa subseção apresenta o resultado da etapa da análise da temperatura de superfície, com o cruzamento dos dados do resultado da imagem termal com o resultado krigagem ordinária, como expõe a Figura 27.

Figura 27 - Fluxograma com destaque das etapas relacionadas à correlação com a temperatura de superfície com a krigagem ordinária.

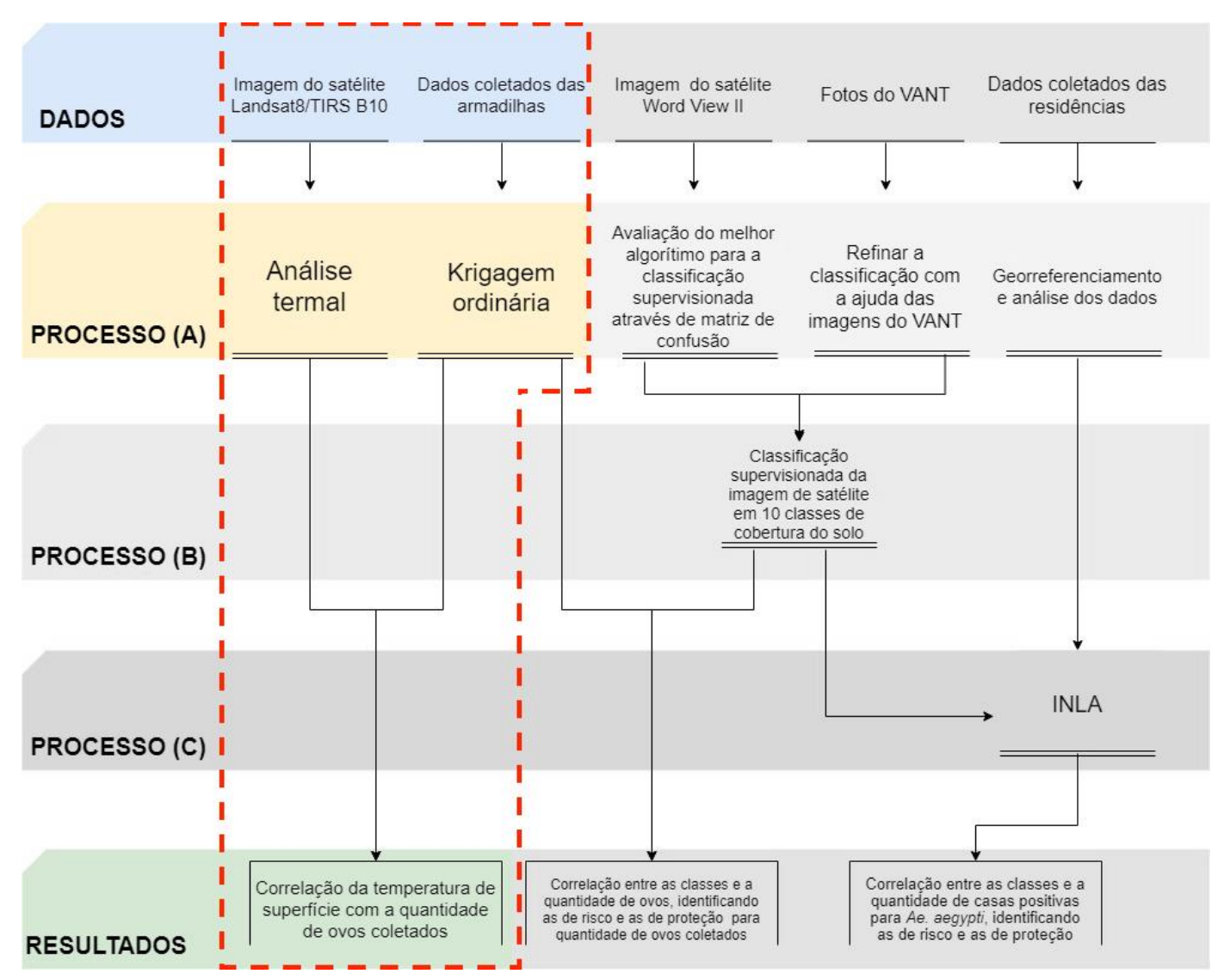

Fonte: Elaborado pela autora.

A seguir serão apresentados todos os resultados obtidos depois de realizada a implementação da metodologia exposta anteriormente. Os produtos resultantes do processamento digital foram realizados no software QGIS utilizando o plugin Land Surface Temperature Estimation das imagens foram representados a partir da aplicação de uma escala 
cromática em cores, que possibilita a distinção das variações de temperatura na área de estudo. As cores de tonalidade vermelha, na imagem, representam as áreas onde foram detectados valores mais elevados de temperatura. Enquanto as cores na tonalidade verde clara correspondem aos valores menos elevados.

Inicialmente, destaca-se a temperatura da superfície, utilizando o método Planck Equation para as áreas de estudo (Figuras 28 e 29).

Figura 28 - Temperatura de superfície calculada pelo método Planck Equation nas áreas de alto risco e controle.

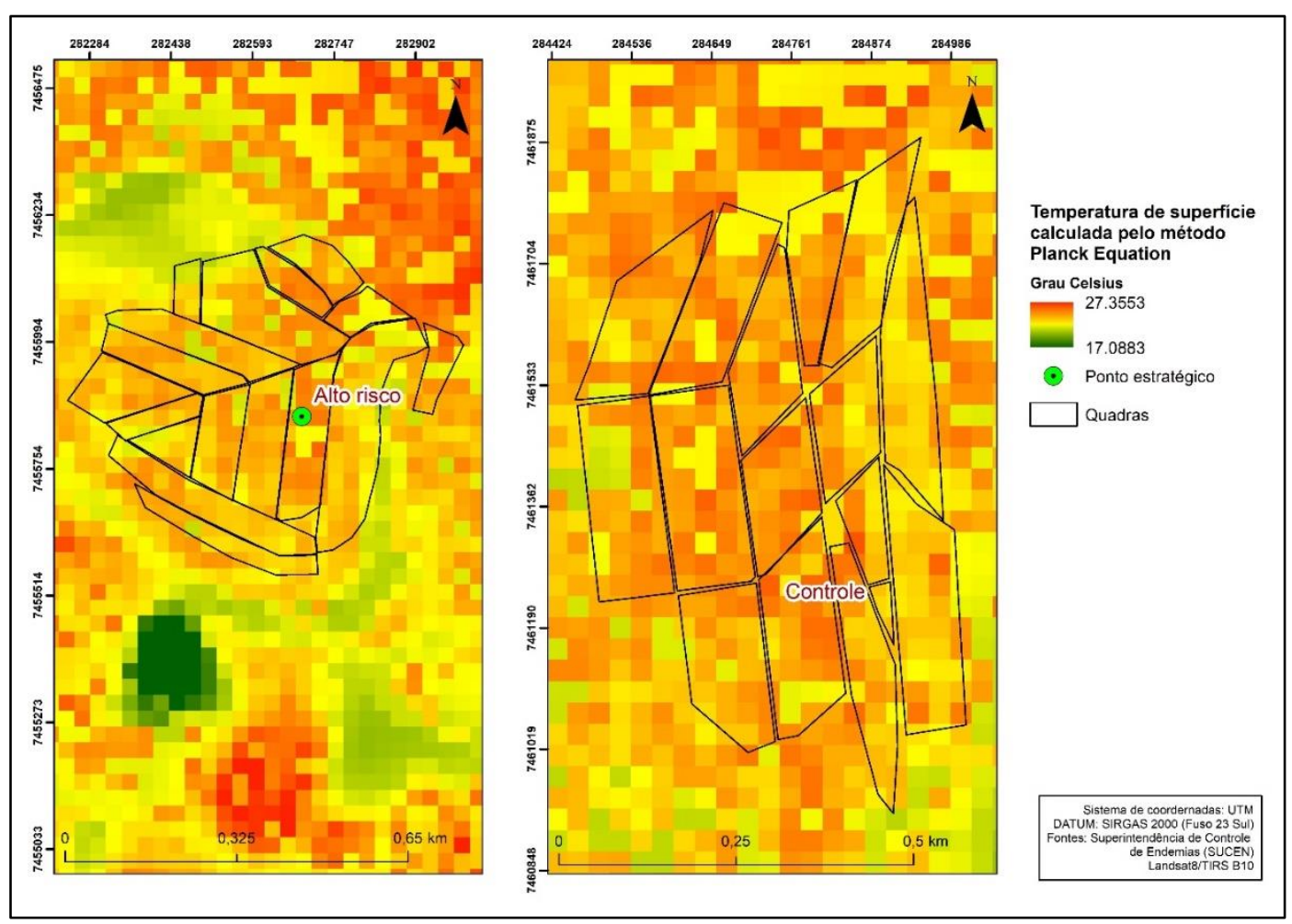

Fonte: Elaborado pela autora. 
Figura 29 - Temperatura de superfície calculada pelo método Planck Equation nas áreas de médio ricos e baixo risco.

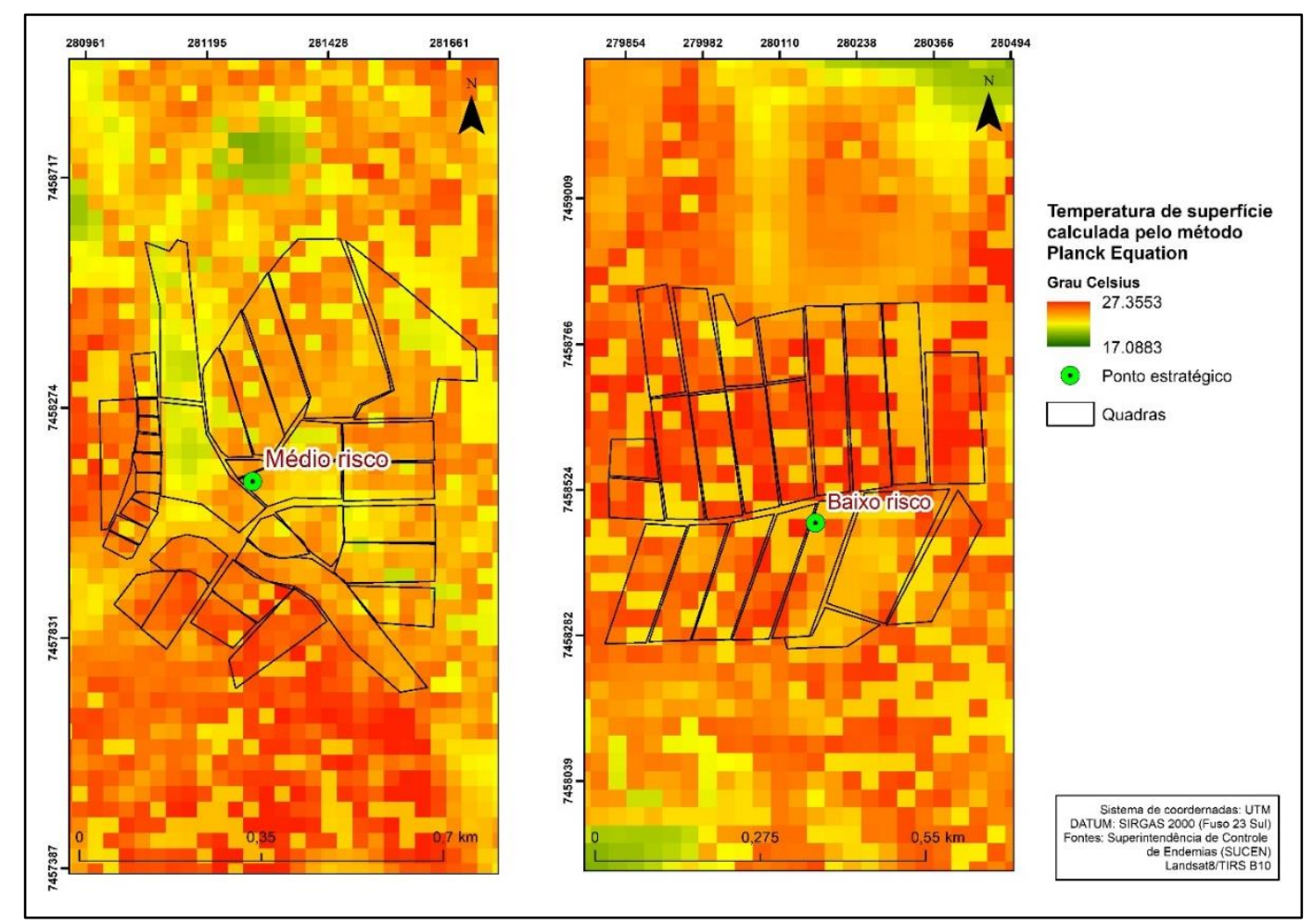

Fonte: Elaborado pela autora.

Depois, foi obtida a temperatura de superfície utilizando outro método chamado Mono Window Algorthim. Para aplicar esse algoritmo é necessário preencher a pressão atmosférica e a temperatura da área estudada. Esses dados foram fornecidos no site http://www.cpa.unicamp.br e assim calculada a média da transmitância atmosférica do ano de 2016 de $952 \mathrm{hPa}$ (hectopascal) e a temperatura atmosférica média efetiva do ano de 2016 de 295,45 Kelvin. As Figuras 30 e 31 apresentam os resultados da aplicação desse método nas áreas de estudo. 
Figura 30 - Temperatura de superfície calculada pelo método Mono Window Algorthim nas áreas de alto risco e controle

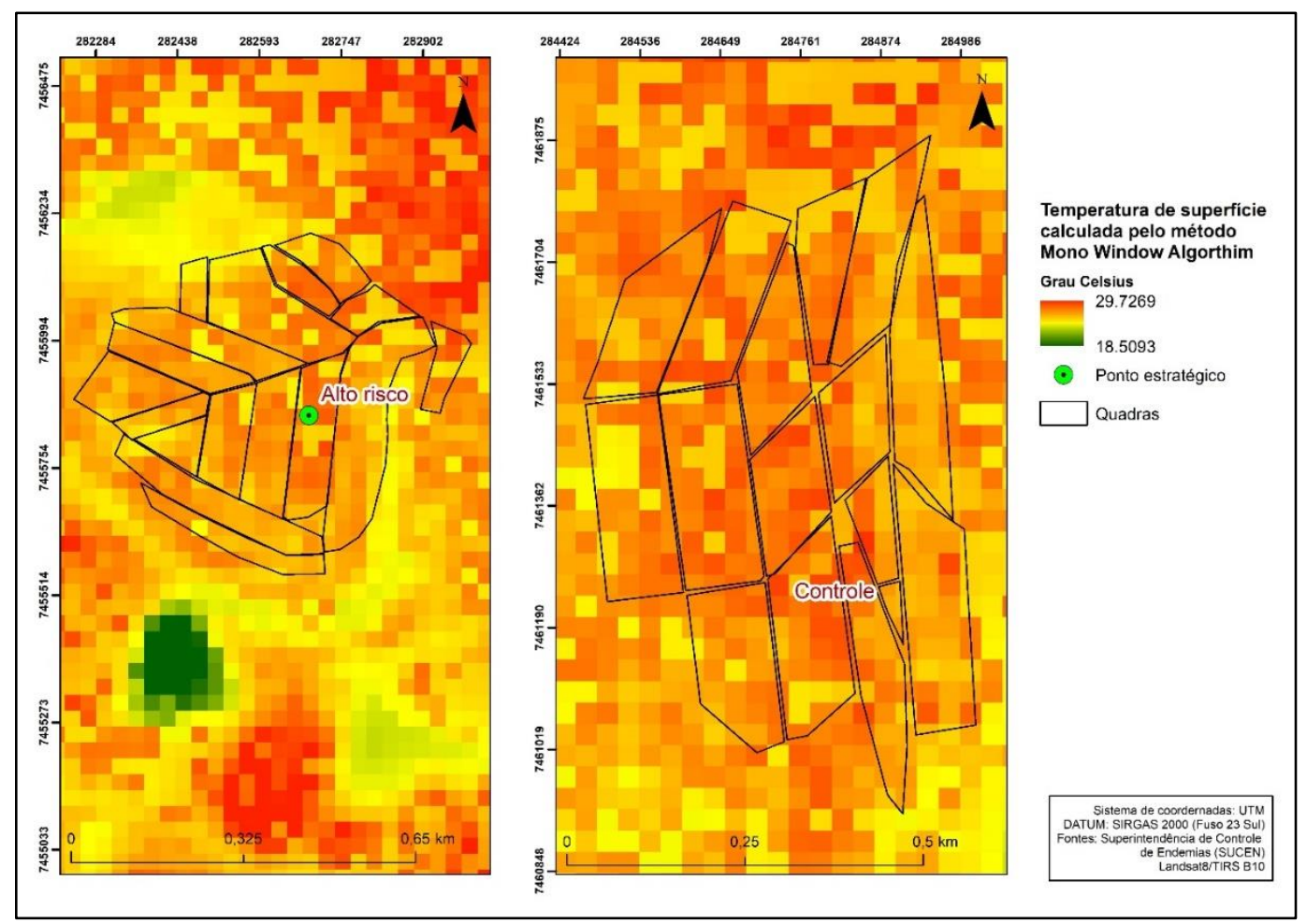

Fonte: Elaborado pela autora.

Figura 31 - Temperatura de superfície calculada pelo método Mono Window Algorthim nas áreas de médio risco e baixo risco.

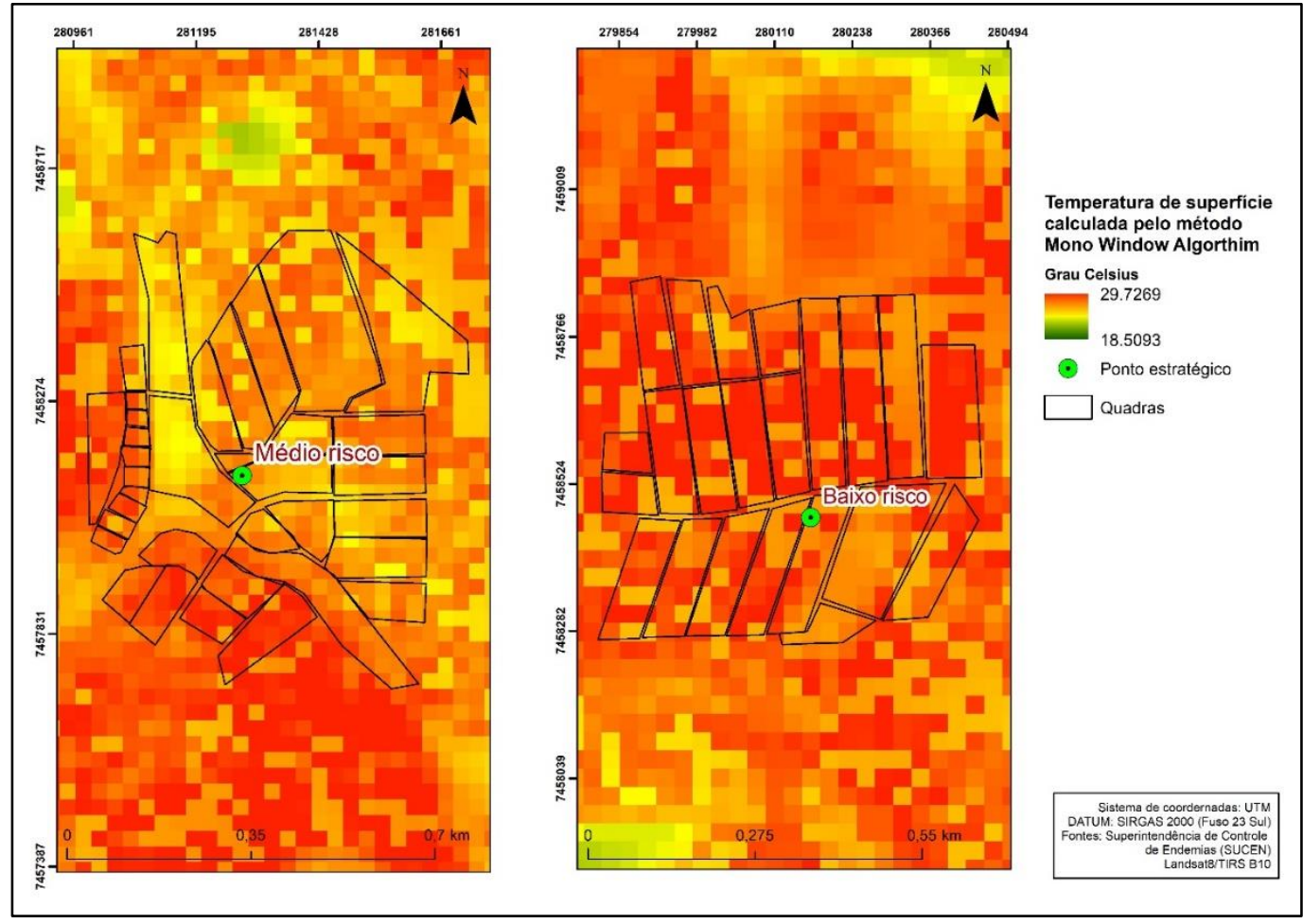

Fonte: Elaborado pela autora. 
Ao analisar o resultado das imagens termais, identificou-se visivelmente, por meio de representação de cores, um elevado nível de temperatura indicada pela cor vermelha nas áreas de médio e baixo risco em ambas as metodologias aplicadas.

Ao comparar os valores de temperatura da superfície obtidos por meio da aplicação das duas metodologias, a última, Mono Window Algorthim, também apresenta temperaturas mais altas em todas as áreas se comparada a metodologia denominada Planck Equation. É necessário enfatizar que a metodologia do Planck Equation é a mais simples de ser utilizada, pois não requer dados atmosféricos durante a passagem do satélite.

Depois do cálculo da temperatura de superfície utilizando os dois modelos, foi possível, através de sobreposição de camadas, avaliar a relação entre as áreas com maior quantidade de ovos coletados (resultado da krigagem) com os resultados obtidos pela análise da temperatura de superfície, conforme é apresentado nos mapas nas Figuras 32, 33, 34 e 35.

Figura 32 - Sobreposição da krigagem ordinária com a temperatura de superfície calculada pelo método Planck Equation nas áreas de alto risco e controle.

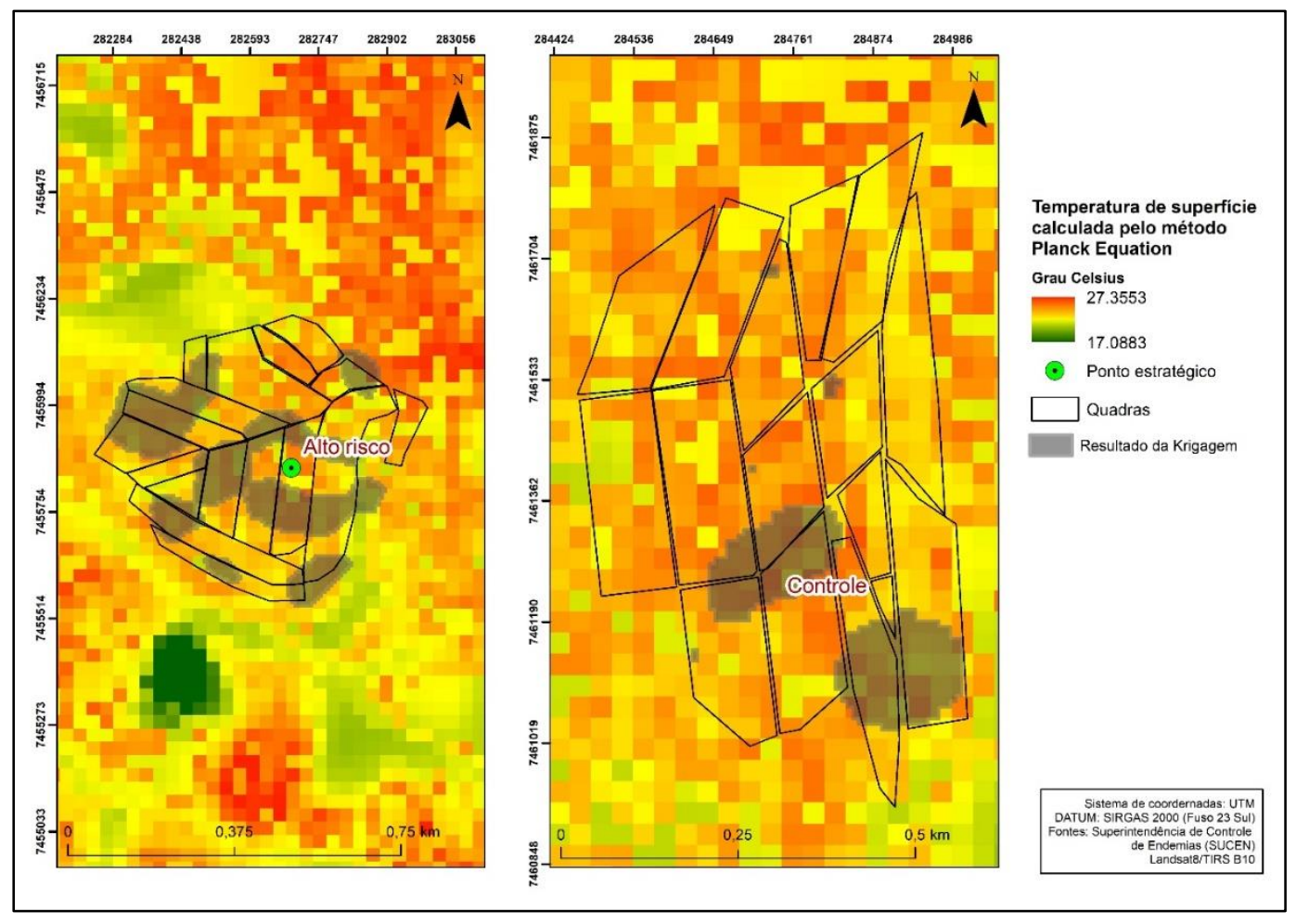

Fonte: Elaborado pela autora. 
Figura 33 - Sobreposição da krigagem ordinária com a temperatura de superfície calculada pelo método Planck Equation nas áreas de médio risco e baixo risco.

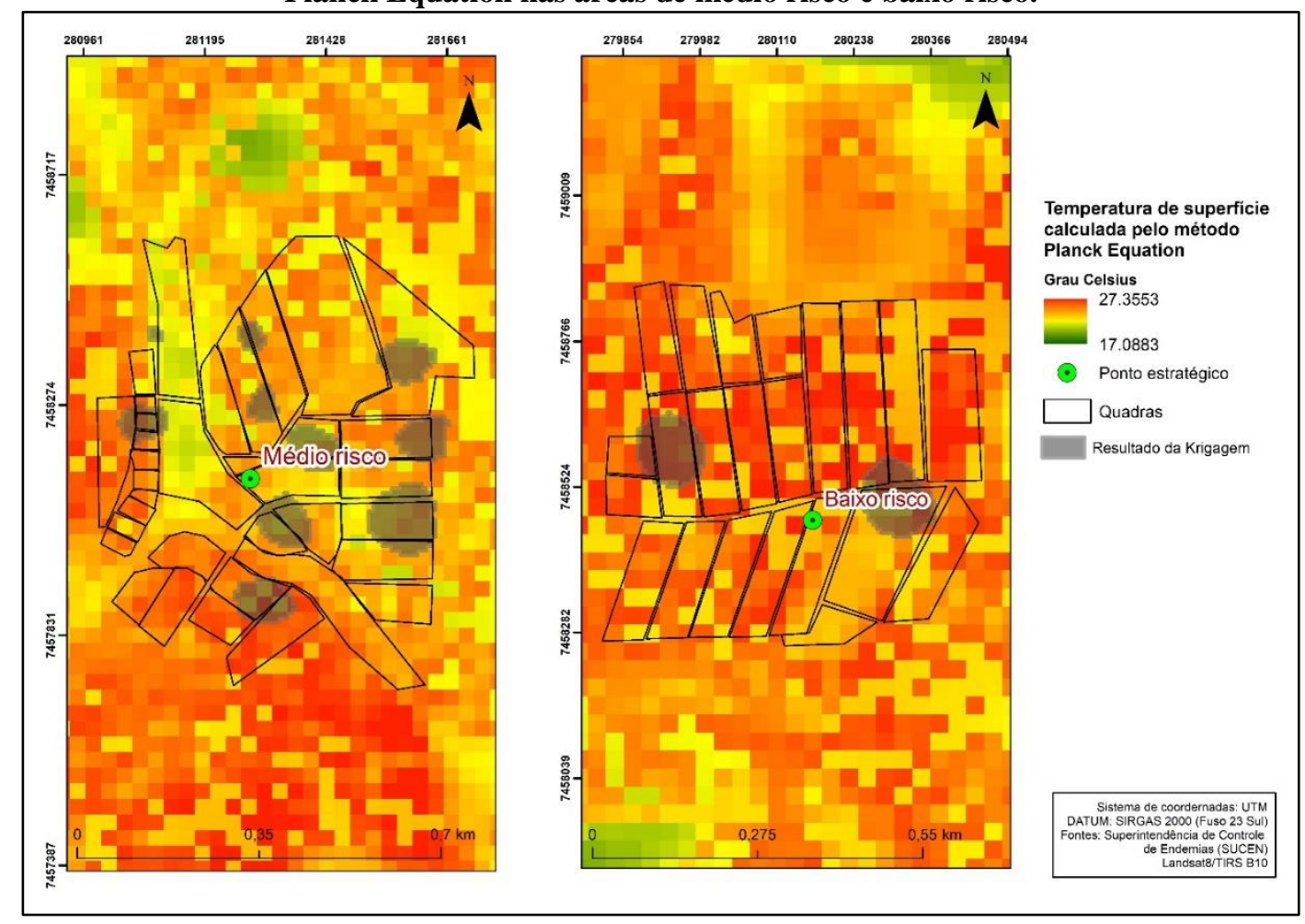

Fonte: Elaborado pela autora.

Figura 34 - Sobreposição da krigagem oridinária com a temperatura de superfície calculada pelo método Mono Window Algorthim nas áreas de alto risco e controle.

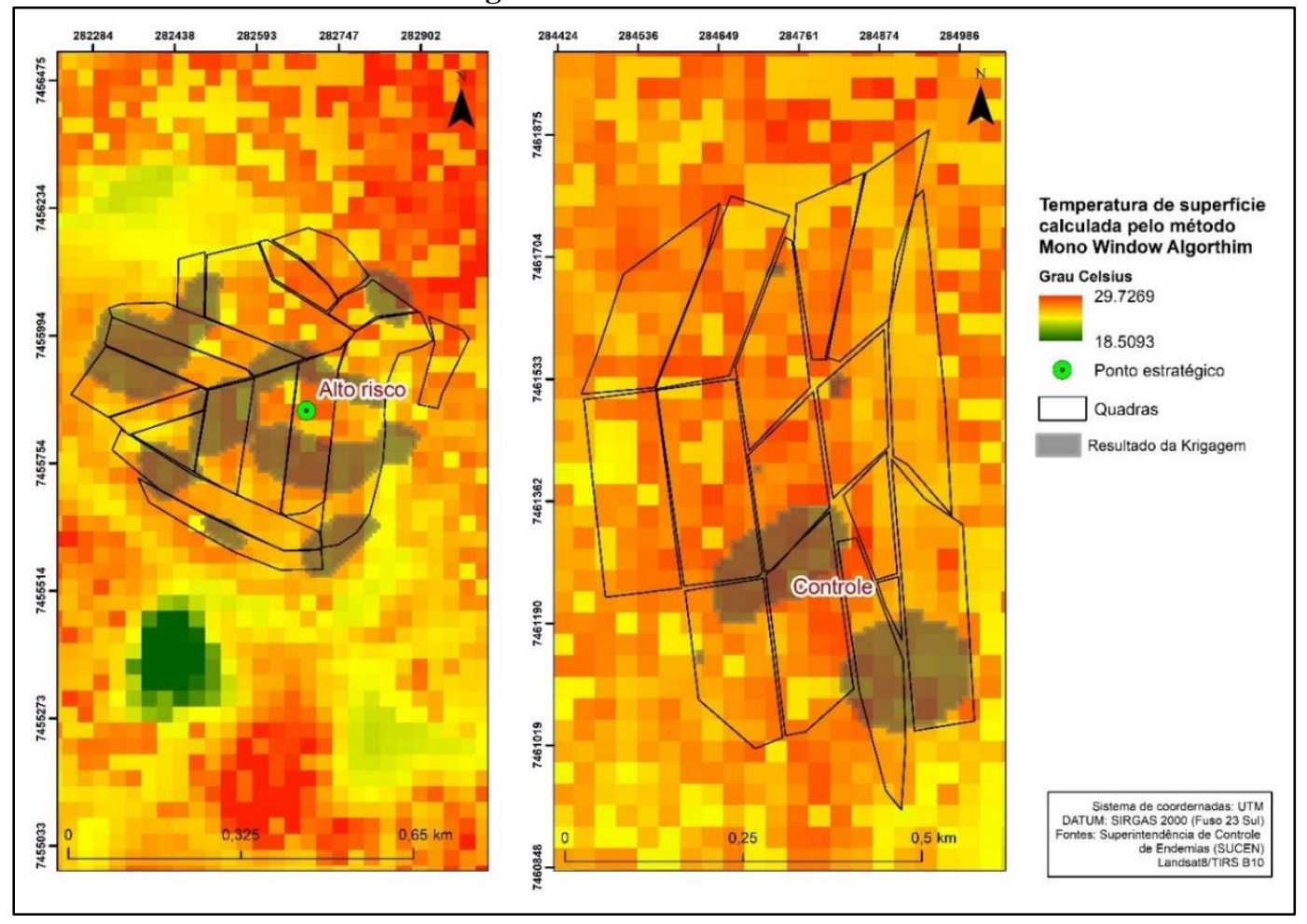

Fonte: Elaborado pela autora. 
Figura 35 - Sobreposição da krigagem oridinária com a temperatura de superfície calculada pelo método Mono Window Algorthim nas áreas de médio risco e baixo risco.

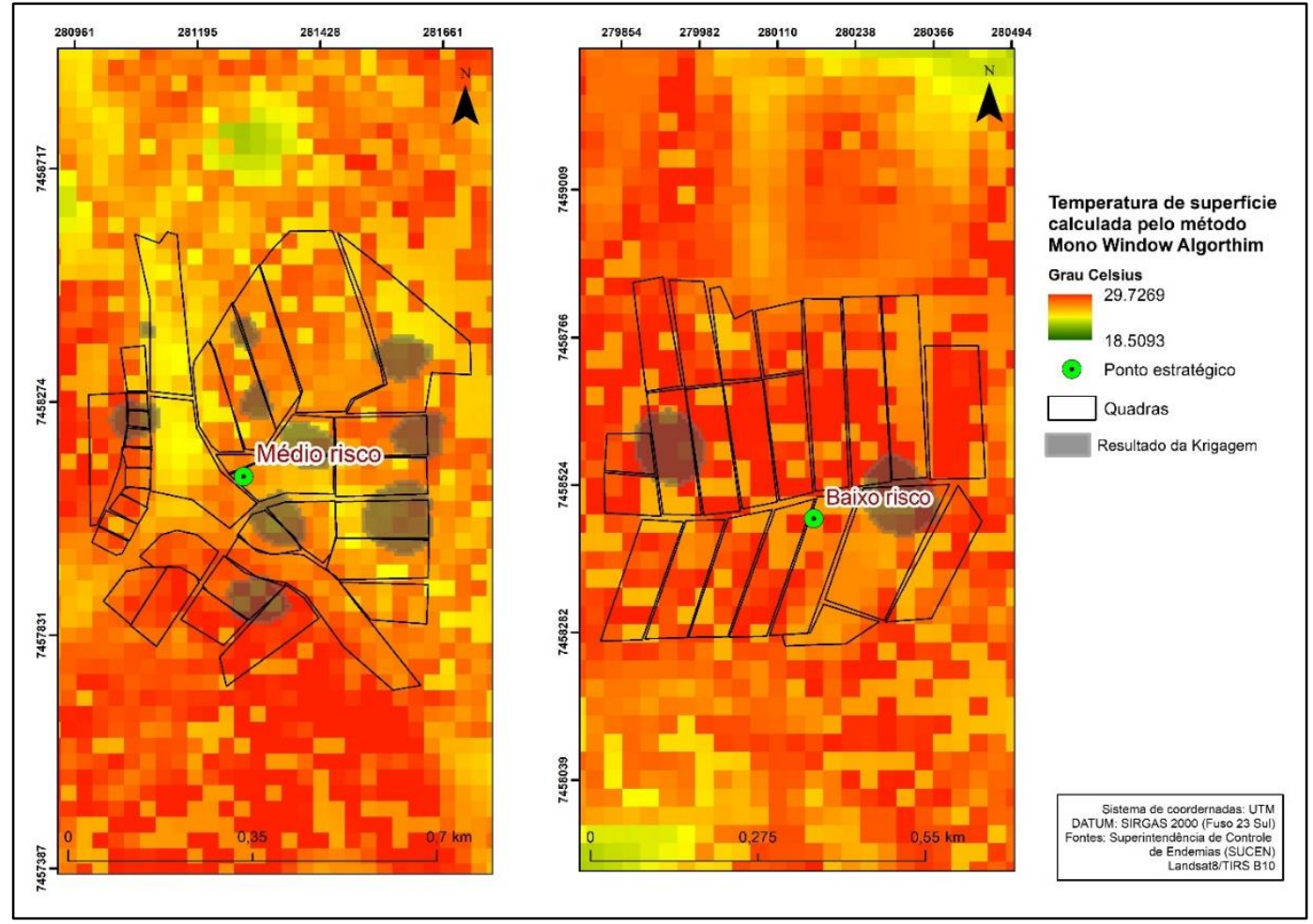

Fonte: Elaborado pela autora.

As diferenças de temperatura de superfície dos dois modelos nas áreas com maior quantidade de ovos coletados nas armadilhas durante o período de estudo são apresentadas na Tabela 18. Foi possível verificar que as temperaturas médias obtidas pelo método Mono Window Algorthim são mais altas em todas as áreas, quando comparadas com as obtidas pelo método Planck Equation.

Tabela 18- Média da temperatura de superfície para cada um dos métodos realizados nas áreas de alta quantidade de coleta de ovos.

\begin{tabular}{|c|c|c|}
\cline { 2 - 3 } \multicolumn{1}{c|}{} & $\begin{array}{c}\text { Temperatura de superfície calculada } \\
\text { pelo método Planck Equation }\end{array}$ & $\begin{array}{c}\text { Temperatura de superfície calculada } \\
\text { pelo método Mono Window Algorthim }\end{array}$ \\
\hline Áreas & Temperatura média em Grau Celsius & Temperatura média em Grau Celsius \\
\hline Alto Risco & 23,71 & 24,89 \\
\hline $\begin{array}{c}\text { Médio } \\
\text { Risco }\end{array}$ & 24,03 & 26,22 \\
\hline Baixo Risco & 24,31 & 27,45 \\
\hline Controle & 24,12 & 25,07 \\
\hline
\end{tabular}

Fonte: Elaborado pela autora. 


\subsection{INLA}

Nessa última etapa dos resultados, foi processada a metodologia INLA com o objetivo de apresentar quais seriam as classes do uso do solo com probabilidades de risco ou de proteção para o mosquito. Com os dados de entrada dos imóveis das 4 áreas estudas e com a classificação supervisionada foi possível realizar essa etapa como apresenta a Figura 36.

Figura 36 - Fluxograma com destaque das etapas relacionadas ao resultado das classes que apresentam risco ou proteção em correlação com a quantidade de casas positivas.

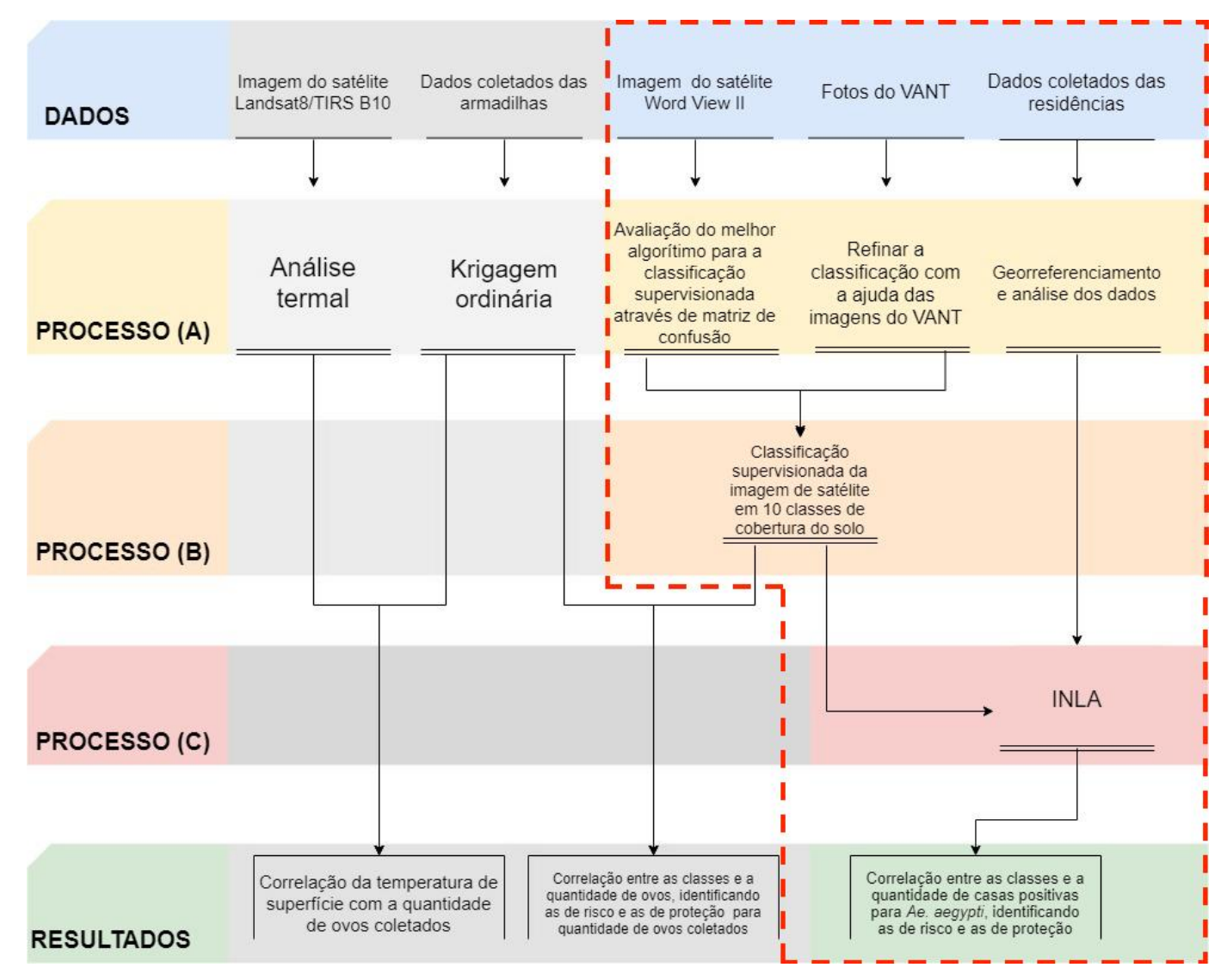

Fonte: Elaborado pela autora.

O primeiro passo para a aplicação da metodologia INLA foi a preparação do banco de dados dos imóveis das 4 áreas de estudos visitados durante o período de agosto de 2015 até setembro de 2016 (Tabela 19). Esses dados fornecem algumas informações como latitude e longitude dos imóveis e se a casa é positiva, ou seja, se foram identificados recipientes com larvas e/ou pupas de Ae. aegypti. 
Tabela 19 - Informações do banco de dados dos imóveis.

\begin{tabular}{|c|c|c|c|c|c|c|}
\cline { 2 - 7 } & $\begin{array}{c}\text { Positividade } \\
\text { da casa }\end{array}$ & UTM (E) & UTM (N) & $\begin{array}{c}\text { Área Alto } \\
\text { Risco }\end{array}$ & $\begin{array}{c}\text { Área } \\
\text { Médio } \\
\text { Risco }\end{array}$ & $\begin{array}{c}\text { Área } \\
\text { Baixo } \\
\text { Risco }\end{array}$ \\
\hline \multirow{4}{*}{ Imóveis } & 0 & -284876 & -7461491 & 1 & 0 & 0 \\
\cline { 2 - 7 } & 0 & -284921 & -7461307 & 0 & 0 & 1 \\
\cline { 2 - 7 } & 0 & -284951 & -7461587 & 0 & 1 & 0 \\
\cline { 2 - 7 } & 1 & -284952 & -7461578 & 1 & 0 & 0 \\
\cline { 2 - 7 } & 1 & -284986 & -7461185 & 0 & 0 & 1 \\
\hline & 0 & -284987 & -7461176 & 0 & 1 & 0 \\
\hline
\end{tabular}

Fonte: Elaborado pela autora.

O segundo passo foi a geoespacialização desses imóveis, através da latitude e longitude coletada no campo, gerando-se pontos no software QGIS, conforme é apresentado na Figura 37, para a áreas de baixo risco. 
Figura 37 - Localização dos imóveis na área de baixo risco.

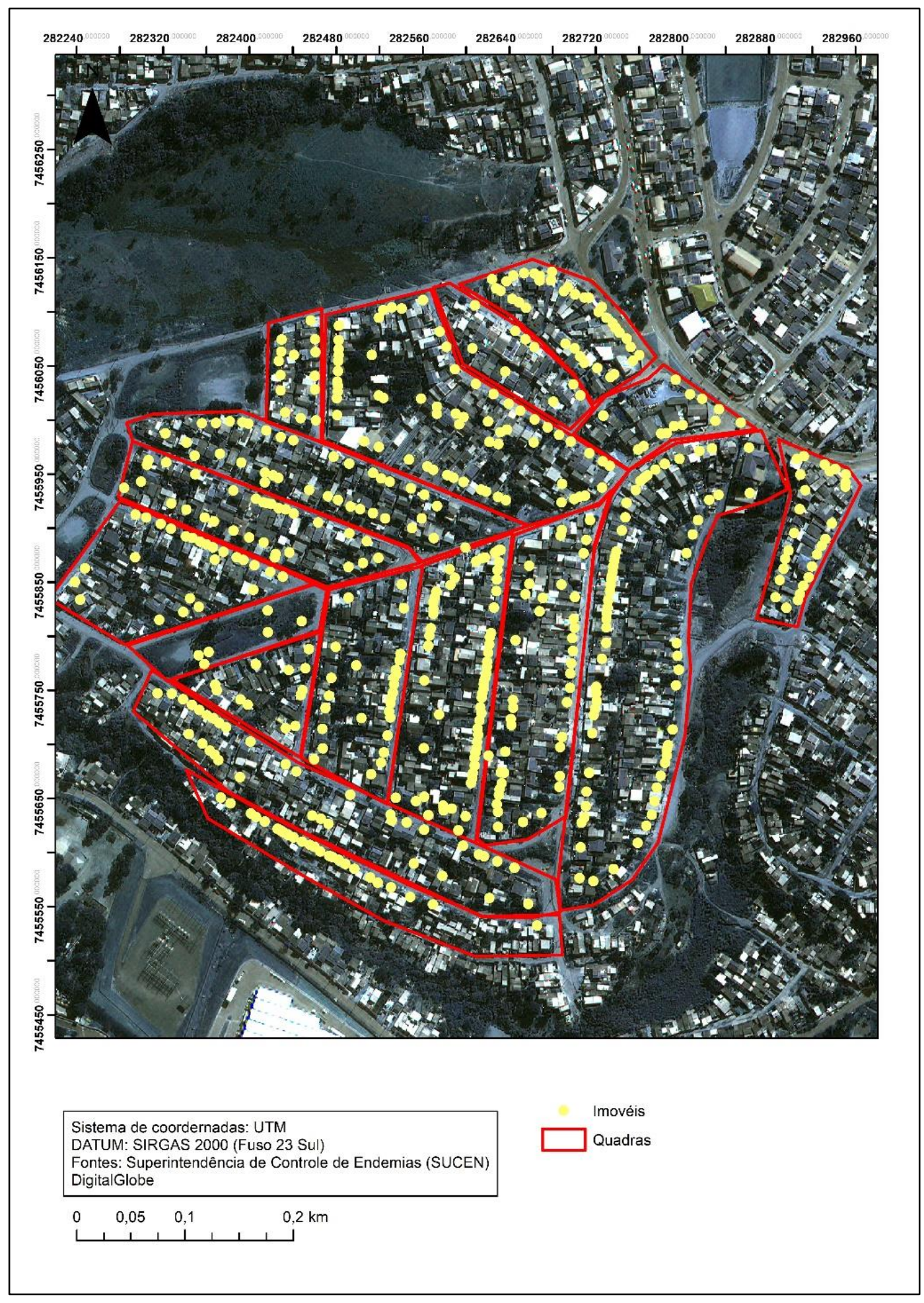

Fonte: Elaborado pela autora.

O terceiro passo foi a realização dos buffers de 5, 10 e 15 metros de raio através dos pontos dos imóveis como demostra a Figura 38. 
Figura 38 - Apresentação dos buffers de 5, 10 e 15 metros.

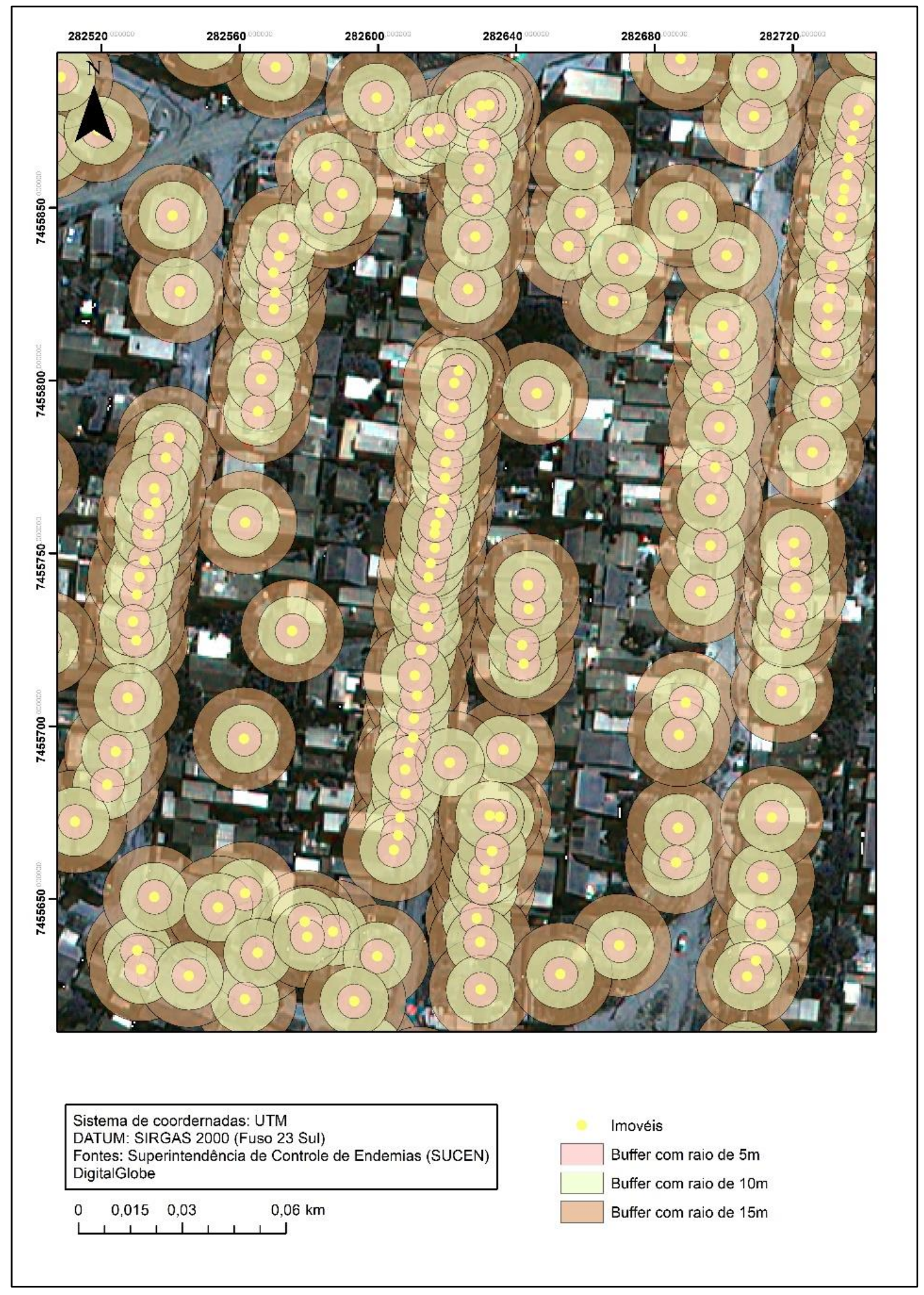

Fonte: Elaborado pela autora.

Realizado esse terceiro passo, foi acrescentado o resultado da classificação supervisionada para cada tamanho de buffer calculado (Figura 39, 40 e 41). 
Figura 39 - Mapa da classificação supervisionada no buffer de 5 metros.

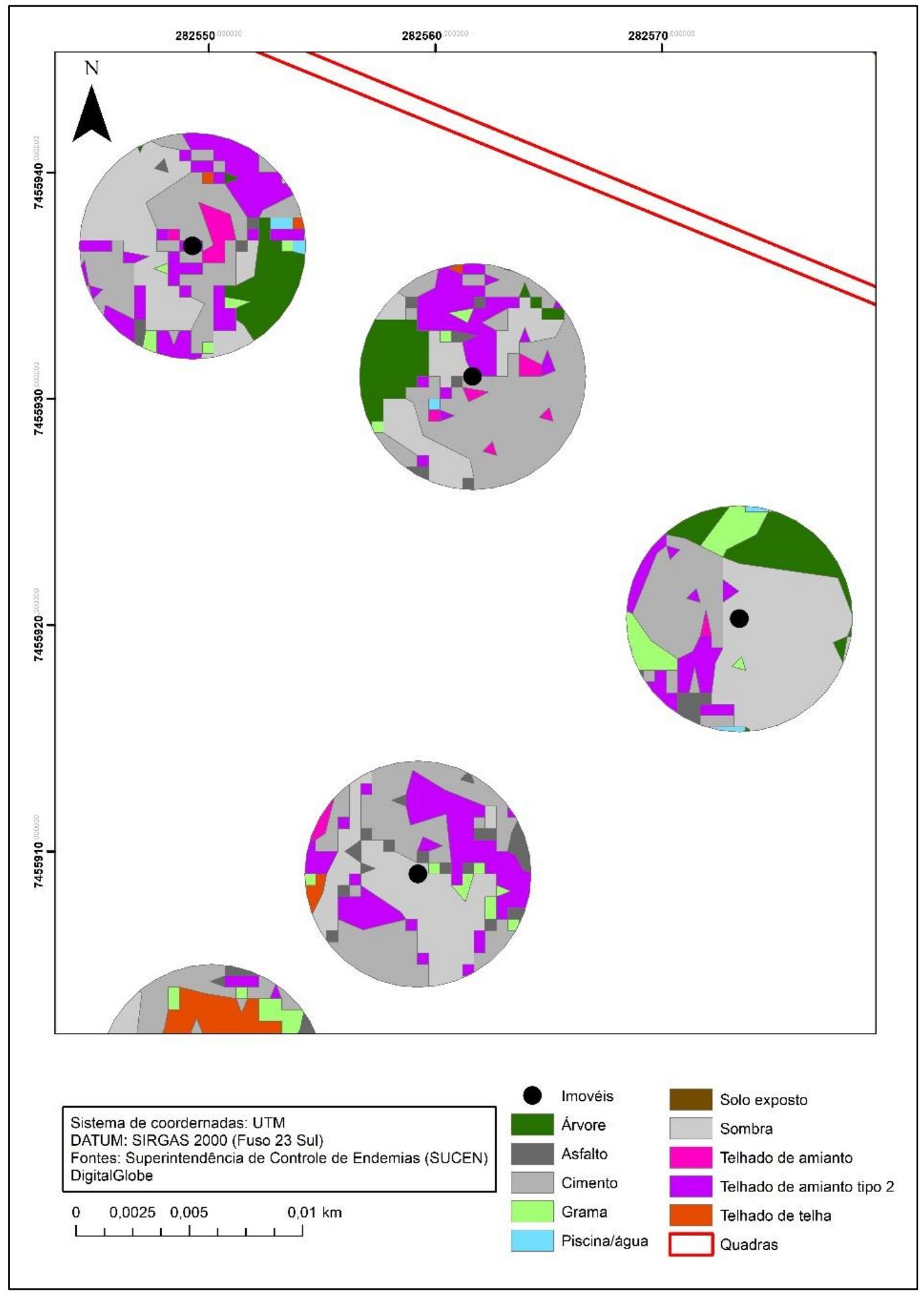

Fonte: Elaborado pela autora. 
Figura 40 - Mapa da classificação supervisionada no buffer de 10 metros.

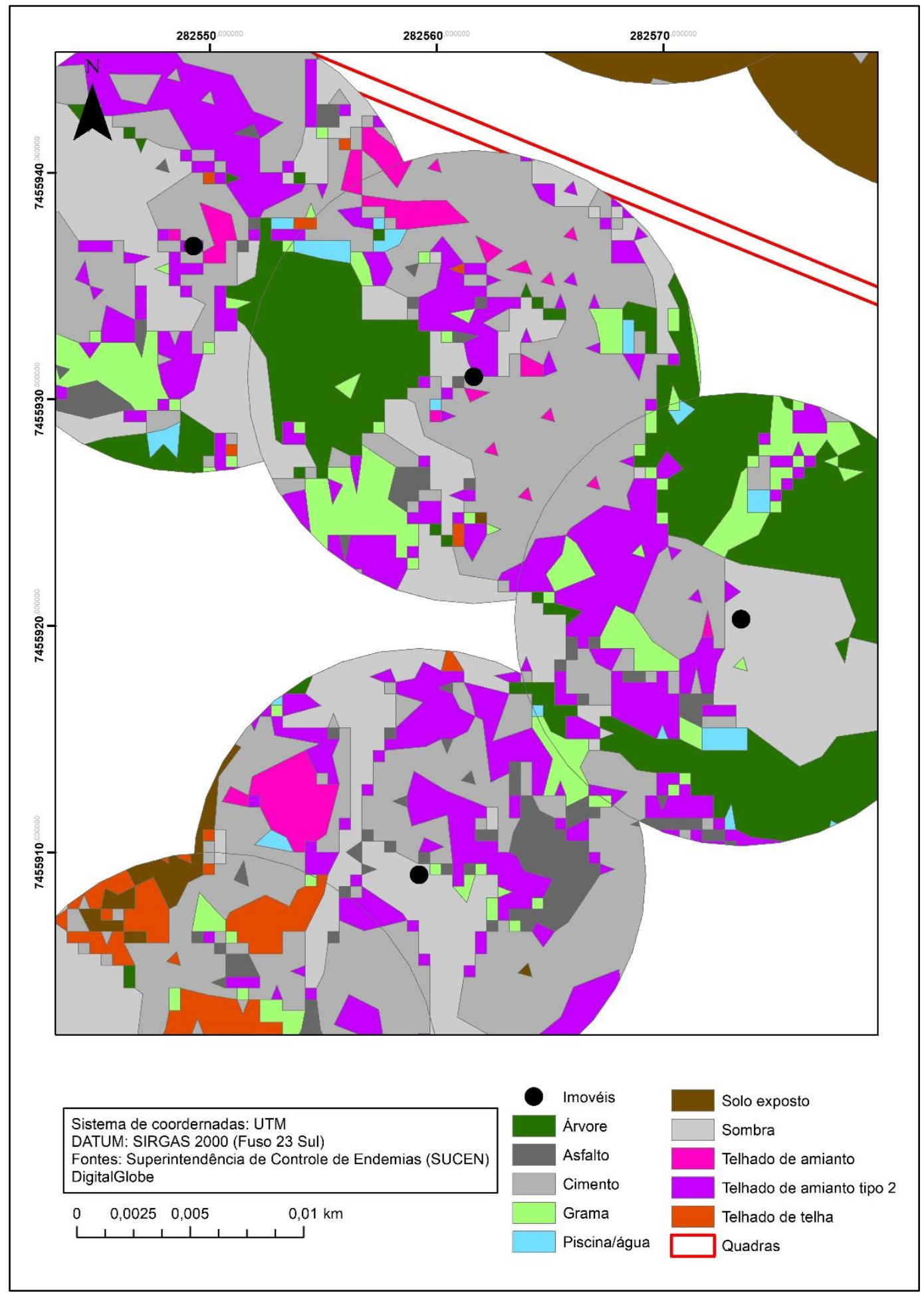

Fonte: Elaborado pela autora. 
Figura 41 - Mapa da classificação supervisionada no buffer de 15 metros.

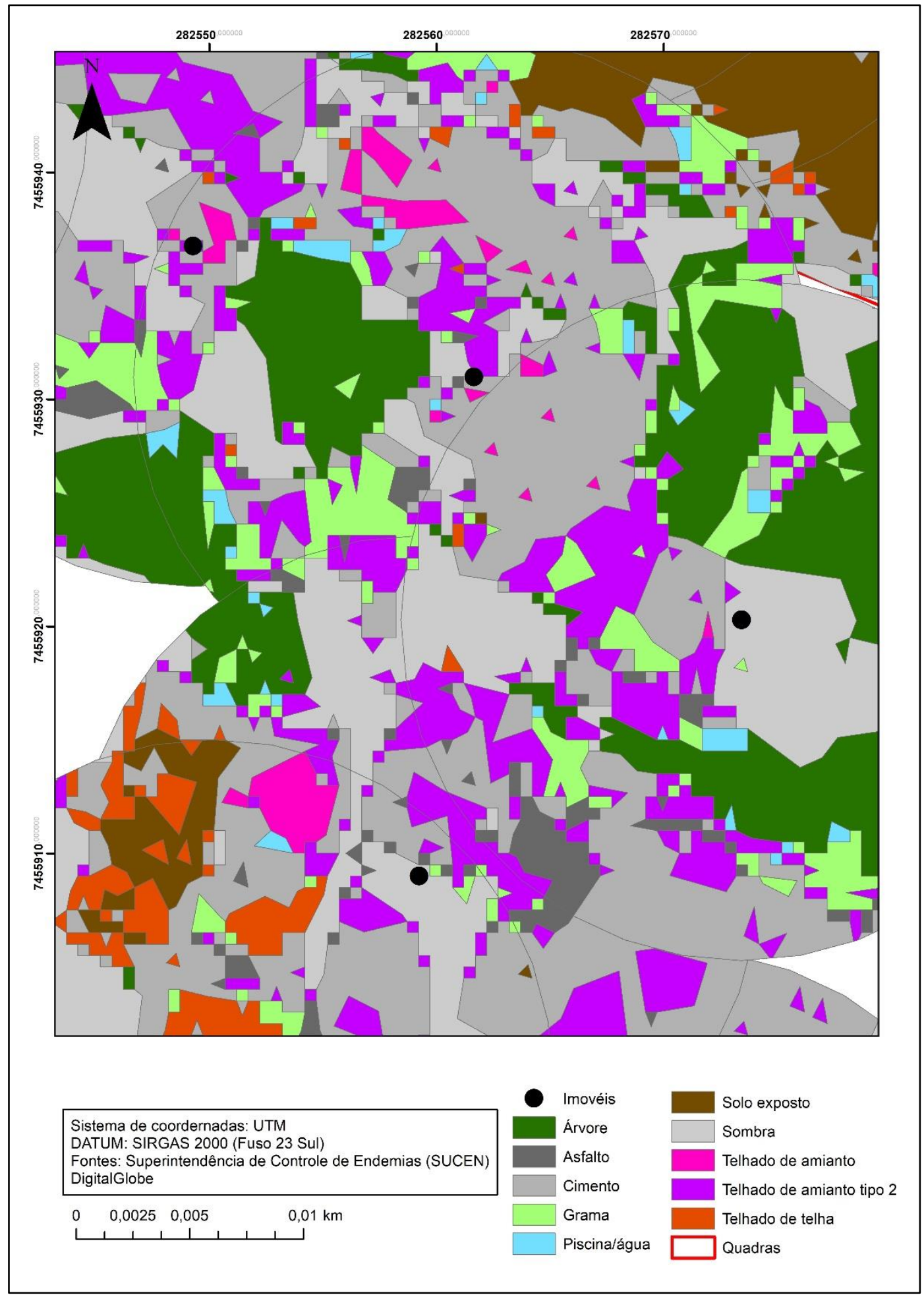

Fonte: Elaborado pela autora. 
Por fim, a partir do banco de dados com a informações sobre a positividade dos imóveis, sua localização geográfica e com o resultado das porcentagens de cada classe com cada raio do buffer, realizou-se a metodologia INLA no software R (Tabela 20).

Tabela 20 -Informações do banco de dados realizado para a metodologia INLA no buffer de 5 metros.

\begin{tabular}{|l|c|c|c|c|c|c|c|}
\cline { 2 - 8 } \multicolumn{1}{l|}{} & \multicolumn{7}{|c|}{ Imóveis } \\
\hline $\begin{array}{l}\text { Positividade } \\
\text { da casa }\end{array}$ & 0 & 0 & 0 & 1 & 1 & 0 & 0 \\
\hline $\begin{array}{l}\text { Longitude } \\
\text { (UTM) }\end{array}$ & -284876 & -284921 & -284951 & -284952 & -284986 & -284987 & -280078 \\
\hline $\begin{array}{l}\text { Latitude } \\
\text { (UTM) }\end{array}$ & -7461491 & -7461307 & -7461587 & -7461578 & -7461185 & -7461176 & -7458480 \\
\hline $\begin{array}{l}\text { Área alto } \\
\text { risco }\end{array}$ & 0 & 1 & 0 & 1 & 1 & 0 & 0 \\
\hline $\begin{array}{l}\text { Área médio } \\
\text { risco }\end{array}$ & 1 & 0 & 0 & 0 & 0 & 1 & 0 \\
\hline $\begin{array}{l}\text { Área baixo } \\
\text { risco }\end{array}$ & 0 & 0 & 1 & 0 & 0 & 0 & 1 \\
\hline $\begin{array}{l}\text { Telhado } \\
\text { tipo 3 (\%) }\end{array}$ & 7,41 & 0 & 0 & 0 & 0 & 0 & 14,39 \\
\hline $\begin{array}{l}\text { Telhado } \\
\text { tipo 2 (\%) }\end{array}$ & 16,6 & 0 & 19,83 & 4,07 & 0,22 & 0,42 & 6,26 \\
\hline $\begin{array}{l}\text { Telhado } \\
\text { tipo 1 (\%) }\end{array}$ & 17,15 & 0 & 5,06 & 0 & 0 & 0 & 7,25 \\
\hline Sombra (\%) & 8,22 & 0 & 0,02 & 0,32 & 54,82 & 34 & 4,55 \\
\hline $\begin{array}{l}\text { Solo exposto } \\
(\%)\end{array}$ & 2,51 & 0 & 11,85 & 0 & 0 & 0 & 0 \\
\hline $\begin{array}{l}\text { Piscina/águ } \\
\text { a (\%) }\end{array}$ & 6,1 & 0 & 0 & 3,13 & 0 & 0 & 21,27 \\
\hline Grama (\%) & 0,54 & 97,29 & 31,4 & 52,86 & 0 & 0 & 5 \\
\hline $\begin{array}{l}\text { Cimento } \\
(\%)\end{array}$ & 40,2 & 0 & 30,25 & 12,41 & 0 & 0 & 28,75 \\
\hline \begin{tabular}{l} 
Asfalto (\%) \\
\hline Árvore (\%)
\end{tabular} & 0,62 & 0 & 1,11 & 1,28 & 0 & 0 & 1,96 \\
\hline
\end{tabular}

Fonte: Elaborado pela autora.

Para a realização da modelagem no INLA foi preciso realizar alguns passos como a leitura do banco de dados, a criação da mesh, ou seja, a criação de um grid para as 4 áreas estudadas. A função inla.mesh.2d é a principal função para a construção de uma malha bidimensional. A definição da malha para um determinado problema é um compromisso entre a precisão de aproximação e o custo computacional. Quanto mais triângulos, maior a precisão 
da aproximação, mas também mais demorado o processo de realização do grid. A malha desejada teria pequenos triângulos onde os dados são mais densos, e teria maiores triângulos onde os dados são mais esparsos.

Os parâmetros para essa etapa foram os seguintes: o offset é o quanto será estendido na parte exterior e interior, assim quando o valor é positivo significa que a distância de extensão é a mesma unidade de escala até as coordenadas fornecidas, nesse caso o valor foi de 1000; já o cutoff é a distância mínima permitida entre os pontos, sendo muito útil nesse caso, pois os pontos são muito próximos, assim evitando a construção de muitos e pequenos triângulos em pontos próximos, então nesse estudo o valor foi de 30; e por último o max edge, sendo o comprimento máximo, na mesma escala que as coordenadas, tendo o valor de 1000. O resultado da mesh é apresentado na Figura 42.

Figura 42: Mesh da área de trabalho

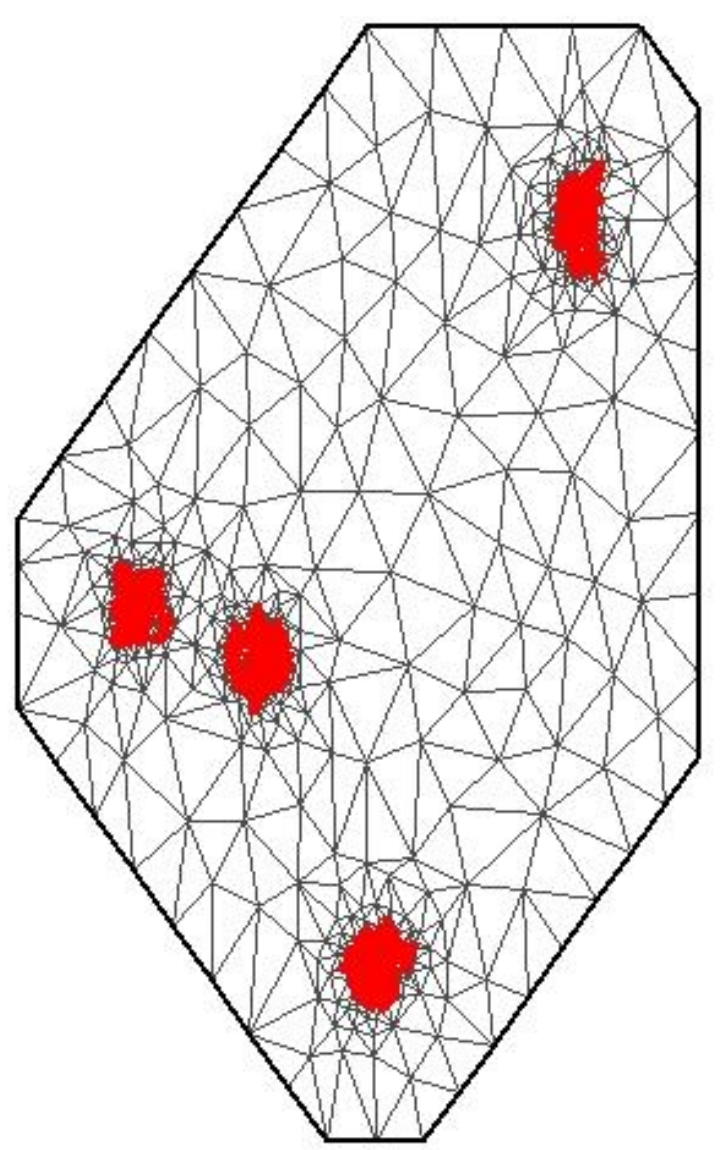

Fonte: Elaborado pela autora. 
Depois foi necessário executar uma análise exploratória dos dados como por exemplo a frequência dos parâmetros, sendo que a distribuição da mesma é importante quando existe uma grande quantidade de dados. A finalidade em agrupar os dados é facilitar a visualização e seus cálculos fornecendo qual é a frequência pela distância entre os pontos (imóveis), representados pelo Gráfico 6.

Gráfico 6: Frequência pela distância dos imóveis da área de estudo

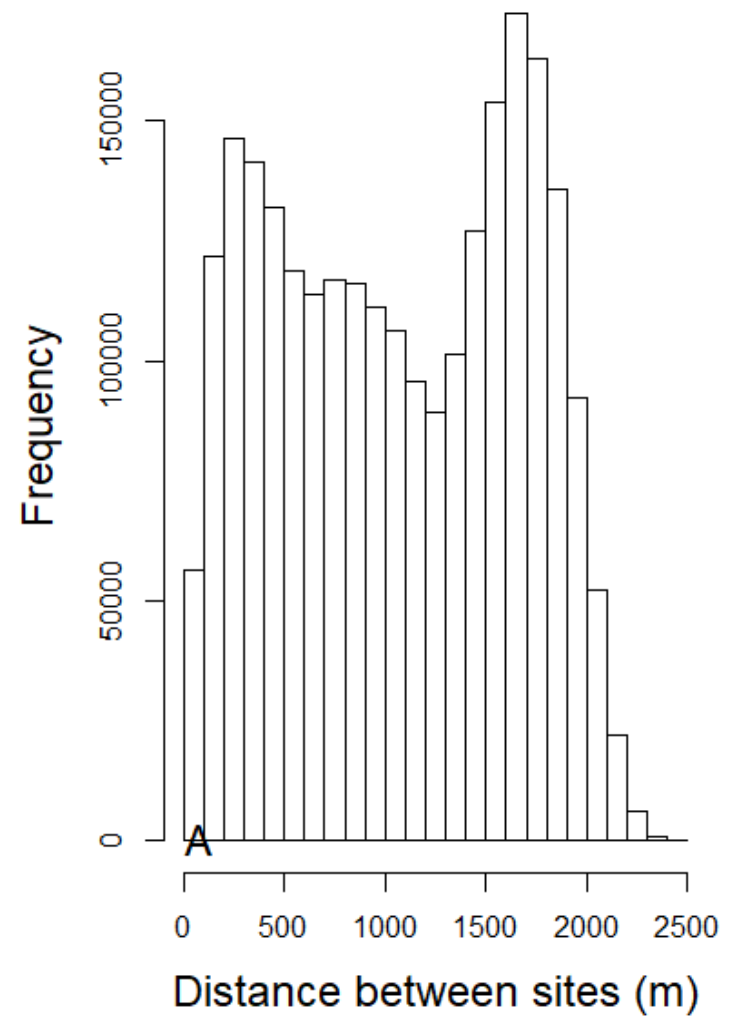

Fonte: Elaborado pela autora.

Outra análise exploratória dos dados é a colinearidade e a multicolinearidade. Este primeiro termo utilizado para expressar a existência de correlação elevada entre duas variáveis independentes, enquanto o último utilizado quando se trata de mais do que duas variáveis independentes fortemente correlacionadas. No entanto, existem autores que definem colinearidade como a existência de relação linear entre duas variáveis independentes e multicolinearidade como a existência de relação linear entre uma das variáveis independentes. 
Para a colinearidade ser diagnosticada é possível verificar se as matrizes de correlações das variáveis independentes mostram correlações elevadas.

A Figura 43 apresenta o resultado da análise de colinearidade, onde verifica-se que, para o buffer de 5 metros, a maior colinearidade é a classe Telhado Tipo 2 com a classe Telhado Tipo 1, informando um valor de -0,46. No buffer de 10 metros as mesmas classes do buffer anterior também foram as que apresentaram maior colinearidade $(-0,44)$ e por fim no buffer de 15 metros as classes Cimento e Árvore foram as que apresentaram maior valor correlação ($0,43)$.

Figura 43: Resultado da colinearidade dos buffers estudados.
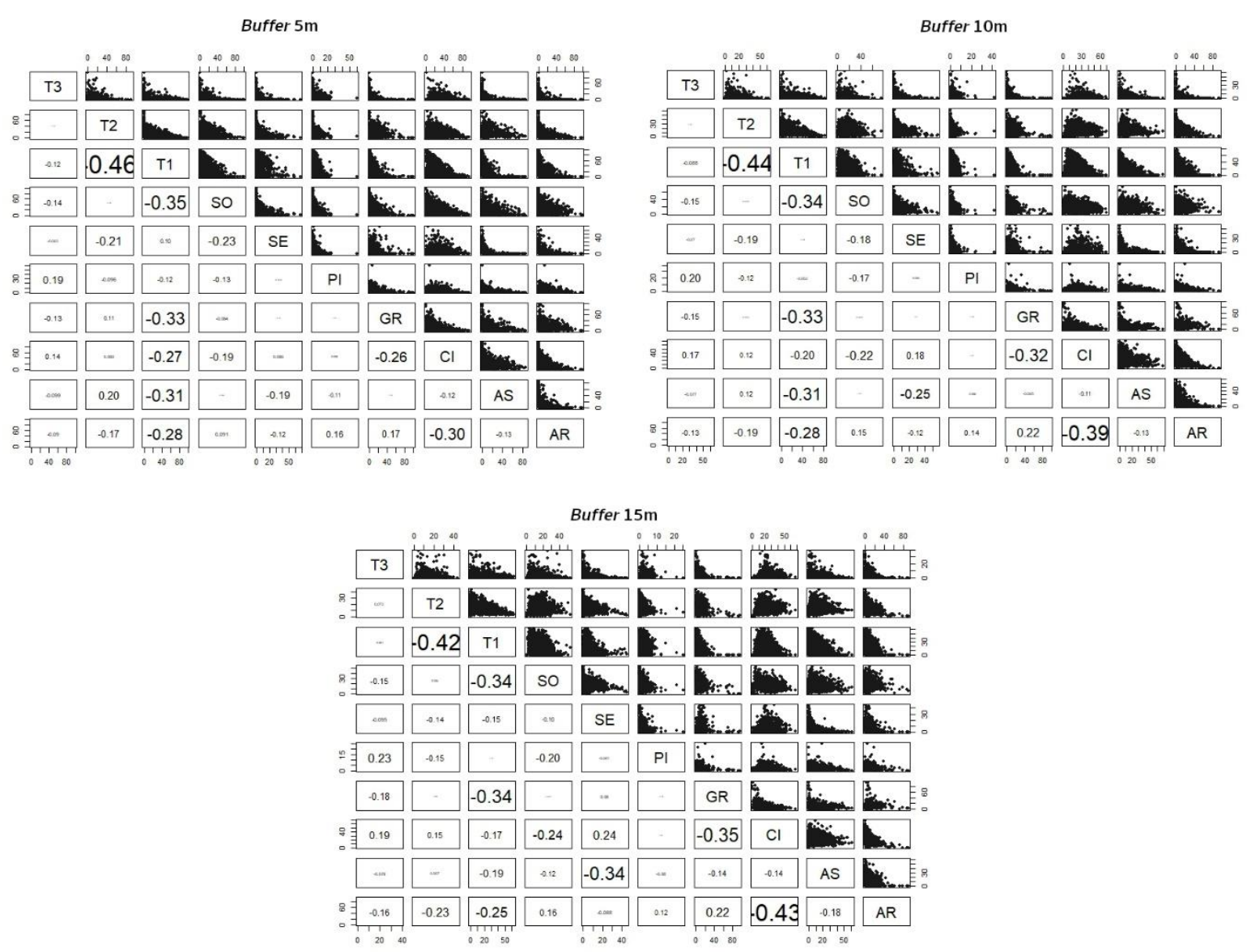

Fonte: Elaborado pela autora.

Como o resultado da colinearidade apresentou algumas classes com uma correlação elevada entre as duas, a próxima etapa foi a realização do cálculo variance inflation factors (VIF). Esse valor representa a razão da variância num modelo com vários termos, dividido pela 
variância de um modelo com um termo sozinho. Ele quantifica a gravidade da multicolinearidade em análise de regressão ordinária por mínimos quadrados, assim fornecendo um índice que mede o quanto a variância de um coeficiente de regressão estimado é aumentado por causa da colinearidade. O menor valor possível de VIF é 1 (ausência de multicolinearidade). Como regra geral, um valor VIF que exceda 5 ou 10 indica uma quantidade problemática de colinearidade (JAMES et al. 2014). No caso desse estudo o VIF apresentou um valor de 1,63.

Em seguida foi aplicado o modelo do INLA, considerando-se uma distribuição de probabilidade binomial, pois a variável dependente é 1 ou 0 , valores correspondentes, respectivamente às condições do imóvel ser positivo (encontro de larva e/ou pupas do mosquito) ou negativo. Os Quadros 1, 2 e 3 apresentam os resultados das modelagens utilizando-se a abordagem INLA.

Quadro 1: Resultado da metodologia INLA no buffer de 5 metros

\begin{tabular}{lrrrrrr} 
& Média & $\begin{array}{r}\text { Desvio } \\
\text { Padrão }\end{array}$ & $2,5 \%$ & Mediana & $95 \%$ & Moda \\
\hline Intercepto & -2.0824 & 0.269 & -2.6336 & -2.0768 & -1.5606 & -2.0648 \\
Área de alto risco & -0.0897 & 0.4094 & -0.8971 & -0.0924 & 0.7327 & -0.0977 \\
Área de baixo risco & -0.7068 & 0.3731 & -1.4793 & -0.699 & 0.0174 & -0.6863 \\
Área de médio risco & -0.1118 & 0.3621 & -0.8376 & -0.1122 & 0.6143 & -0.1139 \\
Árvore & 0.1237 & 0.0867 & -0.0507 & 0.1252 & 0.2899 & 0.1281 \\
Asfalto & 0.0469 & 0.0952 & -0.143 & 0.0479 & 0.2312 & 0.0499 \\
Cimento & 0.1099 & 0.1119 & -0.1115 & 0.1104 & 0.3279 & 0.1116 \\
Grama & 0.0295 & 0.0889 & -0.1556 & 0.0332 & 0.1938 & 0.0405 \\
Piscina/água & 0.1126 & 0.0682 & -0.0252 & 0.114 & 0.2429 & 0.1167 \\
Solo exposto & 0.0058 & 0.0936 & -0.182 & 0.0073 & 0.1855 & 0.0101 \\
Sombra & 0.0347 & 0.0929 & -0.1497 & 0.0354 & 0.2152 & 0.0368 \\
Telhado tipo 1 & 0.0676 & 0.0952 & -0.0431 & 0.0635 & 0.2449 & 0.0635 \\
Telhado tipo 2 & 0.0987 & 0.0858 & -0.0719 & 0.0994 & 0.2653 & 0.1007 \\
Telhado tipo 3 & -0.0323 & 0.0852 & -0.2104 & -0.0286 & 0.1246 & -0.021
\end{tabular}


Quadro 2: Resultado da metodologia INLA no buffer de 10 metros.

\begin{tabular}{lrrrrrr} 
& Média & $\begin{array}{r}\text { Desvio } \\
\text { Padrão }\end{array}$ & $2,5 \%$ & Mediana & $95 \%$ & Moda \\
\hline Intercepto & -2.3687 & 0.1817 & -2.7447 & -2.3669 & -2.0038 & -2.3648 \\
Área de alto risco & -0.2153 & 0.294 & -0.7904 & -0.2163 & 0.3643 & -0.2181 \\
Área de baixo risco & -0.7802 & 0.2677 & -1.3102 & -0.7789 & -0.2577 & -0.7763 \\
Área de médio risco & -0.2197 & 0.254 & -0.7163 & -0.2206 & 0.2817 & -0.2226 \\
Árvore & 0.0765 & 0.0849 & -0.125 & 0.0481 & 0.2084 & 0.0515 \\
Asfalto & -0.1213 & 0.0976 & -0.319 & -0.1191 & 0.0642 & -0.1148 \\
Cimento & -0.0009 & 0.096 & -0.1921 & 0 & 0.1851 & 0.0018 \\
Grama & -0.0051 & 0.0864 & -0.1845 & -0.0017 & 0.1549 & 0.0052 \\
Piscina/água & 0.0907 & 0.0522 & -0.1013 & 0.0543 & 0.1825 & 0.0615 \\
Solo exposto & 0.056 & 0.0825 & -0.1112 & 0.0579 & 0.2129 & 0.0615 \\
Sombra & 0.1081 & 0.0825 & -0.0552 & 0.1086 & 0.2687 & 0.1095 \\
Telhado tipo 1 & 0.1212 & 0.0875 & -0.0136 & 0.1593 & 0.3245 & 0.1575 \\
Telhado tipo 2 & 0.1499 & 0.0797 & -0.0084 & 0.1506 & 0.3045 & 0.1519 \\
Telhado tipo 3 & -0.0391 & 0.086 & -0.2209 & -0.0345 & 0.1174 & -0.0253 \\
& Fonte: Elaborado pela autora. & & &
\end{tabular}

Quadro 3: Resultado da metodologia INLA no buffer de 15 metros.

\begin{tabular}{lrrrrrr} 
& Média & $\begin{array}{l}\text { Desvio } \\
\text { Padrão }\end{array}$ & \multicolumn{1}{c}{$2,5 \%$} & Mediana & \multicolumn{1}{c}{$95 \%$} & \multicolumn{1}{c}{ Moda } \\
\hline Intercepto & -2.3038 & 0.1844 & -2.6854 & -2.301 & -1.9378 & -2.2955 \\
Área de alto risco & -0.0266 & 0.4009 & -0.8159 & -0.0294 & 0.7789 & -0.035 \\
Área de baixo risco & -0.733 & 0.3647 & -1.4867 & -0.7253 & -0.0254 & -0.7127 \\
Área de médio risco & -0.1395 & 0.3527 & -0.8459 & -0.1399 & 0.5669 & -0.1415 \\
Árvore & 0.1342 & 0.0847 & -0.0364 & 0.1358 & 0.2963 & 0.1388 \\
Asfalto & 0.0235 & 0.0948 & -0.1654 & 0.0244 & 0.207 & 0.0262 \\
Cimento & 0.1262 & 0.1048 & -0.0821 & 0.1271 & 0.3298 & 0.1288 \\
Grama & 0.0369 & 0.0875 & -0.1454 & 0.0406 & 0.1985 & 0.048 \\
Piscina/água & 0.1199 & 0.0677 & -0.0169 & 0.1213 & 0.2493 & 0.1239 \\
Solo exposto & 0.0159 & 0.0889 & -0.1634 & 0.0176 & 0.1858 & 0.021 \\
Sombra & 0.0507 & 0.0893 & -0.127 & 0.0515 & 0.2237 & 0.0531 \\
Telhado tipo 1 & 0.0985 & 0.0797 & -0.152 & 0.0854 & 0.2616 & 0.0852 \\
Telhado tipo 2 & 0.1038 & 0.0834 & -0.062 & 0.1044 & 0.2657 & 0.1058 \\
Telhado tipo 3 & -0.033 & 0.0846 & -0.2099 & -0.0293 & 0.1226 & -0.0217
\end{tabular}


Analisando os resultados do INLA é possível fazer algumas afirmações baseando-se na estatística clássica. A classe Piscina/água em todos os raios dos buffers apresentou um número significante, ou seja, a classe Piscina/água nessa metodologia é considerada um tipo de solo que apresenta risco para a proliferação do mosquito. As classes Árvore e Telhado Tipo 2 também chamam a atenção, mas ainda pelos resultados não pode-se afirmar como uma classe de risco em todas as áreas.

Nas análises onde os raios dos buffers foram maiores, ou seja, de 10 e 15 metros, outras classes também chamaram a atenção, sendo elas Sombra e Telhado Tipo 1 no buffer de 10 metros e telhado tipo 1 no buffer de 15 metros, sem deixar de mencionar a classe Cimento, que também se destaca. No estudo de Lorenz et al. (2020) a mesma metodologia foi aplicada, porém utilizando armadilhas para o mosquito adulto fêmea, e o resultado obtido foi a associação das classes Telhado de Telha e Telhado de Amianto com o número de fêmeas do mosquito em buffers de 30 metros (os raios dos buffers foram maiores pois se referem aos raios de voo médios do mosquito adulto Ae. aegypti). Esses resultados são semelhantes aos encontrados no presente estudo, uma vez que essas classes correspondem às classes Telhado Tipo 1 e Telhado Tipo 2, que também mostraram associação com o risco para a criação e proliferação do mosquito. 


\section{CONCLUSÃO}

Com o objetivo proposto de obter uma metodologia que permita a utilização de produtos e ferramentas de sensoriamento remoto orbital e VANT, para o reconhecimento de áreas de risco para criadouros, e a identificação de prováveis locais para a ocorrência dos agravos veiculados pelo mosquito Ae. aegypti no município de Campinas, o presente estudo chega à conclusão de que é possível a aplicação dessa metodologia para reconhecimento das áreas mais propicias à infestação pelo vetor e para a ocorrência de arboviroses. Seus resultados também mostram que essas ferramentas podem ser consideradas para o controle do mosquito.

Os objetivos específicos propostos também foram alcançados. Estimar, por meio da metodologia de krigagem, a distribuição espacial do indicador de quantidade de ovos do mosquito Ae. aegypti coletados nas armadilhas foi uma boa maneira de conseguir expandir a informação coletada do campo nas armadilhas em áreas que apresentam maior quantidade de ovos em uma determinada região.

Também foi viável identificar via imagens de sensoriamento remoto obtidas por satélites e por VANTs, padrões espaciais e espectrais nas imagens que melhor caracterizem as áreas com risco de criadouros do mosquito, com a definição das classes do uso do solo junto com as informações coletadas no campo e as análises espaciais algumas classes do uso do solo onde apresentam alto risco ou proteção.

A avaliação dos resultados da aplicação de técnicas de processamento de imagens para a indicação de áreas prioritárias apresentou bons resultados a correlação entre as classes e a quantidade de ovos, identificando as classes de risco e de proteção para quantidade de ovos coletados, sendo as classes que apresentam alto risco sendo: Cimento, Sombra e Asfalto e as classes que apresentam proteção: telhado tipo 1 (telha), telhado tipo 2 (amianto desgastado) e telhado tipo 3 (amianto novo). Este resultado indica, ao comparar a quantidade de ovos coletados por área e as classes predominantes, a possível tendência do mosquito depositar seus ovos em lugares escuros e frescos.

A identificação e correlação da temperatura de superfície da área de estudo com a quantidade de ovos do mosquito Ae. aegypti coletados nas armadilhas não apresentou correção com o número de ovos encontrados nas armadilhas. É importante salientar que as instalações das armadilhas foram feitas em áreas com alta densidade urbana e também em áreas pequenas 
para a resolução espacial das imagens termais utilizadas, sendo possível situarem-se dentro de uma área de ilhas de calor.

A Identificação das classes do uso e ocupação do solo que apresentam as áreas com risco ou proteção de criadouros do mosquito através da metodologia denominada INLA apresentou resultados de que quanto mais elevada for a percentagem de piscinas/água, telhados de amianto e de lajes utilizadas numa determinada área, tende-se ser maior o número de larvas de mosquitos encontrados. Fatores socioeconômicos podem estar relacionados com o resultado, pois piscina no Brasil é considerado um equipamento de lazer de luxo e o telhado de amianto é um tipo de construção mais barata geralmente utilizado em áreas com população mais pobre

Por fim, a Coligação os dados provenientes de levantamentos feitos pela Imagem de Satélite, VANT e análises espaciais para otimização das rotas de campo e priorização das visitas aos domicílios e ações pelos técnicos obteve um resultado que a aplicação em conjunto, de vários métodos e com diferentes dados, as ferramentas como sensoriamento remoto e SIG ajudam no controle do mosquito Ae. aegypti.

A Tese expõe contribuições acadêmicas como a novidade na aplicação no município de Campinas de diferentes métodos como Sensoriamento Remoto, VANT e INLA na área da Saúde Pública, Epidemiologia e Controle ao mosquito Ae. aegypti. E também contribuições práticas com o auxílio ao combate e ao controle das doenças que esse mosquito provoca, com otimização do tempo, do custo e a minimização do risco de contaminação das equipes de campo em órgãos governamentais.

Várias limitações da tese são dignas de nota, entre elas a ausência em considerar os dados ambientais no modelo, tais como a temperatura térmica das superfícies de cada material urbano. No entanto, estes resultados devem ser motivo de preocupação para os profissionais de saúde pública que procuram melhorar as medidas de controle nas zonas onde há maior ocorrência de sombras, quando se referindo o caso de depósito de ovos, e em áreas com piscina e cobertura de laje de amianto, quando se referindo o caso de larvas do mosquito, são preponderantes nas características da paisagem. Em estudos futuros sugerimos a inclusão de diferentes tipos de zonas e diferentes épocas do ano no modelo, podendo contribuir para uma melhor compreensão do habitat dos mosquitos em abundância. Entre os pontos fortes do nosso estudo, estão a utilização da modelagem estatística utilizando-se da abordagem INLA, o que permitiu o controle da correlação espacial entre os imóveis considerados no estudo e também a interpolação realizada pela krigagem dos dados coletados nas armadilhas. 
Seria interessante que futuros estudos, abordando as mesmas questões tratadas no presente trabalho, utilizassem áreas de estudo de maior magnitude do que a aqui considerada e que testassem modelos que utilizassem imagens livremente disponíveis. As imagens de média resolução podem também identificar padrões na paisagem urbana que sejam propícios para a identificação de habitats Ae. aegypti. Adicionalmente, podem ser úteis a utilização de outros métodos de classificação de imagem, como por exemplo, a classificação por objeto e também a utilização de outras ferramentas como, por exemplo, a inteligência artificial. 


\section{DISCUSSÃO}

$\mathrm{O}$ uso de sensoriamento remoto seria um modo rápido e de baixo custo para caracterização e identificação destes locais e para classificá-los segundo diferentes graus de risco. Alguns estudos utilizaram essa técnica para identificação de áreas de risco para ocorrência de doenças transmitidas por vetores ou ao menos apontaram esta possibilidade, como Moloney et al. (1998); Beck, Lobitz e Wood (2000); Zou, Miller e Schmidtmann (2006); Eisen e Lozano - Fuentes (2009); Little et al. (2011b); Ratmanov, Mediannikov e Raoult (2013) e MorenoMadriñán et al. (2014). Destacam-se os estudos desenvolvidos por Landau e Van Leeuwen (2012) e Lorenz et al. (2020) que, usando imagens de satélite, identificaram relação entre número de fêmeas adultas de Ae. aegypti e presença, respectivamente, de construções e de lajes e telhados de amianto.

O desenvolvimento, nos últimos anos, de técnicas de Inteligência Artificial (IA) e aprendizado de máquina baseadas em aprendizado profundo (Deep Learning), que tem revolucionado o reconhecimento de padrões em imagens e estabelecido o estado da arte em diversas aplicações inclusive em sensoriamento remoto (ZHU et al., 2017), pode ser um diferencial importante na otimização do uso de imagens aéreas na vigilância e controle de arboviroses. Muitos trabalhos têm aplicado aprendizado de máquina em sensoriamento para identificação da cobertura dos solos. São exemplos, as publicações de Gislason, Benediktsson e Sveinsson (2006), Kulkarni e Lowe (2016) e Mulik e Chakraborty (2017) utilizando Random Forest (RF) e Mountrakis, In e Ogole (2011), utilizando Support Vector Machine (SVM).

A maior parte da investigação até essa data tem-se concentrado em mosquitos silvícolas como o Anopheles e Culex (LACAUX et al., 2007; MUSHINZIMANA et al., 2006). No entanto, essa tese mostra a utilidade do sensoriamento remoto na identificação de área de risco para Ae. aegypti em cenários urbanos. A identificação das áreas de risco para o vetor são informações essenciais para facilitar e otimizar o controle do mosquito (TUN-LIN; KAY; BARNES, 1995). As conclusões do presente estudo alinham-se com as de Little et al., (2017) que destacam a enorme escala de heterogeneidades espaciais em habitats de mosquitos em ambientes urbanos.

Estimar a distribuição espacial do indicador de quantidade de ovos do mosquito Ae. aegypti coletados nas armadilhas através da krigagem apresentou ser uma ferramenta para transformar informações pontuais em áreas mais abrangentes. Apresentou, também, uma 
interpolação da localização das áreas que apresentam risco para criadouros, e a identificação de prováveis locais para a ocorrência dos agravos veiculados pelo vetor do mosquito Ae. aegypti no município.

O uso de imagens de sensores orbitais de alta resolução espacial e algoritmos de classificação de imagens, foi o procedimento principal utilizado em diversas etapas dessa tese. A identificação via imagens de sensoriamento remoto obtidas por satélites e por VANTs, de padrões espaciais e espectrais nas imagens que melhor caracterizem as áreas com risco de criadouros do mosquito.

As imagens de VANT, tanto em relação ao alcance da atuação no controle de Ae. aegypti e os agravos relacionados, também poderão ter a função de colaborar para o refinamento da classificação das imagens de satélite. Isso poderia ser feito, por exemplo, com a identificação inicial de áreas prioritárias para controle por satélite, seguida de uma inspeção local com a ajuda de VANT, objetivando-se o refinamento da priorização inicialmente realizada. Por meio do uso do VANT, foi possível destacar de uma melhor forma as 10 classes de uso e ocupação do solo, ajudando na coleta de amostras de treinamento e também sanando dúvidas de algumas regiões das áreas estudadas. Essa etapa apresentou algumas conclusões para esse estudo, sendo a primeira delas a utilização dos quatro algoritmos bem conhecidos e com ampla disposição em diversos softwares, inclusive softwares livres. Na questão dos algoritmos utilizados, três deles não apresentaram grandes diferenças entre si, e o quarto, algoritmo Paralelepípedo, demostrou um resultado inferior aos demais com o menor número de índice Kappa. $\mathrm{O}$ algoritmo que se destacou dentre os quatros testados foi o de Maximum Likelihood, um algoritmo amplamente utilizado para áreas urbanas, e também amplamente disponível em diversas plataformas.

Com os resultados gerados por meio da aplicação de técnicas de processamento de imagens e para a indicação de áreas prioritárias criada pela krigagem, foi possível correlacionálas gerando uma otimização das rotas de campo e uma priorização das visitas aos domicílios e ações pelos técnicos. Os resultados do estudo indicam que quanto mais elevada for a percentagem de cimento, sombra e asfalto e telhado tipo 2 (amianto) contidas numa determinada área, maior será o número de ovos de Ae. aegypti que serão encontrados. Os fatores que mais influenciam a ocorrência de habitats larvares são: (i) O comportamento da comunidade humana, que está relacionado com fatores tais como educação, rendimento, profissão e densidade populacional numa área, e (ii) o estado das habitações humanas, incluindo o saneamento básico do ambiente circundante. Zonas urbanas com problemas sanitários tendem a criar mais habitats larvares para Ae. aegypti (FERREIRA; CHIARAVALLOTI - NETO, 
2007b; LANDAU; VAN LEEUWEN, 2012; LORENZ, 2020; SOUZA-SANTOS; CARVALHO, 2000; TEIXEIRA; CRUZ, 2011).

A análise de Troyo (2008), utilizando imagens QuickBird, mostrou que as áreas residenciais moderadamente urbanizadas com cobertura arbórea moderada são áreas prováveis que contenham um número relativamente elevado de habitats positivos para os ovos e larvas de Ae. aegypti. Isto também é apoiado por estudos que indicam que grandes árvores que geram sombras reduzem a evaporação dos recipientes, proporcionando assim um benefício para a deposição de ovos e criação de larvas do mosquito (BARRERA; AMADOR; CLARK, 2006; VEZZANI; VELÁZQUEZ; SCHWEIGMANN, 2004).

As imagens termais disponíveis gratuitamente com o passar dos anos e com novas tecnologias estão oferecendo bons resultados para o cálculo da temperatura de superfície. Nesse estudo, o cálculo foi realizado em uma área altamente densa e urbana, com pouca vegetação e diversos tipos de materiais, assim não foi possível gerar um resultado com uma grande variação de temperatura. Também é importante ressaltar o tamanho das áreas de estudo, consideradas pequenas em comparação a área total do município de Campinas, sendo possível que as áreas do estudo podem se encontrar dentro de uma ilha de calor no munícipio de Campinas.

No entanto, a associação de coberturas de amianto com infestações por Ae. aegypti pode estar relacionada com a capacidade do amianto para reter calor no local específico (ou seja, as varandas ou garagens com este tipo de telhado tendem a ser mais quentes do que com os azulejos cerâmicos), otimizando a reprodução e ciclo de vida dos mosquitos. Os locais de reprodução não necessariamente se formam no próprio telhado do amianto, mas nos locais que são abrangidas por ela.

Cator et al. (2013) analisaram habitats de repouso urbanos dos mosquitos Anopheles e descobriram que as casas com telhados de amianto eram os habitats mais quentes, com uma temperatura média de $30-33^{\circ} \mathrm{C}$ ao longo do ano. De Azevedo et al. (2018) mostraram que mesmo quando as condições de temperatura afetam negativamente a ocorrência e o desenvolvimento das infestações por Ae. aegypti, as oscilações nos microclimas urbanos foram responsáveis pela alteração dos padrões habituais de dispersão de mosquitos e suas atividades. Temperaturas entre $20^{\circ} \mathrm{C}$ e $31^{\circ} \mathrm{C}$ podem aumentar a taxa metabólica dos mosquitos, encurtar o período de desenvolvimento larval, e otimizar o comportamento e a postura de ovos, levando a um aumento da abundância de mosquitos quando os habitats larvares se tornam disponíveis(ARAÚJO et al., 2015; MISSLIN et al., 2016; MURDOCK et al., 2017). 
As piscinas e os telhados de laje plana podem reter a água da chuva e contribuir para a geração de locais de reprodução temporária de mosquitos. Em relação à sua capacidade de reter água da chuva, Abe et al. (2005) informaram que Ae. aegypti obteve uma produtividade mais alta em recipientes com uma capacidade de 1 a 5 litros. Assim, as coberturas de laje planas podem proporcionar um importante local de reprodução temporária de mosquitos.

O modelo estatístico selecionado INLA foi aplicado com o objetivo de identificar as classes de risco e de proteção de acordo com a positividade da casa, ou seja, se em uma casa positiva (coleta positiva de larvas e/ou pupa no imóvel) pode-se ou não identificar a associação de alguma classe predominante de cobertura do solo que indique risco para a proliferação do mosquito. Do mesmo modo esse tipo de cobertura do solo pode estar relacionado a uma maior probabilidade de as pessoas adoecerem por dengue ou outra arbovirose naquela região ou mesmo no imóvel, sendo possível indicar áreas prioritárias para a adoção de medidas de controle.

Quanto mais elevada for a percentagem de piscinas/água, telhados de amianto e de lajes utilizadas numa determinada área, tende-se ser maior o número de larvas de mosquitos encontrados. Isto pode estar relacionado com vários outros fatores, por exemplo, os fatores socioeconômicos e ambientais. A piscina no Brasil é considerada um equipamento de lazer de luxo, onde requer uma área grande e demanda maior manutenção, enquanto o telhado de amianto é um tipo de construção mais barata, geralmente utilizado em zonas pobres com infraestruturas precárias (BERMAN, 1986). As áreas mais positivas são as áreas socioeconomicamente pobres e com uma maior incidência de dengue ou um número superior de infestações por mosquitos, reforçando os resultados de vários outros estudos (FERREIRA; CHIARAVALLOTI - NETO, 2007a; OLIVEIRA; VALLA, 2001).

A tese conclui que as características físicas da paisagem podem influenciar a distribuição de ovos e larvas dos mosquitos. No entanto, vale mencionar que a associação entre a existência do agrupamento do mosquito e a ocorrência de casos de dengue é uma questão que necessita mais investigação. Outro estudo realizado por Morrison et al. (1998) sugeriu que as medidas de controle devem ser adotados uniformemente em toda a zona afetada por transmissão do mosquito para ser eficiente, pois foram identificados clusters de casos de dengue em distâncias muito curtas, muito provavelmente nas mesmas casas.

Esta tese mostrou a utilidade do sensoriamento remoto para identificar as diferenças paisagísticas numa abordagem de ambiente urbano. É uma abordagem de alta resolução, de detecção remota e de avaliação de habitats de ovos e larvas dos mosquitos, que, se combinada 
com atividades de monitorização e, se devidamente coordenadas por entomologistas, poderiam melhorar a compreensão dos fatores envolvidos na infestação urbana de Ae. aegypti e disseminação dos arboviroses. No entanto, esta aplicação é certamente mais complicada do que outras, dada a complexidade epidemiológica e o envolvimento de agentes patogênicos e vectores num ambiente urbano.

Deduzir associações específicas para áreas biologicamente diferentes é não é uma tarefa fácil. Métodos complementares em diferentes escalas e resoluções poderiam enfrentar este problema, mas as utilizações legítimas dos dados de detecção continuam a depender da qualidade da informação recebida do campo (DE LA ROCQUE et al., 2004). Além disso, uma análise mais aprofundada utilizando outras variáveis, como a temperatura da superfície terrestre e a precipitação, podem apresentar relações mais complexas entre os habitats dos mosquitos urbanos e características da paisagem.

Essa tese fornece resultados descritivos promissores e propõe perspectivas que necessitam testes durante períodos mais longos utilizando imagens de satélite e dados em áreas maiores. As características físicas de uma paisagem podem influenciar a distribuição dos ovos e das larvas dos mosquitos Ae. aegypti. Verificou-se que o vetor está positivamente associado à presença de sombra, piscina/água e telhados. Isto pode estar relacionado com várias outras características da paisagem. Piscinas, corpos d'água e cobertura de laje tendem reter a água da chuva e aumentar o número de locais de reprodução temporária de mosquitos. Mostrou-se também a utilidade de uma abordagem de sensoriamento remoto de alta resolução em identificação de diferenças paisagísticas em um ambiente urbano. Acredita-se que a aplicação desta metodologia possibilitará aos gestores definir melhor as estratégias de ação, economizando recursos e tempo, pois atualmente o programa prevê visitas rotineiras e muitas vezes não são realizadas adequadamente; ou seja, definir diferentes estratégias, como periodicidade, formas de manejo ou eliminação de criadouros para diferentes áreas de risco.

Desenvolver e testar metodologias que fazem uso de imagens de sensores orbitais de alta resolução espacial e algoritmos de classificação de imagens que, associadas às informações do entorno, permitam a identificação de áreas de potenciais criadouros do mosquito serão de grande importância para o programa, que poderá economizar tempo e recurso, intensificando ações em áreas com maior potencial de presença de criadouros do mosquito Ae. aegypti. 


\section{REFERÊNCIAS BIBLIOGRÁFICAS}

ABE, M.; MCCALL, P. J.; LENHART, A.; VILLEGAS, E.; KROEGER, A. The Buen Pastor cemetery in Trujillo, Venezuela: Measuring dengue vector output from a public area. Tropical Medicine and International Health, v. 6, n. 10, p. 597-603, 2005. DOI: https://doi.org/10.1111/j.1365-3156.2005.01428.x.

ACHEE, N. L.; GOULD, F.; PERKINS, T. A.; REINER, R. C.; MORRISON, A. C.; RITCHIE, S. A.; GUBLER, D. J.; TEYSSOU, R.; SCOTT, T. W. A Critical Assessment of Vector Control for Dengue Prevention. PLoS Neglected Tropical Diseases, v. 9, n. 5, p. 1-19, 2015. DOI: https://doi.org/10.1371/journal.pntd.0003655.

ADENIYI, P. O. Digital analysis of multitemporal Landsat data for land-use/land- cover classification in a semi-arid area of Nigeria. Photogrammetric Engineering \& Remote Sensing, v. 51, n. 11, p. 1761-1774, 1985.

ADILSON STEINKE, V.; TORRES STEINKE, E.; HIROO SAITO, C. Estimativa da Temperatura de Superfície em Áreas Urbanas em Processo de Consolidação: Reflexões e Experimento em Planaltina-DF. Revista Brasileira de Climatologia, v. 6, 2010. DOI: https://doi.org/10.5380/abclima.v6i0.25604.

ADIN, A.; MARTÍNEZ-BELLO, D. A.; LÓPEZ-QUÍlEZ, A.; UGARTE, M. D. Two-level resolution of relative risk of dengue disease in a hyperendemic city of Colombia. PLoS ONE, v. 13, n. 9, 2018. DOI: https://doi.org/10.1371/journal.pone.0203382.

AGISOFT. Agisoft PhotoScan User Manual: Professional Edition. Copyright $@ 2018$ Agisoft LLC, 2018. DOI: https://doi.org/10.1016/j.bjps.2011.05.024.

ALBERTI, M.; WEEKS, R.; COE, S. Urban land-cover change analysis in Central Puget Sound. Photogrammetric Engineering and Remote Sensing, v. 70, n. 9, p. 1043-1052, 2004. DOI: https://doi.org/10.14358/PERS.70.9.1043.

ALBRIEU-LLINÁS, G.; ESPINOSA, M. O.; QUAGLIA, A.; ABRIL, M.; SCAVUZZO, C. M. Urban environmental clustering to assess the spatial dynamics of Aedes aegypti breeding sites. Geospatial Health, v. 13, n. 1, p. 135-142, 2018. DOI: https://doi.org/10.4081/gh.2018.654.

ALDSTADT, J.; KOENRAADT, C. J. M.; FANSIRI, T.; KIJCHALAO, U.; RICHARDSON, J.; JONES, J. W.; SCOTT, T. W. Ecological modeling of Aedes aegypti (1.) pupal production in Rural Kamphaeng phet, Thailand. PLoS Neglected Tropical Diseases, v. 5, n. 1, 2011. DOI: https://doi.org/10.1371/journal.pntd.0000940.

ALHAWITI, R. H.; MITSOVA, D. Using Landsat-8 Data To Explorethe Correlation Between Urban Heat Island And Urban Land Uses. International Journal of Research in Engineering and Technology, v. 5, n. 3, p. 457-466, 2016. DOI: https://doi.org/10.15623/ijret.2016.0503083.

AMARAL, M. V. F.; DE SOUZA, A. L.; SOARES, V. P.; SOARES, C. P. B.; LEITE, H. G.; MARTINS, S. V.; FILHO, E. I. F.; DE LANA, J. M. Avaliação e compação de métodos de classificação de imagens de satélites para o mapeamento de estádios de sucessão florestal. Revista Árvore, v. 33, n. 3, p. 575-582, 2009. DOI: https://doi.org/10.1590/s0100$\underline{67622009000300019 .}$. 
AMARASINGHE, A.; SUDUWELLA, C.; NIROSHAN, L.; ELVITIGALA, C.; DE ZOYSA, K.; KEPPETIYAGAMA, C. Suppressing dengue via a drone system. In: 17TH INTERNATIONAL CONFERENCE ON ADVANCES IN ICT FOR EMERGING REGIONS, ICTER 2017 - PROCEEDINGS 2017, Anais [...]. [s.l: s.n.] p. 202-208. DOI: https://doi.org/10.1109/ICTER.2017.8257797.

AMORIM, M. C. C. T.; DUBREUIL, V.; QUENOL H.; NETO J. L.S. Características das ilhas de calor em cidades de porte médio: exemplos de Presidente Prudente (Brasil) e Rennes (França). Confins [Online], n. 7, 2019. Disponível em: http://confins.revues.org/index6070.html. Acessado em: 30 de setembro de 2019.

AMORIM, M. C. C. T. Detecção remota de ilhas de calor superficiais: Exemplos de cidades de porte médio e pequeno do ambiente tropical, Brasil. Finisterra, v. 52, n. 105, p. 111-133, 2017. DOI: https://doi.org/10.18055/finis6888.

AMORIM, M. C. de C. T.; DUBREUIL, V.; CARDOSO, R. S. Modelagem Espacial da Ilha de Calor Urbana em Presidente Prudente (SP) - Brasil. Revista Brasileira de Climatologia, v. 16, n. 16, p. 29-45, 2015. DOI: https://doi.org/10.5380/abclima.v16i0.40585.

ARAÚJO, R. V. et al. São Paulo urban heat islands have a higher incidence of dengue than other urban areas. Brazilian Journal of Infectious Diseases, v. 19, n. 2, p. 146-155, 2015. DOI: https://doi.org/10.1016/j.bjid.2014.10.004.

ASNER, G. P.; KNAPP, D. E.; BOARDMAN, J.; GREEN, R. O.; KENNEDY-BOWDOIN, T.; EASTWOOD, M.; MARTIN, R. E.; ANDERSON, C.; FIELD, C. B. Carnegie Airborne Observatory-2: Increasing science data dimensionality via high-fidelity multi-sensor fusion. Remote Sensing of Environment, v. 124, p. 454-465, 2012. DOI: https://doi.org/10.1016/j.rse.2012.06.012.

BAKKA, H.; RUE, Hå.; FUGLSTAD, G. A.; RIEBLER, A.; BOLIN, D.; ILLIAN, J.; KRAINSKI, E.; SIMPSON, D.; LINDGREN, F. Spatial modeling with R-INLA: A review. WIREs Computational Statistics, 2018. DOI: https://doi.org/10.1002/wics.1443.

BARBOSA, G. L.; HOLCMAN, M. M.; PEREIRA, M.; GOMES, A. H. A.; WANDERLEY, D. M. V. Indicadores de infestação larvária e influência do porte populacional na transmissão de dengue no estado de São Paulo, Brasil: um estudo ecológico no período de 2007-2008. Epidemiologia e Serviços de Saúde, v. 21, n. 2, p. 195-204, 2012. DOI: https://doi.org/10.5123/s1679-49742012000200002.

BARBOSA, G. L.; LAGE, M. O.; ANDRADE, V. R.; GOMES, A. H. A.; QUINTANILHA, J. A.; CHIARAVALLOTI-NETO, F. Influence of strategic points in the dispersion of Aedes aegypti in infested areas TT - Influência de pontos estratégicos na dispersão de Aedes aegypti em áreas infestadas. Revista de Saúde Pública, v. 53, 2019. DOI: https://doi.org/10.11606/s1518-8787.2019053000702.

BARBOSA, G. L.; LOURENÇO, R. W. Análise da distribuição espaço-temporal de dengue e da infestação larvária no município de tupã, Estado de São Paulo. Revista da Sociedade Brasileira de Medicina Tropical, v. 43, n. 2, p. 145-151, 2010. DOI: https://doi.org/10.1590/s0037-86822010000200008.

BARBOSA, R. V. R.; VECCHIA, F. Estudos de ilha de calor urbana por meio de imagens do Landsat 7 ETM + : estudo de caso em São Carlos (SP). Minerva, v. 6, n. 3, p. 273-278, 1996. 
BARCELLOS, C.; BASTOS, F. I. Geoprocessamento, ambiente e saúde: uma união possível? Cadernos de Saúde Pública, v. 12, n. 3, p. 389-397, 1996. DOI: https://doi.org/10.1590/s0102-311x1996000300012.

BARCELlOS, C.; MONTEIRO, A. M. V.; CORVALÁN, C.; GURGEL, H. C.; CARVALHO, M. S.; ARTAXO, P.; HACON, S.; RAGONI, V. Mudanças climáticas e ambientais e as doenças infecciosas: cenários e incertezas para o Brasil. Epidemiologia e Serviços de Saúde, v. 18, n. 3, p. 285-304, 2009. DOI: https://doi.org/10.5123/s1679-49742009000300011.

BARRERA, R.; AMADOR, M.; CLARK, G. G. Ecological Factors Influencing Aedes aegypti (Diptera: Culicidae) Productivity in Artificial Containers in Salinas, Puerto Rico. Journal of Medical Entomology, v. 43, n. 3, p. 484-492, 2006. DOI: https://doi.org/10.1603/00222585(2006)43[484:efiaad]2.0.co;2.

BECK, L. R.; LOBITZ, B. M.; WOOD, B. L. Remote sensing and human health: New sensors and new opportunities. Emerging Infectious Diseases, v. 6, n. 3, p. 217-227, 2000. DOI: https://doi.org/10.3201/eid0603.000301.

BERK, A.; BERNSTEIN, L. S.; ROBERTSON, D. C. MODTRAN: A Moderate Resolution Model for LOWTRAN 7. Massachusetts, USA.

BERMAN, D. M. Asbestos and health in the third world: The case of Brazil. International Journal of Health Services, v. 16, n. 2, p. 253-263, 1986. DOI: 10.2190/3TGT-UTUFHNWR-GCPK.

BERNARDI, H.; DZEDZEJ, M.; CARVALHO, L.; ACERBI JÚNIOR, F. Classificação digital do uso do solo comparando os métodos "pixel a pixel" e orientada ao objeto em imagem QuickBird. In: SIMPÓSIO BRASILEIRO DE SENSORIAMENTO REMOTO 2007, Anais [...]. [s.1: s.n.] p. 5595-5602.

BETT, B. et al. Spatiotemporal analysis of historical records (2001-2012) on dengue fever in Vietnam and development of a statistical model for forecasting risk. PLoS ONE, v. 14, n. 11, 2019. DOI: https://doi.org/10.1371/journal.pone.0224353.

BIVAND, R. S.; GÓMEZ-RUBIO, Vi.; RUE, H. Spatial data analysis with R-INLA with some extensions. Journal of Statistical Software, v. 63, n. 20, p. 1-31, 2015. DOI: https://doi.org/10.18637/jss.v063.i20.

BLANGIARDO, M., CAMELETTI, M. Spatial and Spatio-temporal Bayesian Models with INLA. Chichester.

BLASCHKE, T. Object based image analysis for remote sensing. ISPRS Journal of Photogrammetry and Remote Sensing, v. 65, n. 1, p. 2-16, 2010. DOI: https://doi.org/10.1016/j.isprsjprs.2009.06.004.

BRADY, Ol. J.; SMITH, D. L.; SCOTT, T. W.; HAY, S. I. Dengue disease outbreak definitions are implicitly variable. Epidemics, v. 11, p. 92-102, 2015. DOI: https://doi.org/10.1016/j.epidem.2015.03.002.

BRASIL. Decreto Federal n. ${ }^{\circ}$ 89.817, de 20 de junho de 1984. Diário Oficial da União, 1984.

BRASIL. Monitoramento dos casos de dengue, febre de chikungunya e febre pelo vírus Zika até a Semana Epidemiológica. Boletim Epidemiológico, v. 47, n. 28, p. 1-10, 2016. 
BRITO, P. L.; ARENAS, H.; LAM, N.; QUINTANILHA, J. A. Recognition of urban patterns related to leptospirosis contamination risks using object based classification of aerial photography. Test areas: Informal settlements of the railroad suburb of salvador, Brazil. International Geoscience and Remote Sensing Symposium (IGARSS), 2008. DOI: https://doi.org/10.1109/IGARSS.2008.4778846.

CALlEJAS, I. J. A.; DURANTE, L. Cl.; OlIVEIRA, A. S. De; NOGUEIRA, M. C. d. J. A. Uso do solo e temperatura superficial em área urbana. Mercator, v. 10, n. 23, p. 207-223, 2011. DOI: https://doi.org/10.4215/rm2011.1023.0015.

CÂMARA, F. P.; LÚCIA, R.; THEOPHILO, G.; TEIXEIRA, G.; REGINA, S.; GONÇALVES, F.; CÂMARA, D. C. P.; MATOS, R. C. De. Estudo retrospectivo ( histórico ) da dengue no Brasil : características regionais e dinâmicas Regional and dynamics characteristics of dengue in Brazil : a retrospective study. Revista da Sociedade Brasileira de Medicina Tropical, v. 40, n. 2, p. 192-196, 2007. DOI: https://doi.org/10.1590/s0037-86822007000200009.

CAMPBELL, J. B.; WYNNE., R. H. Introduction to Remote Sensing. New York. DOI: https://doi.org/10.1007/s13398-014-0173-7.2.

CAMPBELL, James. Remote sensing : Digital Data. p. 1-7, 2009.

CARRINGTON, L. B.; ARMIJOS, M. V.; LAMBRECHTS, L.; SCOTT, T. W. Fluctuations at a Low Mean Temperature Accelerate Dengue Virus Transmission by Aedes aegypti. PLoS Neglected Tropical Diseases, $\quad$ v. 7, n. 4, 2013. DOI: https://doi.org/10.1371/journal.pntd.0002190.

CARROLL, R.; LAWSON, A. B.; FAES, C.; KIRBY, R. S.; AREGAY, M.; WATJOU, K. Comparing INLA and OpenBUGS for hierarchical Poisson modeling in disease mapping. Spatial and Spatio-temporal Epidemiology, v. 14, n. 15, p. 45-54, 2015. DOI: https://doi.org/10.1016/j.sste.2015.08.001.

CARVALHO JÚNIOR, O.; COUTO JÚNIOR, A.; SILVA, N.; MARTINS, E.; CARVALHO, A.; GOMES, R. Avaliação dos classificadores espectrais de mínima distância euclidiana e spectral correlation mapper em séries temporais NDVI-MODIS no campo de instrução militar de formosa (GO). Revista Brasileira Cartografia, v. 61, n. 4, 2009.

CARVALHO, M. S.; SOUZA-SANTOS, R. Analysis of spatial data in public health: methods, problems, and perspectivesCadernos de saúde pública / Ministério da Saúde, Fundação Oswaldo Cruz, Escola Nacional de Saúde Pública, 2005.

CASTLEMAN, R. K. Digital image processing. New Jersey.

CATOR, L. J.; THOMAS, S.; PAAIJMANS, K. P.; RAVISHANKARAN, S.; JUSTIN, J. A.; MATHAI, M. T.; READ, A. F.; THOMAS, M. B.; EAPEN, A. Characterizing microclimate in urban malaria transmission settings: a case study from Chennai, India. Malaria journal, v. 12, n. 84, 2013. DOI: https://doi.org/10.1186/1475-2875-12-84.

CHADEE, D. D. Key premises, a guide to Aedes aegypti (Diptera: Culicidae) surveillance and control. Bulletin of Entomological Research, v. 201, n. 7, p. 201-207, 2004. DOI: https://doi.org/10.1079/ber2004297.

CHEN, X. L.; ZHAO, H. M.; LI, P. X.; YIN, Z. Y. Remote sensing image-based analysis of the relationship between urban heat island and land use/cover changes. Remote Sensing of Environment, v. 104, n. 2, p. 133-146, 2006. DOI: https://doi.org/10.1016/j.rse.2005.11.016. 
CHEN, Yi; NASRABADI, N. M.; TRAN, T. D. Hyperspectral image classification using dictionary-based sparse representation. IEEE Transactions on Geoscience and Remote Sensing, $\quad$ v. 49 , n. (10 PART 2), p. 3973-3985, 2011. DOI: https://doi.org/10.1109/TGRS.2011.2129595.

CHIARAVALLOTI-NETO, F. et al. Seroprevalence for dengue virus in a hyperendemic area and associated socioeconomic and demographic factors using a cross-sectional design and a geostatistical approach, state of São Paulo, Brazil. BMC Infectious Diseases, v. 19, n. 1, p. 441, 2019. DOI: https://doi.org/10.1186/s12879-019-4074-4.

CHIARAVALLOTI-NETO, F.; PEREIRA, M.; FÁVARO, E. A.; DIBO, M. R.; MONDINI, A.; RODRIGUES-JUNIOR, A. L.; CHIEROTTI, A. P.; NOGUEIRA, M. L. Assessment of the relationship between entomologic indicators of Aedes aegypti and the epidemic occurrence of dengue virus 3 in a susceptible population, São José do Rio Preto, São Paulo, Brazil. Acta Tropica, v. 142, p. 167-177, 2015. DOI: https://doi.org/10.1016/j.actatropica.2014.11.017.

CHIARAVALlOTI-NETO, F. O geoprocessamento e saúde pública. Arquivos de Ciências da Saúde, v. 23, n. 4, p. 1-2, 2016. DOI: https://doi.org/10.17696/2318-3691.23.4.2016.661.

CHIARAVALLOTI - NETO, F. Descrição da colonização de Aedes aegypti na região de São José do Rio Preto, São Paulo. Revista da Sociedade Brasileira de Medicina Tropical, v. 30, n. 4, p. 279-285, 1997. DOI: https://doi.org/10.1590/s0037-86821997000400002.

CLARO, L. B. L.; TOMASSINI, H. C. B.; ROSA, M. L. G. Prevenção e controle do dengue: uma revisão de estudos sobre conhecimentos, crenças e práticas da população. Cadernos de Saúde Pública, v. 20, n. 6, p. 1447-1457, 2004. DOI: https://doi.org/10.1590/s0102$\underline{311 \times 2004000600002 .}$.

COELHO, A. L. N. Sistema de informações geográficas (SIG) como suporte na elaboração de planos diretores municipais. CAMINHOS DE GEOGRAFIA, v. 10, n. 30, p. 93-110, 2009.

COLE, D. G. Remote Sensing for GIS Managers. Cartographic Perspectives, v. 56, p. 5456, 2007. DOI: https://doi.org/10.14714/cp56.308.

COLOMB, F. R.; ALONSO, C.; HOFMANN, C.; NOLLMANN, I. SAC-C mission, an example of international cooperation. Advances in Space Research, v. 34, n. 10, p. 21942199, 2004. DOI: https://doi.org/10.1016/j.asr.2003.10.039.

COLOMINA, I.; MOLINA, P. Unmanned aerial systems for photogrammetry and remote sensing: A review. ISPRS Journal of Photogrammetry and Remote Sensing, v. 92, p. 79 97, 2014. DOI: https://doi.org/10.1016/j.isprsjprs.2014.02.013.

COMUNICAÇÃO/INSTITUTO OSWALDO CRUZ; MENEZEZ, M. Estudo compara métodos para medir infestação por Aedes aegypti. Instituto Fiocruz, 2014. Disponível em: http://www.fiocruz.br/ioc/cgi/cgilua.exe/sys/start.htm?infoid=2135\&sid=32. Acesso em: $30 \mathrm{de}$ setembro de 2020.

CORREIA, V. R. De M.; MONTEIRO, A. M. V.; CARVALHO, M. S.; WERNECK, G. L. Uma aplicação do sensoriamento remoto para a investigação de endemias urbanas. Cadernos de Saude Publica, v. 23, n. 5, p. 1015-1028, 2007. DOI: https://doi.org/10.1590/s0102$\underline{311 \times 2007000500004 .}$ 
CORREIA, V. R. M.; CARVALHO, M. S.; SABROZA, P. Ch.; VASCONCELOS, C. H. Remote sensing as a tool to survey endemic diseases in Brazil. Cadernos de saúde pública / Ministério da Saúde, Fundação Oswaldo Cruz, Escola Nacional de Saúde Pública, v. 20, n. 4, p. 891-904, 2004. DOI: https://doi.org/10.1590/S0102-311X2004000400003.

COSTA, A. C. C.; CODEÇO, C. T.; HONÓRIO, N. A.; PEREIRA, G. R.; PINHEIRO, C. F. N.; NOBRE, A. A. Surveillance of dengue vectors using spatio-temporal Bayesian modeling. BMC Medical Informatics and Decision Making, v. 15, n. 1, p. 1-12, 2015. DOI: https://doi.org/10.1186/s12911-015-0219-6.

COSTA, F. S.; DA SILVA, J. J.; DE SOUZA, C. M.; MENDES, J. Dinâmica populacional de Aedes aegypti em área urbana de alta incidência de dengue. Revista da Sociedade Brasileira de Medicina Tropical, v. 41, n. 3, p. 309-312, 2008. DOI: https://doi.org/10.1590/S0037$\underline{86822008000300018 .}$.

COSTA, J. V.; DONALISIO, M. R.; SILVEIRA, L. V. de A. Spatial distribution of dengue incidence and socio-environmental conditions in Campinas, São Paulo State, Brazil, 2007. Cadernos de Saude Publica, v. 29, n. 8, p. 1522-1532, 2013. DOI: https://doi.org/10.1590/S0102-311X2013001200005.

CRÓSTA, A. P. Processamento digital de imagens de sensoriamento. Campinas, SP: IG/UNICAMP, 1992.

DE ALMEIDA, A. S.; WERNECK, G. L.; RESENDES, A. P. da C. Object-oriented remote sensing image classification in epidemiological studies of visceral leishmaniasis in urban areas. Cadernos de saude publica, v. 30, n. 8, p. 1639-1653, 2014. DOI: https://doi.org/10.1590/0102-311X00059414.

DE ALMEIDA BIOLCHINI, J. C.; MIAN, P. G.; NATAli, A. C. C.; CONTE, T. U.; TRAVASSOS, G. H. Scientific research ontology to support systematic review in software engineering. Advanced Engineering Informatics, v. 21, n. 2, p. 133-151, 2007. DOI: https://doi.org/10.1016/j.aei.2006.11.006.

DE AZEVEDO, T. S.; BOURKE, B. P.; PIOVEZAN, R.; SALLUM, M. A. M. The influence of urban heat Islands and socioeconomic factors on the spatial distribution of Aedes aegypti larval habitats. Geospatial Health, v. 13, n. 1, p. 179-187, 2018. DOI: https://doi.org/10.4081/gh.2018.623.

DE LA ROCQUE, S.; MICHEL, V.; PLAZANET, D.; PIN, R. Remote sensing and epidemiology: Examples of applications for two vector-borne diseases. Comparative Immunology, Microbiology and Infectious Diseases, v. 27, n. 5, p. 331-341, 2004. DOI: https://doi.org/10.1016/j.cimid.2004.03.003.

DE OLIVEIRA, A. K. M.; FERNANDES, V.; DOS ANJOS GARNÉS, S. J.; DOS SANTOS, C. R. B. Avaliação da perda da vegetação arbórea nativa na Serra da Bodoquena, Mato Grosso doSsul, por meio de sensoriamento remoto. RA'E GA - O Espaco Geografico em Analise, n. 17, p. 43-52, 2009. DOI: https://doi.org/10.5380/raega.v17i0.12657.

DE SOUSA, S. B.; JÚNIOR, L. G. F. Relation between land surface temperature, spectral indices and land cover classes in the city of Goiânia (GO). RA'E GA - O Espaco Geografico em Analise, v. 22, p. 75-99, 2012. 
DE TOLEDO, A. L. A.; ESCOSTEGUY, C. C.; DE ANDRADE MEDRONHO, R.; DE ANDRADE, F. C. Confiabilidade do diagnóstico final de dengue na epidemia 2001-2002 no Município do Rio de Janeiro, Brasil. Cadernos de Saúde Publica, v. 22, n. 5, p. 933-940, 2006. DOI: https://doi.org/10.1590/s0102-311x2006000500006.

DENG, C.; WU, C. Examining the impacts of urban biophysical compositions on surface urban heat island: A spectral unmixing and thermal mixing approach. Remote Sensing of Environment, v. 131, n. 15, p. 262-274, 2013. DOI: https://doi.org/10.1016/j.rse.2012.12.020.

DIGGLE, P.; MOYEED, R.; ROWLINGSON, B.; THOMSON, M. Childhood malaria in the Gambia: A case-study in model-based geostatistics. Journal of the Royal Statistical Society. Series C: Applied Statistics, v. 51, n. 4, p. 493-506, 2002. DOI: https://doi.org/10.1111/1467$\underline{9876.00283 .}$.

DLAMINI, S. N.; BELOCONI, A.; MABASO, S.; VOUNATSOU, P.; IMPOUMA, B.; FALL, I. S. Review of remotely sensed data products for disease mapping and epidemiology. Remote Sensing Applications: Society and Environment, v. 14, p. 108-118, 2019. DOI: https://doi.org/10.1016/j.rsase.2019.02.005.

DOS SANTOS, A. R. et al. Spatial and temporal distribution of urban heat islands. Science of the Total Environment, v. 606-607, p. 946-956, 2017. DOI: https://doi.org/10.1016/j.scitotenv.2017.05.275.

DOWLING, Z.; ARMBRUSTER, P.; LADEAU, S. L.; DECOTIIS, M.; MOTTLEY, J.; LEISNHAM, P. T. Linking mosquito infestation to resident socioeconomic status, knowledge, and source reduction practices in Suburban Washington, DC. EcoHealth, v. 10, n. 1, 2013. DOI: https://doi.org/10.1007/s10393-013-0818-6.

DOWMAN, I. Integration of LIDAR and IFSAR for mapping. International Archives of Photogrammetry and Remote Sensing, v. XXXV, n. B2, p. 90-100, 2004.

DRONOVA, I. Object-based image analysis in wetland research: A review. Remote Sensing, v. 7, n. 5, p. 6380-6413, 2015. DOI: https://doi.org/10.3390/rs70506380.

DU, P.; LIU, P.; XIA, J.; FENG, L.; LIU, S.; TAN, K.; CHENG, L. Remote sensing image interpretation for urban environment analysis: Methods, system and examples. Remote Sensing, v. 6, n. 10, p. 9458-9474, 2014. DOI: https://doi.org/10.3390/rs6109458.

DUTRA, L.V.; SOUZA, R.C.M.; MITSUO, F.A.; MOREIRA, J. C. Análise automática de imagens multiespectrais. São José dos Campos.

EISEN, L.; LOZANO-FUENTES, S. Use of mapping and spatial and space-time modeling approaches in operational control of Aedes aegypti and dengue. PLoS Neglected Tropical Diseases, v. 3, n. 4, 2009. DOI: https://doi.org/10.1371/journal.pntd.0000411.

EISENBEISS, H.; ZURICH, E. T. H.; EISENBEISS, H.; ZÜRICH, E. Te. H. UAV photogrammetry. [s.l: s.n.]. DOI: https://doi.org/10.3929/ethz-a-005939264.

FAUVEL, M.; TARABALKA, Y.; BENEDIKTSSON, J. A.; CHANUSSOT, J.; TILTON, J. C. Advances in spectral-spatial classification of hyperspectral images. Proceedings of the IEEE，v. 101, n. 3, p. 652-675, 2013. DOI: https://doi.org/10.1109/JPROC.2012.2197589. 
FAVARO, E. A.; DIBO, M. R.; PEREIRA, M.; CHIEROTTI, A. P.; RODRIGUES-JUNIOR, A. L.; CHIARAVALLOTI-NETO, F. Aedes aegypti entomological indices in an endemic area for dengue in Sao Paulo State, Brazil. Revista de Saúde Publica, v. 47, n. 3, p. 588-597, 2013. DOI: https://doi.org/10.1590/S0034-8910.2013047004506.

FAY, R. W.; ELIASON, D. A. A Preferred Oviposition Site as a Surveillance Method for Aedes aegypti. Mosquito News, v. 26, n. 4, p. 531-535, 1966.

FERREIRA, A. C.; CHIARAVALLOTI - NETO, F. Infestation of an urban area by Aedes aegypti and relation with socioeconomic levels. Revista de Saude Publica, v. 41, n. 6, p. 915 22, 2007. a. DOI: https://doi.org/10.1590/S0034-89102007000600005.

FERREIRA, A. C.; CHIARAVALLOTI - NETO, F. Infestação de área urbana por Aedes aegypti e relação com níveis socioeconômicos. Revista de Saúde Pública, v. 41, n. 6, p. 915922, 2007. b. DOI: https://doi.org/10.1590/s0034-89102007000600005.

FERREIRA, L. V. Classificação da cobertura da terra na Amazônia com base em imagens de satélite e caracterização das classes com relação à superfície do terreno. Geografia (Londrina), v. 21, n. 3, p. 115-131, 2012.

FIALHO MOREIRA, G.; BRAGANÇA ALVES FERNANDES, R.; FERNANDES FILHO, E. In.; OLIVEIRA VIEIRA, C. A.; DOS SANTOS, K. A. Classificação Automatizada do Uso e Cobertura do Solo a Partir de Imagens Landsat. Revista Brasileira de Geografia Física, v. 6, n. 1, p. 58-65, 2013. DOI: https://doi.org/10.26848/rbgf.v06.1.p058-065.

FITZ, P. R. Geoprocessamento sem complicação. São Paulo: Oficina de textos, 2008.

FLAUZINO, R. F.; SOUZA-SANTOS, R.; BARCELLLOS, C.; GRACIE, R.; MAGALHÃES, M. A. F. M.; OLIVEIRA, R. M. De. Spatial heterogeneity of dengue fever in local studies, City of Niterói, Southeastern Brazil. Revista de saúde publica, v. 43, n. 6, p. 1035-1043, 2009. DOI: https://doi.org/10.1590/S0034-89102009005000064.

FLORENZANO, T. G. Imagens de satélite para estudos ambientais. São Paulo: Oficina de Textos, 2002.

FONG, Y.; RUE, H.; WAKEFIELD, J. Bayesian inference for generalized linear mixed models. Biostatistics, v. 14, n. 2, p. 131-149, 2007. DOI: https://doi.org/10.1093/biostatistics/kxp053.

FOODY, G. M. Status of land cover classification accuracy assessment. Remote Sensing of Environment, $\quad$ v. 80, n. 1, p. 185-201, 2002. DOI: https://doi.org/10.1016/S0034$\underline{4257(01) 00295-4 .}$.

FRIEDL, M. A.; WOODCOCK, C.; GOPAL, S.; MUCHONEY, D.; STRAHLER, A. H.; BARKER-SCHAAF, C. A note on procedures used for accuracy assessment in land cover maps derived from AVHRR data. International Journal of Remote Sensing, 2000. DOI: https://doi.org/10.1080/014311600210434.

GALO, M.; CAMARGO, P. Utilização do GPS no controle de qualidade de cartas. In: 10 CONGRESSO BRASILEIRO DE CADASTRO TÉCNICO MULTIFINALITÁRIOCADASTRO TÉCNICO MULTIFINALITÁRIO C 1994, Florianópolis - SC. Anais [...]. Florianópolis - SC p. 41-48. DOI: https://doi.org/10.13140/RG.2.1.1790.1603. 
GAROFALO, D. F. T.; MESSIAS, C. G.; LIESENBERG, V.; BOLFE, E. L.; FERREIRA, M. C. Análise comparativa de classificadores digitais em imagens do Landsat-8 aplicados ao mapeamento temático. Pesquisa Agropecuaria Brasileira, v. 50, n. 7, p. 593-604, 2015. DOI: https://doi.org/10.1590/S0100-204X2015000700009.

GERMAN, A.; ESPINOSA, M. O.; ABRIL, M.; SCAVUZZO, C. M. Exploring satellite based temporal forecast modelling of Aedes aegypti oviposition from an operational perspective. Remote Sensing Applications: Society and Environment, v. 11, p. 231-240, 2018. DOI: https://doi.org/10.1016/j.rsase.2018.07.006.

GETIS, A.; MORRISON, A. C.; GRAY, K.; SCOTT, T. W. Characteristics of the Spatial Pattern of the Dengue Vector, Aedes aegypti, in Iquitos, Peru. American Journal of Tropical Medicine and Hygiene, v. 69, n. 5, p. 494-505, 2003. DOI: https://doi.org/10.1007/978-3642-01976-0_15.

GISLASON, P. O.; BENEDIKTSSON, J. A.; SVEINSSON, J. R. Random forests for land cover classification. Pattern Recognition Letters, v. 27, p. 294-300, 2006. DOI: https://doi.org/10.1016/j.patrec.2005.08.011.

GONZALEZ, R. C.; WOODS, R. E. Processamento de Imagens Digitais. São Paulo.

GUOLlO, D. S. O.; DA SILVA, R. C.; PELUZIO, J. M.; CARMO FILHO, J. R. Aspectos epidemiologicos da dengue em Cuiabá-MT entre 2007 e 2011. Revista Estudos, v. 42, n. 4, p. 503-516, 2011.

GUZMAN, Maria G.; HARRIS, Eva. Dengue. The Lancet, v. 385, p. 453-465, 2015. DOI: https://doi.org/10.1016/S0140-6736(14)60572-9.

HARTLING, S.; SAGAN, V.; SIDIKE, P.; MAIMAITIJIANG, M.; CARRON, J. Urban tree species classification using a worldview-2/3 and liDAR data fusion approach and deep learning. Sensors, v. 19, n. 6, p. 1-23, 2019. DOI: https://doi.org/10.3390/s19061284.

HERBRETEAU, V.; SALEM, G.; SOURIS, M.; HUGOT, J. P.; GONZALEZ, J. P. Thirty years of use and improvement of remote sensing, applied to epidemiology: From early promises to lasting frustration. Health and Place, v. 13, n. 2, p. 400-403, 2007. DOI: https://doi.org/10.1016/j.healthplace.2006.03.003.

HUANG, X.; LU, Q.; ZHANG, L.; PLAZA, A. New postprocessing methods for remote sensing image classification: A systematic study. IEEE Transactions on Geoscience and Remote Sensing, $\quad$ v. 52, n. 11, p. 7140-7159, 2014. DOI: https://doi.org/10.1109/TGRS.2014.2308192.

IBGE. CENSO DEMOGRÁFICO 2010Atlas censo demografico. [s.1: s.n.]. Disponível em: https://biblioteca.ibge.gov.br/visualizacao/periodicos/94/cd_2010_religiao_deficiencia.pdf. Acesso: 23 de maio de 2020

JAMES, G., WITTEN, D., HASTIE, T., TIBSHIRANI, R. An Introduction to Statistical Learning: With Applications in R. New York. DOI: https://doi.org/10.1007/978-1-4614$\underline{7138-7 .}$.

JENSEN, J. R. Sensoriamento remoto do ambiente: uma perspectiva em recursos terrestres. São José dos Campos: Ed Parêntese, 2009. Disponível em: http://www.parentese.com.br/pdf/jensen.pdf. Acesso: 12 de abril de 2019 
JORGE, L. A. de C.; INAMASU, R. Y. Uso de veículos aéreos não tripulados (VANT) em agricultura de precisão. Embrapa Instrumentação-Capítulo em livro técnico-científico (ALICE), p. 109-134, 2014. Disponível em: https://www.alice.cnptia.embrapa.br/handle/doc/1003485.

KALLURI, S.; GILRUTH, P.; ROGERS, D.; SZCZUR, M. Surveillance of arthropod vectorborne infectious diseases using remote sensing techniques: A review. PLoS Pathogens, v. 3, n. 10, 2007. DOI: https://doi.org/10.1371/journal.ppat.0030116.

KEARNEY, M.; PORTER, W. P.; WILlIAMS, C.; RITCHIE, S.; HOFFMANN, A. A. Integrating biophysical models and evolutionary theory to predict climatic impacts on species' ranges: The dengue mosquito Aedes aegypti in Australia. Functional Ecology, v. 23, n. 3, p. 528-538, 2009. DOI: https://doi.org/10.1111/j.1365-2435.2008.01538.x.

KHATAMI, R.; MOUNTRAKIS, G.; STEHMAN, S. V. A meta-analysis of remote sensing research on supervised pixel-based land-cover image classification processes: General guidelines for practitioners and future research. Remote Sensing of Environment, v. 177, p. 89-100, 2016. DOI: https://doi.org/10.1016/j.rse.2016.02.028.

KHORMI, H. M.; KUMAR, L. Modeling dengue fever risk based on socioeconomic parameters, nationality and age groups: GIS and remote sensing based case study. Science of the Total Environment, v. 409, n. 22, p. 4713-4719, 2011. DOI: https://doi.org/10.1016/j.scitotenv.2011.08.028.

KÖRTING, T. S.; FONSECA, L. M. G.; CASTEJON, E. F.; NAMIKAWA, L. M. Improvements in Sample Selection Methods for Image Classification. Remote Sensing, v. 6, n. 8, p. 7580-7591, 2014. DOI: https://doi.org/10.3390/rs6087580.

KRIEGER, G.; MOREIRA, A.; FIEDLER, H.; HAJNSEK, I.; WERNER, M.; YOUNIS, M.; ZINK, M. TanDEM-X: A satellite formation for high-resolution SAR interferometry. IEEE Transactions on Geoscience and Remote Sensing, v. 45, n. 11, p. 3317-3341, 2007. DOI: https://doi.org/10.1109/TGRS.2007.900693.

KULKARNI, A. D.; LOWE, B. Random Forest Algorithm for Land Cover Classification. International Journal on Recent and Innovation Trends in Computing and Communication, v. 4, n. 3, p. 58-63, 2016.

KYNOVA, A.; DOBROVOLNY, P. A neural nets urban land cover classification: A case study of brno (czechia). Acta Universitatis Carolinae, Geographica, v. 50, n. 2, p. 153-163, 2015. DOI: https://doi.org/10.14712/23361980.2015.94.

LACAUX, J. P.; TOURRE, Y. M.; VIGNOLLES, C.; NDIONE, J. A.; LAFAYE, M. Classification of ponds from high-spatial resolution remote sensing: Application to Rift Valley Fever epidemics in Senegal. Remote Sensing of Environment, v. 106, n. 1, p. 66-74, 2007. DOI: https://doi.org/10.1016/j.rse.2006.07.012.

LADEAU, S. L.; LEISNHAM, P. T.; BIEHLER, D.; BODNER, D. Higher mosquito production in low-income neighborhoods of baltimore and washington, DC: Understanding ecological drivers and mosquito-borne disease risk in temperate cities. International Journal of Environmental Research and Public Health, v. 10, n. 4, p. 1505-1526, 2013. DOI: https://doi.org/10.3390/ijerph10041505. 
LAGE, M. O.; JÚNIOR, L. A.; FILHO, L. E.; HO, L. L.; JOSÉ, A.; SIMÕES, M.; QUINTANILHA, J. Alberto. Modelagem de parâmetros de um VANT equipado com LIDAR em aplicações de monitoramento de linhas de transmissão de energia elétrica. Revista Brasileira de Cartografi a, v. 69, n. 15, 2017.

LALIBERTE, A. S.; RANGO, A. Texture and scale in object-based analysis of subdecimeter resolution unmanned aerial vehicle (UAV) imagery. IEEE Transactions on Geoscience and Remote Sensing, $\quad$ v. 47, n. 3, p. 761-770, 2009. DOI: https://doi.org/10.1109/TGRS.2008.2009355.

LANDAU, K. I.; VAN LEEUWEN, W. J. D. Fine scale spatial urban land cover factors associated with adult mosquito abundance and risk in Tucson, Arizona. Journal of Vector Ecology, v. 37, n. 2, p. 407-418, 2012. DOI: https://doi.org/10.1111/j.19487134.2012.00245.x.

LI, C. C.; ZHANG, G. S.; LEI, T. Ji.; GONG, A. D. Quick image-processing method of UAV without control points data in earthquake disaster area. Transactions of Nonferrous Metals Society of China (English Edition), v. 21, 2011. DOI: https://doi.org/10.1016/S1003$\underline{6326(12) 61635-5 .}$.

LIANG, J.; ZHOU, J.; QIAN, Y.; WEN, L.; BAI, X.; GAO, Y. On the Sampling Strategy for Evaluation of Spectral-Spatial Methods in Hyperspectral Image Classification. IEEE Transactions on Geoscience and Remote Sensing, v. 55, n. 2, p. 862-880, 2017. DOI: https://doi.org/10.1109/TGRS.2016.2616489.

LILLESAND, T. M.; KIEFER, R. W.; CHIPMAN, J. W. Remote sensing and image interpretation. 6th. ed. New York.

LILLESAND, T. M.; KIEFER, R. W. Remote sensing and image interpretation. Remote sensing and image interpretation., 1979. DOI: https://doi.org/10.2307/634969.

LINDGREN, F.; RUE, H. Bayesian spatial modelling with R-INLA. Journal of Statistical Software, v. 63, n. 19, p. 1-25, 2015. DOI: https://doi.org/10.18637/jss.v063.i19.

LITTLE, E.; BARRERA, R.; SETO, K. C.; DIUK-WASSER, M. Co-occurrence patterns of the dengue vector Aedes aegypti and Aedes mediovitattus, a dengue competent mosquito in Puerto Rico. EcoHealth, v. 8, n. 3, p. 365-375, 2011. a. DOI: https://doi.org/10.1007/s10393-0110708-8.

LITTLE, E.; BIEHLER, D.; LEISNHAM, P. T.; JORDAN, R.; WILSON, S.; LADEAU, S. L. Socio-ecological mechanisms supporting high densities of Aedes albopictus (Diptera: Culicidae) in Baltimore, MD. Journal of Medical Entomology, v. 54, n. 5, p. 1183-1192, 2017. DOI: https://doi.org/10.1093/jme/tjx103.

LIU, H. T. W. Aplicações de sensoriamento remoto. $2^{\text {a }}$ ed. Campo Grande: Oficina de Textos, 2007.

LIU, L.; ZHANG, Y. Urban heat island analysis using the landsat TM data and ASTER Data: A case study in Hong Kong. Remote Sensing, v. 3, n. 7, p. 1535-1552, 2011. DOI: https://doi.org/10.3390/rs3071535.

LONGHITANO, G. A. Vants para sensoriamento remoto: aplicabilidade na avaliação e monitoramento de impactos ambientais causados por acidentes com cargas perigosas (Dissertação). 2010. Universidade de São Paulo, 2010. 
LONGHITANO, G. A.; AMARAL, C. H.; ALMEIDA, T. I. R. Detecção da biodiversidade de coberturas vegetais secundárias pela resposta espectral de pigmentos e água foliar em imagens do sensor hiperespectral CASI-1500. In: ANAIS XIV SIMPÓSIO BRASILEIRO DE SENSORIAMENTO REMOTO 2009, Natal, Brasil. Anais [...]. Natal, Brasil p. 1135-1142.

LOPES, N.; NOZAWA, C.; LINHARES, R. E. C. Características gerais e epidemiologia dos arbovírus emergentes no Brasil. Revista Pan-Amazônica de Saúde, v. 5, n. 3, p. 55-64, 2014. DOI: https://doi.org/10.5123/s2176-62232014000300007.

LORENZ, C.; CHIARAVALLOTI-NETO, F.; DE OLIVEIRA LAGE, M.; QUINTANILHA, J. A.; PARRA, M. C.; DIBO, M. R.; FÁVARO, E. A.; GUIRADO, M. M.; NOGUEIRA, M. L. Remote sensing for risk mapping of Aedes aegypti infestations: Is this a practical task? Acta Tropica, v. 205, 2020. DOI: https://doi.org/10.1016/j.actatropica.2020.105398.

LU, D.; WENG, Q. A survey of image classification methods and techniques for improving classification performance. International Journal of Remote Sensing, v. 28, n. 5, p. 823870, 2007. DOI: https://doi.org/10.1080/01431160600746456.

LUZ, N. B. Da; SANTOS, D. J. Dos; ANTUNES, A. F. B. Segmentação de imagens e classificação baseada em regras de conhecimento como novas abordagens para o mapeamento do uso da terra no Estado do Paraná. In: XIV SIMPÓSIO BRASILEIRO DE SENSORIAMENTO REMOTO - SBSR 2009, Natal, Brasil. Anais [...]. Natal, Brasil p. 989 996.

MA, L.; LI, M.; MA, X.; CHENG, L.; DU, P.; LIU, Y. A review of supervised object-based land-cover image classification. ISPRS Journal of Photogrammetry and Remote Sensing, v. 130, p. 277-293, 2017. DOI: https://doi.org/10.1016/j.isprsjprs.2017.06.001.

MANDANICI, E.; TAVASCI, L.; CORSINI, F.; GANDOLFI, S. A multi-image superresolution algorithm applied to thermal imagery. Applied Geomatics, v. 11, n. 3, p. 215-228, 2019. DOI: https://doi.org/10.1007/s12518-019-00253-y.

MAULIK, U.; CHAKRABORTY, D. Remote Sensing Image Classification: A survey of support-vector-machine-based advanced techniques. IEEE Geoscience and Remote Sensing Magazine, v. 5, n. 1, p. 33-52, 2017. DOI: https://doi.org/10.1109/MGRS.2016.2641240.

MEDEIROS, J. B.; DINIZ, M. T. M. Mapeamento de focos de reprodução de Aedes Aegypti na cidade de Caicó/RN com o auxílio de veículo aéreo não tripulado. Revsiat Geonordeste, v. 29, n. 2, p. 196-207, 2018. Disponível em: http://ri.ufs.br/jspui/handle/riufs/10625. Acesso: 23 de maio de 2020

MENDONÇA, F. de A.; SOUZA, A. V.; DUTRA, D. A. Saúde pública, urbanização e dengue no Brasil. Sociedade \& Natureza, v. 21, n. 3, p. 257-269, 2009. DOI: https://doi.org/10.1590/s1982-45132009000300003.

MENESES, P. R. Princípios de sensoriamento remoto. Brasília.

MILTON, E. J.; SCHAEPMAN, M. E.; ANDERSON, K.; KNEUBÜHLER, M.; FOX, N. Progress in field spectroscopy. Remote Sensing of Environment, v. 113, n. SUPPL. 1, p. S92-S109, 2009. DOI: https://doi.org/10.1016/j.rse.2007.08.001. 
MINISTÉRIO DA SAÚDE. Diretrizes Nacionais para a Prevenção e Controle de Epidemias de Dengue. [s.l: s.n.]. Disponível em: http://www.saude.gov.br/svs\%0Ahttp://bvsms.saude.gov.br/bvs/publicacoes/diretrizes_nacion ais_prevencao_controle_dengue.pdf.

MISSLIN, R.; TELLE, O.; DAUDÉ, E.; VAGUET, A.; PAUL, R. E. Urban climate versus global climate change-what makes the difference for dengue? Annals of the New York Academy of Sciences, v. 1386, n. 1, p. 56-72, 2016. DOI: https://doi.org/10.1111/nyas.13084.

MISSLIN, R.; VAGUET, Y.; VAGUET, A.; DAUDÉ, E. Estimating air temperature using MODIS surface temperature images for assessing Aedes aegypti thermal niche in Bangkok, Thailand. Environmental Monitoring and Assessment, v. 190, n. 9, 2018. DOI: https://doi.org/10.1007/s10661-018-6875-0.

MOLINA, P. et al. Navigation and remote sensing payloads and methods of the sarvant unmanned aerial system. ISPRS - International Archives of the Photogrammetry, Remote Sensing and Spatial Information Sciences, v. XL1, p. 275-280, 2013. DOI: https://doi.org/10.5194/isprsarchives-xl-1-w2-275-2013.

MOLINA, P.; WIS, M.; PARÉS, M. E.; BLÁZQUEZ, M.; TATJER, J. C.; COLOMINA, I. New approaches to IMU modelling and INS/GPS integration for UAV-based earth-observation. 21st International Technical Meeting of the Satellite Division of the Institute of Navigation, ION GNSS 2008, p. 1335-1344, 2008.

MOLONEY, J. M.; SKELLY, C.; WEINSTEIN, P.; MAGUIRE, M.; RITCHIE, S. Domestic Aedes aegypti breeding site surveillance: Limitations of remote sensing as a predictive surveillance tool. American Journal of Tropical Medicine and Hygiene, v. 59, n. 2, p. 261264, 1998. DOI: https://doi.org/10.4269/ajtmh.1998.59.261.

MONKEN, M.; BARCELLOS, C. Vigilância em saúde e território utilizado: possibilidades teóricas e metodológicas. Cadernos de Saúde Pública, v. 21, n. 3, p. 898-906, 2005. DOI: https://doi.org/10.1590/s0102-311x2005000300024.

MONTEIRO, A.; LINGNAU, C.; SOUZA, C. M. Classificação Orientada a Objeto Para Detecção Da Exploração Seletiva De Madeira Na Amazônia. Revista Brasileira de Cartografia, v. 59, n. 3, p. 225-234, 2007.

MORAES, E. C. Fundamentos de Sensoriamento Remoto. São José dos Campos: Instituto Nacional de Pesquisas Espaciais - INPE, 2002.

MORAGA, P. SpatialEpiApp: A Shiny web application for the analysis of spatial and spatiotemporal disease data. Spatial and Spatio-temporal Epidemiology, v. 23, p. 47-57, 2017. DOI: https://doi.org/10.1016/j.sste.2017.08.001.

MORENO-MADRIÑÁN, M. J. et al. Correlating remote sensing data with the abundance of pupae of the dengue virus mosquito vector, Aedes aegypti, in central Mexico. ISPRS International Journal of Geo-Information, v. 3, n. 2, p. 732-749, 2014. DOI: https://doi.org/10.3390/ijgi3020732.

MORRISON, A. C.; GETIS, A.; SANTIAGO, M.; RIGAU-PEREZ, J. G.; REITER, P. Exploratory space-time analysis of reported dengue cases during an outbreak in Florida, Puerto Rico, 1991-1992. American Journal of Tropical Medicine and Hygiene, v. 58, n. 3, p. 287 298, 1998. DOI: https://doi.org/10.4269/ajtmh.1998.58.287. 
MOSER, G.; SERPICO, S. B.; BENEDIKTSSON, J. A. Land-cover mapping by markov modeling of spatial-contextual information in very-high-resolution remote sensing images. Proceedings of the IEEE, v. 101, n. 3, p. 631-651, 2013. DOI: https://doi.org/10.1109/JPROC.2012.2211551.

MOUNTRAKIS, G.; IM, J.; OGOLE, C. Support vector machines in remote sensing: A review. ISPRS Journal of Photogrammetry and Remote Sensing, v. 66, n. 3, p. 247-259, 2011. DOI: https://doi.org/10.1016/j.isprsjprs.2010.11.001.

MUKHERJEE, A.; VELEZ-REYES, M.; ROYSAM, B. Interest points for hyperspectral image data. IEEE Transactions on Geoscience and Remote Sensing, v. 47, n. 3, p. 748-760, 2009. DOI: https://doi.org/10.1109/TGRS.2008.2011280.

MURDOCK, C. C.; EVANS, Mi. V.; MCCLANAHAN, T. D.; MIAZGOWICZ, K. L.; TESLA, $B$. Fine-scale variation in microclimate across an urban landscape shapes variation in mosquito population dynamics and the potential of Aedes albopictus to transmit arboviral disease. PLoS

$\begin{array}{llllllll}\text { Neglected Tropical Diseases, } & \text { v. } 11, \quad \text { n. } & \text {, } 2017 . & \text { DOI: }\end{array}$ https://doi.org/10.1371/journal.pntd.0005640.

MURTHY, K.; SHEARN, M.; SMILEY, B. D.; CHAU, Al. H.; LEVINE, J.; ROBINSON, D. SkySat-1: very high-resolution imagery from a small satellite. In: SPIE 9241, SENSORS, SYSTEMS, AND NEXT-GENERATION SATELLITES XVIII 2014, Amsterdam, Netherlands. Anais [...]. Amsterdam, Netherlands DOI: https://doi.org/10.1117/12.2074163.

MUSHINZIMANA, E. et al. Landscape determinants and remote sensing of anopheline mosquito larval habitats in the western Kenya highlands. Malaria Journal, v. 5, n. 13, p. 110, 2006. DOI: https://doi.org/10.1186/1475-2875-5-1.

NARIN, F.; OLIVASTRO, D.; STEVENS, K. A. Bibliometrics/Theory, Practice and Problems. Evaluation Review, $\quad$ v. 18, n. 1, p. 65-76, 1994. DOI: https://doi.org/10.1177/0193841X9401800107.

NDOSSI, M. I.; AVDAN, U. Application of open source coding technologies in the production of Land Surface Temperature (LST) maps from Landsat: A PyQGIS plugin. Remote Sensing, v. 8, n. 5, p. 413, 2016. DOI: https://doi.org/10.3390/rs8050413.

NETZBAND, Maik; JÜRGENS, Carsten. Urban and suburban areas as a research topic for remote sensing. In: Remote Sensing and Digital Image Processing. [s.1.] : Springer, Dordrecht, 2010. DOI: https://doi.org/10.1007/978-1-4020-4385-7_1.

NEWMAN, M. E.; MCLAREN, K. P.; WILSON, B. S. Comparing the effects of classification techniques on landscape-level assessments: Pixel-based versus object-based classification. International Journal of Remote Sensing, v. 32, n. 14, p. 4055-4073, 2011. DOI: https://doi.org/10.1080/01431161.2010.484432.

NICHOL, J. E. A GIS-based approach to microclimate monitoring in Singapore's high- rise housing estates. Photogrammetric Engineering \& Remote Sensing, v. 60, n. 10, p. 12251232, 1994.

NIÑO, L. Uso de la función semivariograma y estimación kriging en el análisis espacial de un indicador entomológico de Aedes aegypti (Diptera: Culicidae). Biomedica, v. 28, n. 4, 2008. DOI: https://doi.org/10.7705/biomedica.v28i4.64. 
NOVO, Evlyn M. L. de Moraes. Sensoriamento Remoto: Príncipios e Aplicações. 4 ed. ed. São Paulo: Blucher, 2010.

NUNES, L. P. M.; SANTOS, J. S.; SILVA, S. C. S.; PIMENTEL, M. A. Variação da temperatura do solo no leste da Amazônia. In: Os Desafios da Geografia Física na Fronteira do Conhecimento. $\quad[$ s.l: $\quad$ s.n. $] . \quad$ p. $\quad 4787-4797 . \quad$ DOI: https://doi.org/10.20396/sbgfa.v1i2017.2187.

OLIVEIRA, R. M. De; VALLA, V. V. As condições e as experiências de vida de grupos populares no Rio de Janeiro: repensando a mobilização popular no controle do dengue. Cadernos de Saúde Pública, v. 17, p. S77-S88, 2001. DOI: 10.1590/s0102https://doi.org/311x2001000700016.

OLIVER, M. A.; WEBSTER, R. Kriging: A method of interpolation for geographical information systems. International Journal of Geographical Information Systems, 1990. DOI: https://doi.org/10.1080/02693799008941549.

OPAS/; WHO. Reported cases of Dengue fever in the Americas by country or territory. Cumulative cases. 2020. Disponível em: https://www.paho.org/data/index.php/en/mnutopics/indicadores-dengue-en/dengue-nacional-en/252-dengue-pais-ano-en.html?start=1.

Acesso: 23 de maio de 2020

OUYANG, Z. T.; ZHANG, M. Q.; XIE, X.; SHEN, Q.; GUO, H. Q.; ZHAO, B. A comparison of pixel-based and object-oriented approaches to VHR imagery for mapping saltmarsh plants. Ecological Informatics, v. 6, n. 2, p. 136-146, 2011. DOI: https://doi.org/10.1016/j.ecoinf.2011.01.002.

PAJARES, G. Overview and current status of remote sensing applications based on unmanned aerial vehicles (UAVs). Photogrammetric Engineering and Remote Sensing, v. 81, n. 4, p. 281-329, 2015. DOI: https://doi.org/10.14358/PERS.81.4.281.

PAPARODITIS, N.; PAPELARD, J. P.; CANNELLE, B.; DEVAUX, A.; SOHEILIAN, B.; DAVID, N.; HOUZAY, E. Stereopolis II a multi-purpose and multi-sensor 3d mobile mapping system for street visualisation and 3d metrology. Revue Francaise de Photogrammetrie et de Teledetection, v. 200, p. 69-79, 2012.

PARSELIA, E.; KONTOES, C.; TSOUNI, A.; HADJICHRISTODOULOU, C.; KIOUTSIOUKIS, I.; MAGIORKINIS, G.; STILIANAKIS, N. I. Satellite Earth Observation data in epidemiological modeling of malaria, dengue and West Nile Virus: A scoping review. Remote Sensing, v. 11, n. 16, 2019. DOI: https://doi.org/10.3390/rs11161862.

PASSO, D. P.; BIAS, E. De S.; BRITES, R. S.; COSTA, G. A. O. P. Uso do sistema Interimage para a identificação de alvos urbanos em imagens do satélite Worldview II. Revista Brasileira de Cartografia, v. 65, n. 6, 2013.

PATINO, J. E.; DUQUE, J. C. A review of regional science applications of satellite remote sensing in urban settings. Computers, Environment and Urban Systems, v. 37, p. 1-17, 2013. DOI: https://doi.org/10.1016/j.compenvurbsys.2012.06.003.

PETRIE, G. Airborne topographic laser scanners. GEO Informatics, p. 34-44, 2011.

PETTA, R. A.; FERNANDES, R. C.; NASCIMENTO, P. S. R. Detecção automática da dinâmica da cobertura da terra por sensoriamento remoto. Geografia (Londrina), v. 17, n. 1, p. 111-125, 2008. DOI: https://doi.org/10.5433/2447-1747.2008v17n1p109. 
PFEIFFER, D. U.; ROBINSON, T. P.; STEVENSON, M.; STEVENS, K. B.; ROGERS, D. J.; CLEMENTS, A. C. A. Spatial Analysis in Epidemiology. [s.1.] : Oxford University Press, 2008. DOI: https://doi.org/10.1093/acprof:oso/9780198509882.001.0001.

POLI, D.; TOUTIN, T. Review of developments in geometric modelling for high resolution satellite pushbroom sensors. Photogrammetric Record, v. 27, n. 137, p. 58-73, 2012. DOI: https://doi.org/10.1111/j.1477-9730.2011.00665.x.

PONZONI, F. J. Sensoriamento Remoto No Estudo Da Vegetação: Diagnosticando a Mata Atlântica. In: Curso De Uso De Sensoriamento Remoto No Estudo Do Meio Ambiente. São José dos Campos: INPE, 2002. p. 27. Disponível em: http://ecologia.ib.usp.br/lepac/bie5759/CAP8_FJPonzoni.pdf.

PUISSANT, A.; HIRSCH, J.; WEBER, C. The utility of texture analysis to improve per-pixel classification for high to very high spatial resolution imagery. International Journal of Remote Sensing, $\quad$ v. 26, n. 4, p. 733-745, $2005 . \quad$ DOI: https://doi.org/10.1080/01431160512331316838.

QIN, Z.; KARNIELI, A.; BERLINER, P. A mono-window algorithm for retrieving land surface temperature from Landsat TM data and its application to the Israel-Egypt border region. International Journal of Remote Sensing, v. 22, n. 18, p. 3719-3746, 2001. DOI: https://doi.org/10.1080/01431160010006971.

QUEIROZ, R. B.; SEVERINO, P. A. da R.; RODRIGUES, A. G.; GÓMEZ, A. T. Redes Neurais: Um comparativo com Máxima Verossimilhança Gaussiana na Classificação de Imagens CBERS 1. In: II WORKSHOP DE TECNOLOGIA DA INFORMAÇÃO APLICADA AO MEIO AMBIENTE - CBCOMP 2004 2004, Anais [...]. [s.l: s.n.] p. 746-749.

RAGONI, V. R. M.; MONTEIRO, A. M. V.; CARVALHO, M. S.; WERNECK, G. L. Uma aplicação do sensoriamento remoto para a investigação de endemias urbanas. Cadernos de Saúde Pública, v. 23, n. 5, p. 1015-1028, 2007. DOI: https://doi.org/10.1590/S0102311X2007000500004.

RAO, P. K. Remote sensing of urban "heat islands" from an environmental satellite. Bull. Am. Meteorol. Soc., v. 53, p. 647-648, 1972.

RATMANOV, P.; MEDIANNIKOV, O.; RAOULT, D. Vectorborne diseases in West Africa: Geographic distribution and geospatial characteristics. Transactions of the Royal Society of Tropical Medicine and Hygiene, v. 107, n. 5, p. 273-284, 2013. DOI: https://doi.org/10.1093/trstmh/trt020.

REITER, P.; AMADOR, M. A.; COLON, N. Enhancement of the CDC ovitrap with hay infusions for daily monitoring of Aedes aegypti populations. Journal of the American Mosquito Control Association, 1991.

REX, F.; KÄFER, P.; DEBASTIANI, A.; KAZAMA, V. Potencial de imagens MSI (SENTINEL-2) para classificação do uso e cobertura da terra. Enciclopédia Biosfera, v. 15, n. 27, p. 219-231, 2018. DOI: https://doi.org/10.18677/encibio_2018a67.

RIBEIRO, A. F.; MARQUES, G. R. A. M.; VOlTOLini, J. C.; CONDINO, M. L. F. Associação entre incidência de dengue e variáveis climáticas. Revista de Saúde Publica, v. 40, n. 4, 2006. DOI: https://doi.org/10.1590/S0034-89102006000500017. 
RIBEIRO, B. M. G.; FONSECA, L. M. G.; KUX, H. J. H. Mapeamento da cobertura do solo urbano utilizando imagens WorldView-II e o sistema InterIMAGE. Revista Brasileira de Cartografia, v. 63, n. Edição Especial 40 Anos, p. 51-63, 2011.

RIBEIRO, P. da C.; DE SOUSA, D. C.; DE ARAÚJO, T. M. E. Perfil clínico-epidemiológico dos casos suspeitos de Dengue em um bairro da zona sul de teresina, PI, Brasil. Revista brasileira de enfermagem, v. 61, n. 2, p. 227-232, 2008.

RIBEIRO, R. J. da C.; BAPTISTA, G. M. de M.; BIAS, E. de S. Comparação dos métodos de classificação supervisionada de imagem Máxima Verossimilhança e Redes Neurais em ambiente urbano. In: ANAIS XIII SIMPÓSIO BRASILEIRO DE SENSORIAMENTO REMOTO, FLORIANÓPOLIS, BRASIL, 21 A 26 ABRIL DE 2007, INPE 2007, Florianópolis, Brasi. Anais [...]. Florianópolis, Brasi: INPE, 2007. Disponível em: http://marte.sid.inpe.br/col/dpi.inpe.br/sbsr@80/2006/10.03.11.59/doc/5471-5478.pdf.

Acesso: 15 de novembro de 2018.

RICHARDS, J. A.; JIA, X. Remote Sensing Digital Image Analysis. $4^{\mathrm{a}}$ ed. [s.1.] : SpringerVerlag Berlin Heidelberg, 1999. DOI: https://doi.org/10.1007/978-3-662-03978-6.

ROBERTSON, L. D.; KING, D. J. Comparison of pixel-and object-based classification in land cover change mapping. International Journal of Remote Sensing, v. 32, n. 6, p. 1505-1529, 2011. DOI: https://doi.org/10.1080/01431160903571791.

ROCCO, I. M. et al. Ocorrência de Dengue no Estado de Säo Paulo, Brasil, de 1986 a 1996 TT - Occurence of dengue in Säo Paulo State, Brazil from 1986 to 1996. Rev. Inst. Adolfo Lutz, v. 57, n. 1, p. 7-12, 1998.

ROCCO, I. M.; SILVEIRA, V. R.; MAEDA, A. Y.; SILVA, S. J. S.; SPENASSATTO, C.; BISORDI, I.; SUZUKI, A. First isolation of dengue 4 in the state of São Paulo, Brazil, 2011. Revista do Instituto de Medicina Tropical de São Paulo, v. 54, n. 1, p. 49-51, 2012. DOI: https://doi.org/10.1590/s0036-46652012000100009.

RODRÍGUEZ CRUZ, R. Estrategias para el control del dengue y del Aedes aegypti en las Américas. Revista cubana de medicina tropical, v. 54, n. 3, p. 189-201, 2002.

ROMERO, M. A. B. A arquitetura bioclimática do espaço público. In: Arquitetura bioclimática. 4. ed. [s.1.] : Edu - Unb, 2016. p. 226.

ROSA, Roberto. Geotecnologias na Geografia aplicada. Revista Do Departamento De Geografia da Universidade de São Paulo, v. 16, 2005. DOI: https://doi.org/10.7154/rdg.2005.0016.0009.

RUE, H.; MARTINO, S.; CHOPIN, N. Approximate Bayesian inference for latent Gaussian models by using integrated nested Laplace approximations. Journal of the Royal Statistical Society. Series B: Statistical Methodology, v. 71, n. 2, p. 319-392, 2009. DOI: https://doi.org/10.1111/j.1467-9868.2008.00700.x.

RUE, H.; RIEBLER, A.; SØRBYE, S. H.; ILLIAN, J. B.; SIMPSON, D. P.; LINDGREN, F. K. Bayesian Computing with INLA: A Review. Annual Review of Statistics and Its Application, v. 4, p. 395-421, 2017. DOI: https://doi.org/10.1146/annurev-statistics-060116$\underline{054045 .}$.

SABINS, F. F. Remote sensing: principles and interpretation. Second edition. Remote sensing: principles and interpretation. Second edition., 1986. 
SALINI, S. An Introduction to Bibliometrics. In: WILEY (org.). Research Methods for Postgraduates: Third Edition. hird Editi ed. [s.l: s.n.]. p. 130-143. DOI: https://doi.org/10.1002/9781118763025.ch14.

SANCHEZ, L.; CORTINAS, J.; PELAEZ, O.; GUTIERREZ, H.; CONCEPCIÓN, D.; VAN DER STUYFT, P. Breteau Index threshold levels indicating risk for dengue transmission in areas with low Aedes infestation. Tropical Medicine and International Health, v. 15, n. 2, p. 173-175, 2010. DOI: https://doi.org/10.1111/j.1365-3156.2009.02437.x.

SANTOS, A. M.; ROMÃO, P. de A. Estudo multitemporal e alteração na paisagem na região do distrito de Luiz Alves, município de São Miguel do Araguaia - GO, a partir de método indireto, sensoriamento remoto. Geografia (Londrina), v. 16, n. 2, p. 85-112, 2007. DOI: https://doi.org/10.5433/2447-1747.2007v16n2p85.

SCARPASSA, V. M.; CARDOZA, T. B.; CARDOSO, R. P. Population genetics and phylogeography of Aedes aegypti (Diptera: Culicidae) from Brazil. American Journal of Tropical Medicine and Hygiene, v. 78, n. 6, p. 895-903, 2008. DOI: https://doi.org/10.4269/ajtmh.2008.78.895.

SCHOTT, J. R.; GERACE, A.; RAQUENO, N.; IENTILUCCI, E.; RAQUENO, R.; LUNSFORD, A. W. Chasing the TIRS ghosts: calibrating the Landsat 8 thermal bands. In: EARTH OBSERVING SYSTEMS XIX 2014, San Diego. Anais [...]. San Diego DOI: https://doi.org/10.1117/12.2063236.

SCHRÖDLE, B.; HELD, L. A primer on disease mapping and ecological regression using INLA. Computational Statistics, v. 26, n. 2, p. 241-258, 2011. DOI: https://doi.org/10.1007/s00180-010-0208-2.

SHACKELFORD, A. K.; DAVIS, C. H. A combined fuzzy pixel-based and object-based approach for classification of high-resolution multispectral data over urban areas. IEEE Transactions on Geoscience and Remote Sensing, v. 41, n. 10 PART I, p. 2354-2363, 2003. DOI: https://doi.org/10.1109/TGRS.2003.815972.

SILVA, L. J. da. O conceito de espaço na epidemiologia das doenças infecciosas. Cadernos de Saúde Pública, v. 13, n. 4, p. 585-593, 1997. DOI: https://doi.org/10.1590/s0102311x1997000400002.

SINGHI, S.; KISSOON, N.; BANSAL, A. Dengue and dengue hemorrhagic fever: management issues in an intensive care unit. Jornal de Pediatria, v. 83, n. 2, p. S22-S35, 2007. DOI: https://doi.org/10.2223/jped.1622.

SMALL, C. Multitemporal analysis of urban reflectance. Remote Sensing of Environment, v. 81, n. 2-3, p. 427-442, 2002. DOI: https://doi.org/10.1016/S0034-4257(02)00019-6.

SNAVELY, N.; SEITZ, S. M.; SZELISKI, R. Modeling the world from Internet photo collections. International Journal of Computer Vision, v. 80, n. 2, p. 189-210, 2008. DOI: https://doi.org/10.1007/s11263-007-0107-3.

SOARES MACHADO, C. A.; KNOPIK BELTRAME, Al. M.; SHINOHARA, E. J.; GIANNOTTI, M. A.; DURIEUX, L.; NÓBREGA, T. M. Q.; QUINTANILHA, J. A. Identifying concentrated areas of trip generators from high spatial resolution satellite images using object-based classification techniques. Applied Geography, v. 53, p. 271-283, 2014. DOI: https://doi.org/10.1016/j.apgeog.2014.06.022. 
SOBRINO, J. A.; JIMÉNEZ-MUÑOZ, J. C.; PAOLINI, L. Land surface temperature retrieval from LANDSAT TM 5. Remote Sensing of Environment, v. 90, n. 4, p. 434-440, 2004. DOI: https://doi.org/10.1016/j.rse.2004.02.003.

SOUZA-SANTOS, R.; CARVALHO, M. S. Spatial analysis of Aedes aegypti larval distribution in the Ilha do Governador neighborhood of Rio de Janeiro, Brazil. Cadernos de Saúde Pública, v. 16, n. 1, p. 31-42, 2000. DOI: https://doi.org/10.1590/S0102311X2000000100004.

SOUZA, Iris de Marcelhas e. Sensoriamento Remoto Orbital Aplicado a Estudos Urbanos. [s.l: s.n.].

STEPHENS, G. L. et al. The cloudsat mission and the A-Train: A new dimension of spacebased observations of clouds and precipitation. Bulletin of the American Meteorological Society, v. 83, n. 12, p. 1771-1790, 2002. DOI: https://doi.org/10.1175/bams-83-12-1771.

STERN, J. M. Construtivismo cognitivo e estatística bayesiana. Scientiae Studia, v. 4, n. 4, p. 98-613, 2006.

SUN, Z.; ZHAO, X.; WU, M.; WANG, C. Extracting Urban Impervious Surface from WorldView-2 and Airborne LiDAR Data Using 3D Convolutional Neural Networks. Journal of the Indian Society of Remote Sensing, v. 47, n. 3, p. 401-412, 2019. DOI: https://doi.org/10.1007/s12524-018-0917-5.

TAHAR, K. N.; AHMAD, A. Capability of low cost digital camera for production of orthophoto and volume determination. In: PROCEEDINGS - 2011 IEEE 7TH INTERNATIONAL COLLOQUIUM ON SIGNAL PROCESSING AND ITS APPLICATIONS, CSPA 2011 (2011) 67-71 2011, Anais [...]. [s.l: s.n.] DOI: https://doi.org/10.1109/CSPA.2011.5759844.

TAUIL, P. L. Urbanization and dengue ecology. Cadernos de Saúde Publica, v. 17, p. 99102, 2001. DOI: https://doi.org/10.1590/S0102-311X2001000700018.

TEIXEIRA, T. R. de A.; CRUZ, O. G. Spatial modeling of dengue and socio-environmental indicators in the city of Rio de Janeiro, Brazil. Cadernos de Saúde Pública, v. 27, n. 3, p. 591-604, 2011. DOI: https://doi.org/10.1590/s0102-311x2011000300019.

TOTH, C.; JÓŹKÓW, G. Remote sensing platforms and sensors: A survey. ISPRS Journal of Photogrammetry and Remote Sensing, v. 115, p. 22-36, 2016. DOI: https://doi.org/10.1016/j.isprsjprs.2015.10.004.

TROYO, A. Analyses of Dengue Fever and Aedes aegypti (Diptera: Culicidae) Larval Habitats in a Tropical Urban Environment of Costa Rica using Geospatial and Mosquito Surveillance Technologies. 2008. University of Miami, 2008.

TUN-LIN, W.; BURKOT, T. R.; KAY, B. H. Effects of temperature and larval diet on development rates and survival of the dengue vector Aedes aegypti in north Queensland, Australia. Medical and Veterinary Entomology, v. 14, n. 1, p. 31-37, 2000. DOI: https://doi.org/10.1046/j.1365-2915.2000.00207.x.

TUN-LIN, W.; KAY, B. H.; BARNES, A. The premise condition index: A tool for streamlining surveys of Aedes aegypti. American Journal of Tropical Medicine and Hygiene, v. 53, n. 6, p. 591-594, 1995. DOI: https://doi.org/10.4269/ajtmh.1995.53.591. 
TYC, G.; TULIP, J.; SCHULTEN, D.; KRISCHKE, M.; OXFORT, M. The RapidEye mission design. Acta Astronautica, v. 56, n. 1-2, p. 213-219, 2005. DOI: https://doi.org/10.1016/j.actaastro.2004.09.029.

U.S. DEPARTMENT OF INTERIOR. Using the USGS Landsat 8 Product. U.S. Department of Interior, 2013.

UGARTE, M. D.; ADIN, A.; GOICOA, T.; MILITINO, A. F. On fitting spatio-temporal disease mapping models using approximate Bayesian inference. Statistical Methods in

Medical Research, v. 23, n. 6, p. 07-530, 2014. DOI: https://doi.org/10.1177/0962280214527528.

UN, UNIDETED NATION. Division for Sustainable Development. Outcome document: open working group on sustainable devepment goals. Disponível em: https://brasil.un.org/pt-br/sdgs Acesso em: 20 de dezembro de 2020.

USGS. Product Guide: Provisional Landsat 8 Surface Reflectance Product. Version 1.7Department of the Interior U.S. Geological Survey. [s.l: s.n.]. DOI: https://doi.org/10.1080/1073161X.1994.10467258.

VALOR, E.; CASELLES, V. Mapping land surface emissivity from NDVI: Application to European, African, and South American areas. Remote Sensing of Environment, v. 57, n. 3, p. 167-184, 1996. DOI: https://doi.org/10.1016/0034-4257(96)00039-9.

VAN DE GRIEND, A. A.; OWE, M. On the relationship between thermal emissivity and the normalized difference vegetation index for natural surfaces. International Journal of Remote Sensing, 1993. DOI: https://doi.org/0.1080/01431169308904400.

VARGAS, W. P.; KAWA, H.; SABROZA, P. Ch.; SOARES, V. B.; HONÓRIO, N. Al.; DE ALMEIDA, A. S. Association among house infestation index, dengue incidence, and sociodemographic indicators: surveillance using geographic information system. BMC Public Health, v. 15, n. 1, 2015. DOI: https://doi.org/10.1186/s12889-015-2097-3.

VASUKI, Ya.; HOLDEN, E. J.; KOVESI, P.; MICKLETHWAITE, S. Semi-automatic mapping of geological Structures using UAV-based photogrammetric data: An image analysis approach. Computers and Geosciences, v. 69, p. 22-32, 2014. DOI: https://doi.org/10.1016/i.cageo.2014.04.012.

VEZZANI, D.; VELÁZQUEZ, S. M.; SCHWEIGMANN, N. Seasonal pattern of abundance of Aedes aegypti (Diptera: Culicidae) in Buenos Aires City, Argentina. Memorias do Instituto Oswaldo Cruz, v. 99, n. 4, p. 351-356, 2004. DOI: https://doi.org/10.1590/S0074$\underline{02762004000400002 .}$

VIANA, J.; SANTOS, J. V.; NEIVA, R. M.; SOUZA, J.; DUARTE, L.; TEODORO, A. C.; FREITAS, A. Remote sensing in human health: A 10-year bibliometric analysis. Remote Sensing, v. 9, n. 12, p. 1-12, 2017. DOI: https://doi.org/10.3390/rs9121225.

VIANA, Di. V.; IGNOTTI, E. A ocorrência da dengue e variações meteorológicas no brasil: Revisão sistemática. Revista Brasileira de Epidemiologia, v. 16, n. 2, p. 240-256, 2013. DOI: https://doi.org/10.1590/S1415-790X2013000200002.

VOOGT, J. A.; OKE, T. R. Thermal remote sensing of urban climates. Remote Sensing of Environment, 2003. DOI: https://doi.org/10.1016/S0034-4257(03)00079-8. 
WATTS, A. C.; AMBROSIA, V. G.; HINKLEY, E. A. Unmanned aircraft systems in remote sensing and scientific research: Classification and considerations of use. Remote Sensing, v. 4, n. 6, p. 1671-1692, 2012. DOI: https://doi.org/10.3390/rs4061671.

WEBSTER, J.; WATSON, R. T. Analyzing the Past to Prepare for the Future: Writing a Literature Review. MIS Quarterly, v. 26, n. 2, p. xiii-xxiii, 2002. DOI: https://doi.org/10.1.1.104.6570.

WHO. Dengue guidelines for diagnosis, treatment, prevention and control. [s.1.] : WHO Library Cataloguing-in-Publication Data, 2009. Disponível em: https://www.who.int/tdr/publications/documents/dengue-diagnosis.pdf. Acesso: 05 de maio de 2018.

WHO, W. H. O. Dengue in the WHO european region. World Health Organisation, p. 8, 2014. Disponível em: http://www.euro.who.int/en/media-centre/sections/factsheets/2014/03/fact-sheets-world-health-day-2014-vector-borne-diseases/fact-sheet-denguein-the-who-european-region. Acesso: 13 de fevereiro de 2020.

WILSON, J. S.; CLAY, M.; MARTIN, E.; STUCKEY, D.; VEDDER-RISCH, K. Evaluating environmental influences of zoning in urban ecosystems with remote sensing. Remote Sensing of Environment, v. 86, n. 3, p. 303-321, 2003. DOI: https://doi.org/10.1016/S00344257(03)00084-1.

WU, M.; ZHAO, X.; SUN, Z.; GUO, H. A Hierarchical Multiscale Super-Pixel-Based Classification Method for Extracting Urban Impervious Surface Using Deep Residual Network from WorldView-2 and LiDAR Data. IEEE Journal of Selected Topics in Applied Earth Observations and Remote Sensing, v. 12, n. 1, p. 210-222, 2019. DOI: https://doi.org/10.1109/JSTARS.2018.2886288.

YAN, G.; MAS, J. F.; MAATHUIS, B. H. P.; XIANGMIN, Z.; VAN DIJK, P. M. Comparison of pixel-based and object-oriented image classification approaches - A case study in a coal fire area, Wuda, Inner Mongolia, China. International Journal of Remote Sensing, v. 27, n. 18, p. 4039-4055, 2006. DOI: https://doi.org/10.1080/01431160600702632.

YU, L. et al. Meta-discoveries from a synthesis of satellite-based land-cover mapping research. International Journal of Remote Sensing, v. 35, n. 13, p. 4573-4588, 2014. DOI: https://doi.org/10.1080/01431161.2014.930206.

ZARA, A. L. de S. A.; SANTOS, S. M. Dos; FERNANDES-OLIVEIRA, E. S.; CARVALHO, R. G.; COELHO, G. E. Estratégias de controle do Aedes aegypti: uma revisão. Epidemiologia e servicos de saúde, v. 25, n. 2, p. 391-404, 2016. DOI: https://doi.org/10.5123/S167949742016000200017.

ZELLER, H.; MARRAMA, L.; SUDRE, B.; VAN BORTEL, W.; WARNS-PETIT, E. Mosquito-borne disease surveillance by the European Centre for Disease Prevention and Control. Clinical Microbiology and Infection, v. 19, n. 8, p. 693-698, 2013. DOI: https://doi.org/10.1111/1469-0691.12230.

ZHANG, J.; WANG, Y.; LI, Y. A C++ program for retrieving land surface temperature from the data of Landsat TM/ETM+ band6. Computers and Geosciences, v. 32, n. 10, p. 17961805, 2006. DOI: https://doi.org/10.1016/j.cageo.2006.05.001.

ZHOU, D. et al. Satellite remote sensing of surface urban heat islands: Progress, challenges, 
and perspectives. Remote Sensing, v. 11, n. 1, 2019. DOI: https://doi.org/10.3390/rs11010048.

ZHOU, G. Near real-time orthorectification and mosaic of small UAV video flow for timecritical event response. IEEE Transactions on Geoscience and Remote Sensing, v. 47, n. 3, p. 739-747, 2009. DOI: https://doi.org/10.1109/TGRS.2008.2006505.

ZHU, X. X.; TUIA, D.; MOU, L.; XIA, G. S.; ZHANG, L.; XU, F.; FRAUNDORFER, F. Deep learning in remote sensing: a review. IEEE Geoscience and Remote Sensing Magazine, v. 5, n. 4, p. 8-36, 2017. DOI: https://doi.org/10.1109/MGRS.2017.2762307.

ZOU, L.; MILLER, S. N.; SCHMIDTMANN, E. T. Mosquito Larval Habitat Mapping Using Remote Sensing and GIS: Implications of Coalbed Methane Development and West Nile Virus. Journal of Medical Entomology, v. 43, n. 4, p. 1034-1041, 2006. DOI: https://doi.org/10.1093/jmedent/43.5.1034.

ZUUR, A.F., IENO, E.N., SAVELIEV, A. A. Spatial, Temporal and Spatio-Temporal Ecological Data Analysis with R-INLA. Newburg United Kingdom: Highland Statistics Ltd., 2017. Disponível em: https://www.highstat.com/Books/BGS/SpatialTemp/Zuuretal2017_TOCOnline.pdf. 


\section{ANEXOS}

- Artigo publicado na revista ACTA TROPICA - fevereiro 2020

Acta Tropica
ELSEVIER

Use of an Extended Premise

Condition Index for detection of

priority areas for vector control

actions

Gerson Laurindo Barbosa ${ }^{a} \otimes$, Mariana de Oliveira Lage ${ }^{b} \otimes$, Valmir Roberto Andrade ${ }^{c} \otimes$

, Antônio Henrique Alves Gomes ${ }^{d} \boldsymbol{\otimes}$, Jose Alberto Quintanilha ${ }^{e} \boldsymbol{\otimes}$, Francisco

Chiaravalloti Neto $f \circ 区$

Show more $\vee$

https://doi.org/10.1016/j.actatropica.2020.105543

Get rights and content 
- Artigo publicado na revista ACTA TROPICA - fevereiro 2020

Acta Tropica 205 (2020) 105398

Contents lists available at ScienceDirect

Acta Tropica

journal homepage: www.elsevier.com/locate/actatropica

Remote sensing for risk mapping of Aedes aegypti infestations: Is this a practical task?

Camila Lorenz $^{\mathrm{a}, 1, *}$, Francisco Chiaravalloti-Neto ${ }^{\mathrm{a}, 1}$, Mariana de Oliveira Lage ${ }^{\mathrm{b}}$, José Alberto Quintanilha ${ }^{\mathrm{b}}$, Maisa Carla Parra ${ }^{\mathrm{c}}$, Margareth Regina Dibo ${ }^{\mathrm{d}}$, Eliane Aparecida Fávaro ${ }^{\mathrm{c}}$, Marluci Monteiro Guirado ${ }^{\mathrm{e}}$, Maurício Lacerda Nogueira ${ }^{\mathrm{c}}$

${ }^{a}$ Departamento de Epidemiologia, Faculdade de Saúde Pública, Universidade de São Paulo, Av. Dr. Arnaldo, 715, São Paulo, SP, Brazil

'Divisão Científica de Gestão, Ciência e Tecnologia Ambiental do Instituto de Energia e Ambiente - IEE da Universidade de São Paulo, São Paulo, SP, Brazil

c Laboratório de Pesquisa em Virologia, Faculdade de Medicina de São José do Rio Preto, São José do Rio Preto, SP, Brazil

${ }^{\mathrm{d}}$ Laboratório de Entomologia, Superintendência de Controle de Endemias, São Paulo, SP, Brazil

e Laboratório de Vetores, Superintendência de Controle de Endemias, São José do Rio Preto, SP, Brazil

A R T I C L E I N F O

\section{Keywords:}

Mosquito control

Bayesian approach

Landscape

Geostatistical analysis

\section{A B S T R A C T}

Mosquito-borne diseases affect millions of individuals worldwide; the area of endemic transmission has been increasing due to several factors linked to globalization, urban sprawl, and climate change. The Aedes aegypti mosquito plays a central role in the dissemination of dengue, Zika, chikungunya, and urban yellow fever. Current preventive measures include mosquito control programs; however, identifying high-risk areas for mosquito infestation over a large geographic region based only on field surveys is labor-intensive and timeconsuming. Thus, the objective of this study was to assess the potential of remote satellite images (WorldView) for determining land features associated with Ae. aegypti adult infestations in São José do Rio Preto/SP, Brazil. We used data from 60 adult mosquito traps distributed along four summers; the remote sensing images were classified by land cover types using a supervised classification method. We modeled the number of Ae. aegypti using a Poisson probability distribution with a geostatistical approach. The models were constructed in a Bayesian context using the Integrated nested Laplace Approximations and Stochastic Partial Differential Equation method. We showed that an infestation of Ae. aegypti adult mosquitoes was positively associated with the presence of asbestos roofing and roof slabs. This may be related to several other factors, such as socioeconomic or environmental factors. The usage of asbestos roofing may be more prevalent in socioeconomically poor areas, while roof slabs may retain rainwater and contribute to the generation of temporary mosquito breeding sites. Although preliminary, our results demonstrate the utility of satellite remote sensing in identifying landscape differences in urban environments using a geostatistical approach, and indicated directions for future research. Further analyses including other variables, such as land surface temperature, may reveal more complex relationships between urban mosquito micro-habitats and land cover features. 
- Artigo submetido na revista EcoHealth - Março 2020

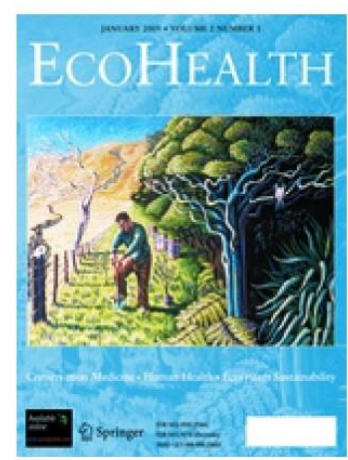

OVIPOSITIONAL DENGUE URBAN AREAS IDENTIFICATION USING WORLDVIEW-2 IMAGE

\begin{tabular}{|r|l|}
\hline Journal: & EcoHealth \\
\hline Manuscript ID & Draft \\
\hline Manuscript Type: & Original Contribution \\
\hline Keywords: & Aedes aegypti, Traps, Ordinary Kriging, Remote Sensing \\
\hline & \\
\end{tabular}

SCHOLARONE

Manuscripts 
- Artigo submetido na Revista Brasileira de Cartografia - Dezembro de 2019

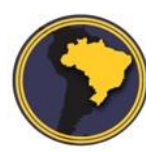

Revista Brasileira de Cartografia

Rev. Bras. Cartogr. / RBC

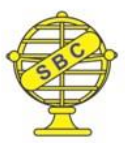

DOI: http://dx.doi.org/10.010101/XXXXX2016-X 017

\section{Identifying the urban-area breeding potential of Aedes aegypti mosquitos through remote sensing}

Identificação do potencial de reprodução de mosquitos Aedes aegypti em áreas urbanas através de sensoriamento remoto

Recebido em Não preencher deNão preencher. Aprovado em Não preencher de Nãe preencher.

\section{ABSTRACT}

Remote orbital sensing technology is a possible tool for investigating difficult-to-access areas, reducing time spent in the field, better understanding complex sites and generating possible detailed information to identify and classify potential areas in which Aedes aegypti (yellow fever mosquitoes) ). In this context, this study was conducted in four areas of the city of Campinas, Brazil. The methodology was applied to information provided by area experts to create classification rules related to the use of high resolution satellite imagery. We thus identified and classified areas of Campinas and nearby surroundings that were at-risk for mosquito breeding based on terrain features found in images obtained with an unmanned aerial vehicle (UAV). This information is further expected to help establish a methodological process for classifying a variety of areas that may be atrisk for the proliferation of Aedes gegypti mosquitoes. Consequent control measures can thus be implemented to reduce instances of dengue fever and the chikungunya and Zika viruses. This article also discusses whether remote sensing products used on a scale equivalent to that of the WorldView-2 satellite permit the proper identification of potential mosquito breeding sites in urban areas. An image-processing task (including principal component analysis (PCA)) and supervised classification technique were thus performed to identify areas with the greatest risk for facilitating the breeding of mosquitos that are disease vectors.

KEYWORDS: Satellite imagery; unmanned aerial vehicle (UAV); principal component analysis (PCA); image classification; land use/land cover; Aedes. gegxpti 
- Artigo publicado na Revista de Saúde Pública - Maio de 2018

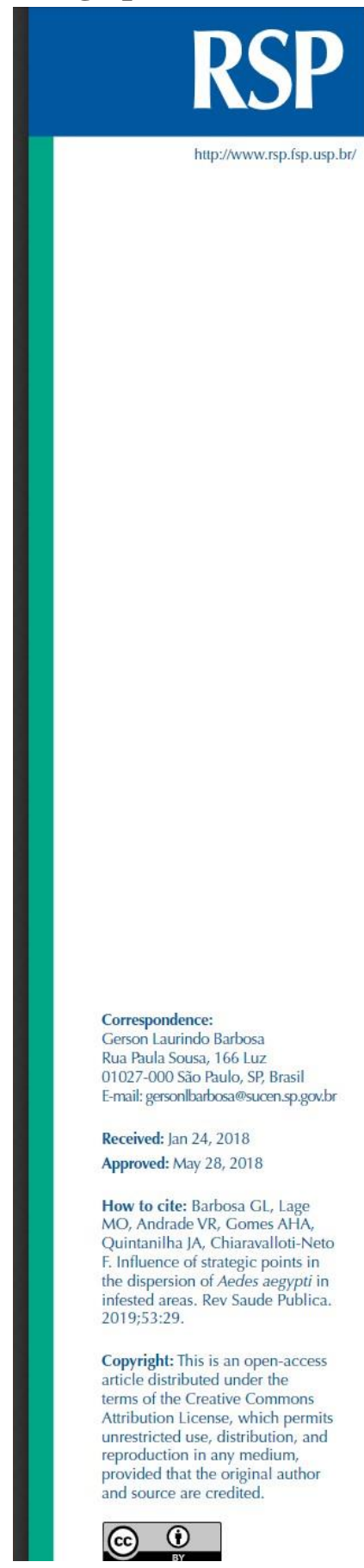

Revista de

Saúde Pública

\title{
Influence of strategic points in the dispersion of Aedes aegypti in infested areas
}

\author{
Gerson Laurindo Barbosa' (D), Mariana de Oliveira Lage" (D), Valmir Roberto Andrade' (D), Antônio \\ Henrique Alves Gomes' (iD), Jose Alberto Quintanilha"l' (iD), Francisco Chiaravalloti-Neto ${ }^{\text {IV }}$ (iD) \\ Secretaria de Estado da Saúde. Superintendência de Controle de Endemias. São Paulo, SP, Brasil \\ " Universidade de São Paulo. Programa de Pós-Graduação em Ciências Ambientais. São Paulo, SP, Brasil \\ II Universidade de São Paulo. Fscograma de Pós-Graduação en Ciências Ambientais. Săo Paulo, SP, Brasil \\ iv Universidade de São Paulo. Faculdade de Saúde Pública. Departamento de Epidemiologia. São Paulo, SP, Brasil
}

\section{ABSTRACT}

OBJECTIVE: To evaluate whether sites with large amount of potential breeding sites for immature forms of Aedes aegypti, called strategic points, influence in the active vector's dispersion into properties in their surroundings.

METHODS: We selected four areas in the municipality of Campinas, three of them with strategic points classified as high, moderate, and low risk according to infestation and a control area, without strategic points. Between October 2015 and September 2016, we monthly installed oviposition traps and evaluated the infestation by Ae, aegypti in all properties of each selected area. To verify if there was vector dispersion from each strategic point, based on its location, we investigated the formation of clusters with excess of eggs or larvae or pupae containers, using the $G$ spatial statistics.

RESULTS: The amount of eggs collected in the ovitraps and the number of positive containers for Ae. aegypti did not show clusters of high values concerning its distance from the strategic point. Both presented random distribution not spatially associated with the positioning of strategic points in the area.

CONCLUSIONS: Strategic points are not confirmed as responsible for the vector's dispersion for properties in their surroundings. We highlight the importance of reviewing the current strategy of the vector control program in Brazil, seeking a balance from the technical, operational, and economic point of view, without disregarding the role of strategic points as major producers of mosquitoes and their importance in the dissemination of arboviruses in periods of transmission. DESCRIPTORS: Aedes aegypti, growth \& development. Oviposition. Spatial Analysis. Vector Control. Communicable Disease Control. 
- Participação no Congresso Spatial Statistics - Julho de 2017

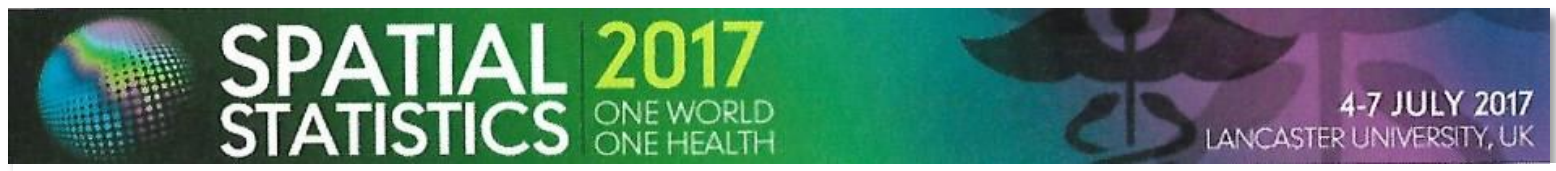

\author{
REMOTE SENSING IMAGES CLASSIFICATION \\ TECHNIQUES FOR THE OPTIMIZATION IN THE \\ IDENTIFICATION OF AREAS OF POTENTIAL DENGUE \\ DEVELOPMENT \\ Mariana de Oliveira Lage ${ }^{1}$ \\ Gerson Barbosa ${ }^{2}$ \\ Valmir Andrade ${ }^{2}$ \\ Henrique Gomes ${ }^{2}$ \\ Francisco Chiaravalloti ${ }^{3}$ \\ José Alberto Quintanilha ${ }^{1}$
}


- Artigo Publicado na Revista Brasileira de Cartografia - 2017

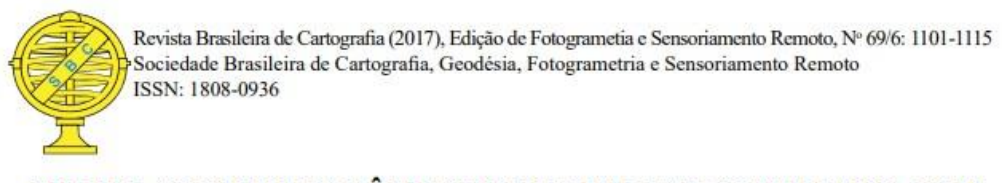

MODELAGEM DE PARÂMETROS DE UM VANT EQUIPADO COM LIDAR EM APLICAÇÕES DE MONITORAMENTO DE LINHAS DE TRANSMISSÃO DE ENERGIA ELÉTRICA

Modeling Parameters of an UAV Equipped with LiDAR in

Powerlines Monitoring Applications

Mariana de Oliveira Lage ${ }^{1}$, Laerte Appolinário Júnior ${ }^{2}$, Leonardo Ercolin $\mathrm{Filho}^{3}$, Linda Lee $\mathrm{Ho}^{4}$, Augustinho José Menin Simões ${ }^{5}$ \& José Alberto Quintanilha ${ }^{2}$ 